\title{
LANDSCAPE VARIABILITY OF VEGETATION CHANGE ACROSS THE FOREST TO TUNDRA TRANSITION OF CENTRAL CANADA
}

by

Mitchell Thurston Bonney

\begin{abstract}
A thesis submitted to the Department of Geography and Planning
In conformity with the requirements for

the degree of Master of Science
\end{abstract}

\author{
Queen's University \\ Kingston, Ontario, Canada
}

(September, 2017)

Copyright @Mitchell T. Bonney, 2017 


\begin{abstract}
Widespread vegetation productivity increases in tundra ecosystems and stagnation, or even productivity decreases, in boreal forest ecosystems have been detected from coarse-scale remote sensing observations over the last few decades. However, finer-scale Landsat studies have shown that these changes are heterogeneous and may be related to landscape and regional variability in climate, land cover, topography and moisture. In this study, a Landsat Normalized Difference Vegetation Index (NDVI) timeseries (1984-2016) was examined for a study area spanning the entirety of the sub-Arctic boreal forest to Low Arctic tundra transition of central Canada (i.e., Yellowknife to the Arctic Ocean). NDVI trend analysis indicated that $27 \%$ of un-masked pixels in the study area exhibited a significant $(\mathrm{p}<0.05)$ trend and virtually all $(99.3 \%)$ of those pixels were greening. Greening pixels were most common in the northern tundra zone and the southern forest-tundra ecotone zone. NDVI trends were positive throughout the study area, but were smallest in the forest zone and largest in the northern tundra zone. These results were supported by ground validation, which found a strong relationship $\left(R^{2}=0.81\right)$ between bulk vegetation volume (BVV) and NDVI for non-tree functional groups in the North Slave region of Northwest Territories. Field observations indicate that alder (Alnus spp.) shrublands and open woodland sites with shrubby understories were most likely to exhibit greening in that area. Random Forest (RF) modelling of the relationship between NDVI trends and environmental variables found that the magnitude and direction of trends differed across the forest to tundra transition. Increased summer temperatures, shrubland and forest land cover, closer proximity to major drainage systems, longer distances from major lakes and lower elevations were generally more important and associated with larger positive NDVI trends. These findings indicate that the largest positive NDVI trends were primarily associated with the increased productivity of shrubby environments, especially at, and north of the forest-tundra ecotone in areas with more favorable growing conditions. Smaller and less significant NDVI trends in boreal forest environments south of the forest-tundra ecotone were likely associated with long-term recovery from fire disturbance rather than the variables analyzed here.
\end{abstract}




\section{Acknowledgements}

First, I would like to acknowledge Dr. Paul Treitz and Dr. Ryan Danby for their support and guidance in helping to make my experience at Queen's University a success. Paul's knowledge on remote sensing and Arctic research in combination with Ryan's knowledge on landscape ecology and treeline research proved to be the perfect combination for this project. I came to Queen's with little remote sensing or northern research experience and have learned so much during my time here. More specifically, I would like to thank Paul for providing me with a work space and a desktop computer to complete my work in the best possible environment. I would like to thank Ryan for supporting my field work in Northwest Territories and for creating a friendly and welcoming lab group. I would like to further acknowledge my LaRSEES lab mates Rebecca Edwards, Ashley Rudy, Amy Blazer, Chen Shang and Karin van Ewijk, as well as my Danby Café lab mates Gregory King, Katherine Dearborn and Dasvinder Kambo for their advice and feedback at different stages of this project.

Thank you as well to Queen's University for financially supporting me with the Geography Graduate Fellowship, Geography Merit Award and TA positions. I would also like to thank the Northern Scientific Training Program (NSTP) and, again, Dr. Ryan Danby and Dr. Paul Treitz for generously covering field work expenses. My field work turned out to be very successful, thanks in no small part to the assistance and hard work of Ryan, Greg and Stuart Thibert who spent five weeks with me on the land (and in the canoe!) in Northwest Territories. I would especially like to acknowledge Stuart for his work in preparing us for the expedition back in Kingston and leading us safely past rapids and other dangers in the field. Thank you to the Tłıchọ community of Wekweètì in general and Adrian Migwi in particular for their hospitality and for allowing us to spend time conducting research on their land.

I would also like to thank my parents back in Maine, Yvonne and Thimi, and my brother, James, for their emotional and financial support throughout my academic career. Without you all I would be lost! This thesis is dedicated to my father, Geoffrey Bonney. You passed away when I was a baby, but without you I would never have been able to make Canada my home and for that I am forever grateful. 


\section{Table of Contents}

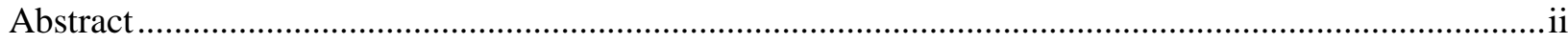

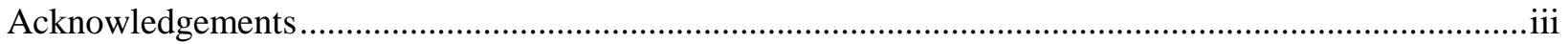

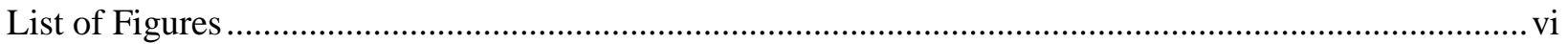

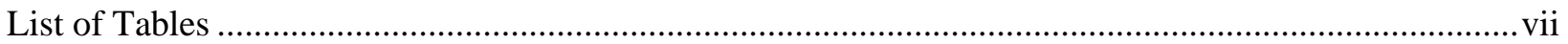

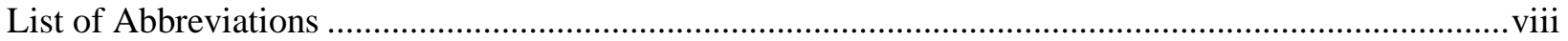

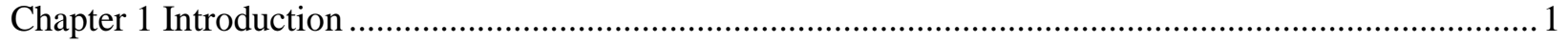

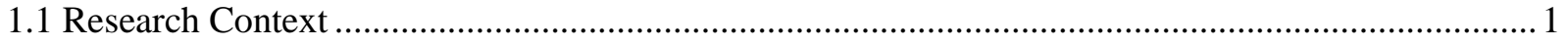

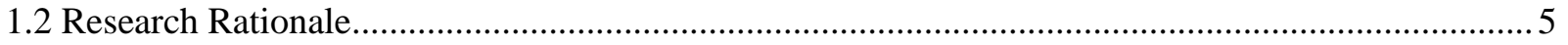

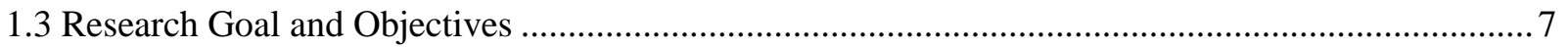

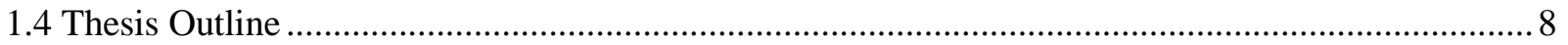

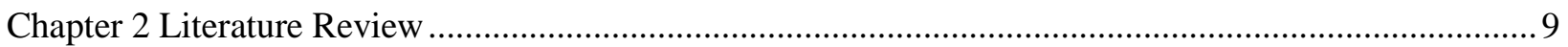

2.1 Recent Vegetation Change across the Forest to Tundra Transition .................................................. 9

2.1.1 The Modern Forest-Tundra Ecotone ...................................................................................... 9

2.1.2 Shrub Expansion at, and north of the Forest-Tundra Ecotone ............................................... 13

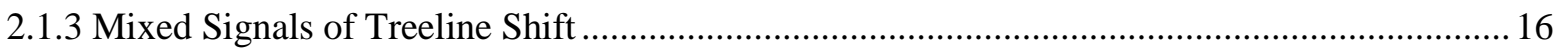

2.1.4 Why are Shrubs Expanding more than Boreal Tree Species?................................................ 19

2.2 Remote Sensing of Vegetation Change across the Forest to Tundra Transition..............................21

2.2.1 NDVI as a Metric of Vegetation Productivity ....................................................................... 22

2.2.2 Remote Sensing Platforms used to Monitor Northern Vegetation Change ..............................23

2.2.3 NDVI Time-series across Northern High Latitudes............................................................ 27

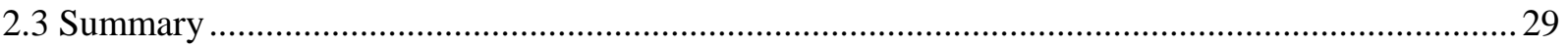

Chapter 3 Landscape Variability of Vegetation Change across the Forest to Tundra Transition of Central

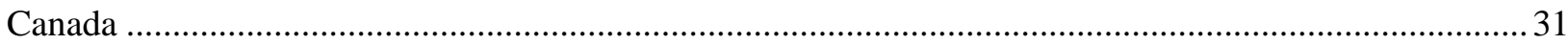

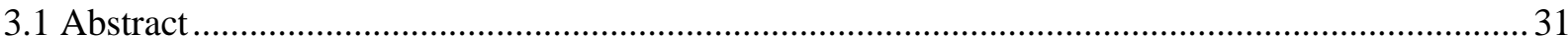

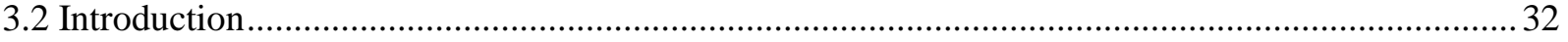

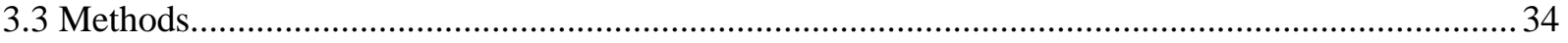

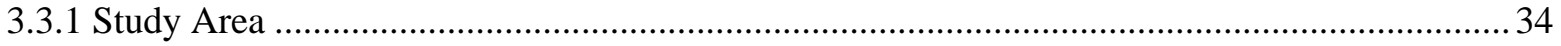

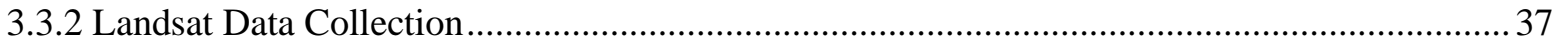

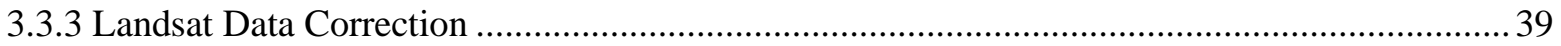

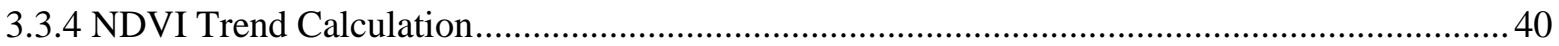

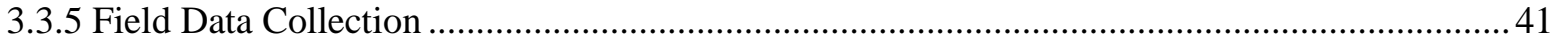

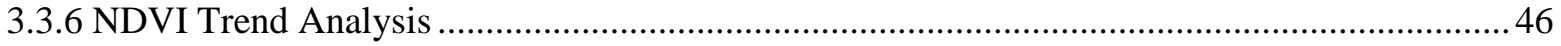




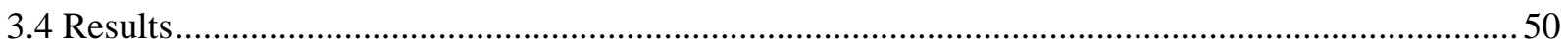

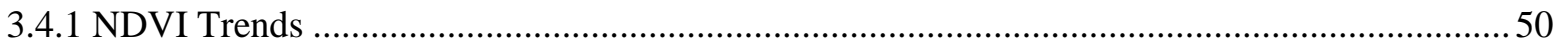

3.4.2 Relationship between NDVI and Bulk Vegetation Volume .................................................54

3.4.3 Landscape and Environmental Influences on NDVI Trends ................................................57

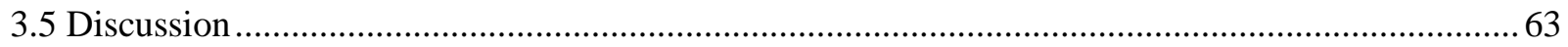

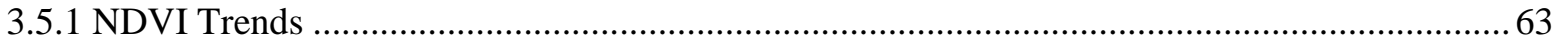

3.5.2 Relationship between NDVI and Bulk Vegetation Volume …...............................................65

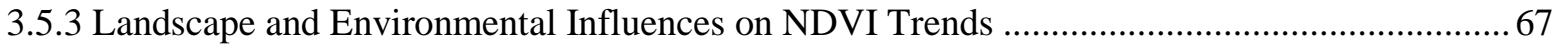

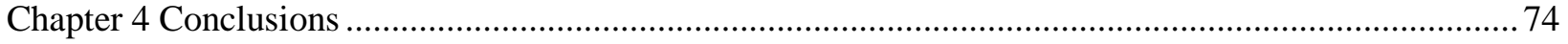

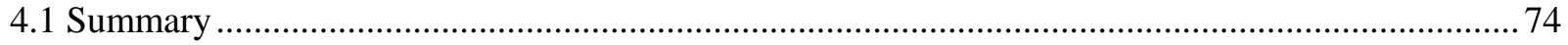

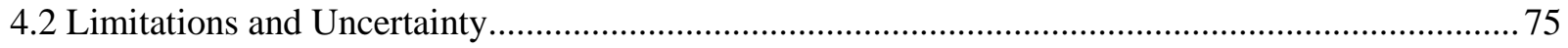

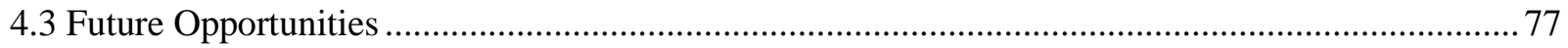

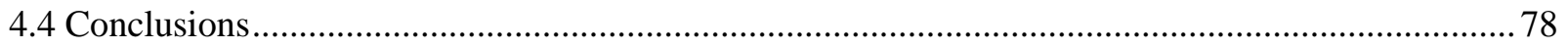

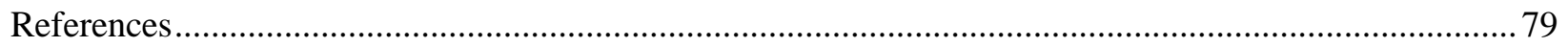

Appendix A Field Expedition Preparation and Methodology .............................................................. 93

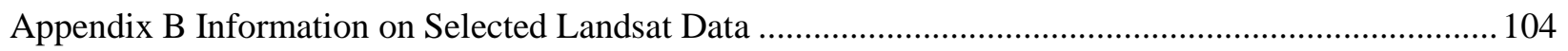

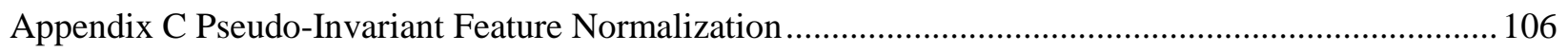

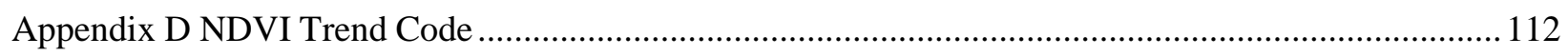

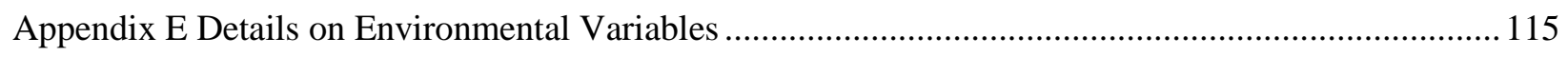

Appendix F Random Forest Code and Other Partial Dependence Plots ............................................... 127 


\section{List of Figures}

Figure 2.1: Boundaries of the forest-tundra ecotone of central Canada based on tree:upland tundra cover

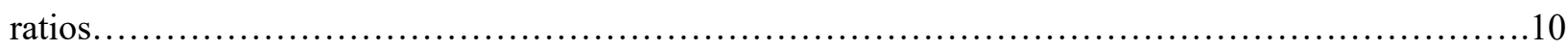

Figure 2.2: Ecoregions of eastern Northwest Territories..................................... 11

Figure 2.3: Summer photosynthetic activity simulations of tundra and conifer forest ecosystems through

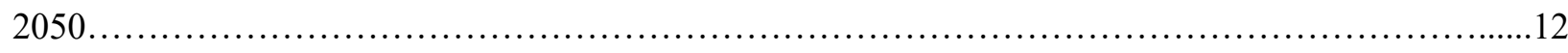

Figure 2.4: Location of shrub change studies across northern high latitudes..............................14

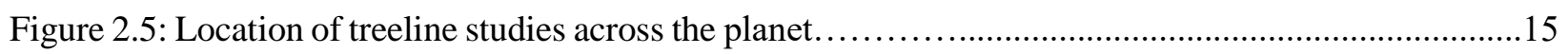

Figure 2.6: Changes in photosynthetic activity across northern high latitudes......................... 18

Figure 2.7: Aerial photographs of shrub expansion in Alaska from 1949-2000.........................24

Figure 3.1: Extent of Landsat frames used for remote sensing analysis............................. 32

Figure 3.2: Temporal distribution of selected Landsat scenes...................................

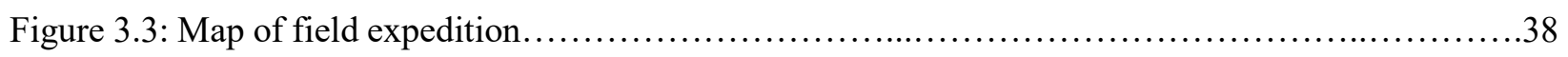

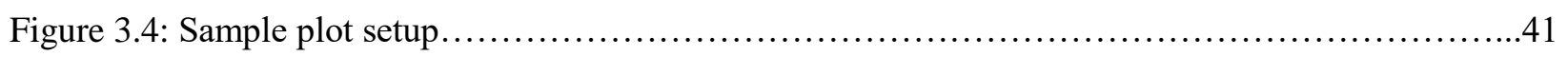

Figure 3.5: Supervised 9-class land-cover classification across the study area...........................44

Figure 3.6: NDVI trends (1984-2016) across the study area......................................47

Figure 3.7: Pixel distribution of NDVI trends across the study area...............................48

Figure 3.8: Percentage of pixels with significant NDVI trends across the study area, split by land cover....49

Figure 3.9: Relationship between NDVI and bulk vegetation volume.............................51

Figure 3.10: Non-tree bulk vegetation volume trends for sample plots............................52

Figure 3.11: Correlation matrix (UTM northings, NDVI trends, environmental variables)................53

Figure 3.12: Importance of environmental variables from Random Forest models.......................55

Figure 3.13: Matrix of partial dependence plots for the most important variables across the study area......58 


\section{List of Tables}

Table 2.1: Commonly used remote sensing platforms for vegetation monitoring..........................22

Table 3.1: Details of potential sample plots (land cover, number of pixels, mean NDVI, plots sampled).....40

Table 3.2: Descriptions of the 12 environmental variables that potentially influence NDVI trends.........42

Table 3.3: Random Forest model details (sample size, error, \% variation explained).....................54 


\section{List of Abbreviations}

\begin{tabular}{ll} 
\%IncMSE & Percent increase in Mean Squared Error \\
6S & Second Simulation of the Satellite Signal in the Solar Spectrum \\
AVHRR & Advanced Very High Resolution Radiometer \\
BVV & Bulk Vegetation Volume \\
CAVM & Circumpolar Arctic Vegetation Map \\
CRU & Climatic Research Unit \\
DEM & Digital Elevation Model \\
ETM+ & Enhanced Thematic Mapper Plus \\
GIMMS & Global Inventory Modeling and Mapping Studies \\
GloVis & Global Visualization Viewer \\
GNWT & Government of Northwest Territories \\
IncNodePurity & Increase in node purity \\
ISODATA & Iterative Self-Organizing Data Analysis Technique \\
L1T & Landsat Standard Terrain Correction \\
LAI & Leaf Area Index \\
LaSRC & Landsat Surface Reflectance Code \\
LEDAPS & Landsat Ecosystem Disturbance Adaptive Processing System \\
MODIS & Moderate Resolution Imaging Spectrometer \\
NASA & National Aeronautics and Space Administration \\
NDVI & Normalized Difference Vegetation Index \\
NOAA & National Oceanic and Atmospheric Administration \\
NTS & National Topographic System \\
OLI & Operational Land Imager \\
PAR & Photosynthetically Active Radiation \\
PIFs & Pseudo-Invariant Features \\
PVC & Percent Vegetation Cover \\
RF & Random Forest \\
SLC & Scan Line Corrector \\
TM & Thematic Mapper \\
TPI & Topographic Position Index \\
TWI & Topographic Wetness Index \\
USGS & United States Geological Survey \\
UTM & Universal Transverse Mercator \\
WGS & World Geodetic System \\
WRS & Worldwide Reference System \\
\hline \hline & \\
&
\end{tabular}




\section{Chapter 1}

\section{Introduction}

\subsection{Research Context}

The Earth system has experienced an increase in average air temperature on the order of $1{ }^{\circ} \mathrm{C}$ since the late 1800s (IPCC, 2013). The scientific community has concluded, beyond a reasonable doubt, that this warming has occurred as a consequence of anthropogenic fossil fuel emissions (IPCC, 2013). This warming trend has had a variety of effects on the Earth system, especially at high latitudes where warming has been significantly greater than the global average. Serreze \& Barry (2011) report that northern high latitudes have warmed 2 to $4{ }^{\circ} \mathrm{C}$ over the last 50 years. This phenomenon, known as Arctic amplification, is the result of a positive feedback mechanism where an initial warming (in this case sparked by global fossil fuel emissions) in the Arctic leads to increased melting of high albedo snow and ice. The loss of these reflective surfaces earlier in the spring, coupled with later accumulation in the fall, allows more insolation to be absorbed by terrestrial and marine surfaces at high latitudes. The enhanced growth of vegetation as a function of warmer temperatures and a longer growing season initiates both positive and negative feedback mechanisms. For instance, increased vegetative growth reinforces a positive feedback given its lower albedo (i.e., increased energy absorption) whereas the associated increase in $\mathrm{CO}_{2}$ sequestration for photosynthesis is a negative feedback mechanism (Chapin et al., 2005; Wookey et al., 2009). Reduced terrestrial albedo and subsequent surface warming has also been linked with the increased emission of longwave radiation (Serreze \& Barry, 2011). When taken collectively, these mechanisms have given rise to increasing temperatures at high latitudes over time.

These increasing Arctic air temperatures are triggering changes in other environmental variables that influence vegetation dynamics. Precipitation in the Arctic is projected to increase 
by more than $50 \%$ by 2100 (Kattsov et al., 2007). This is mainly attributed to increased surface evaporation as a result of Arctic amplification (Bintanja \& Selten, 2014). Arctic and sub-Arctic warming has also led to a reduction in snow cover and sea ice extent (Derksen \& Brown, 2012; Stroeve et al., 2007). Sea ice decline has been linked to increased vegetation growth at northern high latitudes, since the loss of high albedo surfaces (i.e., ice and snow) allows for lower elevation tundra areas near the coast to heat up more (Bhatt et al., 2010). Despite increased precipitation, studies have found a decline in surface water balance at northern high latitudes (Smith et al., 2005; Smol \& Douglas, 2007); which has been linked to permafrost degradation and increased evaporation (Oechel et al., 2000; Bintanja \& Selten, 2014). However, other studies have linked permafrost degradation with increased water coverage in areas with wetter moisture regimes (Jorgenson et al., 2006; Pattison et al., 2015; Raynolds \& Walker, 2016). High latitude boreal forests and bordering shrub tundra regions have also experienced an increase in fire disturbance attributed to the warming climate and increases in biomass (i.e., fuel) (Higuera et al., 2008; Macias-Fauria \& Johnson, 2008).

In the context of these environmental changes occurring at northern high latitudes, there has been an increase in the productivity of vegetation in Arctic and sub-Arctic ecosystems over the last half century. This is primarily spurred by the increased growth and expansion of shrubs across the circumpolar Arctic and sub-Arctic as climatic conditions become more favorable for species previously under stress and at the periphery of their range (Myers-Smith et al., 2011). This is especially evident along the forest-tundra ecotone and in adjacent tundra areas, where shrubs are extending their range into previously inhospitable areas and becoming more abundant where they are already present (Danby \& Hik, 2007; Myers-Smith et al., 2011). Northward expansion of shrubs is expected over a decadal-length timescale along forest-tundra and shrubland-tundra transitions (Epstein et al., 2004). This northward expansion has been heterogeneous, with landscape-scale differences in terrain having an influence on the magnitude 
of vegetation change at high latitudes (Ropars \& Boudreau, 2012; Frost et al., 2014). Shrub expansion has also occurred along rivers and near recently drained lakes (Stow et al., 2004; McManus et al., 2012; Fraser et al., 2014a), illustrating a potential relationship between terrain and moisture availability. However, it should also be noted that in recent years (2011 to 2014) a decline in vegetation productivity has been observed in tundra environments, with the cause still uncertain and likely related to a variety of factors (e.g., warmer winter temperatures leading to more snow cover, increased tundra fires, pest outbreaks, herbivore population growth, etc.) (Bhatt et al., 2013; Epstein et al., 2016; Phoenix \& Bjerke, 2016).

While shrub growth and expansion have been widespread, treeline advance has been mixed, advancing in some locations and remaining static elsewhere (Harsch et al., 2009). Additionally, a decrease in productivity from forest dieback has been detected in boreal ecosystems south of the forest-tundra ecotone based on remote sensing observations (Verbyla, 2008; Beck \& Goetz, 2012; Guay et al., 2014). This has been attributed to higher drought stress in the summer months of the last few decades because of increasing temperatures (Barber at el., 2000; Bunn et al., 2005; Lotsch et al., 2005). Treeline advance has also not occurred at the same rates as shrub expansion because boreal tree range expansion takes longer to respond to warming in general (i.e., there is a significant lag period) (MacDonald et al., 1998; Epstein et al., 2004; Gamache \& Payette, 2005). Specifically, black spruce (Picea mariana) has limited reproductive potential (i.e., lower seed production and less-likely seed germination) for stressed krummholz (i.e., stunted) individuals trying to expand into tundra areas (Black \& Bliss, 1980; Gamache \& Payette, 2004; 2005). Still, it should be noted that trees at the forest-tundra ecotone have shown accelerated height growth in the last few decades in some locations, even if range expansion has not occurred at the same rate as shrubs (Gamache \& Payette, 2004).

Satellite remote sensing data have allowed researchers to quantify vegetation change over a variety of spatial scales in the northern high latitudes as well as globally. These remote sensing 
measures not only allow researchers to quantify change over time but aid in the development of a more thorough understanding of the processes giving rise to the changes observed. Coarse spatial resolution satellite sensors, such as the Advanced Very High Resolution Radiometer (AVHRR), allow for the analysis of vegetation dynamics over large areas and short time scales attributed to the quick revisit time (twice per day for AVHRR) of these sensors (Stow et al., 2004; Latifovic et al., 2005). However, in order to analyze changes in vegetation dynamics at a landscape or local scale, finer spatial resolution data are required (Brown et al., 2006; Olthof et al., 2008; Epstein et al., 2012). The National Aeronautics and Space Administration (NASA) Landsat program, first launched with Landsat 1 in 1972, provides global coverage at a finer spatial resolution (White \& Wulder, 2014). Since the launch of Landsat 4 in 1982, this program has provided the scientific community with a standardized repository of $30 \mathrm{~m}$ spatial resolution data over the entire landmass of the planet (Wulder et al., 2016). Free and open access to this repository beginning in 2008 has spurred increased study of landscape-scale vegetation dynamics across northern high latitudes (Wulder et al., 2012; Banskota et al., 2014).

Researchers concerned with high latitude vegetation dynamics generally utilize specific satellite spectral bands and spectral derivatives that best quantify vegetation characteristics. Vegetation indices have been developed to quantify vegetation change across the landscape through various combinations of these spectral bands. The most common index used to quantify vegetation biomass is the Normalized Difference Vegetation Index (NDVI). NDVI, derived for each pixel, is equal to the near infrared value minus the red value divided by the sum of those two values, and serves as a useful proxy for quantities of vegetation (e.g., percent vegetation cover, biomass) in a satellite image (Rouse at al., 1973). As a result, researchers have utilized satellite data from different years across the boreal forest to tundra transition to create time-series of NDVI, which quantify changes in vegetation over time (Jia et al., 2003; Olthof et al., 2008; Fraser 
et al., 2011; Epstein et al., 2012; McManus et al., 2012; Raynolds et al., 2013; Frost et al., 2014; Guay et al., 2014; Pattison et al., 2015; Ju \& Masek, 2016).

\subsection{Research Rationale}

The growth and expansion of vegetation across northern high latitudes as a function of warming temperatures is an important phenomenon because it influences a variety of processes; the most direct of which may be the capacity of ecosystems to store carbon. It is estimated that the northern high latitudes store $1672 \mathrm{Pg}$ of carbon in permafrost (Schuur et al., 2008). Increases in vegetation growth, attributed to warming temperatures, allow for additional carbon to be released into the atmosphere rather than being stored in permafrost. In fact, high latitude environments have been net sources of carbon to the atmosphere since the 1980s because of increases in vegetation respiration, as well as from widespread permafrost thaw and general climate warming (Oechel et al., 1993; Slater \& Lawrence, 2013). There is strong evidence that future temperature and subsequent vegetation biomass increases in high latitude environments will contribute to soil carbon loss to the atmosphere (Crowther et al., 2016). The release of carbon from permafrost would add significantly to the global warming process as a notable positive feedback in high latitude ecosystems (Schuur et al., 2008; Crowther et al., 2016).

Changes in vegetation biomass in high latitude ecosystems also influences the albedo, or reflectivity, of the landscape. Vegetation growth is expected to lead to an increase in winter snow depth, since forest and forest-tundra communities have deeper snow depths than tundra communities on average (Sturm et al., 2001a; Jacobs et al., 2014). Plots with shrub cover also maintain snow cover for over 30 days longer per year on average than plots without shrubs (Kambo, 2017). Deeper snow patches insulate the ground from cold winter air temperatures, thus warming soil temperatures in the winter, which has been shown to influence subsequent shrub growth (both positively and negatively) over yearly and decadal time-scales (Sturm et al., 2005a; Semenchuk et al., 2016). More recent studies have found that shallow snow depths under shrubs, 
as low as $5 \mathrm{~cm}$, may insulate the ground as effectively as deep snow depths (Kambo, 2017). The intricacies of the snow-shrub relationship are not yet fully understood.

Taller vegetation means that it is more likely to remain exposed above the snow through the winter, thereby decreasing the albedo of the landscape, and representing another positive warming feedback in high latitude ecosystems (Sturm et al., 2005b; Pearson et al., 2013). Shrub expansion and treeline advance at northern high latitudes would impact landscape energy absorption in that tundra has a consistently higher albedo ( 0.8 pre-snowmelt, 0.17 post-snowmelt $)$ than shrubland ( 0.6 pre-snowmelt, 0.15 post-snowmelt $)$ and boreal forest $(0.2$ pre-snowmelt, 0.11 post-snowmelt) throughout the spring and summer (Beringer et al., 2005; Sturm et al., 2005b; Chapin et al., 2005). If shrubification and treeline advance continue, the amplification of climate warming in the Arctic could increase two to seven times given these land cover shifts alone (Chapin et al., 2005). Further study of this phenomenon indicates that annual albedo will decrease by up to $18 \%$ and spring albedo (snowmelt period) will decrease by up to $26 \%$ across northern high latitudes by 2050 (Pearson et al., 2013).

Research on the dynamics of vegetation growth due to climate change have been carried out at many locations across northern high latitudes, yet little work has been done across the expansive forest-tundra ecotone of central Canada (Harsch et al., 2009; Myers-Smith et al., 2011). This region has become an important area of study because of the drastic decline in the population of the Bathurst caribou herd in the last few decades (Boulanger et al., 2011; GNWT, 2015a). My research will therefore extend the geographical range of vegetation change measurements to an area in need of scrutiny. The influence of landscape-scale changes on vegetation change has been noted as a topic in need of further study and this research will also assist in that regard (Myers-Smith et al., 2011). Finally, a vital aspect of this study involves the exploration of vegetation change along a latitudinal gradient, rather than an elevational gradient. Many forest-tundra ecotone studies are conducted in mountainous areas since the ecotone 
changes occur on the order of hundreds of meters and are thus convenient to study. Studies along latitudinal transitions between forest and tundra are less common since ecotone changes often occur over hundreds of kilometers and are thus more difficult to examine, particularly in the context of field measurements (and associated logistics). However, remote sensing measures greatly assist in the examination of vegetation change over large spatial scales. Hence, it is important to conduct research along both gradients (i.e., elevation and latitude) in order to compare results between the different environmental gradients and thus gain a more complete understanding of the forest to tundra transition.

\subsection{Research Goal and Objectives}

The goal of my research was to assess recent ( $\sim 35$ years) vegetation changes occurring across the boreal forest to Low Arctic tundra transition of central Canada using a multispectral remote sensing vegetation index (i.e., NDVI) and to identify the landscape-scale environmental variables that most influence vegetation change across this region.

The main objectives of this study were to: (1) quantify recent vegetation changes across the forest to tundra transition of central Canada using a Landsat NDVI time-series; (2) link those trends to field measurements; and (3) determine the extent to which environmental variables (i.e., climate, land cover, topography, waterbodies) influence patterns of vegetation change across the transition. I anticipated that the results would demonstrate increases in the extent of vegetation distribution across the region, with the most significant increases occurring within and north of the forest-tundra ecotone. I also expected that vegetation expansion would have been greatest in lowland areas north of the ecotone (i.e., range extension) as well as in upland areas to the south (i.e., infilling patches). Riverine areas would likely be positively associated with vegetation expansion in the tundra, as shrubs tend to expand northward into this type of sheltered environment. These predictions were based on conclusions drawn from a variety of landscaperelated vegetation growth studies across circumpolar high latitudes (Gamache \& Payette, 2005; 
Fraser et al., 2011; McManus et al., 2012; Ropars \& Boudreau., 2012; Frost et al., 2014) but were examined here across spatial and temporal scales utilizing remote sensing data.

\subsection{Thesis Outline}

Chapter 1 has provided the context, rationale and specific goals and objectives for my research. Chapter 2 presents an extensive review of the scientific literature that supports this research, including recent vegetation changes across the forest to tundra transition and the application of remote sensing to monitor that process. Chapter 3 (in manuscript form) presents the methodology (including a description of the study area in north-central Canada and the collection and analyses of field measurements and Landsat satellite data), results and discussion of the

findings of this research. Chapter 4 presents the overall conclusions of the study, including a summary of findings, a discussion of limitations and future opportunities. 


\section{Chapter 2}

\section{Literature Review}

\subsection{Recent Vegetation Change across the Forest to Tundra Transition}

The region of transition from sub-Arctic boreal forest to Low Arctic tundra, of which the forest-tundra ecotone is the most abrupt transition, has become an important focus for vegetation change studies given its sensitivity to climate change. Treeline, specifically the 1:1000 tree:tundra ratio line (Timoney et al., 1992) on the Circumpolar Arctic Vegetation Map (CAVM), is the commonly accepted boundary between the sub-Arctic and Low Arctic for researchers and policy makers concerned with monitoring high latitude ecosystems (Walker et al., 2005). Studies have demonstrated that the forest-tundra ecotone and adjacent Low Arctic tundra have been key areas for significant NDVI increases (i.e., greening), especially in shrub-dominated environments (McManus et al., 2012; Myers-Smith et al., 2015). However, recent evidence on boreal ecosystem productivity has been mixed with some continental boreal forests exhibiting a significant decrease in NDVI (i.e., browning) (Verbyla et al., 2008; Beck \& Goetz, 2012; Guay et al., 2014). The differences in the responses of these ecosystems to climatic and environmental pressures deserves more study, especially at finer spatial scales. In the long term, remote sensing data will facilitate the monitoring of these changes at multiple spatial and temporal scales.

\subsubsection{The Modern Forest-Tundra Ecotone}

The forest-tundra ecotone represents the area of transition between boreal forest and tundra communities that occurs across northern high latitudes and in alpine environments (Payette et al., 2001). The term was brought into widespread use by Clements (1936) as part of his discussion on 'climax vegetation', or when climate dictates the boundary between biomes. Although originally defined by Clements (1936) as an alpine transition, more recent studies have characterized the latitudinal transition connecting sub-Arctic boreal forests to Low Arctic tundra 
as the forest-tundra ecotone as well (McManus et al., 2012; Berner et al., 2013). The southern limit of the forest-tundra ecotone is marked by a gradual decrease in tree cover moving away from closed-canopy boreal forests. In the north, the forest-tundra ecotone ends with the last tree found on the landscape (i.e., treeline) (Payette et al., 2001).

The forest-tundra ecotone is complex, with forested and non-forested areas in close proximity. Payette et al. (2001) described the forest-tundra ecotone as a "constellation of subArctic tree lines" influenced by historical fire disturbance, bedrock geology, soil quality and topography. Epstein et al. (2004) noted two types of latitudinal forest-tundra ecotones in Alaska. The first occurs along major drainage systems, where forested ecosystems transition into shrubdominated ecosystems over tens of meters. This more abrupt forest-tundra ecotone is attributed to the relative lack of permafrost on these floodplains and nutrient-rich soils. In non-riverine areas, the forest-tundra ecotone can stretch for many kilometers across the landscape. Timoney (1995) found examples of these ecotones in north-central Canada, such as the Thelon River tree oasis where trees can be found up to $300 \mathrm{~km}$ north of their counterparts in non-riverine areas (Figure 2.1). The general northern treeline shift west of Great Slave Lake is associated with fine textured and nutrient-rich soils derived from sedimentary rocks. It is also possible for sub-fossil trees and resilient krummholz patches to be found well past modern treeline as remnants of past advance (Danby, 2011; Trant et al., 2011).

The modern forest-tundra ecotone has been mapped across northern high latitudes through a combination of field expeditions and remote sensing analyses. In northern Canada, the forest-tundra ecotone was mapped from Hudson Bay to the Alaskan border by Timoney et al. (1992) (Figure 2.1). The authors analyzed aerial photographs to derive tree:upland tundra cover ratio isolines across the landscape and verified these results on the ground across multiple field seasons. Timoney et al. (1992) defined the southern boundary of the forest-tundra ecotone as the 1000:1 tree:tundra ratio line and northern boundary (i.e., treeline) as the 1:1000 tree:tundra ratio 
line. Further research in this region linked intricacies of the forest-tundra ecotone to parent materials and soils, elevation and distance to rivers and lakes (Timoney et al., 1993; 1995).

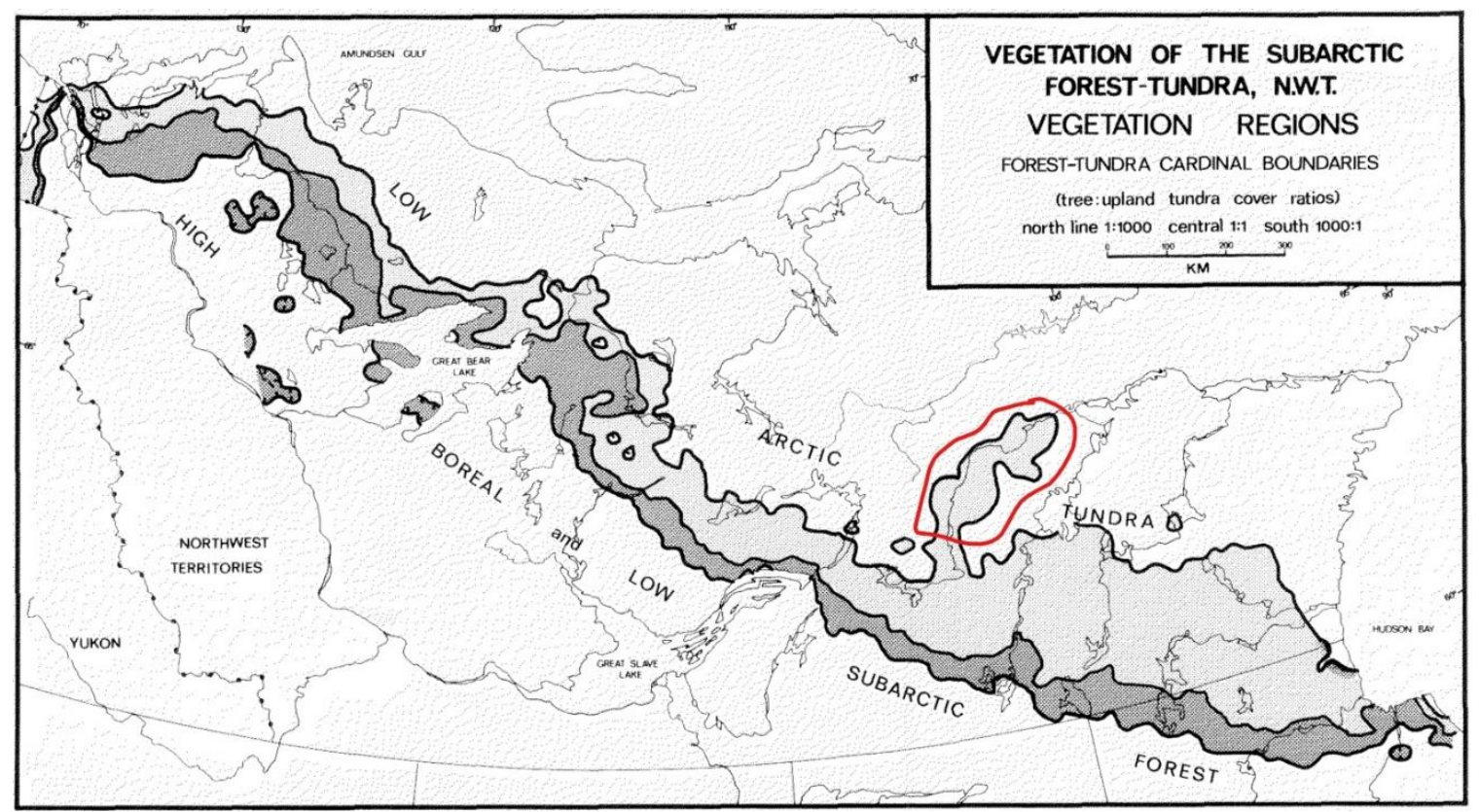

Figure 2.1: Boundaries of the forest-tundra ecotone in central Canada based on tree:upland tundra cover ratios. Thelon River tree oasis circled in red. Figure from Timoney et al. (1992).

The government of Northwest Territories (GNWT) has developed detailed ecosystem classification reports describing the Taiga Shield and Southern Arctic ecological regions within the territory (Ecosystem Classification Group, 2008; 2012). The boundary between these Level II Ecoregions coincides with the transition from forest to tundra dominated environments (Figure 2.2) and follows a similar outline as Timoney et al.'s (1992) treeline (Figure 2.1). The difference between the Taiga Shield's cold continental climate and the Southern Arctic's polar climate also helps mark their boundary (Ecosystem Classification Group, 2008; 2012). A comparable ecosystem classification for Nunavut is not currently available. 


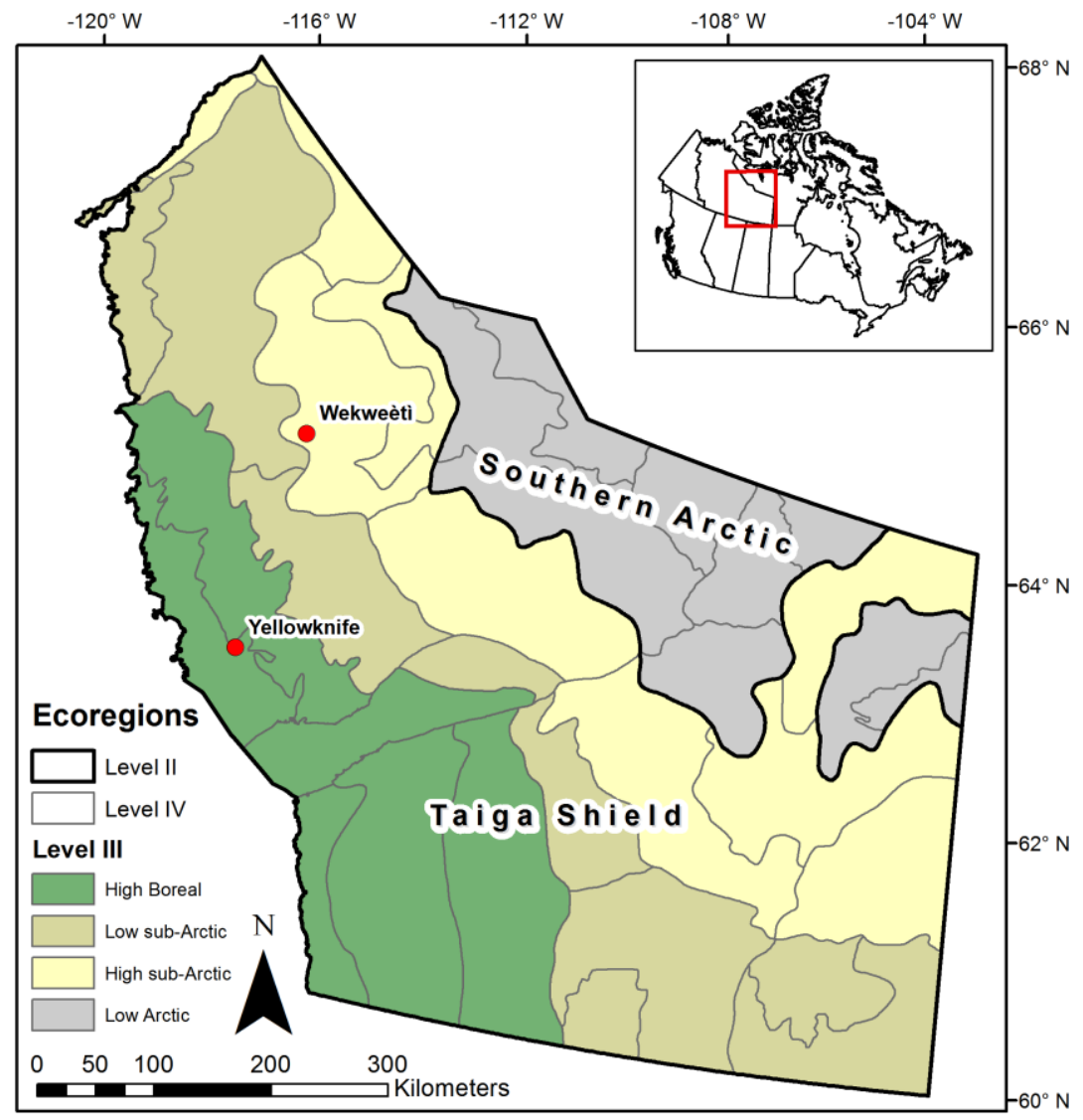

Figure 2.2: Ecoregions of eastern Northwest Territories. Data from Ecosystem Classification Group (2012) and the GNWT.

Additional intricacies between sub-Arctic boreal forest and Low Arctic tundra are noted in GNWT's ecoregion classification (Figure 2.2) (Ecosystem Classification Group, 2008; 2012). In the Taiga Shield, the High Boreal ecoregion is classified as having dense forest stands, predominantly comprised of black spruce (Picea mariana), and discontinuous permafrost. The Low sub-Arctic ecoregion mostly contains shorter and more open black and white spruce (Picea glauca) forests with widespread permafrost. In the High sub-Arctic ecoregion, smaller spruce stands are found mostly in protected areas such as lakeshores, lower slopes, eskers and gullies. Permafrost is widespread and becomes continuous near the Southern Arctic ecoregion boundary. In the Southern Arctic, the Low Arctic ecoregion mainly consists of erect- and dwarf-shrub tundra underlain by continuous permafrost. 


\subsubsection{Shrub Expansion at, and north of the Forest-Tundra Ecotone}

Increasing shrub growth and expansion has been documented at, and north of the foresttundra ecotone in the last few decades. Sturm et al. (2001b), here deemed as the original "shrubification" paper, used repeat aerial photographs to illustrate shrub expansion in northern Alaska in the late 1900s and attributed this increase to climate warming. On the Seward Peninsula in western Alaska, shrub advances of around $100 \mathrm{~m}$ were found in valleys and along riverbeds (Silapaswan et al., 2001). Tape et al. (2006; 2012) built upon these early studies and documented shrub expansion across Alaska from aerial photographs, especially in riparian areas. Predictive models based on climate data and photosynthetic activity also project that shrub tundra ecosystems will continue to become more productive for the foreseeable future (Figure 2.3) (Bunn et al., 2005; Epstein et al., 2007; Pearson et al., 2013; Zhang et al., 2013). Satellite-based remote sensing analyses conducted across northern high latitudes demonstrate increased vegetation productivity in shrub-dominated environments as well (although some more recent studies indicate that tundra productivity may be decreasing), but quantifying the influence of landscape variability and other environmental pressures on those changes remains elusive over larger areas (see section 2.2).

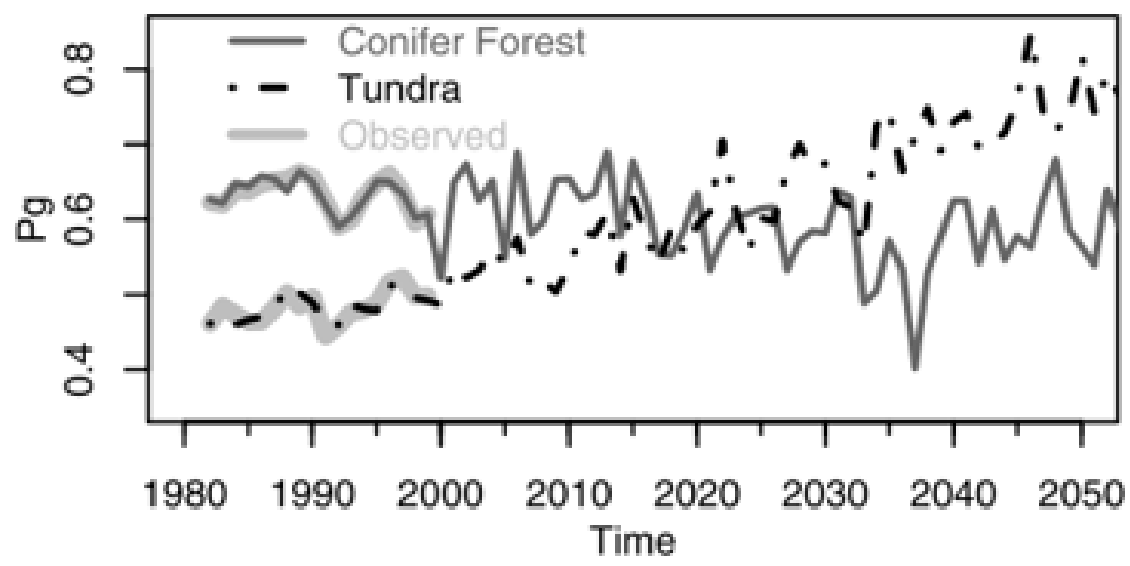

Figure 2.3: Summer photosynthetic activity (Pg) of tundra and conifer forest ecosystems through 2050 using global climate model data and satellite observations from 1981-2000. Figure from Bunn et al. (2005). 
More recent studies have found shrub growth and expansion has also occurred in Siberia. Forbes et al. (2010) found that there has been a significant increase in willow shrub (Salix spp.) growth since the 1940s based on an annual ring chronology. This chronology had a strong relationship with summer temperatures over this time period. In northeastern Siberia, the ring widths of various shrub species correlated positively with summer precipitation and peak summer NDVI (Blok et al., 2011). Further satellite NDVI and tree-ring studies in tundra shrublands and boreal woodlands in that region revealed that mean summer NDVI increases were primarily associated with shrub-dominated locations (Berner et al., 2013). Sites disturbed by frost-heave, which create mineral-rich sites for shrub recruitment, have been documented as key locations for shrub expansion north of treeline in Siberia (Frost et al., 2013). The long-term greening of these Siberian shrub-dominated landscapes is borne out in NDVI time-series analyses as well (see section 2.2).

In addition to Alaska and Siberia, shrub growth has also been observed in northern Canada. In the Mackenzie Delta Region there has been a $68 \%$ increase in alder (Alnus spp.) stem density and a $15 \%$ increase in general tall shrub cover since 1972 (Lantz et al., 2013). This growth is likely sensitive to temperature increases and a higher frequency of tundra fires in the area (Lantz et al., 2010; 2013). In eastern Canada, marked increases in vegetation productivity have been observed in northern Québec (Ju \& Masek, 2016). Ropars and Boudreau (2012) found that hilltops and terraces in particular exhibited increases in shrub cover and that much of this growth had been associated with dwarf birch (Betula glandulosa). Shrub (mainly Betula spp.) cover increased on over $50 \%$ of land available for expansion and infilling in this region (Tremblay et al., 2012). Climate and landscape topography have been important drivers of shrub expansion here (Ropars et al., 2015).

Broad-scale studies have looked to synthesize the information gained from the collection of local-scale efforts to demonstrate widespread shrubification. Epstein et al. (2004) found that 
the current boundary between forest and tundra was primarily associated with climate, in addition to differences in permafrost coverage. Myers-Smith et al. (2011) noted that shrub growth and expansion has been found across northern high latitudes over the last century (Figure 2.4). This increase in productivity fell into three categories: infilling of existing patches, growth increase and shrubline advance (either up slope or northward depending on landscape topography). Of the 23 sites considered by Myers-Smith et al. (2011), 18 had observed shrub increase and none had observed a shrub decrease. Elmendorf et al. (2012) conducted plot-scale studies across 46 tundra locations in the Arctic and Antarctica and found that shrubs were increasing in height, growing more leaves and spreading in extent across the biome. It is thus well supported that shrub growth is occurring across northern high latitudes in areas proximal to, and north of the forest-tundra ecotone.

a)

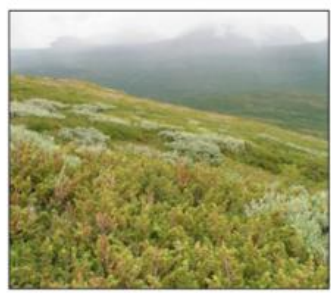

b)
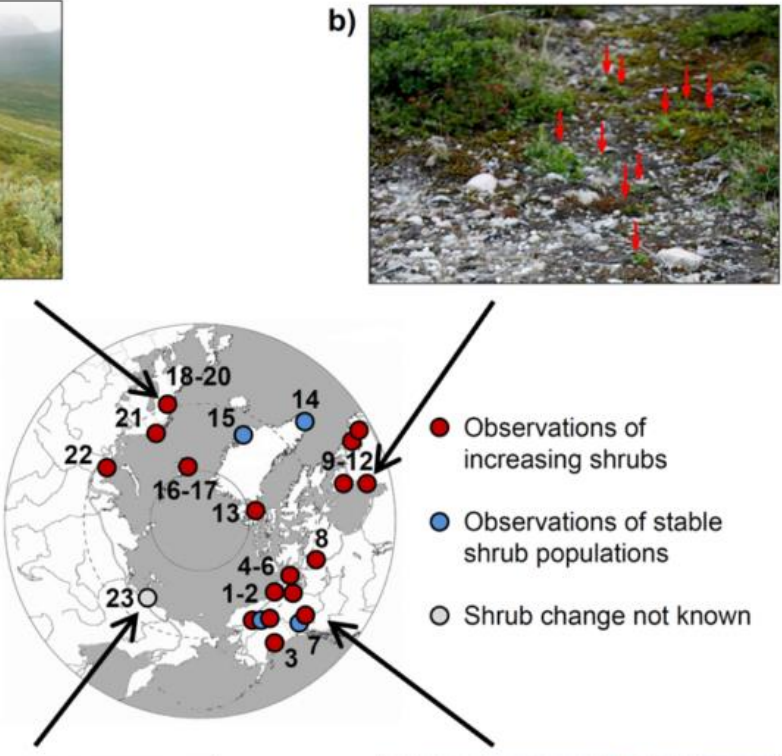

c)

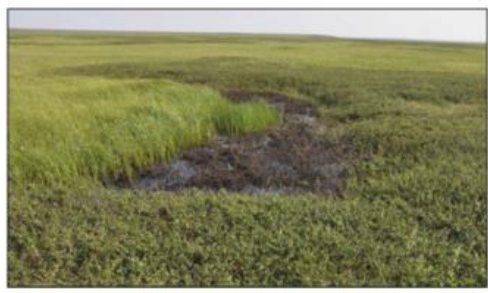

d)

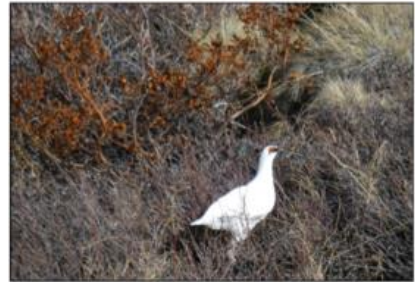

Figure 2.4: Shrub change studies across northern high latitudes synthesized by Myers-Smith et al. (2011). Photos (a-d) indicate different shrub responses at specific sites. Figure from Myers-Smith et al. (2011). 


\subsubsection{Mixed Signals of Treeline Shift}

Although shrubs have exhibited significant growth increases at, and north of the foresttundra ecotone, reports of an actual shift in treeline have been mixed (Figure 2.5). A synthesis of treeline studies published before June 2008 were collected to monitor global treeline change since 1900 (Harsch et al., 2009). It was found that treeline advance, meaning new recruitment $10 \mathrm{~m}$ beyond the historical position for altitudinal treeline and $80 \mathrm{~m}$ for latitudinal treeline, had occurred at $52 \%$ of sites ( 87 of 166). Treeline remained stable at 77 of 166 sites (46\%) and receded at just 2 of the 166 sites (in both cases likely attributed to disturbance). Harsch et al. (2009) also found that $80 \%$ of diffuse treelines, where tree density decreases gradually as altitude or latitude increases, had advanced compared to only $22 \%$ of abrupt or krummholz treelines. Diffuse treelines were often summer temperature limited, while abrupt and krummholz treelines were often winter temperature limited or a result of damage (i.e., from wind, snow and desiccation). These environmental pressures, as well as others, that determine whether a treeline will advance or not are not yet fully understood.

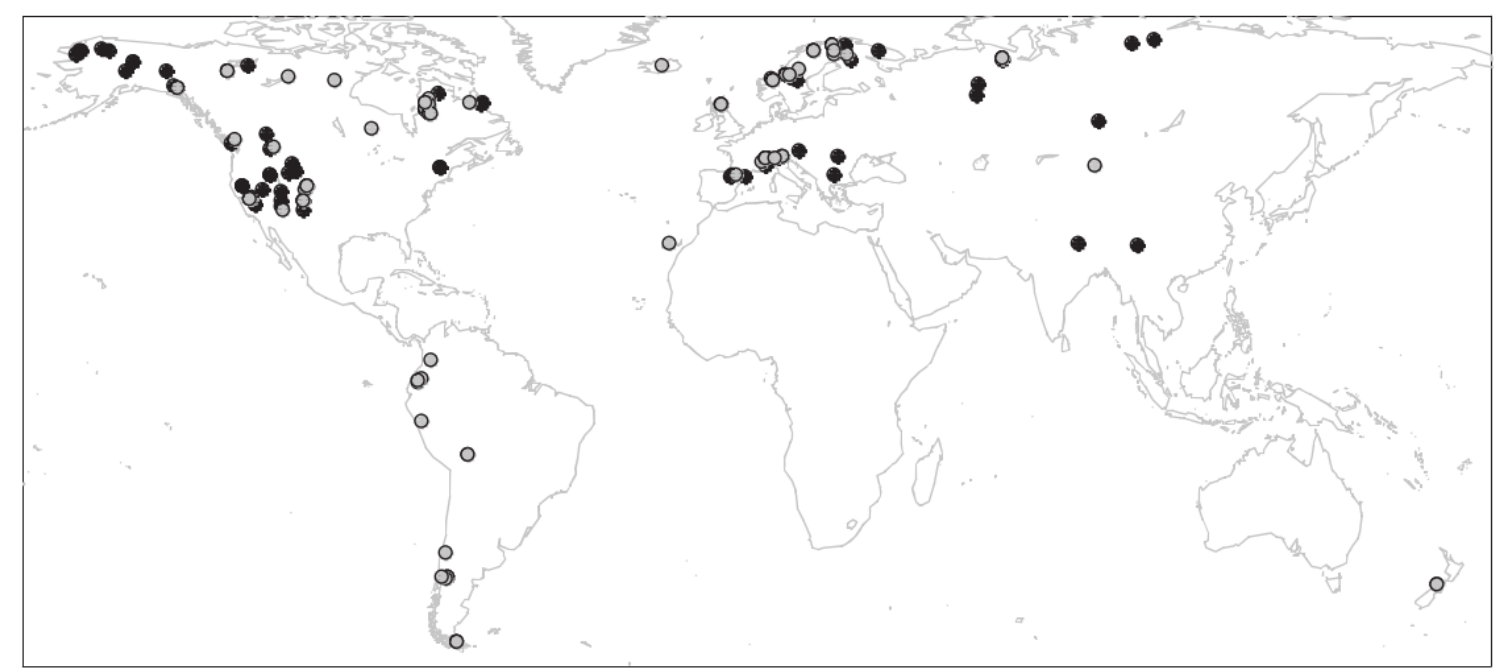

Figure 2.5: Location of treeline studies analyzed by Harsch et al. (2009). Advancing sites are indicated with black circles and stable sites are indicated with gray circles. Figure from Harsch et al. (2009). 
Although treeline shift has not occurred in all areas, studies have detected treeline advance in many locations across northern high latitudes. Simulations of vegetation dynamics across northern high latitudes indicate a notable northern shift of the forest-tundra ecotone in Siberia and Canada over the next century (Zhang et al., 2013). Suarez et al. (1999) found that forest stands had shifted up to $100 \mathrm{~m}$ into what were previously tundra ecosystems in the past 200 years based on tree age analysis at the ecotone edge in Alaska. On Alaska's Seward Peninsula, boreal forest has gradually pushed into tundra ecosystems and become more dense where it has been present since the early 1900s (Lloyd et al., 2003). In Siberia, Lloyd et al. (2011) also found significant increases in productivity in northern boreal tree populations near treeline; although more southern populations experienced decreases in productivity.

Forest-tundra ecotone studies in Canada (mostly in Yukon and northern Québec) have also noted both altitudinal and latitudinal treeline advance, as well as forest density increases below treeline. In the Kluane Range of southwest Yukon, Danby \& Hik (2007) used dendroecological techniques to demonstrate that spruce trees had advanced up to $85 \mathrm{~m}$ on warmer south-facing slopes and that colder north-facing slopes, where treeline had remained static, did have increases in forest density since the early 1900s. Landsat data has indicated that vegetation productivity has increased in established forest stands near treeline elsewhere, which has been attributed to increases in forest density (Zhang et al., 2009). In northern Québec, trees have both increased in height and expanded slightly into tundra hilltops in the last 50 years (Gamache \& Payette, 2004; 2005). Establishment has been slow because of the difficulty for krummholz to grow in dry, wind-exposed tundra sites. A shrub-based study in the region found that $25 \%$ of plots above treeline contained tamarack (Larix laricina) seedlings and saplings, indicating that treeline shift into tundra could still be occurring (Tremblay et al., 2012).

Even in studies where treeline advance has been recorded, further expansion is considered potentially limited by factors such as wind, moisture availability and other landscape 
variables that make new establishment less likely (Suarez, 1999; Gamache \& Payette, 2005; Lloyd et al., 2011). In central Canada, MacDonald et al. (1998) found no northward advancement of spruce forest from an examination of dendrochronological and historical records. Remote sensing analysis of the forest-tundra ecotone in Northwest Territories and Québec also revealed no noticeable forest advance between 1970 and 2000 (Masek, 2001). Meanwhile, a long-term simulation of forest-tundra ecotone dynamics in northwestern Alaska indicated that it could take up to 4000 years for forests to expand onto the North Slope of the Brooks Range even with $9{ }^{\circ} \mathrm{C}$ temperature increases (Rupp et al., 2001). In this case, topography plays a major role as the Brooks Range forms a barrier to seed dispersal that is currently too inhospitable to colonize. Short-term simulations across the forest to tundra transition, which show substantial increases in tundra productivity, indicate that boreal forest productivity in general could remain relatively static or even decrease slightly (Figure 2.3) (Bunn et al., 2005).

There is little evidence of treeline itself significantly receding at northern high latitudes in recent decades. Foster \& D'Amato (2015) found that forest ecotones shifted downslope for some areas of the Appalachian Mountains of the northeastern United States since 1984, likely attributable to human disturbance rather than any climate phenomenon. However, research has noted that some boreal forest ecosystems south of the forest-tundra ecotone are becoming less productive in recent decades. A dendrochronology-based study in boreal Alaska demonstrated that, contrary to trends elsewhere, tree ring growth had decreased as temperatures increased (Barber et al., 2000). Remote sensing analyses have also noted this, with results across northern high latitudes indicating significant productivity increases in tundra ecosystems matched with significant productivity decreases in some boreal ecosystems (Goetz et al., 2005; Verbyla, 2008; Guay et al., 2014; Ju \& Masek, 2016) (Figure 2.6). Similar results were found in Siberia, with forest-tundra ecotone areas increasing in productivity while more southern locations were decreasing in productivity (Lloyd et al., 2011). Positive correlations between NDVI and tree ring 
widths have been used to link smaller ring growth to decreased forest productivity across both Russia and Canada (Berner et al., 2011). This decrease in productivity has not been observed everywhere and in other boreal forest ecosystems productivity has been slowly increasing (McManus et al., 2012). The reasons for this dichotomy require further research.

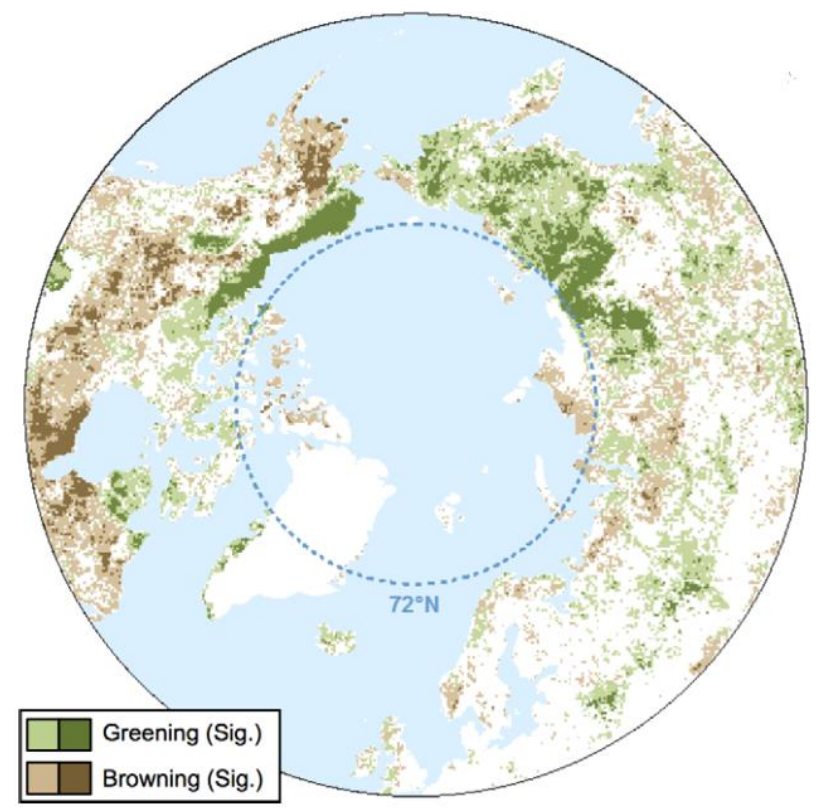

Figure 2.6: Changes in photosynthetic activity (greening and browning) across northern high latitudes from Global Inventory Modeling and Mapping Studies (GIMMS) data (1982 - 2008). Dark colors highlight significant change $(\mathrm{p}<0.05)$. Figure from Guay et al. (2014).

\subsubsection{Why are Shrubs Expanding more than Boreal Tree Species?}

Shrub growth and expansion have been occurring across northern high latitudes in almost every case. Increases in precipitation, whether it be snow or rain, provide vegetation with water during the summer; thereby facilitating increased vegetation growth, especially in tundra environments (Sturm et al., 2001a; Gamon et al, 2013). Sturm et al. (2005a) hypothesized a positive feedback where increased summer temperature initiates increased shrub growth; while in the winter, shrubs can trap snow, thereby insulating the soil and increasing winter soil temperatures. However, Semenchuk et al. (2016) found, after multiple years, that deeper snowpacks significantly reduced vegetation respiration rates during the growing season. In the end, a 
combination of factors related to the Arctic amplification phenomenon, especially the decline of sea ice extent and volume, are likely spurring shrub growth and expansion in coastal locations across northern high latitudes (Bhatt et al., 2010). However, more research is required to confirm and quantify these and other environmental influences on Low Arctic tundra productivity.

The significant increase in productivity of tundra ecosystems documented since the mid1900s has not been matched in boreal forest ecosystems. First, boreal trees (e.g., black spruce) colonize new areas at slower rates than shrubs (Black \& Bliss, 1980; Gamache \& Payette, 2005). Increasing temperatures, while allowing shrubs in higher moisture environments to expand, is leading to drought in dry continental boreal ecosystems as a result of increased evapotranspiration (Barber et al. 2000; Verbyla, 2008). Drought stress is a serious limitation on boreal ecosystems ability to sequester carbon, meaning that these forests may be less able to sequester carbon from the atmosphere in the future (Barber et al., 2000).

Fire disturbance is another factor that influences boreal forest productivity. This is especially true in central NWT, which has been subject to regular fire disturbance since regular monitoring began in 1965 (GNWT, 2015b). Fires in high latitude boreal forests are common, with an average of 600,000 ha burned in Northwest Territories every year (GNWT, 2015b). The forested area burned by fires has steadily increased across Canada since the late 1970s (MaciasFauria \& Johnson, 2008). Increases in fire disturbance have been associated with the transition from high biomass closed-canopy boreal forests to lichen-woodlands across parts of northern Québec (Girard et al., 2008). Fires in tundra ecosystems are less common than in boreal forests, but are becoming more common as the climate warms and vegetation biomass increases in those areas (Higuera et al., 2008). A massive fire that occurred on the Anaktuvuk River in northern Alaska in 2007 has been a focus of recent studies that link remote sensing techniques to fire disturbance in tundra environments (Jones et al., 2009; Kolden \& Roganf, 2013). 


\subsection{Remote Sensing of Vegetation Change across the Forest to Tundra Transition}

The collection, processing and analyses of remote sensing data, acquired from ground, airborne or satellite platforms, has become a common method for monitoring vegetation dynamics at northern high latitudes. Given the difficulty of mounting intensive (and extensive) field expeditions at high latitudes, remote sensing data are being relied upon to collect spatial and temporal information about vegetation properties, including change, across large areas. Today, remote sensing data are routinely collected at a range of spatial and temporal scales. These data allow for the analysis of various biogeophysical variables across space and through time. For instance, leaf area index (LAI) is commonly used to model vegetation productivity; however, LAI is not applied routinely at northern high latitudes since accurate relationships between remote sensing data and LAI are dependent on accurate field measures (Fan et al., 2009; Abuelgasim \& Leblanc, 2011). NDVI studies have become more common in this regard since NDVI can be accurately derived from open access Landsat data (Wulder et al., 2012).

Ground validation of NDVI is also possible, with the metric having relationships with field measurement techniques, such as LAI and others. Based on field measures of percent vegetation cover (PVC), regression models have been developed that estimate PVC spatially at high latitudes based on NDVI data derived from satellite remote sensing platforms (Purevdorj et al., 1998; Laidler et al., 2008; Liu \& Treitz, 2016). Vegetation volume has been similarly linked with NDVI (Chen et al., 2009; Gregory, 2011). Tree ring width has also been positively correlated with satellite-derived NDVI in Russia and Canada (Berner et al., 2011), although this link with wood biomass is far less clear (e.g., Brehaut 2015). Other field measurement techniques, such as fraction of absorbed photosynthetically active radiation (fAPAR) and biomass collection, can be linked to remote sensing NDVI measurements as well (Jia et al., 2003; Yuan et al., 2007; Epstein et al., 2012). Ground validation of remote sensing results is important to 
confirm that changes observed by the satellite sensor actually reflect real changes on the ground, but are not undertaken by many remote sensing-based studies due to time and cost constraints.

\subsubsection{NDVI as a Metric of Vegetation Productivity}

NDVI is a metric indicative of vegetation productivity and is based on the differential response (i.e., absorption/reflectance) of vegetation to red (R) and near infrared (NIR) wavelengths (Rouse et al., 1973; Tucker, 1979):

$$
\mathrm{NDVI}=(\mathrm{NIR}-\mathrm{R}) /(\mathrm{NIR}+\mathrm{R})
$$

In general, healthy green vegetation absorbs PAR in the visible portion of the spectrum for photosynthesis; but more specifically, chlorophyll a and $\mathrm{b}$ absorb very strongly in the $\mathrm{R}$ portion of the visible spectrum. Meanwhile, healthy green vegetation reflects very strongly in the NIR as this wavelength is not utilized for photosynthesis. Thus, healthy vegetation appears dark in the $\mathrm{R}$ band (low reflectance) and bright in the NIR band (high reflectance); this relationship allows the NDVI to correlate well with the amount of healthy vegetation present in the sensor's field of view.

NDVI has been demonstrated as a useful metric for studies concerned with vegetation productivity. It was first utilized in the early 1970s to monitor vegetation growth in the U.S. Great Plains (Rouse et al., 1973). Further research by Tucker (1979) indicated that the NIR and R combination was superior for estimating photosynthetically active biomass than other band combinations. The success of NASA's Landsat program (1972-present) at providing global satellite coverage at an intermediate spatial resolution has allowed for many NDVI-based studies to be completed worldwide (Wulder et al., 2012; 2016).

Early study involving the remote sensing of high latitude vegetation began with measurements of the albedo of various sub-Arctic land-cover types in Québec and Labrador (Davies, 1962; Petzold \& Rencz, 1975). NDVI-based studies in the Low Arctic were initially focused on monitoring vegetation disturbance from pollution in Siberia and elsewhere (Rees et 
al., 1998). Preliminary investigations revealed that NDVI was more sensitive to land-cover type than biomass in high latitude environments (Rees et al., 1998). After interest in monitoring northern vegetation grew, studies demonstrated that NDVI correlated closely to biomass and other vegetation structural attributes (Raynolds et al., 2006; Boelman et al., 2011; Epstein et al., 2012). Rees et al. (2002) reported that NDVI derived from satellite data was the optimal method for monitoring the forest-tundra ecotone, particularly at landscape and regional scales. Research on vegetation change using spectral indices (e.g., NDVI) has occurred mostly in the last 15 years.

\subsubsection{Remote Sensing Platforms used to Monitor Northern Vegetation Change}

Depending on the scale of the study in question, different remote sensing platforms can be considered for examining vegetation change across northern high latitudes (Stow et al., 2004) (Table 2.1). Ground-level sensors, such as field spectro-radiometers, provide fine-scale spectral data for studies interested in plot level NDVI. NDVI cameras that capture data in the NIR and visible regions of the electro-magnetic spectrum are also used for field data collection (Liu \& Treitz, 2016). Aerial photography, which provides high spatial resolution data as far back as the early 1940s, is useful for landscape-scale studies. High spatial resolution satellite data, such as commercially available IKONOS or WorldView, are able to link spectral information directly with field data (i.e., plots or local areas). Landsat data (i.e., $30 \mathrm{~m}$ spatial resolution) have allowed for the analysis of NDVI trends across landscapes and regions since 1984 (White \& Wulder, 2014). Meanwhile, coarse spatial resolution satellite data, such as the Moderate Resolution Imaging Spectrometer (MODIS) or the Advanced Very High Resolution Radiometer (AVHRR), are useful for regional and continental scale studies looking at NDVI trends over large areas.

At fine-scales, field spectro-radiometers are used to measure NDVI values at the individual or plot level. Laidler et al. (2008) collected surface reflectance measurements across multiple large plots in a tundra environment to derive NDVI measures for comparison to IKONOS and Landsat spectral indices for vegetation types on Boothia Peninsula, Nunavut. 
Boelman et al. (2011) collected plot-level measurements to demonstrate differences in NDVI associated with vegetation canopy structure at different times during the growing season. Pattison et al. (2015) utilized spectro-radiometer data to compare to coarser spatial resolution satellite data in order to detect trends in NDVI and changes in tundra vegetation composition in Alaska since 1984. These studies demonstrate the utility of surface-derived NDVI for modelling biophysical variables measured in the field (i.e., PVC, biomass, etc.). NDVI data collected at the ground-level also allow for comparison with satellite-derived NDVI, in order to compare and account for any atmospheric effects that could affect the quality of satellite data (Laidler et al., 2008; Pattison et al., 2015). Plot level NDVI data collected by spectro-radiometers are useful at fine spatial scales but the lack of a long-term data repository limits their utility for time-series analysis.

Table 2.1: Commonly used remote sensing platforms for vegetation monitoring at northern high latitudes. Satellite information from Xie et al. (2008) and Wulder et al. (2016).

\begin{tabular}{|c|c|c|c|c|c|}
\hline $\begin{array}{l}\text { Remote Sensing } \\
\text { Platform }\end{array}$ & $\begin{array}{l}\text { Spatial } \\
\text { Resolution }\end{array}$ & Revisit Time & $\begin{array}{l}\text { Temporal } \\
\text { Range } \\
\end{array}$ & $\begin{array}{l}\text { Spatial } \\
\text { Range }\end{array}$ & Example Studies \\
\hline $\begin{array}{l}\text { Ground-level } \\
\text { Sensors (NDVI } \\
\text { cameras; } \\
\text { Spectro- } \\
\text { radiometers) } \\
\end{array}$ & $\begin{array}{l}\text { Usually } \\
\text { less than } 10 \\
\mathrm{~cm}\end{array}$ & $\begin{array}{l}\text { Determined by } \\
\text { user in the } \\
\text { field }\end{array}$ & $\begin{array}{l}\text { 1990s to } \\
\text { present }\end{array}$ & $\begin{array}{l}\text { Small } \\
\text { Scale }\end{array}$ & $\begin{array}{l}\text { Laidler et al., 2008; } \\
\text { Boelman et al., 2011; } \\
\text { Pattison et al., 2015 }\end{array}$ \\
\hline $\begin{array}{l}\text { Aerial } \\
\text { Photography }\end{array}$ & $\begin{array}{l}\text { Usually } \\
\text { less than } 1 \\
\mathrm{~m}\end{array}$ & Variable & $\begin{array}{l}\text { 1940s to } \\
\text { present }\end{array}$ & $\begin{array}{l}\text { Historical } \\
\text { flight } \\
\text { paths. On } \\
\text { Demand }\end{array}$ & $\begin{array}{l}\text { Sturm et al., 2001b; Tape } \\
\text { et al., 2006; Ropars \& } \\
\text { Boudreau, 2012; } \\
\text { Tremblay et al., 2012; } \\
\text { Fraser et al., 2014a }\end{array}$ \\
\hline $\begin{array}{l}\text { High Spatial } \\
\text { Resolution } \\
\text { Satellites } \\
\text { (IKONOS, } \\
\text { Worldview etc.) } \\
\end{array}$ & 0.5 to $10 \mathrm{~m}$ & On Demand & $\begin{array}{l}\text { Late } 1990 \mathrm{~s} \\
\text { to present }\end{array}$ & $\begin{array}{l}\text { On } \\
\text { Demand }\end{array}$ & $\begin{array}{l}\text { Laidler et al., 2008; } \\
\text { Ropars \& Boudreau, } \\
\text { 2012; Simms \& Ward, } \\
\text { 2013; Frost et al., 2014; } \\
\text { Guay et al., 2014 }\end{array}$ \\
\hline $\begin{array}{l}\text { Intermediate } \\
\text { Spatial } \\
\text { Resolution } \\
\text { Satellites } \\
\text { (Landsat TM, } \\
\text { ETM+, OLI) } \\
\end{array}$ & $30 \mathrm{~m}$ & $\begin{array}{l}8 \text { to } 16 \text { days } \\
\text { (low latitude), } \\
2 \text { to } 8 \text { days } \\
\text { (high latitude) }\end{array}$ & $\begin{array}{l}1982 \text { to } \\
\text { present }\end{array}$ & Worldwide & $\begin{array}{l}\text { Masek, 2001; Fraser et } \\
\text { al., 2011; McManus et } \\
\text { al., 2012; Raynolds et } \\
\text { al., 2013; Frost et al., } \\
\text { 2014; Ju \& Masek, } 2016\end{array}$ \\
\hline $\begin{array}{l}\text { Coarse Spatial } \\
\text { Resolution } \\
\text { Satellites } \\
\text { (AVHRR, } \\
\text { MODIS) } \\
\end{array}$ & $>200 \mathrm{~m}$ & 1 to 2 days & $\begin{array}{l}1978 \text { to } \\
\text { present }\end{array}$ & Worldwide & $\begin{array}{l}\text { Jia et al., 2003; Verbyla, } \\
\text { 2008; Bhatt et al., 2010; } \\
\text { Berner et al., 2011; } \\
\text { Lloyd et al., 2011; } \\
\text { Epstein et al., 2012 }\end{array}$ \\
\hline
\end{tabular}


Aerial photography has routinely been collected since the 1940s. Although image quality varies, these photographs allow for high spatial resolution quantification of vegetation change over the landscape for a longer time-series than are available from any other remote sensing platform. Sturm et al. (2001b) found compelling evidence of shrub expansion in Alaska by comparing oblique aerial photographs collected in 1949 and 2000 (Figure 2.7). Tape et al. (2006) expanded on this by comparing over 200 pairs of aerial photographs from across northern Alaska and linking observed shrub expansion to increases in NDVI in those same areas. Aerial photography can also be analyzed in combination with satellite data to provide multiple scales of coverage over a study area, as has been done in northern Québec to link vegetation change to local topography (Ropars \& Boudreau, 2012). Further research in northern Québec by Tremblay et al. (2012) demonstrate that aerial photographs can be used to discern between different densities of shrub cover in order to quantify those changes over $50+$ years. Studies wishing to use aerial photography to conduct vegetation change analyses are limited by the lack of consistent annual revisit times, scales of acquisition and the limited extent of historical flight paths.

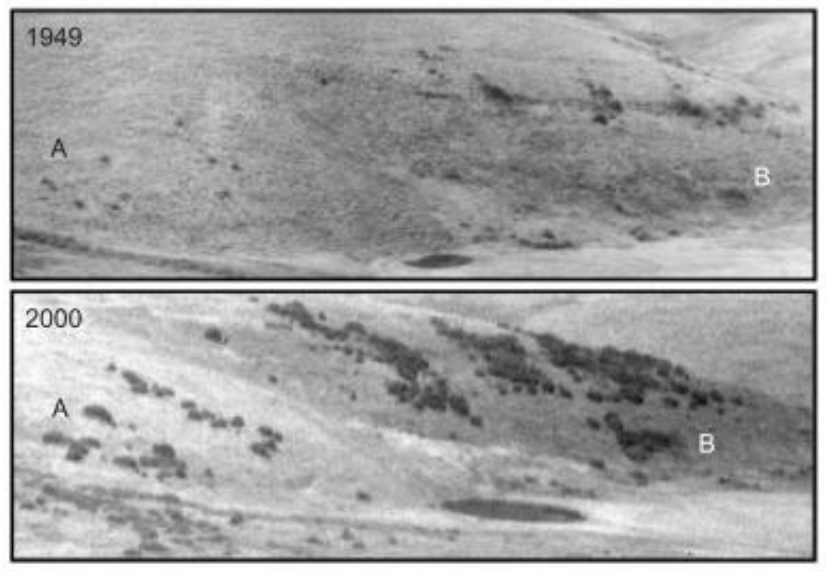

Figure 2.7: Oblique aerial photographs from 1949 and 2000 showing an increase in the density and extent of shrubs near the Ayiyak River in Alaska. Figure from Sturm et al. (2001b).

High spatial resolution satellites provide commercially available access to 1 to $10 \mathrm{~m}$ spatial resolution data anywhere on Earth. Often, high spatial resolution data are used in 
combination with either ground measurements or coarser spatial resolution data to observe the landscape in question at multiple scales (Laidler et al., 2008; Guay et al., 2014). An interesting example of this was reported by Frost et al. (2014), who utilized declassified U.S. military high spatial resolution satellite data from the 1960s to supplement a Landsat NDVI time-series in Siberia. Simms \& Ward (2013) utilized this principle in the creation of a five image NDVI timeseries (1983-2008) in the Mealy Mountains of Labrador from five different satellite platforms. Landsat MSS (80 m), TM (30 m) and ETM+ (30 m), as well as ASTER (15 m) and SPOT HRVIR (10 m) were used to monitor NDVI trends at this alpine forest-tundra ecotone. High spatial resolution data does not have as long of a temporal range as coarser spatial resolution sensors though, with most platforms in this category launching only in the late 1990s.

Researchers wanting to create NDVI time-series using high spatial resolution data are also limited by the need to purchase images from these sensor platforms. The costs associated with these acquisitions, along with the lack of long-term data limit NDVI time-series mostly to coarse and intermediate spatial resolution remote sensing data.

The coarse spatial resolution AVHRR provides data extending back to the late 1970s and is useful for monitoring vegetation change at continental scales. Jia et al. (2003) utilized AVHRR data to monitor NDVI trends on Alaska's North Slope and to compare with change across northern high latitudes. More recently, the GIMMS $3^{\text {rd }}$ generation dataset (based on AVHRR data) was developed specifically for the northern high latitudes and has been used in other broadscale studies (Verbyla, 2008; Bhatt et al., 2010; Guay et al., 2014). Research in Siberia has linked GIMMS NDVI values with tree ring widths across the forest-tundra ecotone (Lloyd et al., 2011; Berner et al., 2011; 2013). The coarse spatial resolution and quick revisit time, along with a data repository dating back to 1978 , make the AVHRR an ideal candidate for continental-scale, longterm, NDVI time-series analyses. 


\subsubsection{NDVI Time-series across Northern High Latitudes}

Continental-scale NDVI time-series are generally derived from AVHRR data because of these aforementioned benefits. Verbyla (2008) created an NDVI time-series across Alaska from 1982 to 2003 that demonstrated decreasing linear trends for boreal ecosystems and increasing linear trends for tundra ecosystems. Epstein et al. (2012) utilized AVHRR NDVI data and field biomass data to quantify the heterogeneity of biomass increases across the Arctic's five bioclimate subzones (Walker et al., 2005). Guay et al. (2014) compared northern high latitude vegetation change between two different GIMMS datasets and found greening in Arctic tundra and browning in boreal forest areas. More recently, AVHRR data have indicated decreasing tundra productivity across northern high latitudes from 2011 to 2014 (Epstein et al., 2016).

AVHRR data excel at these types of broad-based vegetation studies that span entire continents. However, the coarse spatial resolution of the sensor means that any landscape- and local-scale changes in vegetation productivity, including the influence of environmental variables on those changes, are often missed.

At the landscape scale, which is the main focus of my study, Landsat satellite data have been widely used by the scientific community due to easy and free access (since 2008) from the United States Geological Survey (USGS). Landsat data from the early 1980s (early 1970s for Landsat $60 \mathrm{~m}$ Multispectral Scanner) to present are readily and freely available, thus providing a $30+$ year repository. These data have been applied to map vegetation classes and canopies in high latitude environments, including efforts across northern Canada (Brook \& Kenkel, 2002; Olthof et al., 2009; Selkowitz, 2010). Earlier Landsat studies concerning vegetation dynamics followed a simpler change detection approach, where researchers would compare two images from different years (but at the same time of year). This was done by Masek (2001), who analyzed forest-tundra ecotone change in northern Québec (1974 and 1999) and eastern Northwest Territories (1972 and 2000) with two pairs of Landsat images. 
With an expanding archive of imagery, northern high latitude studies examining recent vegetation change are now able to apply Landsat data to create NDVI time-series. This is usually performed by processing a 'stack' of images from multiple years at the same location and ideally at the same time of year (i.e., anniversary dates). Images should be collected during the peak growing season, which is generally between July 1 and August 31 and more specifically from the middle of July to early August. Selected images should then be (i) radiometrically calibrated; (ii) converted to top-of-atmosphere reflectance; and (iii) subsequently converted to surface reflectance when possible (Fraser et al., 2012). This process has been streamlined by the Landsat Ecosystem Disturbance Adaptive Processing System (LEDAPS) that converts raw Landsat data to surface reflectance data using the MODIS/Second Simulation of the Satellite Signal in the Solar Spectrum (6S) atmospheric correction protocols (Masek et al., 2006). Any cloud cover should be masked and then pixel level trend analyses can be conducted where the slope and significance of NDVI trends over time for every pixel in the stack can be derived (Fraser et al., 2012).

Workflows like this have been used to create Landsat NDVI time-series across northern high latitudes. Time-series (1986-2006) analyses in the Mackenzie Delta region and in northern Québec indicated that most vegetation communities exhibited increasing NDVI, but more so for vascular vegetation than for lichen-dominated communities (Olthof et al., 2008). Increasing vegetation productivity, especially in shrub-dominated valleys, was detected from 1986 to 2009 in four national parks across northern Canada (Fraser et al., 2011). On the North Slope of Alaska, an NDVI time-series (1985-2007) examined by Raynolds et al. (2013) found that greening trends depended largely on differences in glacial history and topography. In Siberia, an NDVI timeseries (1985-2010) demonstrated that greening had occurred in most areas, but especially in areas that had been colonized by tall alder shrubs (Frost et al., 2014). 
More recent research utilizing Landsat NDVI time-series data have involved the creation of image stacks over large spatial areas by mosaicking frames together. In northern Québec, McManus et al. (2012) created an NDVI time-series (1985-2010) covering nine mosaicked frames constituting 26 million ha across the forest to tundra transition. They found that shrub and graminoid dominated pixels were more likely to have greening trends than boreal forest pixels. Ju \& Masek (2016) created an NDVI time-series over more than $90 \%$ of Canada and Alaska between 1984 and 2012. Using automated methods, they were able to select over 85,000 mostly cloud free Landsat scenes and run per-pixel trend analyses across the entire study region. They found that $29.4 \%$ of Canada and Alaska had greening trends, mostly in tundra areas, and that 2.9 $\%$ had browning trends, mostly in boreal forest areas.

These studies, as well as others, demonstrate that Landsat NDVI time-series have been conducted over much of the northern high latitudes. This includes the extent of my study area as well as in the case of Ju \& Masek (2016). However, the forest to tundra transition of central Canada remains an understudied region in terms of remote sensing based research on vegetation change, with a lack of in-depth analyses and ground validation of NDVI trends there. In addition, most of these studies have demonstrated that vegetation productivity has increased over the last $30+$ years, especially north of the forest-tundra ecotone. Some of these studies have even concluded that changes in vegetation productivity are heterogeneous and influenced by differences in terrain and other variables. However, the combined influence of environmental pressures on landscape-scale vegetation change, and how those influences change across the entirety of the sub-Arctic forest to Low Arctic tundra transition, has not yet been properly addressed.

\subsection{Summary}

The forest-tundra ecotone, as well as bordering boreal forest and tundra areas, is a region of interest for researchers concerned with vegetation change due to climate warming across 
northern high latitudes. This transition zone, which spans across Canada, Scandinavia and Siberia, is complex with tundra, shrubland and boreal forest patches in close proximity. Landscape-scale environmental variables, such as topography and moisture regime, seem to be important factors in determining the intricacies of this changing environment. The evidence from remote sensing and field-based studies across northern high latitudes strongly suggest that shrubs are expanding their range and becoming increasingly dense where already present. However, the evidence indicates that treeline advance is not as clear. Some drier interior boreal forest ecosystems appear to be undergoing a decrease in productivity in recent decades as a result of warming, even as tundra ecosystems have mostly been increasing in productivity. Despite the large number of studies analyzing vegetation changes across northern high latitudes, central Canada remains an understudied region. Further research is required to quantify the influence of landscape-scale variables on high latitude vegetation change. Recent advances in remote sensing technologies and methods, especially in regards to Landsat NDVI time-series analyses, provide an opportunity to examine these influences in an understudied region. 


\section{Chapter 3}

\section{Landscape Variability of Vegetation Change across the Forest to Tundra Transition of Central Canada}

\subsection{Abstract}

Widespread vegetation productivity increases in tundra ecosystems and stagnation, or even productivity decreases, in boreal forest ecosystems have been detected from coarse-scale remote sensing observations over the last few decades. However, finer-scale Landsat studies have shown that these changes are heterogeneous and may be related to landscape and regional variability in climate, land cover, topography and moisture. In this study, a Landsat Normalized Difference Vegetation Index (NDVI) time-series (1984-2016) was examined for a study area spanning the entirety of the sub-Arctic boreal forest to Low Arctic tundra transition of central Canada (i.e., Yellowknife to the Arctic Ocean). NDVI trend analysis indicated that $27 \%$ of unmasked pixels in the study area exhibited a significant $(\mathrm{p}<0.05)$ trend and virtually all $(99.3 \%)$ of those pixels were greening. Greening pixels were most common in the northern tundra zone and the southern forest-tundra ecotone zone. NDVI trends were positive throughout the study area, but were smallest in the forest zone and largest in the northern tundra zone. These results were supported by ground validation, which found a strong relationship $\left(R^{2}=0.81\right)$ between bulk vegetation volume (BVV) and NDVI for non-tree functional groups in the North Slave region of Northwest Territories. Field observations indicate that alder (Alnus spp.) shrublands and open woodland sites with shrubby understories were most likely to exhibit greening in that area. Random Forest (RF) modelling of the relationship between NDVI trends and environmental variables found that the magnitude and direction of trends differed across the forest to tundra transition. Increased summer temperatures, shrubland and forest land cover, closer proximity to major drainage systems, longer distances from major lakes and lower elevations were generally 
more important and associated with larger positive NDVI trends. These findings indicate that the largest positive NDVI trends were primarily associated with the increased productivity of shrubby environments, especially at, and north of the forest-tundra ecotone in areas with more favorable growing conditions. Smaller and less significant NDVI trends in boreal forest environments south of the forest-tundra ecotone were likely associated with long-term recovery from fire disturbance rather than the variables analyzed here.

\subsection{Introduction}

The Earth has been subject to climate warming since the late 1800s, especially at high latitudes where warming has been significantly greater than the global average (Serreze \& Barry, 2011; IPCC, 2013). This high latitude warming has been linked to the increase in productivity of broadleaf shrubs in Low Arctic and sub-Arctic ecosystems as climatic conditions become more favorable for species previously under stress and at the edge of their range (Myers-Smith et al., 2011). The northward and upslope expansion of shrubs is thus expected over a decadal-length timescale in these tundra and forest-tundra ecotone environments (Epstein et al., 2004). However, the intricacies of shrub expansion are still not fully understood, with recent studies indicating that it has been heterogeneous and that landscape-scale variability can influence the magnitude of vegetation change at high latitudes (McManus et al., 2012; Ropars \& Boudreau, 2012; Frost et al., 2014). Differences in land cover, topography and moisture access have been noted as possible controls on shrub expansion and other vegetation changes.

While shrub growth and expansion has been widespread, treeline advance has been mixed; advancing in some locations while remaining static elsewhere (Harsch et al., 2009). Treeline advance has not occurred at the same rates as shrub expansion because boreal tree range advance takes longer to respond to warming in general (i.e., there is a significant lag period) (MacDonald et al., 1998; Epstein et al., 2004; Gamache \& Payette, 2005). However, there has been observations of accelerated height growth, patch infilling and small advances of treeline in 
certain locations (Gamache \& Payette, 2005). Browning, or a decrease in productivity from forest dieback, has also been observed in some boreal ecosystems south of the forest-tundra ecotone (Lloyd et al., 2011; Berner et al., 2011). This has been attributed to higher drought stress in the summer months of the last few decades because of increasing temperatures (Barber at el., 2000; Lotsch et al., 2005).

Satellite remote sensing data have allowed researchers to quantify these vegetation changes over a variety of spatial and temporal scales at northern high latitudes. Coarse spatial resolution data from the Advanced Very High-Resolution Radiometer (AVHRR) has been used to monitor vegetation changes at continental scales, which has provided evidence for widespread productivity increases in tundra regions and some productivity decreases across continental boreal forest regions (Bunn et al., 2005; Verbyla, 2008; Beck \& Goetz, 2012; Epstein et al., 2012; Guay et al., 2014). Landsat data has also been widely used at landscape and regional scales for this purpose (Olthof et al., 2008; Fraser et al., 2011; McManus et al., 2012; Raynolds et al., 2013; Frost et al., 2014; Pattison et al., 2015; Ju \& Masek, 2016). Ground validation, when conducted by researchers, has found a link between vegetation biomass measurements and remote sensing vegetation indices in areas without tree cover (Jia et al., 2003; Laidler et al., 2008; Gregory, 2011; Epstein et al., 2012).

In this study, recent ( $\sim 35$ years) vegetation changes occurring across the sub-Arctic boreal forest to Low Arctic tundra transition of central Canada were assessed using Landsat satellite imagery and ground-level validation. To this point, little research has been conducted on the dynamics of vegetation growth in this region, which has recently become an important area of study for those interested in caribou population dynamics (Boulanger et al., 2011). This study also aims to identify the landscape-scale environmental variables that influence vegetation changes across the region and understand the direction and magnitude of that influence. The influence of landscape-scale terrain variation on vegetation change has been noted as a topic in 
need of further study and this research will assist in this regard (Myers-Smith et al., 2011). Hence, the main objectives of this study were to: (1) quantify recent vegetation changes across the foresttundra ecotone of central Canada using a Landsat Normalized Difference Vegetation Index (NDVI) time-series; (2) link those trends to field measurements; and (3) determine the extent to which environmental variables (i.e., climate, land cover, topography, waterbodies) influence patterns of vegetation change across the transition.

\subsection{Methods}

\subsubsection{Study Area}

The study area for this project was a 130,000 $\mathrm{km}^{2}$ transect extending from Yellowknife, NWT to Coronation Gulf east of Kugluktuk, NU (Figure 3.1). This study area was chosen because it is an understudied region in terms of northern high latitude vegetation change research. It is characterized by low rolling hills, large numbers of lakes and rivers and a variety of vegetation communities. The study area was delineated into three zones based on the foresttundra ecotone that crosses it in the North Slave region of NWT. The area south of the 1000:1 tree:tundra ratio line, as mapped by Timoney et al. (1992), was defined as the forest zone (i.e., closed-canopy boreal forest) and the area north of the 1:000 tree:tundra ratio line was defined as the tundra zone (i.e., tree-less tundra). The area that fell between the 1000:1 and 1:1000 lines was defined as the ecotone zone (i.e., forest-tundra ecotone). 


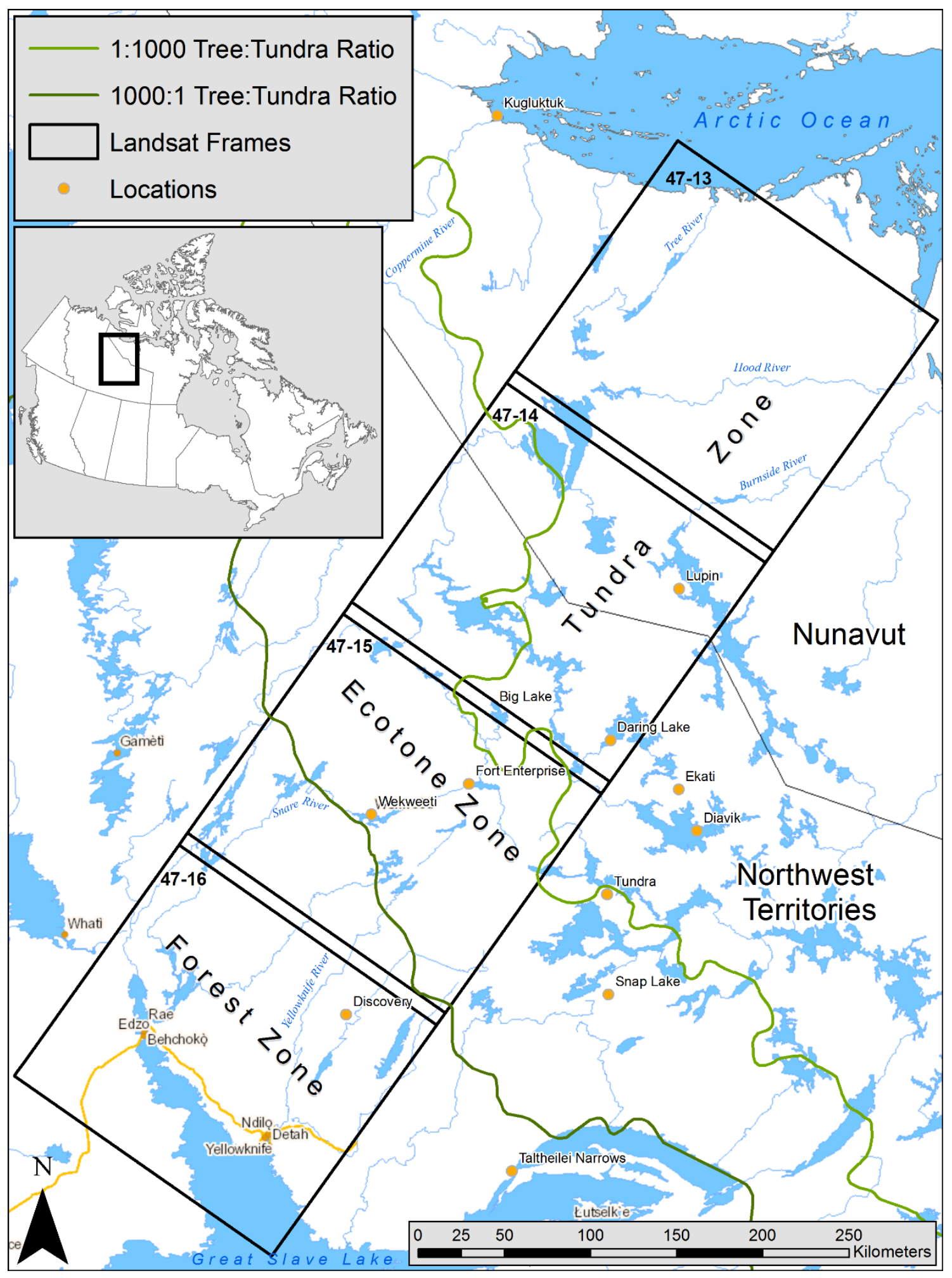

Figure 3.1: The spatial extent of Landsat frames used for remote sensing analysis. Numbers in the upper corner of each Landsat frame represent the Worldwide Reference System (WRS) path-row. The location of communities, mines and other points of interest are shown. Forest, ecotone and tundra zones are delineated by the tree:tundra ratio lines shown (based on Timoney et al., 1992). Basemap provided by Government of Northwest Territories (GNWT) Centre for Geomatics. 
The study area spans the transition from the Taiga Shield to the Southern Arctic Level II Ecoregions (Ecosystem Classification Group, 2008; 2012). Permafrost coverage is discontinuous in the southern half of the study area and continuous in the north (Heginbottom et al., 1995; Throop et al., 2012). Fires have been common in the forest zone and the southern portion of the ecotone zone, but are less frequent farther north (GNWT, 2015b). The Nunavut portion of the tundra zone overlaps the calving grounds of the Bathurst caribou herd, which has seen a precarious drop in size over the last three decades from an estimated 203,800 individuals in 1986 to an estimated 16,400 in 2009 (Boulanger et al., 2011; GNWT, 2015a). Thirty-year (1981-2010) climate normals from the Environment Canada weather station at Yellowknife Airport $\left(62^{\circ} 26^{\prime} \mathrm{N}\right.$ and $114^{\circ} 23^{\prime} \mathrm{W}$ ) indicate a mean annual July temperature of $17^{\circ} \mathrm{C}$ and a mean annual January temperature of $-25.6^{\circ} \mathrm{C}$. Climate normals at Kugluktuk Airport $\left(67^{\circ} 49^{\prime} \mathrm{N}\right.$ and $\left.115^{\circ} 5^{\prime} \mathrm{W}\right)$ indicate a mean annual July temperature of $10.9^{\circ} \mathrm{C}$ and a mean annual January temperature of $27.3{ }^{\circ} \mathrm{C}$. Yellowknife Airport averages $288.6 \mathrm{~mm}$ of precipitation each year (157.6 mm as snow) while Kugluktuk Airport averages $247.2 \mathrm{~mm}$ (182.1 $\mathrm{mm}$ as snow).

The forest zone lowland areas north of Great Slave Lake, including the area around Yellowknife, are characterized by dense boreal forest with many bedrock outcrops (Ecosystem Classification Group, 2008). Farther north, past the abandoned Discovery Mine and towards Wekweètì in the ecotone zone, scattered woodlands become more common. Boreal forest stands with shrubby understories are often limited to more sheltered lowland areas with shrub cover dominating hilltop areas (Ecosystem Classification Group, 2008). The northern portion of the ecotone zone and the southern portion of the tundra zone also contain a notable amount of graminoid-dominated wetlands (Ecosystem Classification Group, 2008). In the southern portion of the tundra zone, such as around the Daring Lake Tundra Ecosystem Research Station, trees are mostly absent and shrubs dominate the landscape (Walker et al., 2005; Ecosystem Classification Group, 2012). Northwards through Nunavut towards the Arctic Ocean, vegetation transitions 
from dense shrubland to open shrubland and graminoid tundra with lichen groundcover dominant (Walker et al., 2005). Shrubland riparian zones can be found along the edge of major rivers in the northern portion of the tundra zone, such as the Tree, Hood and Burnside Rivers.

A field expedition was conducted in the North Slave region of NWT (i.e., between Big Lake and Wekweètì along the Snare River system) during the summer of 2016. This location was chosen because of the relatively short distance between the forest zone and the tundra zone, allowing for canoe travel and sampling across the forest-tundra ecotone. This location was also relatively accessible compared to other possible routes (see Appendix A), with daily flights from the Tłı̨chǫ community of Wekweètì $\left(64^{\circ} 11^{\prime} \mathrm{N}\right.$ and $\left.114^{\circ} 10^{\prime} \mathrm{W}\right)$ to Yellowknife. This field expedition followed the path of Sir John Franklin's expedition of 1819 to 1822 that aimed to explore Canada's northern coastline and map a potential northwest passage between the Atlantic and Pacific Oceans (Houston, 1994).

\subsubsection{Landsat Data Collection}

A Landsat time-series (1984-2016) was assembled in order to quantify recent vegetation change in the study area. Scenes from four Landsat frames that form a transect across the study area (Figure 3.1) were selected and downloaded from the United States Geological Survey (USGS) Global Visualization Viewer (GloVis). Clear-sky scenes (i.e., less than $20 \%$ cloud cover from GloVis estimates) that fell within the peak growing season (defined here as July 11 August 11) were selected. Only scenes from Landsat 4-5 Thematic Mapper (TM), Landsat 7 Enhanced Thematic Mapper Plus (ETM+ SLC-on) and Landsat 8 Operational Land Imager (OLI) were utilized in order to avoid comparability issues with $60 \mathrm{~m}$ resolution Landsat 1-5 MSS data and to avoid data-loss issues with scan-line gaps from the Landsat 7 ETM+ sensor after the scan line corrector (SLC) failed in May 2003. The quality of selected Landsat scenes was assessed by visually inspecting scenes in GloVis and in ENVI 5.3.1 (Harris Geospatial Solutions). USGS provides cloud cover estimates in GloVis but it was found that this often did not account for high 
altitude cirrus clouds or smoke from forest fires. Scenes were thus ranked in terms of relative cloud cover in order to determine which scenes would have the most cloud-free pixels for Landsat time-series analysis (see Appendix B). Scenes that had a higher quality rating, were obtained at peak growing season and were Landsat standard level terrain (L1T) corrected were selected for subsequent analysis. The final selection was made in order to ensure a minimum of 10 scenes per frame and that scenes were distributed evenly throughout the 32-year period. The final image stack included 40 scenes, 10 for each of the four Landsat frames (Figure 3.2).

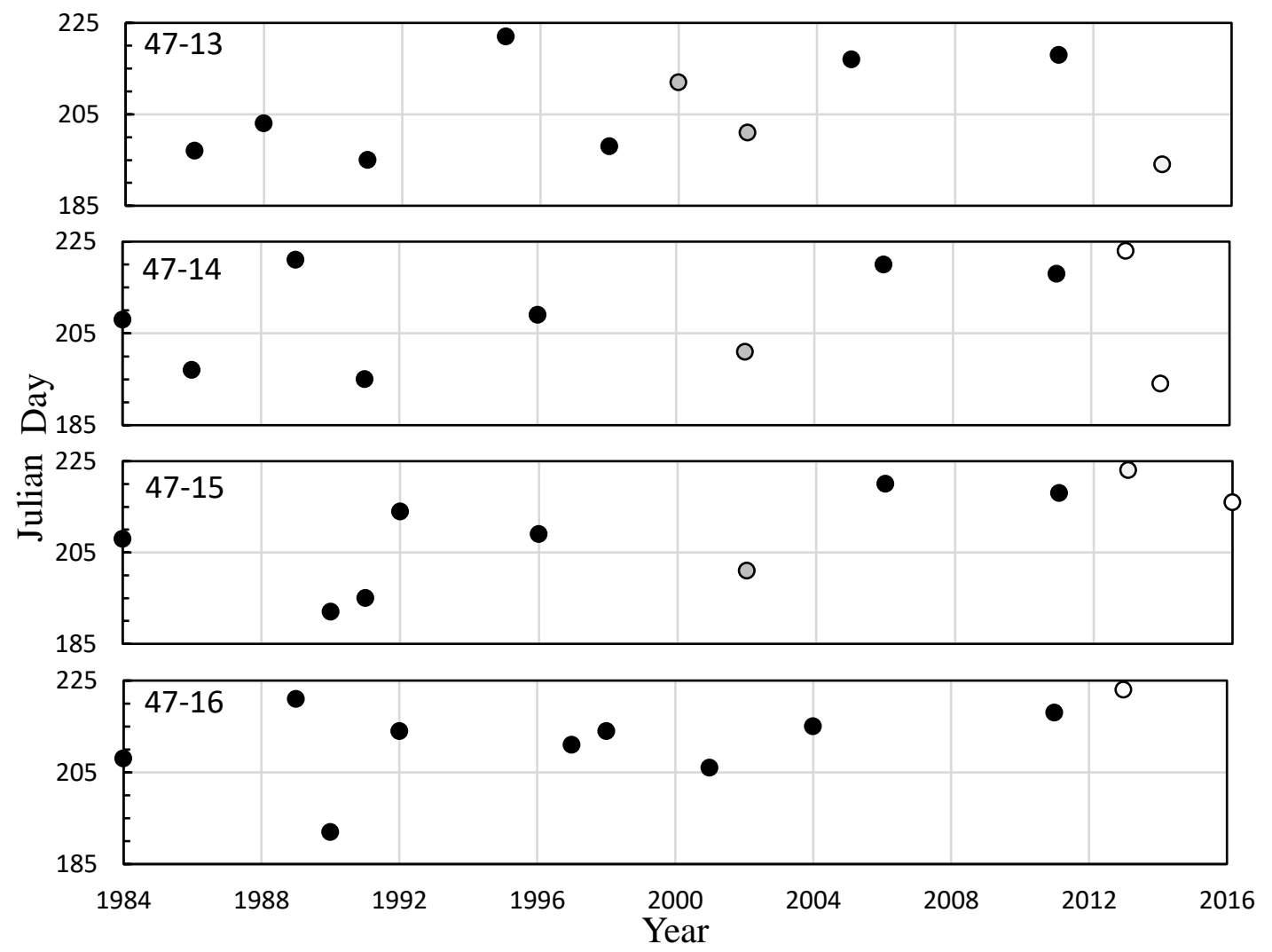

Figure 3.2: Temporal distribution of selected Landsat scenes (sensu McManus et al., 2012). The four plots represent the Landsat frames (path-row indicated in top left of each) that make up the study area from north to south. All scenes date between 1984 and 2016 and were collected between Julian day 192 and 223 (July 11 - August 11). Black circles represent Landsat TM scenes, gray circles ETM+ scenes and white circles OLI scenes. See Appendix B for more details on selected scenes. 


\subsubsection{Landsat Data Correction}

Selected Landsat TM and ETM+ scenes were converted from digital number to top-ofatmosphere reflectance and then corrected to surface reflectance using the Landsat Ecosystem Adaptive Processing System (LEDAPS) algorithm, an automated procedure provided by the National Aeronautics and Space Administration (NASA) (Masek et al., 2006). LEDAPS corrects for atmospheric effects through the Second Simulation of the Satellite Signal in the Solar Spectrum (6S) code that models the gases and molecules that make up the atmosphere between the satellite and the ground (Vermote et al., 1997). LEDAPS estimates aerosol optical thickness using the dense dark vegetation method, ozone concentrations from Total Ozone Mapping Spectrometer data, as well as water vapor, air temperature and surface pressure information from National Oceanic and Atmospheric Administration (NOAA) environmental prediction data (Masek et al., 2006). LEDAPS has become the most common form of atmospheric correction for broad-scale Landsat studies in the last few years (Banskota et al., 2014).

Selected OLI scenes were corrected to surface reflectance in the same process using the Landsat Surface Reflectance Code (LaSRC) algorithm (USGS, 2016; Vermote et al., 2016). LaSRC builds upon the TM and EMT+ LEDAPS algorithm and has been updated for OLI, taking into account its narrower spectral bands and the new coastal aerosol $(0.4333-0.453 \mu \mathrm{m})$ band. Radiative transfer between satellite and ground is again modeled with 6S code. Aerosol optical thickness, water vapor, ozone concentrations and air temperature are calculated from Moderate Resolution Imaging Spectrometer (MODIS) climate modeling grids and surface pressure is derived from MODIS elevation data (Vermote et al., 2016). The coastal aerosol band is also used to provide aerosol properties. Together, these surface reflectance algorithms from NASA allow for a standardized in-house approach for removing the influence of atmospheric effects on Landsat data across all recent sensors.

Both LEDAPS and LaSRC surface reflectance algorithms generate a cloud mask layer (Masek et al., 2006; Vermote et al., 2016). However, the LEDAPS cloud mask struggled with 
identifying wispy cirrus clouds and cloud shadows. The LaSRC cloud mask layer performed better at identifying most clouds and cloud shadows because of the addition of the "cirrus" band $(1.360-1.390 \mu \mathrm{m})$, but was only available for selected OLI scenes (Vermote et al., 2016).

Selected Landsat scenes were thus masked for clouds and cloud shadows manually to ensure that all cloud covered pixels were removed from further analysis (see Appendix B). The red (R) and near infrared (NIR) bands of surface reflectance scenes were then used to calculate NDVI: (NIR $\mathrm{R}) /(\mathrm{NIR}+\mathrm{R})$.

Recent studies have shown that NDVI derived from Landsat ETM+ and OLI are marginally higher than NDVI derived from Landsat TM based on the overlapping areas between adjacent passes by the different sensors at higher latitudes (Holden \& Woodcock, 2016; Ju \& Masek, 2016; Roy et al., 2016). These differences are attributed to small variations in the Landsat sensors, rather than actual vegetation change on the ground, and thus warrant correction. Since 75 $\%$ of the Landsat scenes used in this study were Landsat TM, corrections to ETM+ and OLI were made to ensure temporal continuity with Landsat TM. A scaling factor of 0.964 , based on between-sensor discrepancies (Ju \& Masek, 2016), was applied to adjust Landsat ETM+ NDVI to a TM equivalent. Landsat OLI was adjusted to a TM equivalent by applying the ordinary least square transformation function between OLI and ETM+ $(\mathrm{ETM}+=0.0029+0.9589(\mathrm{OLI}))$ recommended by Roy et al. (2016) combined with the 0.964 scaling factor. NDVI trends derived from pseudo-invariant features (PIFs), a relative normalization procedure for atmospheric effects (Jensen, 2016), exhibited a moderately strong relationship with surface reflectance NDVI trends $\left(\mathrm{R}^{2}=0.63, \mathrm{p}<0.001\right)($ See Appendix C).

\subsubsection{NDVI Trend Calculation}

With atmospheric effects corrected, NDVI time-series were analysed to determine if there was evidence of vegetation change across the study area. NDVI time-series were compiled as RasterStacks using the 'raster' package in the computer program R (R Development Core Team, 
2010). Bivariate linear regressions, with NDVI as the y-axis (response variable) and time as the x-axis (predictor variable), were applied across all pixels in each RasterStack (see Appendix D for $\mathrm{R}$ code). The output was a mosaicked raster with pixel values equal to the slope of each linear regression (i.e., the magnitude of NDVI trend per pixel per year). A second output was a raster of the corresponding p-values (based on a two-tailed t-test) of each linear regression. NDVI trends with $p<0.05$ were considered significant. Significant positive NDVI trends were considered 'greening' and significant negative NDVI trends were considered 'browning'.

To ensure that the NDVI trends accurately represented vegetation productivity changes throughout the last three decades, pixels that were cloud covered four or more times in a RasterStack were removed from further analysis. In addition, all scenes in each RasterStack were split into decadal groups (i.e., mid-1980s to mid-1990s, mid-1990s to mid-2000s, mid-2000s to present) and pixels that were covered by clouds across all years in at least one decade group were removed from analysis. Where Landsat frames overlapped, areas with less cloud cover were preserved during the mosaicking procedure. These steps ensured that NDVI trends were only based on linear regressions that were evenly spaced across the time period in question and had sufficient cloud-free samples. Cloud cover was a concern, but over $68 \%$ of the study area had sufficient cloud-free pixels to be useful for time-series analysis. Waterbodies (NDVI $<0$, classified as water in the land-cover map) and fire scars (1965-2014) (GNWT, 2015b) were also masked and removed from the analysis.

\subsubsection{Field Data Collection}

A canoe-based field expedition was conducted across the forest-tundra ecotone of the North Slave region of NWT near Wekweètì (Figure 3.3). The objective of the field expedition was to obtain measurements for use in establishing a relationship between satellite-derived NDVI and an in situ biophysical variable, i.e., bulk vegetation volume (BVV), in order to provide ground validation for the remote sensing data analysis (Chen et al., 2009; Gregory, 2011). It was 
very important that the field expedition encompass the extent of the forest-tundra ecotone in order to allow for sampling in both tundra and boreal forest dominated environments. Sample plots were thus established across Timoney et al.'s (1992) tree:tundra cover ratio lines. During the field expedition there was also an opportunity to speak with local residents to gain first-hand knowledge of the region from their perspectives.

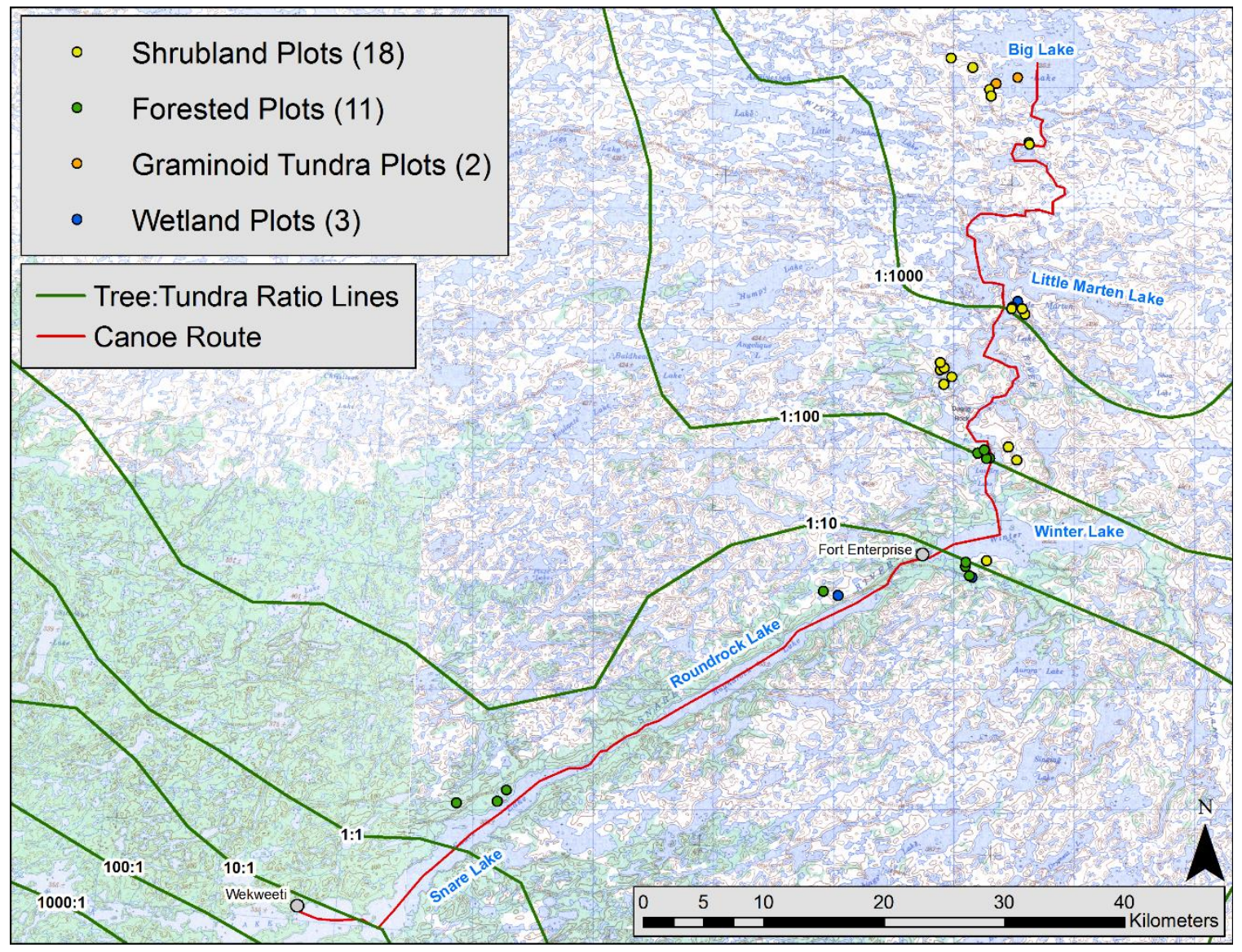

Figure 3.3: Map of the field expedition, including the location of sample plots, in the North Slave region of NWT. Travel was by canoe from Big Lake to Wekweètì across the tree:tundra ratio lines mapped by Timoney et al. (1992). Sample plots were grouped into shrubland, forested, graminoid tundra and wetland based on dominant land-cover types encountered on the ground. The number of times each plot grouping was sampled is in parentheses.

In order to ensure there was an adequate representation of different land-cover types across sample plots, an unsupervised land-cover classification was derived to stratify the study area. This was performed using the most recent (2011) Landsat cloud-free mosaic over the two 
frames corresponding to the location of the field expedition (47-14 \& 47-15). An Iterative SelfOrganizing Data Analysis (ISODATA) method was applied in ENVI to cluster pixels into 15 different classes (Tou \& Gonzalez, 1974). ISODATA classifications were cross-referenced with high spatial resolution imagery where available, geo-referenced photographs from past travelers along the route and from book descriptions (Losey, 1973; McCreadie, 1995; Thomas, 2003; Pitt, 2014). NWT Ecosystem Classification Reports provided further land cover information on a broader scale (Ecosystem Classification Group, 2008; 2012).

Because of the canoe-based nature of the field expedition, there was a certain level of uncertainty as to where along the route sample plots could be established. A map of potential sample plots was created that was limited to homogenous areas of a single class based on the ISODATA classification. The centers of spectral classes that were a minimum of $4 \mathrm{x} 4$ pixels in size and within $5 \mathrm{~km}$ of the proposed route were identified as potential sampling locations. This methodology provided access to many possible sampling plots during the field expedition, allowing for a flexible sampling strategy. See Appendix A for maps of the potential sampling locations used for sample plot selection in the field.

The field expedition was conducted between July 20 and August 25, 2016, during which time 34 plots were sampled, accounting for a range of land-cover classes (Table 3.1). For the majority of cases, land cover identified in the field corresponded with the unsupervised landcover classification. When it was not possible (because of time or travel constraints) to establish a full study plot, supplementary photos of the area of interest were acquired, descriptions were noted and GPS coordinates were collected with a Trimble GPS unit. This latter approach was done often for burn scars, non-vegetated eskers and rock gardens. Again, see Appendix A for details and descriptions of all study plots and other points of interest. 
Table 3.1: Details of potential sample plots based on 15 ISODATA land-cover classes from a 2011 Landsat TM mosaic (47-14 \& 47-15). Classes are color coded as they appeared in field maps (see Appendix A). Number of pixels indicates pixels within a reasonable over-land travel distance $(5 \mathrm{~km})$ from the field expedition route that were in the center of a homogenous area of that class and thus suitable for sampling. Note that some classes were more common than others and thus were more likely to be sampled multiple times, although efforts were made to sample across all classes. Average NDVI of potential sample pixels indicates that classes fell across a range of biomass conditions. At least one $900 \mathrm{~m}^{2}$ study plot was established for all more densely vegetated classes, while photos and GPS points were recorded for sediment and lichen barren classes.

\begin{tabular}{|l|c|c|c|}
\hline $\begin{array}{c}\text { Land-cover Class } \\
\text { (unsupervised ISODATA) }\end{array}$ & $\begin{array}{c}\text { Number of Pixels } \\
\text { (within 5 km of route) }\end{array}$ & $\begin{array}{c}\text { Mean NDVI } \\
\mathbf{\pm} \text { SD }\end{array}$ & $\begin{array}{c}\text { Plots Sampled } \\
(\mathbf{n = 3 4 )}\end{array}$ \\
\hline Closed-canopy Boreal Forest & 192 & $0.53 \pm 0.03$ & 1 \\
\hline Less Dense Boreal Forest & 2522 & $0.58 \pm 0.03$ & 3 \\
\hline Woodland & 1147 & $0.49 \pm 0.02$ & 3 \\
\hline Open Woodland & 8281 & $0.50 \pm 0.03$ & 3 \\
\hline Rocky Woodland & 43 & $0.42 \pm 0.03$ & 1 \\
\hline Dense Tall Shrubs & 11293 & $0.63 \pm 0.03$ & 3 \\
\hline Dense Low Shrubs & 5536 & $0.60 \pm 0.04$ & 4 \\
\hline Low Shrub Tundra & 5274 & $0.50 \pm 0.02$ & 3 \\
\hline Erect Dwarf-shrub Tundra & 202 & $0.43 \pm 0.02$ & 1 \\
\hline Peatland & 4176 & $0.54 \pm 0.02$ & 4 \\
\hline Wetland Fen & 719 & $0.43 \pm 0.04$ & 3 \\
\hline Sedge/Moss Tundra & 2768 & $0.50 \pm 0.03$ & 3 \\
\hline Herb/Cryptogam Barrens & 568 & $0.42 \pm 0.03$ & 2 \\
\hline Sediments - Low Vegetation & 114 & $0.13 \pm 0.07$ & 0 \\
\hline Lichen Barren - Bedrock & 356 & $0.29 \pm 0.07$ & 0 \\
\hline
\end{tabular}

Once a suitable sample location was identified in the field, BVV was measured within a $30 \mathrm{~m}$ x $30 \mathrm{~m}\left(900 \mathrm{~m}^{2}\right)$ plot; corresponding to the spatial resolution of Landsat. At each plot, measures of vegetation height were obtained at 49 points corresponding to a rectangular grid (Figure 3.4). The height of different vegetation functional groups was measured at each point with a tape measure, although a Vertex IV transponder (Haglöf Sweden) was used for taller trees. Functional groups used were: trees, erect-shrubs, dwarf-shrubs, herbaceous forbs, pteridophytes (primarily Equisetum spp.), graminoids, moss, lichen, and non-vegetated surfaces (i.e., rock, soil, gravel and water). Trees, erect-shrubs and dwarf-shrubs were identified to the species level while all other functional groups were recorded by the functional group name in order to save time when sampling. GPS coordinates, photographs and other supplementary data were also recorded at each plot. See Appendix A for additional details. 


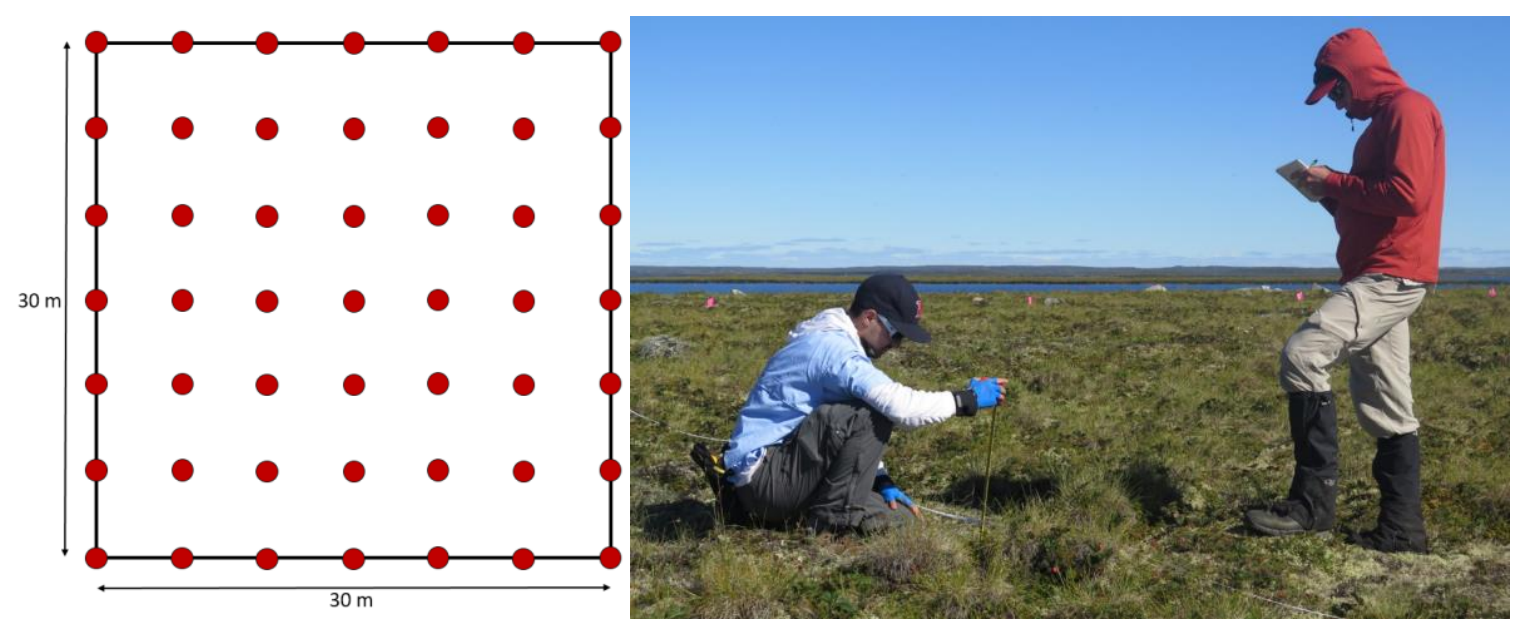

Figure 3.4: Sample plot setup (diagram at left). Plots were established as $30 \mathrm{~m} \mathrm{x} 30 \mathrm{~m}\left(900 \mathrm{~m}^{2}\right)$ squares and measurements were obtained at 49 points (red) at $5 \mathrm{~m}$ intervals. At each point, the height of each vegetation functional group was measured (photograph at right). Pink flags in the background of the photograph marked the edge of the sample plot.

BVV at the plot level was calculated based on these vegetation height measurements

(Chen et al., 2009; Gregory, 2011).

$\begin{array}{lr}\text { BVV }= & \\ \text { Average Height Trees } * 900 \mathrm{~m}^{2} *(\mathrm{X} / 49) & + \\ \text { Average Height Erect-shrubs } * 900 \mathrm{~m}^{2} *(\mathrm{X} / 49) & + \\ \text { Average Height Dwarf-shrubs } * 900 \mathrm{~m}^{2} *(\mathrm{X} / 49) & + \\ \text { Average Height Forbs } * 900 \mathrm{~m}^{2} *(\mathrm{X} / 49) & + \\ \text { Average Height Pteridophytes } * 900 \mathrm{~m}^{2} *(\mathrm{X} / 49) & + \\ \text { Average Height Graminoids } * 900 \mathrm{~m}^{2} *(\mathrm{X} / 49) & + \\ \text { Average Height Moss } * 900 \mathrm{~m}^{2} *(\mathrm{X} / 49) & + \\ \text { Average Height Lichen } * 900 \mathrm{~m}^{2} *(\mathrm{X} / 49) & +\end{array}$

This equation is the average height of all measured individuals within a functional group multiplied by the area of the plot $\left(900 \mathrm{~m}^{2}\right)$ and the percent vegetation cover (PVC) of that functional group (i.e., number of points containing that functional group [X] out of 49) summed for all functional groups. BVV takes into account denser high biomass canopies, where different functional groups correspond to different layers of vegetation within the canopy. BVV calculations for each sample plot were compared using least squares regression with corresponding NDVI values derived from the 2011 Landsat data. 


\subsubsection{NDVI Trend Analysis}

NDVI trends were compared to a variety of spatially referenced environmental variables to evaluate geographical influences on the pattern and magnitude of NDVI trends across the study area. Twelve environmental variable raster layers were acquired or generated (Table 3.2). These variables account for differences in land cover, topography (elevation, slope, aspect, topographic position and wetness), waterbody influence (distance to rivers, lakes, major lakes and major drainage systems) and climate (summer temperature and precipitation change).

Table 3.2: Descriptions of the 12 environmental variables that may influence NDVI trends. Canada Digital Elevation Model (DEM) and National Topographic System (NTS) map sheets were acquired from Natural Resources Canada (2012). Flow accumulation: the accumulated sum of all upslope pixels that flow into each downslope pixel. Yearly climate data from Climatic Research Unit (CRU) TS3.24.01 0.5 global climate grid (University of East Anglia CRU, 2008). See Appendix E to view raster images for each of these variables.

\begin{tabular}{|c|c|}
\hline Variable & Description \\
\hline Land cover & $\begin{array}{l}\text { 9-Class supervised classification from } 2011 \text { Landsat scene mosaic (see Figure } \\
\text { 3.5) }\end{array}$ \\
\hline Elevation & Canada DEM based on $10 \mathrm{~m}$ contour lines from 1:50,000 NTS maps \\
\hline Slope & Slope $\left(^{\circ}\right)$ calculated from Canada DEM \\
\hline Aspect & $\begin{array}{l}\text { Aspect }\left(^{\circ}\right) \text { calculated from Canada DEM, converted to categorical variable } \\
\text { (i.e., northeast facing }=22.5^{\circ} \text { to } 67.5^{\circ} \text { ) }\end{array}$ \\
\hline $\begin{array}{l}\text { Topographic Position } \\
\text { Index (TPI) }\end{array}$ & $\begin{array}{l}\text { Difference }(\mathrm{m}) \text { between center point and average elevation of a } 15 \times 15 \text { pixel } \\
\text { moving window, above } 0=\text { exposed, below } 0=\text { sheltered (Weiss, 2001; } \\
\text { Jenness, 2006) }\end{array}$ \\
\hline $\begin{array}{l}\text { Topographic Wetness } \\
\text { Index (TWI) }\end{array}$ & $\begin{array}{l}\text { Ln }((\text { Flow Accumulation + 1) / (Tan }(((\text { Slope }) * 3.14159265) / 180))) \\
\text { Quantifies wetness of the landscape (Beven \& Kirkby, 1979; Dilts, 2015). }\end{array}$ \\
\hline $\begin{array}{l}\text { Distance to Rivers } \\
\text { (Rivers) }\end{array}$ & Euclidean distance $(\mathrm{m})$ from nearest river (NTS maps) over $100 \mathrm{~m}$ long \\
\hline $\begin{array}{l}\text { Distance to Lakes } \\
\text { (Lakes) }\end{array}$ & $\begin{array}{l}\text { Euclidean distance (m) from nearest lake (NTS maps) over } 900 \mathrm{~m}^{2} \text { area } \\
\text { (Landsat pixel size) }\end{array}$ \\
\hline $\begin{array}{l}\text { Distance to Major } \\
\text { Lakes (Major Lakes) }\end{array}$ & $\begin{array}{l}\text { Euclidean distance (m) from nearest major lake (NTS maps) over } 10 \text { million } \\
\mathrm{m}^{2} \text { area }\end{array}$ \\
\hline $\begin{array}{l}\text { Distance to Major } \\
\text { Drainage Systems } \\
\text { (Drainages) }\end{array}$ & $\begin{array}{l}\text { Euclidean distance }(\mathrm{m}) \text { from nearest water route (rivers and lakes that form } \\
\text { major drainage systems in the region) with a flow accumulation of over } 1 \\
\text { million inflowing pixels }\end{array}$ \\
\hline $\begin{array}{l}\text { Temperature Change } \\
\text { (Temp Change) }\end{array}$ & $\begin{array}{l}\text { Summer (June - August) temperature change }\left({ }^{\circ} \mathrm{C} / \text { year}\right) \text { between } 1980 \text { and } \\
2015 * \text { number of years. i.e., Slope of linear trend derived from a regression. }\end{array}$ \\
\hline $\begin{array}{l}\text { Precipitation Change } \\
\text { (Precip Change) }\end{array}$ & $\begin{array}{l}\text { Summer (June - August) precipitation change }(\mathrm{mm} / \mathrm{year}) \text { between } 1980 \text { and } \\
2015 * \text { number of years. i.e., Slope of linear trend derived from a regression. }\end{array}$ \\
\hline
\end{tabular}


Land cover was developed as a 9-class supervised maximum likelihood classification based on a mostly cloud-free 2011 Landsat scene mosaic of all four frames in the study area (Figure 3.5). Calibration data were applied based on personal observations gathered from the field expedition (including the preliminary 15-class ISODATA classification) and a past expedition down the Coppermine River in the summer of 2013. Available high spatial resolution imagery, geo-tagged photographs and Streetview images (NWT Highway 1 and 3) from Google Earth were also examined. NWT Ecosystem Classification Reports (Ecosystem Classification Group, 2008; 2009; 2012) in the southern portion of the study area and the Circumpolar Arctic Vegetation Map (CAVM) (Walker et al., 2005) in the northern portion of the study area provided broader scale information on land-cover classes. A fine-scale land-cover map of the area around Daring Lake was also consulted (Obst, 2011). Olthof et al.'s (2009) circa 2000 Landsat land-cover map of northern Canada provided a useful base of comparison with conditions at that time.

Topographic variables were derived from the $\sim 20 \mathrm{~m}$ spatial resolution Canada DEM (Natural Resources Canada, 2012). Topographic Positon Index (TPI) quantifies landscape exposure and shelter, with exposed landscapes having positive values and sheltered landscapes having negative values (Weiss, 2001; Jenness, 2006). Topographic Wetness Index (TWI) is a unitless measure of landscape wetness (Beven \& Kirkby, 1979; Dilts, 2015). Waterbody influences were examined based on the distance to rivers and lakes of various sizes using the NTS map shapefiles (Natural Resources Canada, 2012). The distance to major drainage systems, such as the Hood, Snare and Yellowknife River systems, was also quantified. Summer temperature and precipitation change from 1980 to 2015 were evaluated at a regional scale using data from the CRU TS3.24.01 0.5 global climate grid (University of East Anglia CRU, 2008). All datasets were, if required, resampled (cubic convolution) to $30 \mathrm{~m}$ spatial resolution and projected to WGS (World Geodetic System) 1984: UTM (Universal Transverse Mercator) Zone 12N in order to align with the Landsat coverage. 


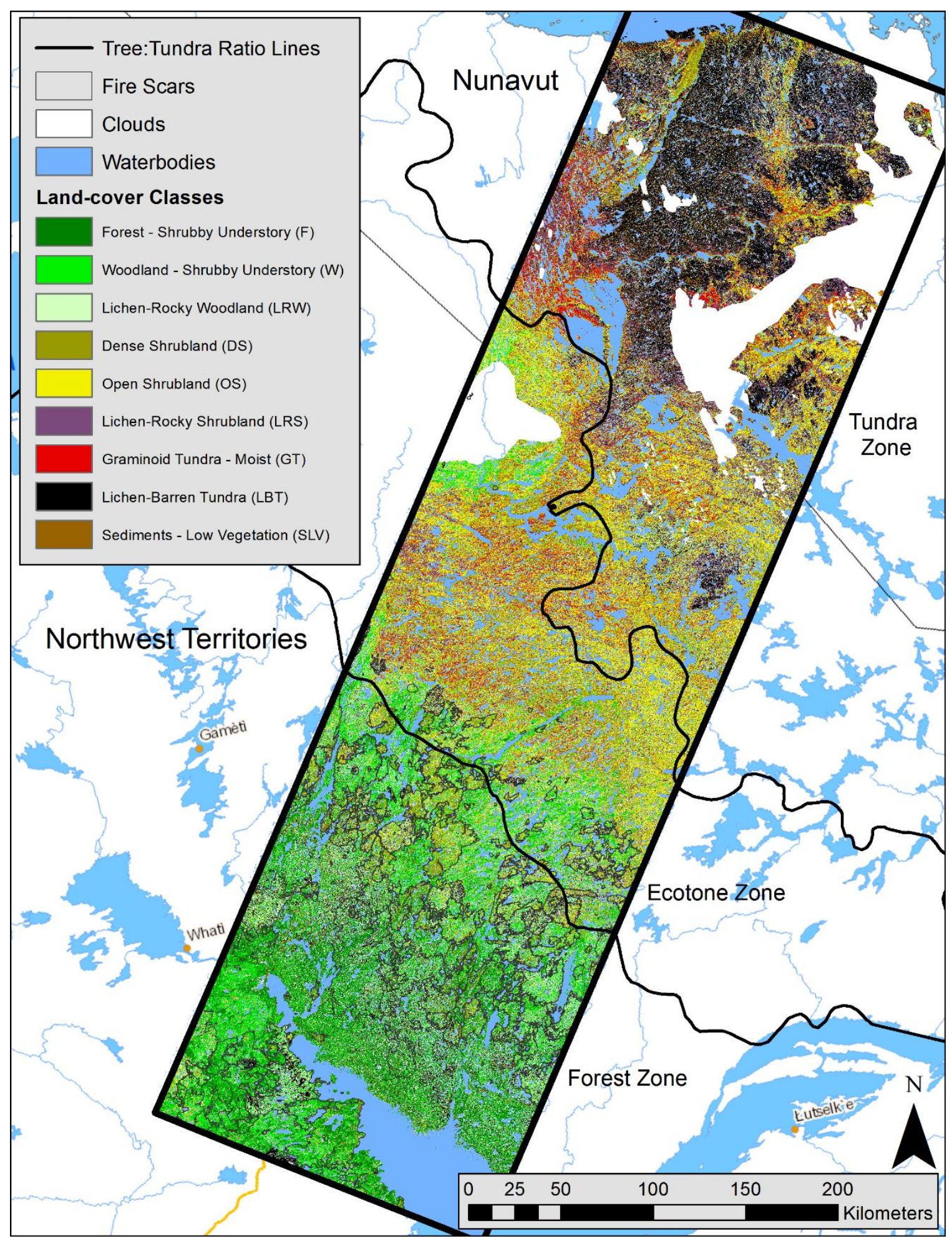

Figure 3.5: Supervised 9-class land-cover classification from a mostly cloud-free 2011 Landsat mosaic. Timoney et al. (1992) 1:1000 (top) and 1000:1 (bottom) tree:tundra ratio lines that define the three zones are shown. See Appendix E for detailed class descriptions across each zone in the study area. Basemap provided by Government of Northwest Territories Centre for Geomatics. 
The environmental variables were used as predictors (with NDVI trends as the response variable) for a Random Forest (RF) regression model, using the 'randomForest' package in $\mathrm{R}$ (Liaw \& Wiener, 2002; R Development Core Team, 2010) (see Appendix F for R code). RF models create a large number of high variance decision trees that are built using bootstrap sampling (i.e., with replacement) from the original sample dataset (Breiman, 2001; Hastie et al., 2009). Each decision tree represents a tree-like model of binary splits optimized where the selected predictor variable has the greatest influence on the response variable. RF models can efficiently handle large datasets with low bias, portray complex interactions among input variables and are resistant to overfitting (Breiman, 2001).

The sample dataset input into the RF model was a random $1 \%$ subset of the study area $(608,807$ pixels) with a 100 m proximity buffer between selected pixels. Genuer et al. (2017) found that sampling $1 \%$ of the data provided an acceptable balance between processing time and model accuracy when using RF models for big data problems. RF models for the forest, ecotone and tundra zones were also created from the pixels in the subset that were part of each zone. Each RF model included 500 decision trees (ntree), with four environmental variables being randomly selected at each node split in each tree (mtry). The minimum terminal node size was set at 100 pixels, since smaller values had a large negative impact on processing time. Model outputs were robust over multiple $1 \%$ subsamples.

RF modelling allows for the importance of all predictor variables to be tested in relation to the response variable. The percent increase in mean squared error (MSE) of the predicted output if the variable in question is randomly permuted (\%IncMSE) is the most commonly used metric to measure variable importance in RF models. The increase in node purity from decision tree splits based on the variable in question (IncNodePurity) is also widely used to measure variable importance (Hastie et al., 2009). These two variable importance metrics were used to rank the overall importance of the environmental variables across all four RF models. The most 
important environmental variables (i.e., higher \%IncMSE and IncNodePurity) related to NDVI trends were evaluated further with partial dependence plots. Partial dependence plots portray the marginal influence of the variable in question on the response variable across their range of values, after averaging out (but not removing) the influence of all other variables (Hastie et al., 2009). Partial dependence plots are considered one of the most effective means of interpreting the results of a high dimensional machine learning model such as RF.

\subsection{Results}

\subsubsection{NDVI Trends}

There was an increase in NDVI across most the study area (Figure 3.6a), with $90 \%$ of un-masked pixels having a positive trend and $10 \%$ having a negative trend (Figure 3.7a). Fire scars, which were masked, exhibited large positive NDVI trends for older recorded fires and large negative NDVI trends for more recent fires. The statistical distribution of pixels (Figure 3.7a) indicates that the overall trends were skewed towards lower levels of annual increase. Most pixels (81\%) had a positive trend between 0 and $0.004 \mathrm{NDVI} \mathrm{yr}^{-1}$. Overall, the mean trend increased across the study area $\left(0.0019 \pm 0.0016 \mathrm{NDVI} \mathrm{yr}^{-1}\right)$.

Approximately one-quarter (27\%) of all un-masked pixels exhibited a statistically significant NDVI trend (Figure 3.6b) and virtually all of those (99.3\%) were greening (Figure 3.7a). One-third (33\%) of pixels in the tundra zone exhibited greening and were mostly found in the northern portion. Slightly less than one-quarter $(24 \%)$ of pixels in the ecotone zone exhibited greening and were mostly found in the southern portion. A smaller proportion (17\%) of pixels in the forest zone exhibited greening and were clustered primarily near the west arm of Great Slave Lake. Less than $0.5 \%$ of all pixels exhibited browning in each of the three zones. The mean trend for significant pixels was more positive than for all pixels across the study area $(0.0034 \pm 0.0013$ NDVI $\left.\mathrm{yr}^{-1}\right)$. 


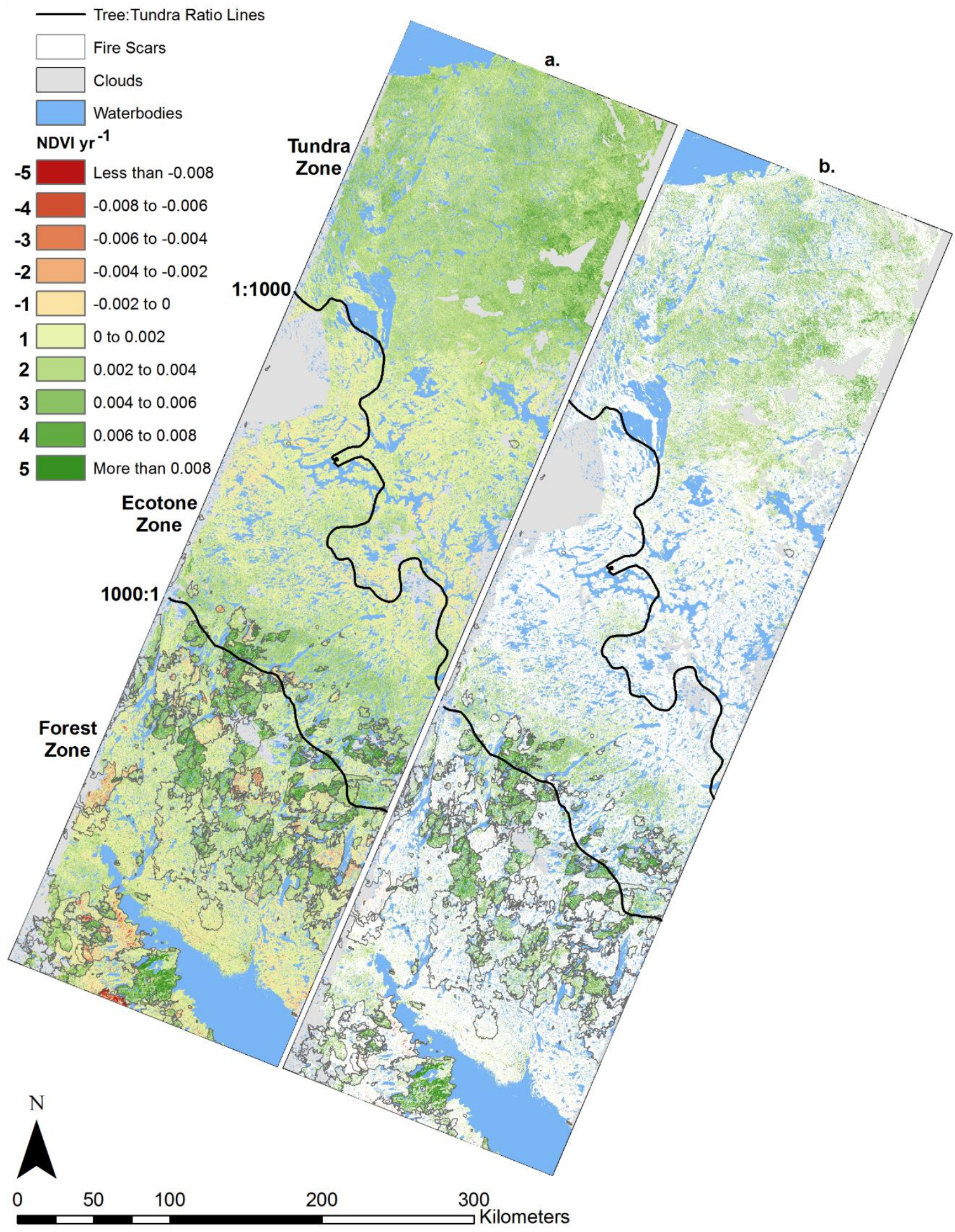

Figure 3.6: Landsat NDVI trends (1984-2016) for the study area as determined using ordinary least squares regression. (a) All NDVI trends. (b) Significant $(\mathrm{p}<0.05$ ) trends only. NDVI trends were binned into 10 levels $(-5=$ most negative, $5=$ most positive), as seen in the legend, for visualization purposes following an approach similar to Ju \& Masek (2016). Fire scars (outlined in gray) were masked and not incorporated into the analysis. Waterbodies and areas with excess cloud cover were also removed. Tree:tundra ratio lines that were used to delineate zones are shown. 
There were regional differences in the extent and magnitude of NDVI trends observed across the study area (Figure 3.7b). The largest positive NDVI trends were found in the tundra zone, where over $60 \%$ of all pixels increased more than $0.002 \mathrm{NDVI} \mathrm{yr}^{-1}$ and over $15 \%$ increased by more than $0.004 \mathrm{NDVI} \mathrm{yr}^{-1}$. Smaller positive NDVI trends below $0.002 \mathrm{NDVI} \mathrm{yr}^{-1}$ were more common in the ecotone (54\% of pixels) and forest zones (55\% of pixels). However, pixels in the ecotone zone were more likely to increase more than $0.002 \mathrm{NDVI} \mathrm{yr}^{-1}$ and less likely to decrease in NDVI than those in the forest zone. The mean NDVI trend was smallest in the

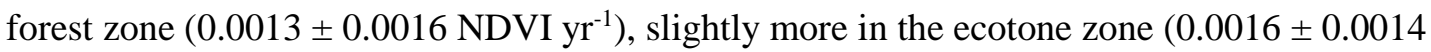
NDVI $\left.\mathrm{yr}^{-1}\right)$ and largest in the tundra zone $\left(0.0025 \pm 0.0015 \mathrm{NDVI} \mathrm{yr}^{-1}\right)$. In terms of significant trends, they were mostly consistently skewed towards stronger greening across all zones, with over $85 \%$ of significant pixels greening more than $0.002 \mathrm{NDVI} \mathrm{yr}^{-1}$ in all cases. However, greening above $0.004 \mathrm{NDVI} \mathrm{yr}^{-1}$ was more common in the tundra zone than elsewhere while $3 \%$ of significant forest zone pixels exhibited browning.

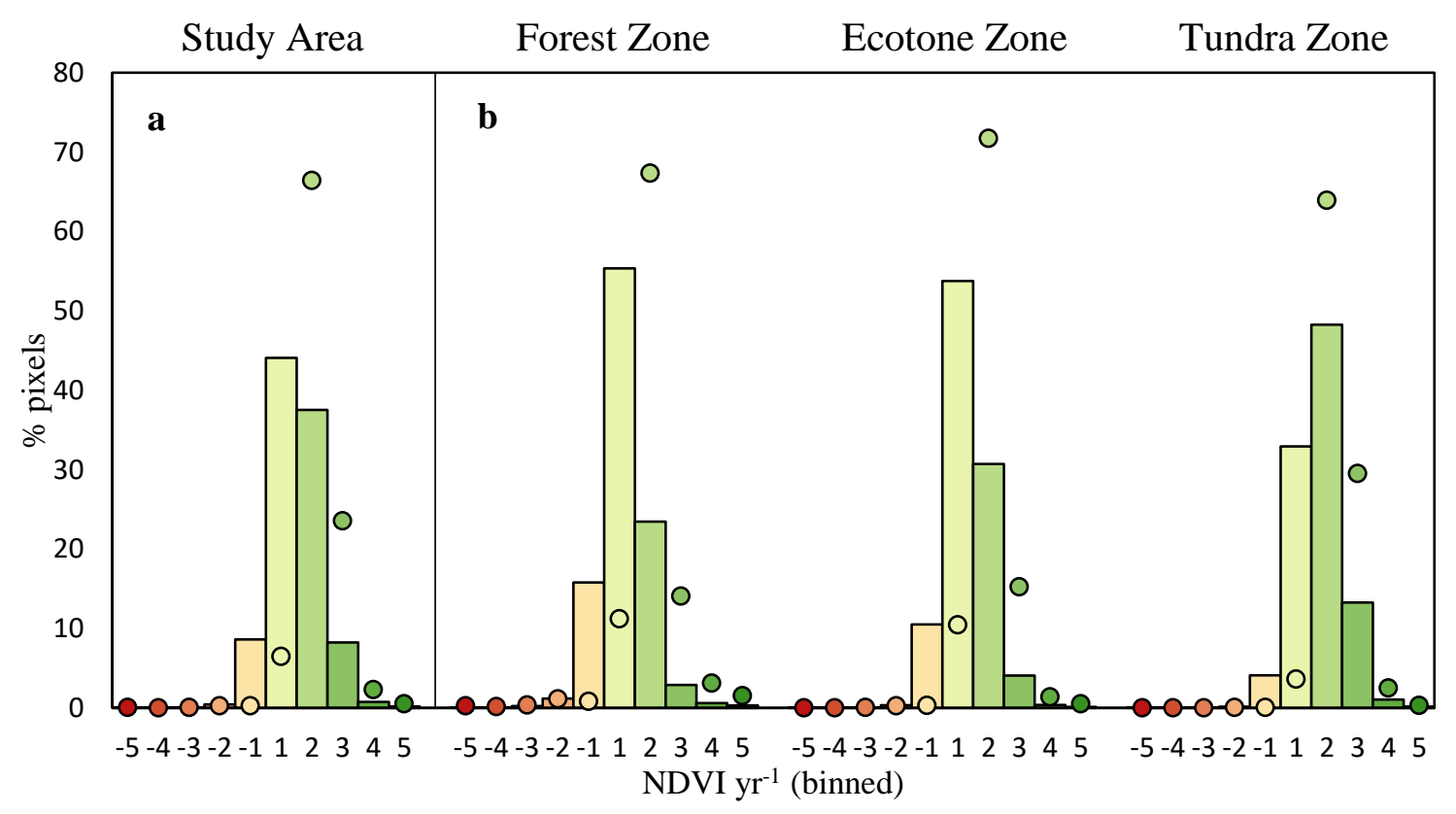

Figure 3.7: Pixel distribution of NDVI trends for the study area (a) and each of the zones (b). Bars indicate the percentage of all un-masked pixels that fall into each bin, corresponding to Figure 3.6a. Points indicate the percentage of significant pixels that fall into each bin, corresponding to Figure 3.6b. NDVI trends binned and colored as in Figure $3.6(-5=$ most negative, $5=$ most positive $)$. 
Significant trends varied with land cover across the study area as well (Figure 3.8). In the forest zone, 14 to $21 \%$ of forested land-cover classes (Forest [F], Woodland [W], Lichen-Rocky Woodland [LRW]), which comprised most of the landscape, exhibited greening trends. Landcover classes that were less densely vegetated (Lichen-Rocky Shrubland [LRS], Lichen-Barren Tundra [LBT], Sediments - Low Vegetation [SLV]) exhibited less greening and even some notable browning. Dense Shrubland (DS), Open Shrubland (OS) and Graminoid Tundra (GT) classes exhibited the most greening, but were also the least common land-cover classes in the forest zone. Similarly, in the ecotone zone, the more densely vegetated land-cover classes generally exhibited more greening than the less densely vegetated classes. The lower density forested land-cover classes (LRW and W) exhibited the strongest trends, with $34 \%$ of LRW pixels greening in the ecotone zone.

In the tundra zone, the less densely vegetated LRS, LBT and SLV land-cover classes, which were the most common and located primarily farther north, exhibited more greening than the shrubland (DS, OS) and GT classes. Almost $50 \%$ of LBT pixels in the tundra zone exhibited greening, with most of those pixels geographically distributed towards the edge of that class's extent. OS, which was primarily found in the southern portion of the tundra zone, only had $18 \%$ of its pixels exhibit a greening trend. However, OS pixels located in the northern portions of the tundra zone exhibited almost $50 \%$ greening when considered separately. In the northern portion of the tundra zone, inter-class differences were smaller than for the tundra zone as a whole and all land-cover classes present exhibited 35 to $50 \%$ greening (see Appendix E for figure). 


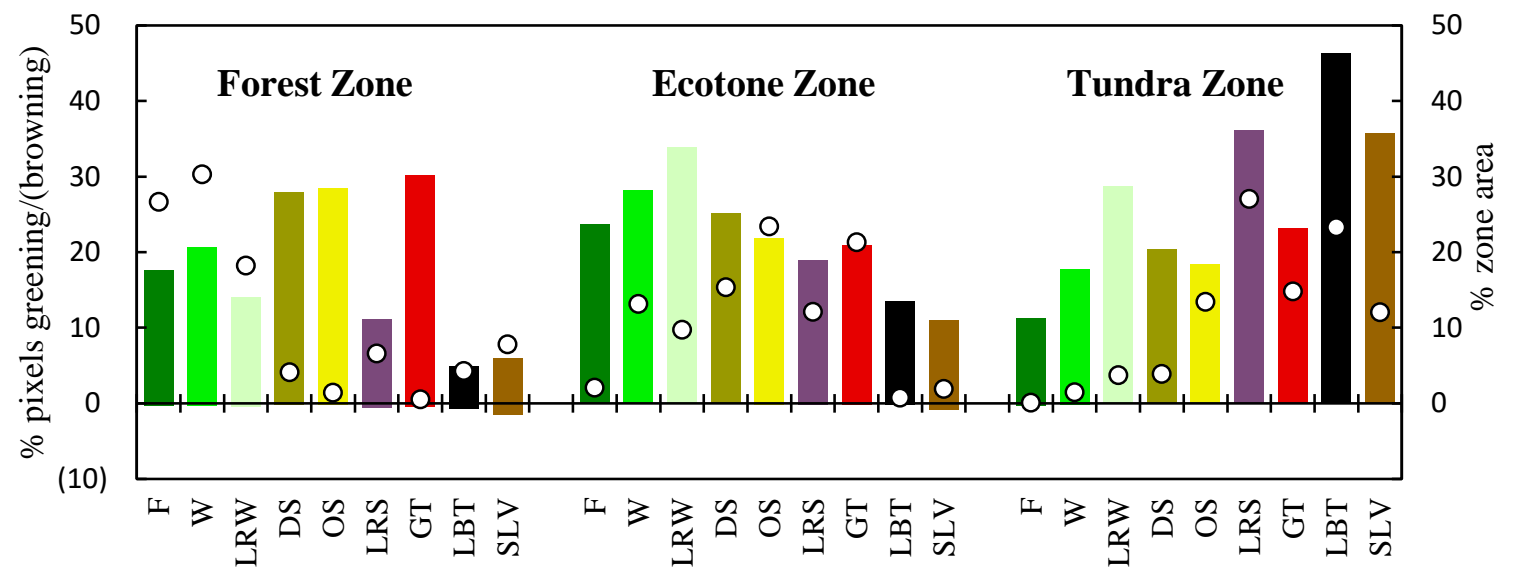

Figure 3.8: Percentage of Landsat pixels with significant NDVI trends in each of the three zones across the study area, split by land-cover type (sensu Frost et al., 2014). Values above 0 indicate greening while values below 0 (in parenthesis) indicate browning. The percentage of the zone in question that is comprised by each land-cover class is indicated as points plotted against the right $y$-axis. Land-cover classes are colored as in Figure 3.5: F = Forest, $\mathrm{W}=$ Woodland, LRW = Lichen-Rocky Woodland, DS = Dense Shrubland, OS = Open Shrubland, LRS = Lichen-Rocky Shrubland, GT = Graminoid Tundra, LBT = Lichen-Barren Tundra, SLV $=$ Sediments - Low Vegetation.

\subsubsection{Relationship between NDVI and Bulk Vegetation Volume}

Of the plots sampled during the field expedition, 11 were classified on the ground as forested, 18 as shrubland, two as graminoid tundra and three as wetland (Figure 3.2). Forested plots were almost all open black spruce (Picea mariana) canopies (51 \pm 14 tree PVC, $1048 \pm 335$ $\mathrm{m}^{3}$ per plot), with one lichen-woodland plot interspersed with white spruce (Picea glauca) and paper birch (Betula papyrifera). Understories of erect-shrubs (25 $\pm 14 \mathrm{PVC}, 135 \pm 78 \mathrm{~m}^{3}$ per plot) and dwarf-shrubs ( $84 \pm 16$ PVC, $108 \pm 39 \mathrm{~m}^{3}$ per plot) were common at forested plots. Shrubland plots were mostly dominated by birch shrubs (Betula spp.), but alder (Alnus spp.) and willow (Salix spp.) shrubs were common and even dominant at some plots. These erect-shrubs were present at a majority (56 $\pm 19 \mathrm{PVC}, 248 \pm 182 \mathrm{~m}^{3}$ per plot) of shrubland sample points, while dwarf-shrubs were present at most ( $88 \pm 7 \mathrm{PVC}, 69 \pm 35 \mathrm{~m}^{3}$ per plot) sample points. Many shrubland plots, especially those with lower BVV, were strewn with boulders. The most dominant dwarf-shrubs across all plots were northern Labrador tea (Rhododendron tomentosum, $51 \%$ of dwarf-shrub volume), blueberry (Vaccinium uliginosum, $25 \%$ ) and low-bush cranberry 
(Vaccinium vitis-idaea, $13 \%$ ). The most dominant erect-shrub types by volume were birch (69\% of erect-shrub volume), alder (23\%) and willow (7\%). Graminoids were the dominant vegetation in graminoid tundra $\left(52 \pm 7 \mathrm{PVC}, 45 \pm 3 \mathrm{~m}^{3}\right.$ per plot $)$ and wetland $\left(73 \pm 20 \mathrm{PVC}, 108 \pm 44 \mathrm{~m}^{3}\right.$ per plot) plots. Lichen was common in all plots (59 \pm 24 PVC) and moss (23 \pm 20 PVC), as expected, was found mostly in wetter areas.

The BVV of all non-wetland sample plots had only a weak relationship $\left(\mathrm{R}^{2}=0.221, \mathrm{p}=\right.$ 0.089) with the 2011 NDVI (Figure 3.9a). Wetland plots were removed because standing water within those plots negatively influenced the NDVI signal (Raynolds \& Walker, 2016). Shrubland plots had a lower mean BVV $\left(362 \pm 246 \mathrm{~m}^{3}\right.$ per plot $)$ than forested plots $\left(1365 \pm 367 \mathrm{~m}^{3}\right.$ per plot $)$ but exhibited a slightly higher mean NDVI $(0.63 \pm 0.07)$ than forested plots $(0.62 \pm 0.06)$. In general, the NDVI of forested plots was lower than expected based on their BVV. However, when the volume contributed by individual trees was removed, the relationship between this revised bulk vegetation volume ( $\left.{ }_{\mathrm{NT}} \mathrm{BVV}\right)$ and NDVI was strong, with an $\mathrm{R}^{2}$ of $0.81(\mathrm{p}<0.001)$ (Figure 3.9b). This relationship was logarithmic, with an increase in NDVI of 0.1 (i.e., 0.0031 NDVI $\mathrm{yr}^{-1}$ if considered over time) equating to a $316 \%$ increase in ${ }_{\mathrm{NT}} \mathrm{BVV}$.

NDVI trends were converted to ${ }_{\mathrm{NT}} \mathrm{BVV}$ trends for non-wetland sample plots based on the strength of this relationship, using the equation $\left(\mathrm{NDVI}=0.087 \ln (\mathrm{NTBVV})+0.1366, \mathrm{R}^{2}=0.81, \mathrm{p}\right.$ $<0.001$ ) in Figure 3.9b. Field-collected ${ }_{\mathrm{NT}} \mathrm{BVV}$ values from 2016 aligned well with earlier satellite-derived trends for most plots. Forested plots (Figure 3.10a) exhibited the largest positive mean ${ }_{\mathrm{NT}} \mathrm{BVV}$ trend $\left(5.05 \pm 2.47 \mathrm{~m}^{3}\right.$ per plot $\left.\mathrm{yr}^{-1}\right)$. Four of the 11 forested plots exhibited greening and all ${ }_{\mathrm{NT}} \mathrm{BVV}$ trends were positive. All three of the forested plots classified for field sampling as open woodland (Table 3.1), the lowest density forest class, exhibited greening. Shrubland plots (Figure 3.10b) exhibited a positive mean ${ }_{\mathrm{NT}} \mathrm{BVV}$ trend overall, but with high variation $(3.09 \pm$ $5.22 \mathrm{~m}^{3}$ per plot $\left.\mathrm{yr}^{-1}\right)$. Two of the 18 shrubland plots exhibited greening and 13 exhibited positive ${ }_{\mathrm{NT}} \mathrm{BVV}$ trends. These two greening plots were the only shrubland plots where alders constituted 
the majority of erect-shrub volume (i.e., alder-dominant sites). The two graminoid tundra plots (Figure 3.10c) exhibited a slightly decreasing mean ${ }_{\mathrm{NT}} \mathrm{BVV}$ trend $\left(-1.43 \pm 0.63 \mathrm{~m}^{3}\right.$ per plot $\left.\mathrm{yr}^{-1}\right)$ and neither were significant.
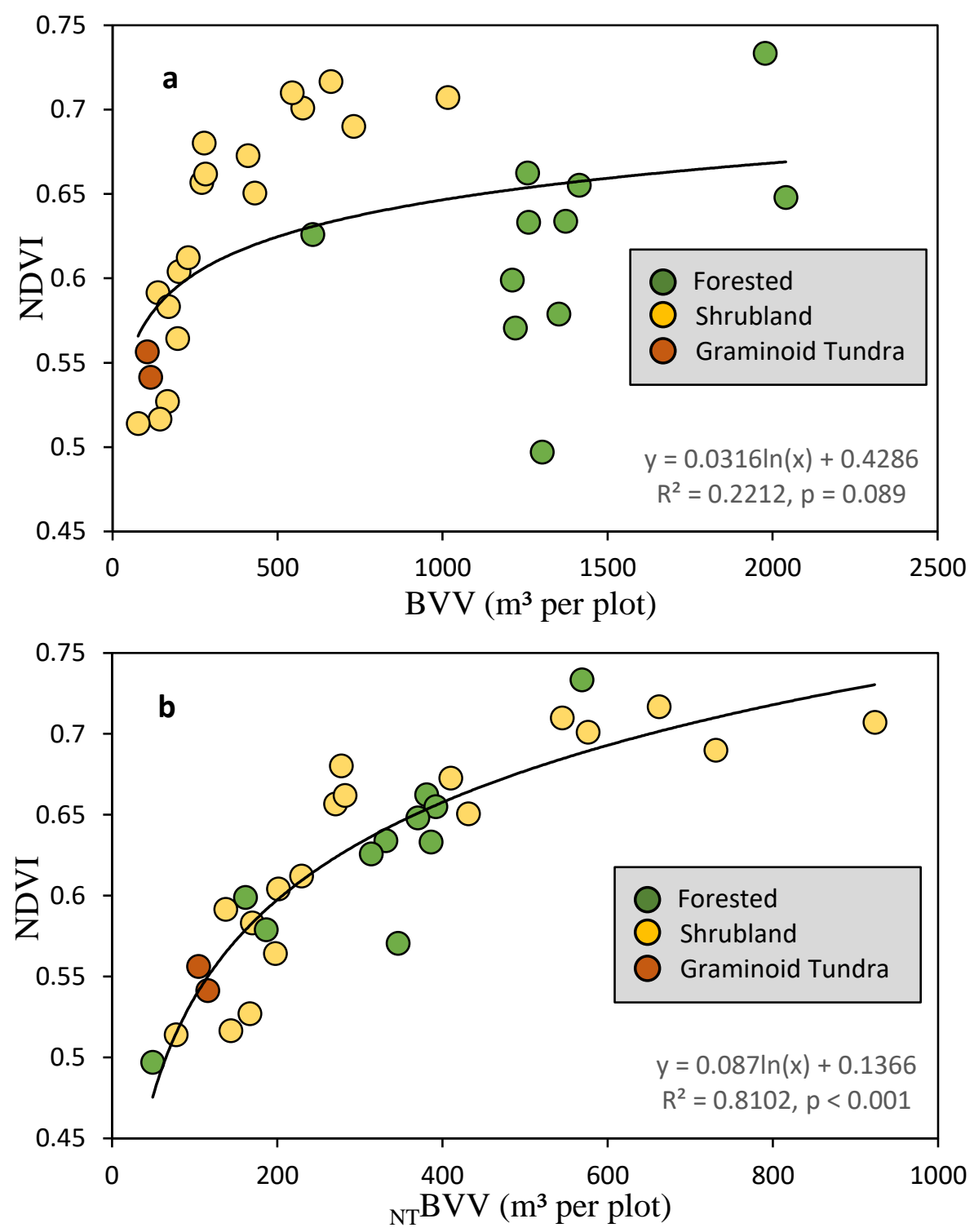

Figure 3.9: The relationship (logarithmic regression) between Landsat-derived NDVI (2011) and fieldmeasured bulk vegetation volume $\left(\mathrm{m}^{3}\right.$ per Landsat-size plot). NDVI was calculated from the same scenes used to create the ISODATA classification from which sample plots were selected. Equation, coefficient of determination $\left(\mathrm{R}^{2}\right)$ and p-value shown. These relationships are logarithmic because as the (NT)BVV of a sample plot increased the influence of those changes on NDVI decreased. (a) All non-wetland plots using all functional group measurements (b) All non-wetland plots with the volume of individual trees removed. 


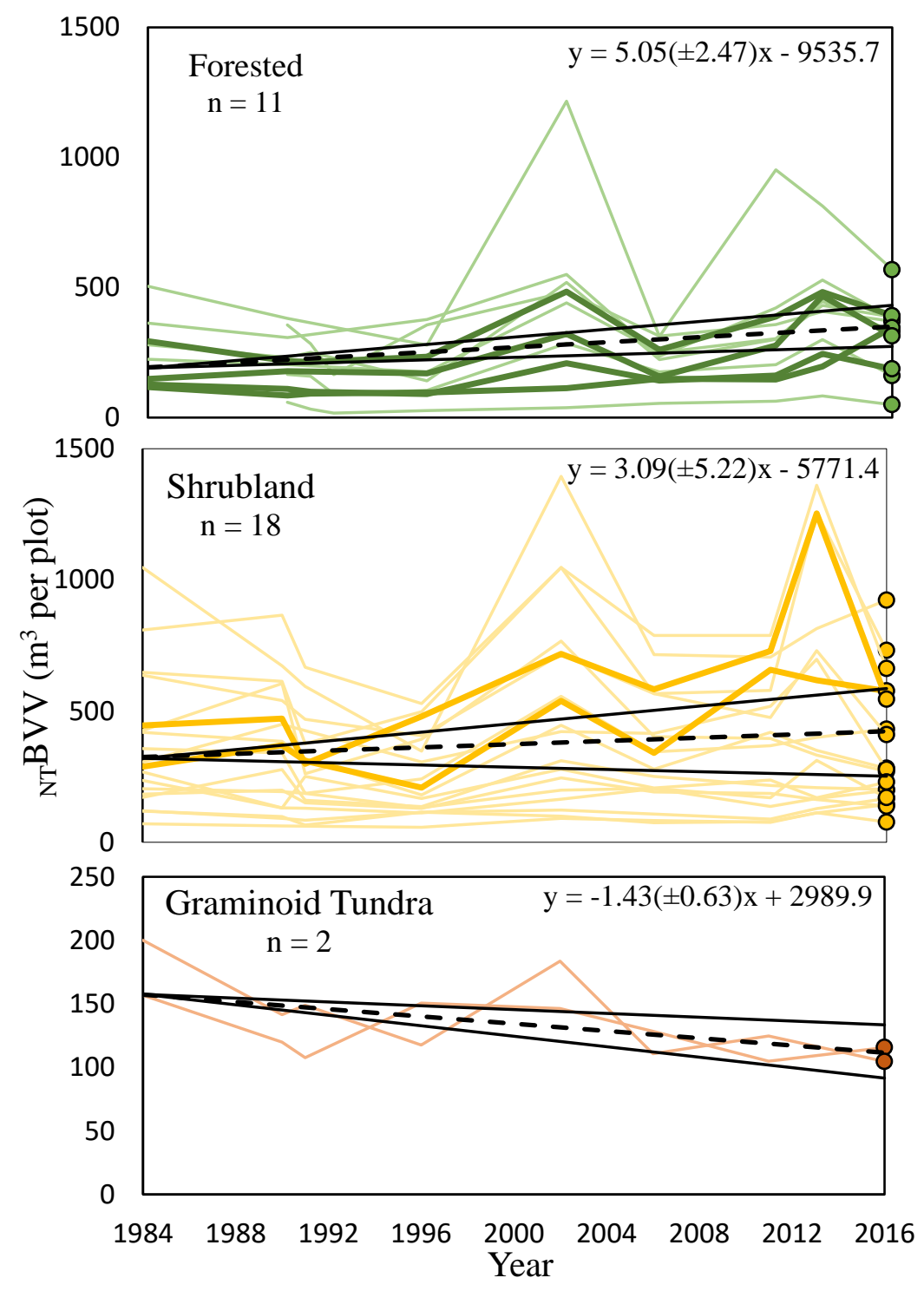

Figure 3.10: Non-tree bulk vegetation volume $\left(\mathrm{m}^{3}\right.$ per Landsat-size plot) trends for (a) forested, (b) shrubland and (c) graminoid tundra sample plots based on the relationship between ${ }_{\mathrm{NT}} \mathrm{BVV}$ and NDVI. NDVI was converted to ${ }_{\mathrm{NT}} \mathrm{BVV}$ using the equation from Figure 3.9b. Thick colored lines indicate plots with significant linear trends, while thin colored lines represent plots without significant trends. Colored circles indicate actual ${ }_{\mathrm{NT}} \mathrm{BVV}$ values collected for each plot during the 2016 field expedition. The dashed black line indicates the mean change in ${ }_{\mathrm{NT}} \mathrm{BVV}$ per year across all sampled plots of each type $( \pm \mathrm{SD}$ indicated by solid black lines).

\subsubsection{Landscape and Environmental Influences on NDVI Trends}

The results of Pearson's correlation analyses (Figure 3.11) illustrate that NDVI trends

$\left(\mathrm{NDVI} \mathrm{yr}^{-1}\right)$ across the full extent of the study area did not exhibit strong relationships with any 
single environmental variable. The strongest positive relationship of any environmental variable was with temperature change $(\mathrm{R}=0.30, \mathrm{p}<0.01)$ and the distance to major lakes $(\mathrm{R}=0.24, \mathrm{p}<$ $0.01)$. The strongest negative correlation was with precipitation change $(\mathrm{R}=-0.27, \mathrm{p}<0.01)$. NDVI trends also exhibited positive correlations with UTM northings (northing, $\mathrm{R}=0.39, \mathrm{p}<$ 0.01), indicating that NDVI trends were more positive at higher latitudes. Correlations between the environmental variables were low for the most part, except for between precipitation and temperature change. These correlations were consistent across multiple $1 \%$ subsamples of the original dataset.

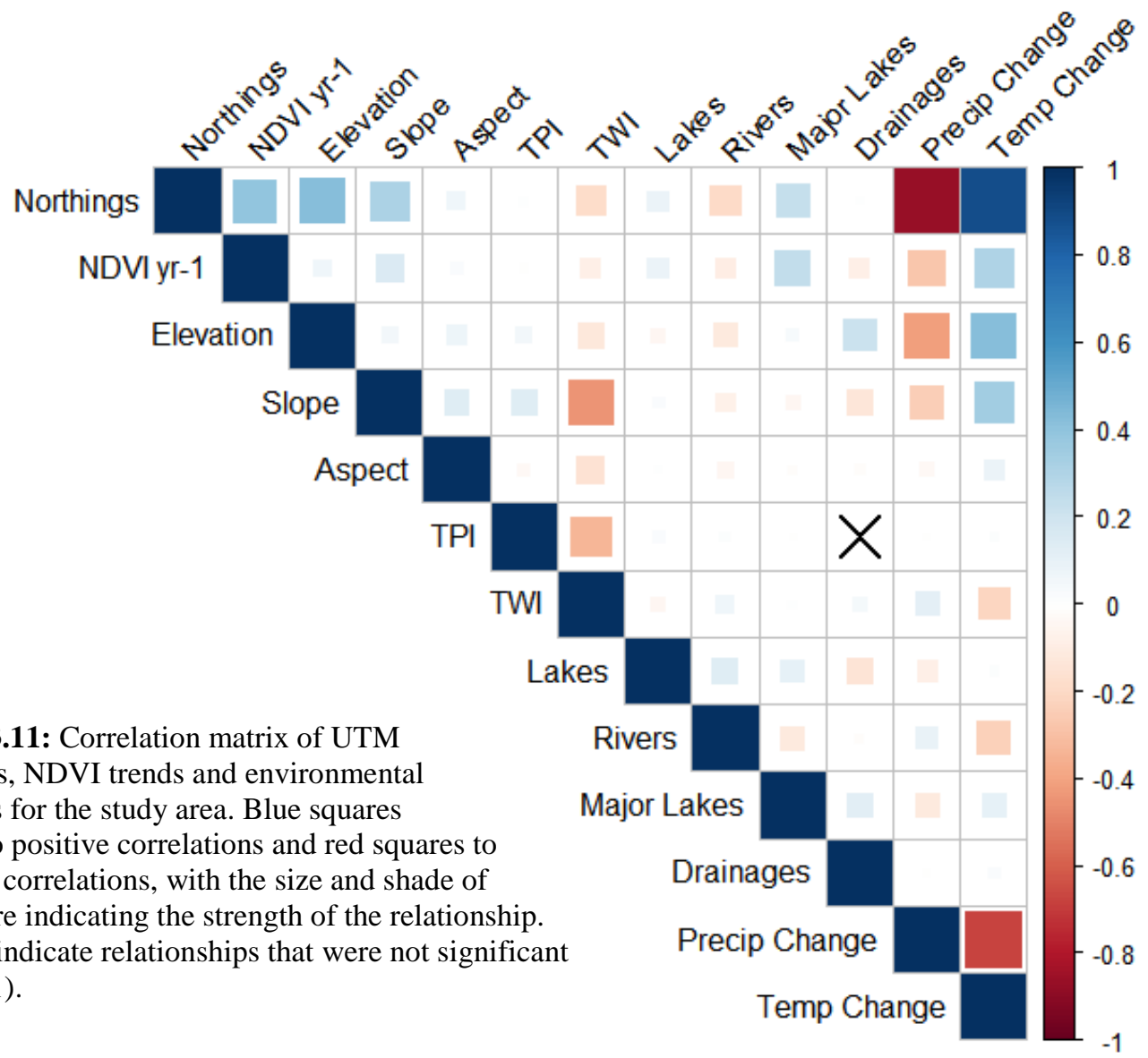

Figure 3.11: Correlation matrix of UTM northings, NDVI trends and environmental variables for the study area. Blue squares equate to positive correlations and red squares to negative correlations, with the size and shade of the square indicating the strength of the relationship. Crosses indicate relationships that were not significant $(\mathrm{p}>0.01)$

Results of RF modeling indicated that environmental variables differed in their ability to account for variability of NDVI trends across the study area (Table 3.3). For the study area as a 
whole, almost half of all variation was explained by the input variables. When analyzed separately, the forest zone had the lowest variation explained at $21.6 \%$. The ecotone zone performed better, with over $40 \%$ of the variation explained. Meanwhile, $55.3 \%$ of the variation in NDVI trends was explained by input variables in the tundra zone.

Table 3.3: RF model details for the study area and each of the three zones. Sample sizes represent $1 \%$ of pixels that make up the overall extent of each model. Error is the average out-of-bag mean square error (MSE). Percent (\%) Variation explained is the pseudo $\mathrm{R}^{2}:(1-$ Error / variation in training data) $* 100$.

\begin{tabular}{|l|c|c|c|}
\hline \multicolumn{1}{|c|}{ Extent } & Sample Subset Size & Error & \% Variation Explained \\
\hline Study Area & 608,807 & $1.31 \mathrm{E}-06$ & 48.24 \\
\hline Forest Zone & 138,010 & $2.02 \mathrm{E}-06$ & 21.55 \\
\hline Ecotone Zone & 177,803 & $1.19 \mathrm{E}-06$ & 41.08 \\
\hline Tundra Zone & 292,994 & $1.02 \mathrm{E}-06$ & 55.26 \\
\hline
\end{tabular}

Based on \%IncMSE and IncNodePurity, RF models showed that land cover and temperature change were considered the most important variables for the study area and for each of the three zones in determining the direction and magnitude of NDVI trends (Figure 3.12). The one exception was the forest zone, where precipitation change was indicated as more important than temperature change. Precipitation change, distance to major drainage systems, elevation and distance to major lakes also had high importance rankings for both \%IncMSE and IncNodePurity. There was a decline in importance for the other environmental variables, which focused primarily on finer scale landscape variation. A final ranking based on the average rankings of \%IncMSE and IncNodePurity across the four RF models found that land cover was the most important variable overall, followed by temperature change, precipitation change, distance to major drainage systems, elevation and distance to major lakes. Distance to all lakes and rivers, slope, TPI, TWI and aspect were indicated as less important. 

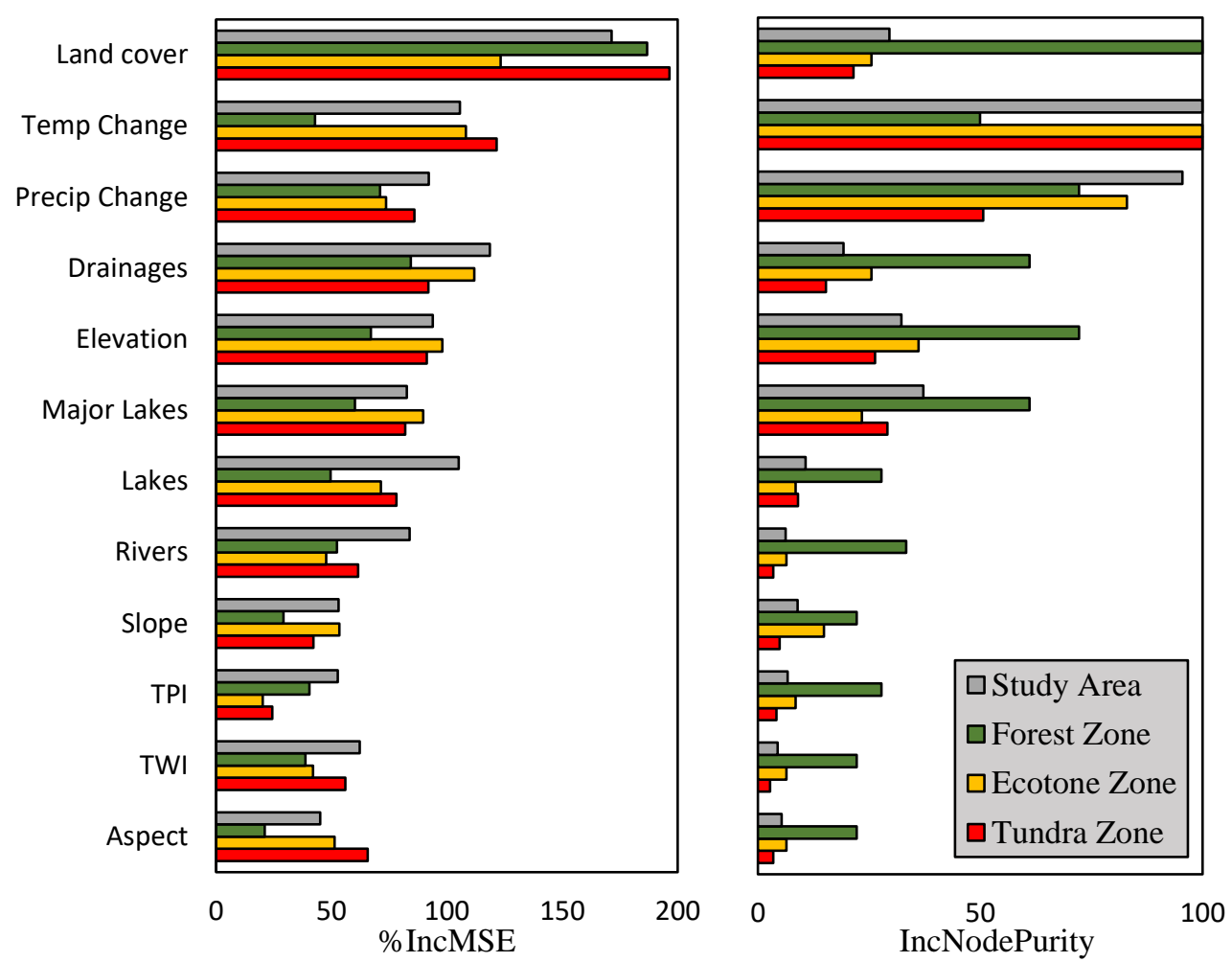

\begin{tabular}{|c|c|c|c|c|c|c|c|c|c|}
\hline & \multicolumn{4}{|c|}{$\%$ IncMSE } & \multicolumn{4}{|c|}{ IncNodePurity } & \\
\hline & $\begin{array}{l}\text { Study } \\
\text { Area }\end{array}$ & $\begin{array}{l}\text { Forest } \\
\text { Zone }\end{array}$ & $\begin{array}{l}\text { Ecotone } \\
\text { Zone }\end{array}$ & $\begin{array}{l}\text { Tundra } \\
\text { Zone }\end{array}$ & $\begin{array}{l}\text { Study } \\
\text { Area }\end{array}$ & $\begin{array}{l}\text { Forest } \\
\text { Zone }\end{array}$ & $\begin{array}{l}\text { Ecotone } \\
\text { Zone }\end{array}$ & $\begin{array}{l}\text { Tundra } \\
\text { Zone }\end{array}$ & $\begin{array}{l}\text { Average } \\
\text { Rank }\end{array}$ \\
\hline Land cover & 1 & 1 & 1 & 1 & 5 & 1 & 4 & 5 & 2.375 \\
\hline Temp Change & 3 & 8 & 3 & 2 & 1 & 6 & 1 & 1 & 3.125 \\
\hline Precip Change & 6 & 3 & 6 & 5 & 2 & 3 & 2 & 2 & 3.625 \\
\hline Drainages & 2 & 2 & 2 & 3 & 6 & 4 & 5 & 6 & 3.75 \\
\hline Elevation & 5 & 4 & 4 & 4 & 4 & 2 & 3 & 4 & 3.75 \\
\hline Major Lakes & 8 & 5 & 5 & 6 & 3 & 5 & 6 & 3 & 5.125 \\
\hline Lakes & 4 & 7 & 7 & 7 & 7 & 9 & 9 & 7 & 7.125 \\
\hline Rivers & 7 & 6 & 10 & 9 & 10 & 7 & 12 & 11 & 9 \\
\hline Slope & 10 & 11 & 8 & 11 & 8 & 10 & 7 & 8 & 9.125 \\
\hline TPI & 11 & 9 & 12 & 12 & 9 & 8 & 8 & 9 & 9.75 \\
\hline TWI & 9 & 10 & 11 & 10 & 12 & 11 & 10 & 12 & 10.625 \\
\hline Aspect & 12 & 12 & 9 & 8 & 11 & 12 & 11 & 10 & 10.625 \\
\hline
\end{tabular}

Figure 3.12: Importance of environmental variables from RF models. (a) The percent increase in MSE if the variable in question has its values randomly permuted (\%IncMSE). (b) The increase in node purity based on the function by which best splits are chosen in decision trees (IncNodePurity). IncNodePurity scaled to 100 for each model to gauge relative importance (Hastie et al., 2009). More important variables have higher \%IncMSE and IncNodePurity. Bottom: table of importance rankings for environmental variables from 1 to $12(1=$ most important, $12=$ least important $)$ used to determine overall importance ranking (i.e., lowest average rank).

Partial dependence plots for land cover (Figure 3.13), which was considered one of the two most important variables in every RF model, indicated that the more densely vegetated classes exhibited larger positive NDVI trends than the less densely vegetated classes. DS and OS exhibited among the most positive NDVI trends and LBT and SLV exhibited the weakest trends 
in all models. Forested classes also exhibited larger positive NDVI trends, especially in the ecotone zone. These results are in agreement with greening trend results, with the exception of the tundra zone where LRS, LBT and SLV were greening the most and inter-class differences were larger (Figure 3.8). This difference is attributed to the strong positive influence of temperature warming on NDVI trends in the tundra zone, which likely supersedes any large influence by differences in land cover. The differences between Figure 3.8 and 3.13 in the tundra zone thus indicate that those classes with stronger greening trends (LRS, LBT, SLV) were located primarily in the northern portion of the tundra zone where the most pronounced warming has occurred. In this northern area, all land-cover classes exhibited large positive NDVI trends and shrubland land covers (DS, OS, LRS) were the largest (Figure 3.13).

The strongest influence on NDVI trends for any partial dependence plot was attributed to temperature change in the tundra zone, where NDVI trends doubled from 0.0015 to 0.003 NDVI $\mathrm{yr}^{-1}$ where more warming had occurred (Figure 3.13). Increased summer warming led to larger positive NDVI trends in general. However, the ecotone zone was the notable exception, and summer temperature warming was associated with a decline in NDVI trends in that zone. The influence of precipitation changes, which were small ( $<8 \mathrm{~mm}$ from 1980 to 2015), on NDVI trends was variable across the study area. Across all models, NDVI trends were more positive when closer to major drainage systems. Gradual changes in elevation above sea level did not have a notable influence on NDVI trends, except for around $350 \mathrm{~m}$ a.s.1., where a break point occurred. In all models except for the forest zone, NDVI trends tended to be more positive at elevations below $350 \mathrm{~m}$ a.s.l. than above that elevation. Proximity to major lakes, which was consistently one of the two least important variables of these six, generally exhibited a negative influence on NDVI trends. In all models except for the forest zone, NDVI trends were more positive when farther away from major lakes. Overall, NDVI trends were more positive in the tundra zone than in the forest or ecotone zones for all variables. 


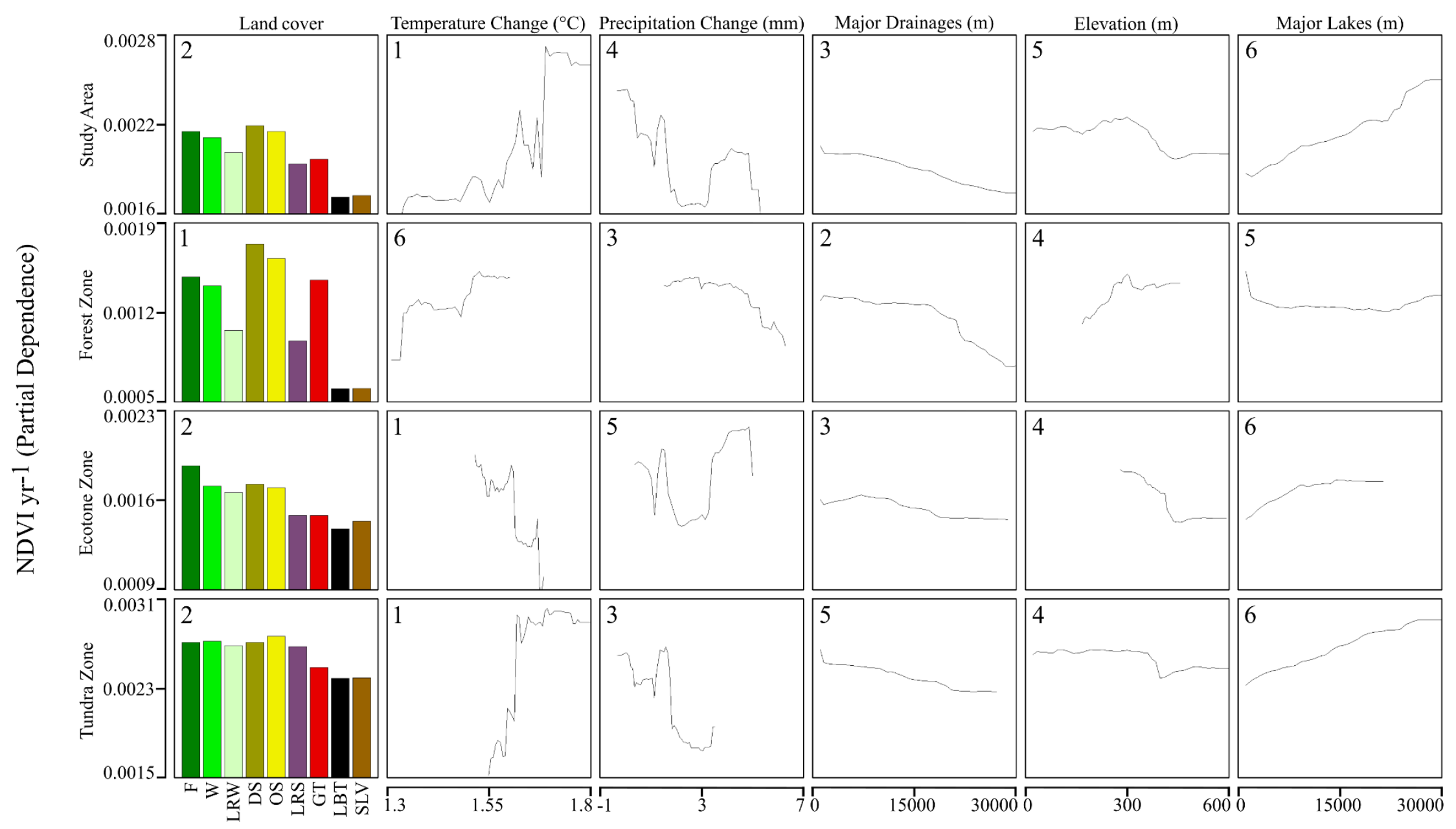

Figure 3.13: Matrix of partial dependence plots for the six overall (across all four models) most important variables across the study area. Variable importance rankings for these six variables (shown in the top left corner of each plot) are based on both the \%IncMSE and IncNodePurity ranking for each model. Partial dependence plots indicate the marginal influence of the variable in question on NDVI trends, with all other (11) variables averaged out (but not ignored). Land cover colored as in Figure 3.5 and follows same naming conventions as in Figure 3.8. See Appendix F to view the partial dependence plots for the six leastimportant variables considered, which generally influenced NDVI trends at a much smaller scale. 


\subsection{Discussion}

\subsubsection{NDVI Trends}

NDVI trend analyses indicated that vegetation productivity has been increasing throughout the study area, but that increases have been heterogeneous across the forest to tundra transition. The majority of greening pixels and the largest positive NDVI trends were located in the northern portion of the tundra zone and southern portion of the ecotone zone, with smaller and less significant trends elsewhere. Browning pixels were rare and negative NDVI trends were generally small. The geography and magnitude of these trends are in general agreement with a Landsat NDVI time-series developed across Canada and Alaska by Ju \& Masek (2016), which shows similar NDVI $\mathrm{yr}^{-1}$ changes as found in my study area. In terms of the overall significance of trends, a similar Landsat transect in northern Québec by McManus et al. (2012) found that 34 $\%$ of pixels exhibited significant positive NDVI trends ( $99 \%$ greening). The results of trend analyses in my study area indicates slightly less (27\%) significant trends (also $99 \%$ greening), which is not surprising given that northern Québec has experienced a recent rapid increase in vegetation productivity (Ju \& Masek, 2016). Greening pixels in both areas were primarily located at, and north of the forest-tundra ecotone.

The largest increases in NDVI and the majority of greening pixels across the study area were found in the northern portion of the tundra zone. This area is primarily comprised of lichendominated land cover (LRS, LBT, SLV), of which about half of all pixels were greening. Similarly, Landsat-based studies in the Alaskan and western Canadian Arctic have observed greening in lichen-dominated areas (Raynolds et al., 2013; Fraser et al., 2014a) while plot-based studies have demonstrated a reduction of lichen cover and an increase in shrub cover in those regions (Walker et al., 2006). OS land cover, which is common along riparian corridors, also exhibited nearly $50 \%$ greening in the northern portion of the tundra zone. Greening of shrubland areas has been detected using Landsat elsewhere in Arctic North America (Olthof et al., 2008; 
McManus et al., 2012; Fraser et al., 2014a). Several AVHRR-based remote sensing studies conducted across northern high latitudes have also found widespread greening along much of the northern coast of mainland Canada, including in the area corresponding to the northern tundra zone (Jia et al., 2003; Goetz et al., 2005; Beck \& Goetz, 2012; Epstein et al., 2012; Guay et al., 2014; Epstein et al., 2016). Greening has thus been common across this area, regardless of land cover.

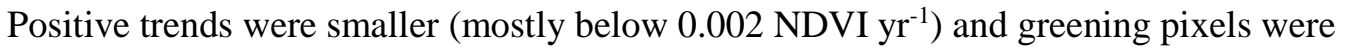
less common in areas south of the northern tundra zone. These results coincide with NDVI trends derived for the same area in other studies, as well as east across the inland Low Arctic region of mainland Nunavut (Ju \& Masek, 2016). This portion of the study area, which crosses into the northern portion of the ecotone zone, is dominated by OS (30\%) and GT (22\%) land-cover classes and is occupied by many small lakes and wetlands (Ecosystem Classification Report, 2008). Epstein et al. (2012) found that wet mires in the Low Arctic had the smallest phytomass increase of any vegetation type across circumpolar high latitudes in their AVHRR-based study, indicating that tundra areas with wet moisture regimes have been greening less than drier areas. NDVI is also known to be negatively influenced by standing water, which has an NDVI value of zero, as well as by high moisture content in soils (Laidler et al., 2008; Raynolds \& Walker, 2016). In fact, wetland plots sampled during the field expedition were removed from analysis because the large amount of standing water present resulted in an uncertain NDVI to ${ }_{\mathrm{NT}} \mathrm{BVV}$ relationship for those plots.

Farther south, the largest NDVI trends and highest percentage of greening pixels were found in the southern ecotone zone, which is characterized by the transition between shrubland and forest along a latitudinal gradient. Hence, it is not surprising that forested land cover had the highest percentage of greening pixels in the ecotone zone. Similarly, McManus et al. (2012) detected large positive NDVI trends in the proximity of treeline in northern Québec. However, for 
their entire study area, forest land cover had the lowest percentage of greening pixels (16\%) of all land covers. In the ecotone zone for my study, forested pixels (F, W, LRW) had the highest percentage of greening ( 24 to $34 \%$ ). This difference is related to the delineation of zones; in the forest zone (where the majority of forested pixels were located), a similar percentage (14 to $21 \%$ ) of forested pixels were greening (as in McManus et al. 2012). It thus appears that these forested areas are more likely to be greening when closer to their range margins.

South of the forest-tundra ecotone, some continental boreal forest communities have exhibited decreases in productivity, frequently attributed to warming-induced drought stress (Barber et al., 2000). The browning of these conifer forests has been reported in Siberia, Alaska and northern Canada from a variety of remote sensing and field-based studies (Barber et al., 2000; Goetz et al., 2005; Verbyla, 2008; Berner et al., 2011; Beck \& Goetz, 2012; Guay et al., 2014). In my study area, the mean trends were smallest in the forest zone $(0.0013 \pm 0.0016$ NDVI $\left.\mathrm{yr}^{-1}\right)$, but forested pixels were still at least 20 times more likely to be greening than browning. Even bedrock outcroppings (LBT, SLV) in the forest zone, which exhibited the lowest greening and highest browning percentages of any land cover across the study area, were four times more likely to be greening than browning. Ju \& Masek's (2016) map of NDVI trends over North America similarly shows that boreal areas are browning in some locations (i.e., interior Alaska, northern Saskatchewan) but that elsewhere, including the area corresponding to the forest zone, there is little change or small increases in NDVI. The browning of boreal forests observed elsewhere has thus not occurred here (note that fire scars have been removed from this analysis).

\subsubsection{Relationship between NDVI and Bulk Vegetation Volume}

The canoe-based field expedition in the North Slave region of NWT was able to provide ground validation for these remote sensing results, especially for non-tree vegetation.

Observations made in the field were also key to gathering information not possible from Landsat data alone, such as species-level and other local-scale influences on NDVI trends. Results 
indicated a significant positive relationship $\left(\mathrm{R}^{2}=0.81, \mathrm{p}<0.001\right)$ between ${ }_{\mathrm{NT}} \mathrm{BVV}$ and NDVI for sample plots, confirming that Landsat-derived NDVI is strongly indicative of vegetation volume in the study area. This means that changes in satellite-derived NDVI can be confidently associated with similar changes in vegetation volume on the ground. This methodology, adapted from Chen et al. (2009), was also shown to be strongly linked with aboveground biomass and leaf area index (LAI) across 196 plots elsewhere in the Canadian tundra. Gregory (2011) found that ${ }_{\mathrm{NT}} \mathrm{BVV}$ had the strongest relationship with NDVI of any biophysical metric tested at a High Arctic site. My results further support the strong relationship between ${ }_{\mathrm{NT}} \mathrm{BVV}$ and NDVI in tundra environments and demonstrate that this methodology can also be successful at sites with lower density tree cover, which was not tested in either Chen et al. (2009) or Gregory (2011). However, this relationship overestimated the predicted NDVI of forested plots when the volume added by trees was included. It appears that trees had a negligible impact on NDVI at the scale of Landsat data. These trees, predominantly open canopies of black spruce at the edge of their habitable range, were primarily small, thin individuals with proportionately low leaf biomass compared to wood biomass. Broadleaf shrub understories, by comparison, were more densely packed with leaves (indicating a higher LAI). Shadows cast by trees on understory vegetation has been shown to have a negative influence on the NDVI of lower density coniferous forests, especially near treeline where the understory often constitutes much of the biomass (McDonald et al., 1998; Rees et al., 2002). It is thus evident that the volume, and therefore NDVI, added by needles from these trees was offset by the shadows they cast on higher LAI understory shrubs.

The ${ }_{\mathrm{NT}} \mathrm{BVV}-\mathrm{NDVI}$ relationship was logarithmic, where higher volume sites had limited additional positive influence on NDVI. Similar relationships between biophysical variables and NDVI have been noted in other studies. Jia et al. (2003) found strong correlations between NDVI and aboveground biomass in Alaskan tundra, with diminishing impact on NDVI as biomass increased. Epstein et al. (2012) also found a strong logarithmic relationship between NDVI and 
biomass from 13 sites across the circumpolar Arctic subzones. The structure of this relationship is the result of NDVI saturation, where NDVI becomes increasingly insensitive to further biomass increases in high biomass environments (Raynolds et al., 2012). Frost et al. (2014) also noted this when explaining why shrub expansion in a high biomass area can lead to a smaller NDVI trend increase than the same shrub expansion in a lower biomass area.

\subsubsection{Landscape and Environmental Influences on NDVI Trends}

RF modelling also indicated that NDVI trends were heterogeneous across the study area and were influenced by a number of environmental variables. Variable importance indices and partial dependence plots indicated that land cover and temperature change had the most influence on NDVI trends. Precipitation change, distance to major drainage systems, elevation and distance to major lakes also notably influenced NDVI trends. The fact that these variables were highlighted by RF modelling demonstrates the importance of broader scale environmental variables on NDVI trends. Distance to all lakes and rivers, slope, TPI, TWI and aspect, all of which focus on finer scale changes, were indicated as less important and had much smaller partial dependence trends.

In the tundra zone, temperature was identified as the most important variable and positive NDVI trends were twice are large (0.0015 to $\left.0.003 \mathrm{NDVI} \mathrm{yr}^{-1}\right)$ where summer temperatures have experienced greater increases. A major break point occurred at $+1.6^{\circ} \mathrm{C}$, which geographically corresponds to the boundary between the larger greening trends of the northern tundra zone and the smaller, less significant, NDVI trends farther south. It is well established that warming temperatures have been the main driver of tundra greening across the circumpolar Arctic (Sturm et al., 2001b; Walker et al., 2006; Elmendorf et al., 2012; Fraser et al., 2014a; Myers-Smith et al., 2015 etc.). Hence, it is not surprising that increased warming in the Low Arctic tundra in the far north of my study area had the greatest influence on NDVI trends across all zones and variables. In tundra regions across northern high latitudes, this additional greening has been linked to sea ice 
decline that spurs increased warming in low elevation (<300 $\mathrm{m}$ a.s.1.) areas (Bhatt et al., 2010). Similarly, NDVI trends were more positive below 350 to $400 \mathrm{~m}$ a.s.l. in the tundra zone. It thus appears that temperature and elevation, possibly related to regional sea ice decline, are key environmental controls on trends in vegetation productivity in the tundra zone.

With temperature change in the tundra zone accounted for, the influence of different land-cover classes on NDVI trends was small. However, positive NDVI trends were slightly larger for shrubland classes (DS, OS, LRS), which were most common closer to riparian corridors (i.e., the Tree, Hood and Burnside Rivers). Furthermore, NDVI trends were more positive when closer to major drainage systems. This was especially true for areas within one kilometer of major drainages in the tundra zone, indicating a local as well as regional influence. Similarly, Fraser et al. (2011) found more greening in shrubland areas along river valleys in four of Canada's northern national parks. And the largest positive NDVI trends detected in northern Québec by McManus et al. (2012) were located along two major rivers north of the forest-tundra ecotone. The largest positive NDVI trends for my study area were similarly located in the region between the Hood and Burnside Rivers in the northern tundra zone. This particular region coincides closely with the current (since the mid-1990s) peak calving grounds of the Bathurst caribou herd (Gunn et al., 2008). Other studies have noted that caribou trampling can initiate shrub growth in lichen-dominated areas and point to this as a notable local-scale influence on greening trends (McManus et al., 2012; Fraser et al., 2014a).

Elsewhere in the North American Low Arctic, strong greening trends have been most often associated with shrubification, or the expansion of erect and dwarf-shrubs into previously inhospitable areas. In northern Alaska, shrub advance has been documented north of the foresttundra ecotone (Sturm et al., 2001b; Silapaswan et al., 2001; Tape et al., 2006; 2012). In the Mackenzie Delta region of western Canada, shrub expansion into lichen-dominated areas has also been widespread near the Arctic Ocean coast (Lantz et al., 2013; Fraser et al., 2014a). In northern 
Québec, birch shrub expansion has been widespread (Tremblay et al., 2012). Similar studies have been mostly absent in the central Canadian Low Arctic, except for around the Daring Lake Tundra Ecosystem Research Station where some birch shrub expansion has been recorded (Myers-Smith et al., 2011; Andruko, 2016). In many of these cases, shrub expansion has been occurring most rapidly on floodplains and along streams in river valleys. The strong greening trends detected for shrubland along riparian corridors and at lower elevations in the northern tundra zone are also likely indicative of shrubification, but other mechanisms (i.e., the growth and increased density of existing vegetation) cannot be discounted without the appropriate in situ field research.

In the tundra zone (as well as the ecotone zone), positive NDVI trends were larger at greater distances from major lakes. The relationship between NDVI trends and distance to all lakes, regardless of size, was the same but weaker, indicating that larger lakes have a stronger influence on the vegetation dynamics of the surrounding landscape. It is possible that these large lakes, which often remain ice covered longer into the summer than smaller lakes, have a cooling influence on the surrounding landscape during the growing season. Raynolds et al. (2008) found that NDVI regression residuals with the summer warmth index were negative across northern high latitudes in areas with greater than $2 \%$ lake coverage, and that they became more negative as lake coverage increased (up to -0.4 at $50+\%$ lake coverage). They found that the central Canadian tundra (i.e., my study area) had lower NDVI values than predicted from its relationship with summer warmth index because of the large expanse of waterbodies in the region.

In the ecotone zone, summer temperature was also indicated as the most important variable and had the largest influence on NDVI trends. However, in this case, warming was negatively associated with NDVI trends. This was an unexpected result that does not follow the general trend as the rest of the study area and may be related to regional geography of the ecotone zone. GT, which is more common in the northern portion, exhibited smaller positive NDVI trends 
(despite increased summer warming) than the main shrubland to forest transition farther south. It is possible that permafrost degradation, brought on by warmer temperatures, has led to increased water coverage in graminoid tundra and other wet areas (Jorgenson et al., 2006). Increasing water coverage has been associated with unexpectedly low NDVI trends at wet shrubland and graminoid tundra sites in northern Alaska (Pattison et al., 2015; Raynolds \& Walker, 2016). Similarly, graminoid tundra plots sampled near Big Lake (i.e., just north of the ecotone zone boundary) exhibited small negative trends in ${ }_{\mathrm{NT}} \mathrm{BVV}$, even as shrubland and forested plots to the south were mainly positive.

The southern extent of the ecotone zone appears to be a key secondary greening area within the study area. Elevation is lowest in this area and NDVI trends were positively associated with lower elevations in this zone. Forested land cover, followed by shrubland, also had the largest positive influence on NDVI trends in the ecotone zone. An explanation for this greening could be that spruce advance into shrubland tundra has occurred, as has been observed at some sites in Alaska and south-west Yukon (Suarez et al., 1999; Lloyd et al., 2003; Danby \& Hik, 2007). However, this is challenged by MacDonald et al. (1998), who found no northward advancement of spruce forest in central Canada from dendrochronological and historical records. The ecotone forests in my study area are primarily composed of black spruce. Studies along the forest-tundra ecotone in northern Québec indicate that the recent black spruce advance into tundra has been small, where it has occurred at all, and that expansion is limited by the species' low reproductive capacity (Gamache \& Payette, 2004; 2005; Dufour-Tremblay et al., 2012). Similarly, remote sensing analysis north of the east arm of Great Slave Lake (just east of my study area), found that there was no expansion of forest into tundra from the 1970s to 1990s, reflecting a lag-time between warming and treeline response (Masek, 2001; Epstein et al., 2004).

That the strongest greening trends were located primarily farther south in the ecotone zone, between the 1:10 and 1000:1 tree:tundra ratio lines (Timoney et al., 1992), indicates that 
established forest stands are likely increasing in productivity rather than expanding northward. Infilling within and between adjacent stands is also a possibility. Gamache \& Payette (2005) noted that black spruce seedling establishment has been more efficient in the southern foresttundra and that notable height increases of established individuals has occurred. At an alpine ecotone site in Alaska, Stueve et al. (2011) found that proximity to trees was the most important variable for explaining seedling establishment. Similarly, forest patches encountered during the field expedition in central Canada often had many new seedlings growing within and immediately around the patches. It is also possible that positive NDVI trends in the southern ecotone zone were influenced by gradual recovery from century-old fire disturbance, especially in W and LRW areas (Girard et al., 2008). However, this does not account for the widespread greening trends, which require significant increases in vegetation volume since 1984.

It is likely that the majority of the greening observed in the southern ecotone zone is associated with the increasing productivity of shrubs, especially in the understory of forested areas. As in the tundra zone, greening trends were strongest when closer to major drainage systems. The largest drainage system in the ecotone zone is the Snare River, around which greening trends were strongest. Results from the field expedition, which crossed the ecotone zone by way of the Snare River system, indicated that open woodland plots with dense shrubdominated understories were greening most extensively. Shrubland plots, which were sampled farther north (i.e., outside of the southern ecotone greening area), were less likely to be greening than forested plots. However, overall, shrubland (OS, DS) exhibited larger positive NDVI trends, behind only forest land cover in the ecotone zone. In particular, alder-dominated plots were found to be greening. Alder shrub expansion has been recorded in Alaska and Siberia within and north of the forest-tundra ecotone, especially in close proximity to rivers (Sturm et al., 2001b; Tape et al., 2006; Lantz et al., 2013; Frost et al., 2013; 2014; Fraser et al., 2014a). 
In the forest zone, land cover was indicated as the most important variable and had the largest influence on NDVI trends. Shrubland (DS, OS) and GT land covers exhibited the largest positive NDVI trends in the forest zone. These classes, which were rare, were often located in calcium-rich thermokarst wetlands in the Great Slave Plain and Great Slave Lowland High Boreal ecoregions (Ecosystem Classification Report, 2008; 2009) where water levels have dropped slightly since 1985 (Fraser et al., 2014b). Shrub and graminoid colonization of newly exposed shorelines, especially on the north shore of Great Slave Lake, has been observed in this region by Landsat imagery and oblique photography (Fraser et al., 2014b) and would explain why NDVI trends were most positive within one kilometer of major lakes in the forest zone. These classes were also common in areas recovering from fires, some of which may not have been recorded by GNWT (2015b) and thus not removed from analysis. It is likely that disturbance, followed by subsequent succession, has positively influenced NDVI trends for these classes in the forest zone.

Of the land covers that were common in the zone, more densely forested pixels $(\mathrm{F}, \mathrm{W})$ exhibited the largest positive NDVI trends and bedrock outcrops (LBT, SLV) exhibited the smallest. As in the other zones, NDVI trends were more positive when closer to drainage systems, with the largest concentration of greening pixels in this zone found in densely forested lowlands near the west arm of Great Slave Lake; an area that consists of multiple river systems. These results indicate that lowland forests are slowly increasing in productivity while areas of shallow soil and bedrock outcroppings remain mostly static and appear to be resisting colonization by trees and shrubs. This slow increase in productivity, albeit largely not significant, was also detected in forested areas by McManus et al. (2012), who attributed it to long-term recovery from fire disturbance.

Fire disturbance, and subsequent vegetative recovery, is a factor that may be influencing the small positive NDVI trends in the forest zone as well. Although all fire scars recorded by GNWT (2015b) were removed from my analysis, this record only dates back to 1965 and does 
not account for longer-term productivity and land cover changes initiated by older fires. Similar long-term fire succession has been associated with a shift from closed-canopy forest to lichenwoodlands in parts of northern Québec (Girard et al., 2008). The small positive NDVI trends attributed to the long-term post-fire recovery of these successional areas likely outweighs other climatic and environmental pressures (McManus et al., 2012). Similarly, temperature change was not considered a highly important variable in the forest zone. This was unexpected as temperature change had been considered the most important variable in the other zones and across the study area. Overall, the forest zone RF model had notably lower variation explained $(21.55 \%)$ than the other zones, indicating that the variables included in this analysis were less effective at explaining NDVI trends across this zone in particular. It thus appears that sub-Arctic boreal forest environments are responding more to different environmental pressures (i.e., fire disturbance and recovery) than forest-tundra and Low Arctic tundra environments. 


\section{Chapter 4}

\section{Conclusions}

\subsection{Summary}

This study was able to successfully meet the three main objectives:

1. Quantify recent vegetation changes across the forest to tundra transition of central Canada using a Landsat NDVI time-series

NDVI trends (1984-2016) and their significance were calculated for a study area spanning from boreal forest environments around Great Slave Lake to coastal tundra environments near the Arctic Ocean. Results show that greening has been occurring mostly in the far north of the study area (northern tundra zone) and secondly across the transition from boreal forest to shrubland dominated landscapes (southern ecotone zone). Denser boreal forest landscapes farther south (forest zone) had smaller NDVI trends, though positive, and were less likely to be significant. These results are in general agreement with other remote sensing studies conducted across northern North America.

\section{Link NDVI trends to field measurements}

Field measurements across the forest-tundra ecotone in the center of the study area were successful in demonstrating a strong relationship between NDVI and bulk vegetation volume ( $\left.{ }_{\mathrm{NT}} \mathrm{BVV}\right)$. This relationship was logarithmic, with higher ${ }_{\mathrm{NT}} \mathrm{BVV}$ sites having limited additional positive influence on NDVI. Exploration of this relationship over time indicated that low density forests with shrub-dominated understories and alder (Alnus spp.) shrublands were more likely to be greening (i.e., adding ${ }_{\mathrm{NT}} \mathrm{BVV}$ ). This relationship did not incorporate the volume added by trees, which overestimated the volume of forested plots if included. It was determined, in these range-edge forested sites, that trees do not have a notable effect on the NDVI signal. Any volume added by needles from these individuals appears to be offset by the shadows they cast on the higher LAI (leaf area index) understory vegetation. These results indicate that changes in 
satellite-derived NDVI can be confidently associated with similar changes in vegetation volume on the ground in tundra, shrubland and low density forested areas near treeline.

3. Determine the extent to which environmental variables (i.e., climate, land cover, topography, waterbodies) influence patterns of vegetation change across the study area

Random Forest (RF) modelling was able to determine that certain environmental variables had a stronger influence on NDVI trends depending on the location within the study area (i.e., forest, ecotone, tundra zones). Overall, fine-scale terrain variability was considered less useful at explaining NDVI trends than broad-scale variables. Temperature warming in the tundra zone had the strongest influence on NDVI trends of any variable in any zone, with positive NDVI trends being twice as large where the temperature had warmed more. In both the tundra and ecotone zones, NDVI trends were more positive at greater distances from major lakes. In all zones, positive NDVI trends were larger closer to major drainage systems. Forest and shrubland pixels had larger positive NDVI trends than less densely vegetated classes in all zones.

Differences in topography did not have a major influence on NDVI trends, with the exception of elevation, where trends were more positive below $350 \mathrm{~m}$ a.s.l. than above that point in the ecotone and tundra. These results indicate that influences on NDVI trends differ across the study area, but that the strongest positive NDVI trends were associated with the increasing productivity of shrubby environments within and north of the forest-tundra ecotone in areas with more favorable growing conditions.

\subsection{Limitations and Uncertainty}

When selecting Landsat scenes to be used for time-series analysis, there was some uncertainty associated with the temporal distribution of data. Cloud-cover across the study area, and smoke from fires farther south, was a notable issue that limited scene selection. In addition, only ETM+ scenes from 1999 to 2002 were considered useable because of the scan line corrector (SLC) failure in May 2003. Access to a smaller selection of useable scenes meant that it was more difficult to maintain a consistent acquisition time (i.e., similar day of year and gap in years). 
However, efforts were made to be as consistent as possible and all scenes selected were within a one-month period of each other during the peak growing season (July 11 - August 11). In addition, gaps between acquisition years were kept as consistent as possible, with no gap being larger than seven years and the majority of gaps being smaller than four years. Relationships between Julian day and year, as well as between Julian day and NDVI of a random selection of pixels, were mostly not significant $(\mathrm{p}>0.05)$ across the study area. Uncertainty related to the slight variation in NDVI derived from different Landsat sensors (TM, ETM+, OLI) was also addressed and corrected (Ju \& Masek, 2016; Roy et al., 2016).

There were some limitations encountered when assembling the environmental variable datasets needed for RF modelling because of the paucity of useful data. The study area is a remote region of northern Canada where high quality data across the entire extent was often not available. For example, useful data on surficial geology was not available and thus could not be included in the analysis. It would also have been interesting to study the influences of variables such as snow-pack depth or permafrost degradation, but the lack of data meant these could not be directly examined. It is possible that these variables are indirectly related to variables that were tested, such as deeper snow-pack depth with denser shrub land cover (Sturm et al., 2005a).

The fine-scale topographical variables (i.e., slope, aspect, TPI, TWI) that were found to be less important than the more broad-scale variables were all at least partly based on the Canada Digital Elevation Model (DEM). This DEM, which was the highest quality dataset that covered the extent of the study area, was built from $10 \mathrm{~m}$ contour intervals extrapolated to $1 \mathrm{~m}$ elevations. This meant that small changes in these topographical variables were not as well represented, and a "terracing" effect was evident in flat areas. Terracing was mitigated by smoothing the datasets, but it did not have a noticeable effect on the overall results. It is thus possible that the nature of the DEM may have played a role in these variables being less influential in RF results. However, other variables may have been more suitable surrogates for terrain variability. For example, 
terrain variability (e.g., low rolling hills, eskers, rocky outcrops) in the study area was often accompanied by different land-cover types. Higher quality datasets would have helped with this uncertainty if available, but these issues are expected when working across large, remote regions.

\subsection{Future Opportunities}

Studies based on remote sensing benefit from field work, which allows for the validation of those results on the ground. Bulk vegetation volume (BVV), a non-destructive and relatively non-intensive measurement, has been shown to relate strongly with NDVI in tundra areas (Chen et al., 2009; Gregory, 2011). My study has indicated that it is also possible to achieve accurate results in low density forested areas due to the low impact of these trees on the NDVI signal. With an updated methodology for forested sites, it should be possible to relate BVV with NDVI without disregarding trees. I suggest that future work in this area could allow for the more accurate measurement of forest BVV by accounting for the lower LAI and shading effect of trees at high latitude sites.

RF modelling has shown to be a useful tool for understanding the intricacies of the relationship between NDVI trends and environmental variables across a variety of landscapeenvironmental conditions. This study should serve as a guide for future work and allow for researchers to focus on vegetation change in the context of some of these important environmental variables. In particular, the influence of waterbodies (i.e., drainage systems and major lakes) on vegetation changes in the northern high latitudes deserves more study. RF modelling itself is also useful in that it accounts for the overlapping influence of variables that would be overlooked when individual variables are considered separately. These machine learning techniques thus allow for the important marginal relationships to be drawn out from large and complex datasets. Thus, there is an opportunity to build on these results by using machine learning in a smaller study area where higher quality datasets are available for more variables. This would allow for uncertainty related to data selection to be reduced. 


\subsection{Conclusions}

Climate has been warming across the planet in recent decades (IPCC, 2013). Warming has been especially strong at northern high latitudes because of Arctic amplification (Serreze \& Barry, 2011). This has led to changes in vegetation productivity across northern tundra and boreal forest ecosystems (Sturm et al., 2001b; Beck \& Goetz, 2012; Guay et al., 2014; Ju \& Masek, 2016 etc.). Shrub expansion has been observed across northern high latitudes, while treeline advance has been mixed (Harsch et al., 2009; Myers-Smith et al., 2011). The browning of continental boreal forest ecosystems has been observed in some locations (Barber et al., 2000; Verbyla, 2008). The landscape-level influences on these vegetation changes, and how they vary across the sub-Arctic boreal forest to Low Arctic tundra transition has not been fully explored.

By delineating the forest to tundra transition of central Canada into separate zones and considering the influence of different environmental variables on NDVI trends across those zones, this study was able to identify and analyze the intricacies of vegetation change on a landscape to regional scale in a way not seen elsewhere. It is clear that vegetation in sub-Arctic boreal forests, forest-tundra ecotone areas and Low Arctic tundra ecosystems have responded differently to environmental pressures. Many past studies have observed vegetation changes occurring in boreal forest, forest-tundra or tundra regions, but they are not often considered together in a way to allow for a direct comparison. Here, RF modelling also allowed for the relative importance of many variables to be compared across the zones, highlighting those deserving further study. The influence of these variables on NDVI trends was again dependent on position within the forest to tundra transition, further indicating the complexity of vegetation changes in these regions. This study thus has provided a comprehensive understanding of vegetation changes ongoing across the forest to tundra transition of central Canada; including analysis of the geographic distribution and ground validation of trends, as well as an exploration of environmental variables that most influence the location and magnitude of trends. 


\section{References}

Abuelgasim, A. A., \& Leblanc, S. G. (2011). Leaf area index mapping in northern Canada. International Journal of Remote Sensing, 32(18), 5059-5076.

Andruko, R. (2016). Primary controls on decadal growth patterns of birch shrubs across a low Arctic landscape. BSc dissertation. Kingston ON, Queen's University.

Banskota, A., Kayastha, N., Falkowski, M. J., Wulder, M. A., Froese, R. E., \& White, J. C. (2014). Forest monitoring using Landsat time series data: A review. Canadian Journal of Remote Sensing, 40, 362-384.

Barber, V. A., Juday, G. P., \& Finney, B. P. (2000). Reduced growth of Alaskan white spruce in the twentieth century from temperature-induced drought stress. Nature, 405, 668-673.

Beck, P. S. A., \& Goetz, S. J. (2012). Corrigendum: Satellite observations of high northern latitude vegetation productivity changes between 1982 and 2008: ecological variability and regional differences. Environmental Research Letters, 7, 029501.

Beringer, J., Chapin, F. S., Thompson, C. C., \& McGuire, A. D. (2005). Surface energy exchanges along a tundra-forest transition and feedbacks to climate. Agricultural and Forest Meteorology, 131, 143-161.

Berner, L. T., Beck, P. S. A., Bunn, A. G., Lloyd, A. H., \& Goetz, S. J. (2011). High-latitude tree growth and satellite vegetation indices: correlations and trends in Russia and Canada (1982-2008). Journal of Geophysical Research: Biogeosciences, 116, G01015.

Berner, L. T., Beck, P. S. A, Bunn, A. G., \& Goetz, S. J. (2013). Plant response to climate change along the forest-tundra ecotone in northeastern Siberia. Global Change Biology, 19, $3449-3462$.

Beven, K. J., \& Kirkby, M. J. (1979). A physically based, variable contributing area model of basin hydrology. Hydrological Sciences, 24(1), 43-69.

Bhatt, U. S., Walker, D. A., Raynolds, M. K., Comiso, J. C., Epstein, H. E., Jia, G., Gens, R., Pinzon, J. E., Tucker, C. J., Tweedie, C. E., \& Webber, P. J. (2010). Circumpolar Arctic tundra vegetation change is linked to sea ice decline. Earth Interactions, 14(8), 1-20.

Bhatt, U. S., Walker, D. A., Raynolds, M. K., Bieniek, P. A., Epstein, H. E., Comiso, J. C., Pinzon, J. E., Tucker, C. J., \& Polyakov, I. V. (2013). Recent declines in warming and vegetation greening trends of pan-Arctic tundra. Remote Sensing, 5, 4229-4254.

Bintanja, R., \& Selten, F. M. (2014). Future increases in Arctic precipitation linked to local evaporation and sea-ice retreat. Nature, 509, 479-482.

Black, R. A., \& Bliss, L. C. (1980). Reproductive ecology of Picea mariana (Mill.) BSP., at tree line near Inuvik, Northwest Territories, Canada. Ecological Monographs, 50(3), 331-354. 
Blok, D., Sass-Klaassen, U., Schaepman-Strub, G., Heijmans, M. M. P. D., Sauren, P., \& Berendse, F. (2011). What are the main climate drivers for shrub growth in northeastern Siberian tundra? Biogeosciences, 8, 1169-1179.

Boelman, N. T., Gough, L., McLaren, J. R., \& Greaves, H. (2011). Does NDVI reflect variation in the structural attributes associated with increasing shrub dominance in arctic tundra? Environmental Research Letters, 6, 035501.

Boulanger, J., Gunn, A., Adamczewski, J., \& Croft, B. (2011). A data-driven demographic model to explore the decline of the Bathurst caribou herd. Journal of Wildlife Management, 75(4), 883-896.

Brehaut, L. D. (2015) The use of NDVI and tree ring-widths to evaluate changes in vegetation production in a mountainous boreal landscape. MSc dissertation. Kingston ON, Queen's University.

Breiman, L. (2001). Random forests. Machine Learning, 45, 5-32.

Brook, R. K., \& Kenkel, N. C. (2002). A multivariate approach to vegetation mapping of Manitoba's Hudson Bay Lowlands. International Journal of Remote Sensing, 23(21), 4761-4776.

Brown, M. E., Pinzon, J. E., Didan, K., Morisette, J. T., \& Tucker, C. J. (2006). Evaluation of the consistency of Long-term NDVI time series derived from AVHRR, SPOT-vegetation, SeaWiFS, MODIS, and Landsat ETM+ sensors. IEEE Transactions on Geoscience and Remote Sensing, 44(7), 1787-1793.

Bunn, A. G., Goetz, S. J., \& Fiske, G. J. (2005). Observed and predicted responses of plant growth to climate across Canada. Geophysical Research Letters, 32, L16710.

Chapin, F. S., Sturm, M., Serreze, M. C., McFadden, J. P., Key, J. R., Lloyd, A. H., McGuire, A. D., Rupp, T. S., Lynch, A. H., Schimel, J. P., Beringer, J., Chapman, W. L., Epstein, H. E., Euskirchen, E. S., Hinzman, L. D., Jia, G., Ping, C. L., Tape, K. D., Thompson, C. D. C., Walker D, A., \& Welker, J. M. (2005). Role of land-surface changes in Arctic summer warming. Science, 310, 657-660.

Chen, W., Li, J., Zhang, Y., Zhou, F., Koehler, K., Leblanc, S. G., Fraser, R. H., Olthof, I., Zhang, Y., \& Wang, J. (2009). Relating biomass and leaf area index to non-destructive measurements in order to monitor changes in Arctic vegetation. Arctic, 62(3), 281-294.

Clements, F. E. (1936). Nature and structure of the climax. Journal of Ecology, 24, 252-284. 
Crowther, T. W., Todd-Brown, K. E. O., Rowe, C. W., Wieder, W. R., Carey, J. C., Machmuller, M. B., Snoek, B. L., Fang, S., Zhou, G., Allison, S. D., Blair, J. M., Bridgham, S. D., Burton, A. J., Carrillo, Y., Reich, P. B., Clark, J. S., Classen, A. T., Dijkstra, F. A., Elberling, B., Emmett, B. A., Estiarte, M., Frey, S. D., Guo, J., Harte, J., Jiang, L., Johnson, B. R., Kröel-Dulay, G., Larsen, K. S., Laudon, H., Lavallee, J. M., Luo, Y., Lupascu, M., Ma, L. N., Marhan, S., Michelsen, A., Mohan, J., Niu, S., Pendall, E., Peñuelas, J., Pfeifer-Meister, L., Poll., C., Reinsch, S., Reynolds, L. L., Schmidt, I. K., Sistla, S., Sokol, N. W., Templer, P. H., Treseder, K. K., Welker, J. M., \& Bradford, M. A. (2016). Quantifying global soil carbon losses in response to warming. Nature, 540, 104-108.

Danby, R. K., \& Hik, D. S. (2007). Variability, contingency and rapid change in recent Subarctic alpine tree line dynamics. Journal of Ecology, 95, 352-363.

Danby, R. K. (2011). Monitoring forest-tundra ecotones at multiple scales. Geography Compass, 5(9), 623-640.

Davies, J. A. (1962). Albedo measurements over sub-Arctic surfaces. McGill Sub-Arctic Research Paper, 13, 1-86.

Derksen, C., \& Brown, R. (2012). Spring snow cover extent reductions in the 2008-2012 period exceeding climate model projections. Geophysical Research Letters, 39, L19504.

Dilts, T. E. (2015). Riparian Topography Tools for ArcGIS 10.x. University of Nevada Reno. Available at: http://www.arcgis.com/home/item.html?id=b13b3b40fa3c43d4a23a1a09c5fe96b9

Dufour-Tremblay, G., Lévesque, E., \& Boudreau S. (2012). Dynamics at the treeline: differential responses of Picea mariana and Larix laricina to climate change in eastern subarctic Québec. Environmental Research Letters, 7, 044038.

Ecosystem Classification Group. (2008). Ecological Regions of the Northwest Territories Taiga Shield. Department of Environment and Natural Resources, Government of the Northwest Territories, Yellowknife, NT, Canada.

Ecosystem Classification Group. (2009). Ecological Regions of the Northwest Territories Taiga Plains. Department of Environment and Natural Resources, Government of the Northwest Territories, Yellowknife, NT, Canada.

Ecosystem Classification Group. (2012). Ecological Regions of the Northwest Territories Southern Arctic. Department of Environment and Natural Resources, Government of the Northwest Territories, Yellowknife, NT, Canada. 
Elmendorf, S. C., Henry, G. H. R., Hollister R. D., Björk, R. G., Boulanger-Lapointe, N., Cooper, E. J., Cornelissen, J. H. C., Day, T. A., Dorrepaal, E., Elumeeva, T. G., Gill, M., Gould, W. A., Harte, J., Hik, D. S., Hofggard, A., Johnson, D. R., Johnstone, J. F., Jónsdóttir, I. S., Jorgenson, J. C., Klanderud, K., Klien, J. A., Koh, S., Kudo, G., Lara, M., Lévesque, E., Magnússon, B., May, J. L., Mercado-Díaz, J. A., Michelsen, A., Molau, U., MyersSmith, I. H., Oberbauer, S. F., Onipchenko, V. G., Rixen, C., Schmidt, N. M., Shaver, G. R., Spasojevic, M. J., Pórhallsdóttir, P. E., Tolvanen, A., Troxler, T., Tweedie, C. E., Villareal, S., Wahren, C. H., Walker, X., Webber, P. J., Welker, J. M., \& Wipf, S. (2012). Plot-scale evidence of tundra vegetation change and links to recent summer warming. Nature Climate Change, 2, 453-457.

Epstein, H. E., Beringer, J., Gould, W. A., Lloyd, A. H., Thompson, C. D., Chapin, F. S., Michaelson, G. J., Ping, C. L., Rupp, T. S., \& Walker, D. A. (2004). The nature of spatial transitions in the Arctic. Journal of Biogeography, 31, 1917-1933.

Epstein, H. E., Yu, Q., Kaplan, J. O., \& Lischke, H. (2007). Simulating future changes in Arctic and Subarctic vegetation. Computing in Science and Engineering, 9, 12-23.

Epstein, H. E., Raynolds, M. K., Walker, D. A., Bhatt, U. S., Tucker, C. J., \& Pinzon, J. E. (2012). Dynamics of aboveground phytomass of the circumpolar Arctic tundra during the past three decades. Environmental Research Letters, 7, 015506.

Epstein, H. E., Bhatt, U. S., Raynolds, M. K., Walker, D. A., Forbes, B. C., Macias-Fauria, M., Loranty, M., Phoenix, G. K., \& Bjerke, J. (2016). Tundra Greenness, In: Arctic Report Card: Update for 2016, J. Richter-Menge, J.E. Overland, and J. T. Mathis, (eds.), NOAA, Silver Spring, MD. Available at: http://www.arctic.noaa.gov/Report-Card/

Fan, L., Gao, Y., Brück, H., \& Bernhofer, C. (2009). Investigating the relationship between NDVI and LAI in semi-arid grassland in Inner Mongolia using in-situ measurements. Theoretical and Applied Climatology, 95, 151-156.

Forbes, B. C., Macias-Fauria M., \& Zetterberg, P. (2010). Russian Arctic warming and 'greening' are closely tracked by tundra shrub willows. Global Change Biology, 16, 1542-1554.

Foster, J. R., \& D'Amato, A. W. (2015). Montane forest ecotones moved downslope in northeastern USA in spite of warming between 1984 and 2011. Global Change Biology, 21, 4497-4507.

Fraser, R. H., Olthof, I., Carrière, M., Deschamps, A., \& Pouliot, D. (2011). Detecting long-term changes to vegetation in northern Canada using the Landsat satellite image archive. Environmental Research Letters, 6, 045502.

Fraser, R. H., Olthof, I., Carrière, M., Deschamps, A., \& Pouliot, D. (2012). A method for trendbased change analysis in Arctic tundra using the 25-year Landsat archive. Polar Record, 48(244), 83-93.

Fraser, R. H., Lantz, T. C., Olthof, I., Kokelj, S. V., \& Sims, R. A. (2014a). Warming-induced shrub expansion and lichen decline in the western Canadian Arctic. Ecosystems, 17, $1151-1168$. 
Fraser, R. H., Olthof, I., Kokelj, S. V., Lantz, T. C., Lacelle, D., Brooker, A., Wolfe, S., \& Schwarz, S. (2014). Detecting landscape changes in high latitude environments using Landsat trend analysis: 1. Visualization. Remote Sensing, 6, 11533-11557.

Frost, G. V., Epstein, H. E., Walker, D. A., Matyshak, G., \& Ermokhina, K. (2013). Patternedground facilitates shrub expansion in Low Arctic tundra. Environmental Research Letters, 8, 015035.

Frost, G. V, Epstein, H. E., \& Walker, D. A. (2014). Regional and landscape-scale variability of Landsat-observed vegetation dynamics in northwest Siberian tundra. Environmental Research Letters, 9, 025004.

Gamache, I., \& Payette, S. (2004). Height growth response of tree line black spruce to recent climate warming across the forest-tundra of eastern Canada. Journal of Ecology, 92, 835845 .

Gamache, I., \& Payette, S. (2005). Latitudinal response of Subarctic tree lines to recent climate change in eastern Canada. Journal of Biogeography, 32, 849-862.

Gamon, J. A., Huemmrich, K. F., Stone, R. S., \& Tweedie, C. E. (2013). Spatial and temporal variation in primary productivity (NDVI) of coastal Alaskan tundra: Decreased vegetation growth following earlier snowmelt. Remote Sensing of Environment, 129, $144-153$.

Genuer, R., Poggi, J. M., Tuleau-Malot, C., Villa-Vialaneix, N. (2017). Random Forests for big data. Big Data Research (preprint submitted).

Geological Survey of Canada (1932). Summary Report 1932, Part C. J. O. (No. 2332). Ottawa, Canada: Patenaude Acting King's Printer.

Girard, F., Payette S. \& Gagnon, R. (2008). Rapid expansion of lichen woodlands within the closed-crown boreal forest zone over the last 50 years cause by stand disturbances in eastern Canada. Journal of Biogeography, 35, 529 - 537.

Goetz, S. J., Bunn, A. G., Fiske, G. J. \& Houghton, A. R. (2005). Satellite-observed photosynthetic trends across boreal North America associated with climate and fire disturbance. Proceedings of the National Academy of Sciences of the United States of America, 102(38), 13521-13525.

Government of Northwest Territories. (2015a). Environment and Natural Resources. Barrenground Caribou. Retrieved from http://www.enr.gov.nt.ca/en/state-environment/154trends-barren-ground-caribou-population-size-tundra-taiga-ecosystems

Government of Northwest Territories. (2015b). Environment and Natural Resources. Area burned and number of fires. Retrieved from http://www.enr.gov.nt.ca/stateenvironment/143-annual-area-burned-and-number-fires

Gregory, F. M. (2011). Biophysical remote sensing and terrestrial $\mathrm{CO}_{2}$ exchange at Cape Bounty, Melville Island. MSc dissertation. Kingston ON, Queen's University. 
Guay, K. C., Beck, P. S. A., Berner, L. T., Goetz, S. J., Baccini, A., \& Buermann, W. (2014). Vegetation productivity patterns at high northern latitudes: A multi-sensor satellite data assessment. Global Change Biology, 20, 3147-3158.

Gunn A., Poole, K. G., Wierzchowski, J. (2008). A geostatistical analysis for the patterns of caribou occupancy on the Bathurst calving grounds 1966-2007. Indian and Northern Affairs Canada, Yellowknife, NWT.

Harsch, M. A., Hulme, P. E., McGlone, M. S., \& Duncan, R. P. (2009). Are treelines advancing? A global meta-analysis of treeline response to climate warming. Ecology Letters, 12, 1040-1049.

Hastie, T., Tibshirani, R., \& Friedman J. (2009). The Elements of Statistical Learning: Data Mining, Inference, and Prediction $2^{\text {nd }}$ Edition. New York, NY: Springer.

Heginbottom, J. A., Dubreuil, M. A., \& Harker, P. A. (1995). Canada-permafrost, in National Atlas of Canada 5th edition, Plate 2.1. Ottawa Canada: Natural Resources Canada (MCR 4177; scale 1:7,500,000)

Higuera, P. E., Brubaker, L. B., Anderson, P. M., Brown, T. A., Kennedy, A. T., \& Hu, F. S. (2008). Frequent fires in ancient shrub tundra: Implications of paleorecords for Arctic environmental change. PLOS ONE, 3(3), e0001744.

Holden, C. E., \& Woodcock, C. E. (2016). An analysis of Landsat 7 and Landsat 8 underflight data and the implications for time series investigations. Remote Sensing of Environment, $185,16-36$

Houston, S. (1994). To the Arctic by Canoe 1819-1821: the Journal and Paintings of Robert Hood, Midshipman with Franklin. Canada: McGill-Queen's University Press.

IPCC. (2013). Summary for policymakers. Climate change 2013: The physical science basis. Contribution of working group I to the fifth assessment report of the intergovernmental panel on climate change. Cambridge University Press, Cambridge, UK and New York, NY.

Jacobs, J. D., Chan, S., \& Sutton, E. (2014). Climatology of the forest-tundra ecotone at a maritime Subarctic-alpine site, Mealy Mountains, Labrador. Arctic, 67(1), 28-42.

Jenness, J. (2006). Topographic position index (tpi_jen.avx) extension for ArcView 3.x, v. 1.2. Jenness Enterprises. Available at http://www.jennessent.com/arcview/tpi.htm

Jensen, J. R. (2016). Introductory Digital Image Processing: a Remote Sensing Perspective $4^{\text {th }}$ edition. Glenview, IL: Pearson Education, Inc.

Jia, G., Epstein, H. E., \& Walker, D. A. (2003). Greening of Arctic Alaska, 1981-2001. Geophysical Research Letters, 30(20), 3-6.

Jones, B. M., Kolden, C. A., Jandt, R., Abatzoglou, J. T., Urban, F., \& Arp, C. D. (2009). Fire behavior, weather, and burn severity of the 2007 Anaktuvuk River tundra fire, North Slope, Alaska. Arctic, Antarctic, and Alpine Research, 41(3), 309-316. 
Ju, J., \& Masek, J. G. (2016). The vegetation greenness trend in Canada and US Alaska from 1984-2012 Landsat data. Remote Sensing of Environment, 176, 1-16.

Jorgenson, M. T., Shur, Y. L., \& Pullman, E. R. (2006). Abrupt increase in permafrost degradation in Arctic Alaska. Geophysical Research Letters, 33, L02503.

Kambo, D. S. (2017). Fine-scale mechanisms influencing germination success, seedling growth and survival in an alpine forest-tundra ecotone. PhD dissertation. Kingston ON, Queen's University.

Kattsov, V. M., Walsh, J. E., Chapman, W. L., Govorkova, V. A., Pavlova, T. V., \& Zhang, X. (2007). Simulation and projection of Arctic freshwater budget components by the IPCC AR4 global climate models. Journal of Hydrometeorology, 8, 571-589.

Kolden, C. A, \& Roganf, J. (2013). Mapping wildfire burn severity in the Arctic tundra from downsampled MODIS data. Arctic, Antarctic, and Alpine Research, 45(1), 64-76.

Laidler, G. J., Treitz, P. M., \& Atkinson, D. M. (2008). Remote sensing of arctic vegetation: relations between the NDVI, spatial resolution and vegetation cover on Boothia Peninsula, Nunavut. Arctic, 61(1), 1-13.

Lantz, T. C., Gergel, S. E., \& Kokelj, S. V. (2010). Spatial heterogeneity in the shrub tundra ecotone in the Mackenzie Delta Region, Northwest Territories: Implications for Arctic environmental change. Ecosystems, 13, 194-204.

Lantz, T. C., Marsh, P., \& Kokelj, S. V. (2013). Recent shrub proliferation in the Mackenzie Delta Uplands and microclimate implications. Ecosystems, 16, 47-59.

Latifovic, R., Trishchenko, A. P., Chen, J., Park, W. B., Khlopenkov, K. V., Fernandes, R., Pouliot, D, Ungureanu, C., Luo, Y., Wang, S., Davidson, A., \& Cihlar, J. (2005). Generating historical AVHRR $1 \mathrm{~km}$ baseline satellite data records over Canada suitable for climate change studies. Canadian Journal of Remote Sensing, 31(5), 324-346.

Liaw, A., \& Wiener, M. (2002). Classification and regression by randomForest. $R$ News, 2(3), 1822.

Liu, N., \& Treitz, P. M. (2016). Modelling high Arctic percent vegetation cover using field digital images and high resolution satellite data. International Journal of Applied Earth Observation and Geoinformation, 52, 445-456.

Lloyd, A. H., Rupp, T. S., Fastie, C. L., \& Starfield, A. M. (2003). Patterns and dynamics of treeline advance on the Seward Peninsula, Alaska. Journal of Geophysical Research, 108(D2), 8161.

Lloyd, A. H., Bunn, A. G., \& Berner, L. T. (2011). A latitudinal gradient in tree growth response to climate warming in the Siberian taiga. Global Change Biology, 17, 1935-1945.

Losey, T. C. (1973). An Interdisciplinary Investigation of Fort Enterprise, Northwest Territiroies 1970-1973. Edmonton, AB: University of Alberta Press. 
Lotsch, A., Friedl, M. A., Anderson, B. T., \& Tucker, C. J. (2005). Response of terrestrial ecosystems to recent Northern Hemispheric drought. Geophysical Research Letters, 32, L06705.

MacDonald, G. M., Szeicz, J. M., Claricoates, J. \& Dale, K. A. (1998). Response of the central Canadian treeline to recent climatic changes. Annals of the Association of American Geographers, 88(2), 183-208.

Macias-Fauria, M., \& Johnson, E. A. (2008). Climate and wildfires in the North American boreal forest. Philosophical Transactions of the Royal Society of London. Series B, Biological Sciences, 363, 2317-2329.

Masek, J. G. (2001). Stability of boreal forest stands during recent climate change: Evidence from Landsat satellite imagery. Journal of Biogeography, 28, 967-976.

Masek, J. G., Vermote, E. F., Saleous, N. E., Wolfe, R., Hall, F. G., Huemmrich, K. F., Gao, F., Kutler, J., \& Lim, T. K. (2006). A Landsat surface reflectance dataset for North America, 1990-2000. IEEE Geoscience and Remote Sensing Letters, 3(1), 68-72.

McCreadie, M. (1995). Canoe Canada's Northwest Territories: A Paddler's Guide. Toronto, ON: Key Porter Books.

McDonald, A. J., Gemmell, F. M., \& Lewis, P. E. (1998). Investigation of the utility of spectral vegetation indices for determining information on coniferous forests. Remote Sensing of Environment, 66, 250-272.

McManus, K. M., Morton, D. C., Masek, J. G., Wang, D., Sexton, J. O., Nagol, J. R., Ropars, P., $\&$ Boudreau, S. (2012). Satellite-based evidence for shrub and graminoid tundra expansion in northern Québec from 1986 to 2010. Global Change Biology, 18, 23132323.

Myers-Smith, I. H., Forbes, B. C., Wilmking, M., Hallinger, M., Lantz, T. C., Blok, D., Tape, K. D., Macias-Fauria, M., Sass-Klaassen, U., Lévesque, E., Boudreau, S., Ropars, P., Hermanutz, L., Trant, A. J., Colier, L. S., Weijers, S., Rozema, J., Rayback, S. A., Schmidt, N. M., Schaepman-Strub, G., Wipf, S., Rixen, C., Ménard, C. B., Venn, S., Goetz, S. J., Andreu-Hayles, L., Elmendorf, S. C., Ravolainen, V., Welker, J. M., Grogan, P., Epstein, H. E., \& Hik, D. S. (2011). Shrub expansion in tundra ecosystems: Dynamics, impacts and research priorities. Environmental Research Letters, 6, 045509.

Myers-Smith, I. H., Elmendorf, S. C., Beck, P. S. A., Wilmking, M., Hallinger, M., Blok, D., Tape, K. D., Rayback, S. A., Macias-Fauria, M., Forbes, B. C., Speed, J. D. M., Boulanger-Lapointe, N., Rixen, C., Lévesque, E., Schmidt, N. M., Baittinger, C., Trant, A. J., Hermanutz, L., Collier, L. S., Dawes, M. A., Lantz, T. C., Weijers, S., Jørgensen, R. H., Buchwal., A., Buras, A., Naito, A. T., Ravolainen, V., Schaepman-Strub, G., Wheeler, J. A., Wipf, S., Guay, K. C., Hik, D. S., \& Vellend, M. (2015). Climate sensitivity of shrub growth across the tundra biome. Nature Climate Change, 5, 887-891.

Natural Resources Canada. (2012). Canadian Digital Elevation Model (CDEM). Retrieved from http://geogratis.gc.ca/api/en/nrcan-rncan/ess-sst/c40acfba-c722-4be1-862e146b80be738e.html\#distribution 
Obst, J. (2011). Breeding phenology, densities and population trends of tundra breeding birds at Daring Lake, Southern Arctic Ecozone, Northwest Territories, 1998 - 2010. Department of Environment and Natural Resources, Government of Northwest Territories report.

Oechel, W. C., Hastings, S. J., Vourlitis, G., Jenkins, M., Riechers, G., \& Grulke, N. (1993). Recent change of Arctic tundra ecosystems from a net carbon dioxide sink to a source. Nature, 361, 520-523.

Oechel, W. C., Vourlitis, G. L., Hastings, S. J., Zulueta, R. C., Hinzman, L., \& Kane, D. (2000). Acclimation of ecosystem $\mathrm{CO}_{2}$ exchange in the Alaskan Arctic in response to decadal climate warming. Nature, 406, 978-981.

Olthof, I., Pouliot, D., Latifovic, R., \& Chen, W. (2008). Recent (1986-2006) vegetationspecific NDVI trends in northern Canada from satellite data. The Arctic Institute of North America, 61(4), 381-394.

Olthof, I., Latifovic, R., \& Pouliot D. (2009). Development of a circa 2000 land cover map of northern Canada at $30 \mathrm{~m}$ resolution from Landsat. Canadian Journal of Remote Sensing, $35(2), 152-165$.

Pattison, R. R., Jorgenson, J. C., Raynolds, M. K., \& Welker, J. M. (2015). Trends in NDVI and tundra community composition in the Arctic of NE Alaska between 1984 and 2009. Ecosystems, 18, 707-719.

Payette, S., Fortin, M. J., \& Gamache, I. (2001). The Subarctic forest-tundra: The structure of a biome in a changing climate. BioScience, 51(9), 709-718.

Pearson, R. G., Phillips, S. J., Loranty, M. M., Beck, P. S. A., Damoulas, T., Knight, S. J., \& Goetz, S. J. (2013). Shifts in Arctic vegetation and associated feedbacks under climate change. Nature Climate Change, 3, 673-677.

Petzold, D. E., \& Rencz, A. N. (1975). The albedo of selected Subarctic surfaces. Arctic, Antarctic, and Alpine Research, 7(4), 393-398.

Phoenix, G. K., \& Bjerke, J. W. (2016). Arctic browning: extreme events and trends reversing Arctic greening. Global Change Biology, 22, 2960-2962.

Pitt, M. D. (2014). Franklin, OOPS, Mud \& Cupcake. Victoria, BC: Agio Publishing House.

Purevdorj, T. S., Tateishi, R., Ishiyama, T., \& Honda, Y. (1998). Relationships between percent vegetation cover and vegetation indices. International Journal of Remote Sensing, 19(18), 3519-3535.

R Development Core Team. (2010). R: a language and environment for statistical computing. Vienna: Austria: R Foundation for Statistical Computing.

Raynolds, M. K., Walker, D. A., \& Maier, H. A. (2006). NDVI patterns and phytomass distribution in the circumpolar Arctic. Remote Sensing of Environment, 102, 271-281. 
Raynolds, M. K., Comiso, J. C., Walker, D. A., \& Verbyla, D. L. (2008). Relationship between satellite-derived land surface temperatures, arctic vegetation types, and NDVI. Remote Sensing of Environment, 112, 1884-1894.

Raynolds, M. K., Walker, D. A., Epstein, H. E., Pinzon, J. E., \& Tucker, C. J. (2012). A new estimate of tundra-biome phytomass from trans-Arctic field data and AVHRR NDVI. Remote Sensing Letters, 3(5), 403-411

Raynolds, M. K., Walker, D. A., Verbyla, D. L., \& Munger, C. A. (2013). Patterns of change within a tundra landscape: 22-year Landsat NDVI trends in an area of the northern foothills of the Brooks Range, Alaska. Arctic, Antarctic, and Alpine Research, 45(2), 249-260.

Raynolds, M. K. \& Walker, D. A. (2016). Increased wetness confounds Landsat-derived NDVI trends in the central Alaska North Slope region, 1985-2011. Environmental Research Letters, 11, 085004.

Rees, W. G., Golubeva, E. I., \& Williams, M. (1998). Are vegetation indices useful in the Arctic? Polar Record, 34(191), 333-336.

Rees, W. G., Brown, I., Mikkola, K., Virtanen, T., \& Werkman, B. (2002). How can the dynamics of the tundra-taiga boundary be remotely monitored? Ambio Special Report 12, Tundra-Taiga Treeline Research, 56-62.

Ropars, P., \& Boudreau, S. (2012). Shrub expansion at the forest-tundra ecotone: Spatial heterogeneity linked to local topography. Environmental Research Letters, 7, 015501.

Ropars, P., Lévesque, E., Boudreau, S. (2015). How do climate and topography influence the greening of the forest-tundra ecotone in northern Québec? A dendrochronological analysis of Betula glandulosa. Journal of Ecology, 103, 679-690.

Rouse, J. W., Haas, R. H., Schell, J. A., \& Deering, D. W. (1973). Monitoring vegetation systems in the Great Plains with ERTS. Proceedings, $3^{\text {rd }}$ Earth Resource Technology Satellite (ERTS) Symposium, 1, 309-318.

Roy, D. P., Kovalskyy, V., Zhang, H. K., Vermote, E. F., Yan, L., Kumar, S. S., \& Egorov, A. (2016). Characterization of Landsat-7 to Landsat-8 reflective wavelength and normalized difference vegetation index continuity. Remote Sensing of Environment, 185, 57-70.

Rupp, T. S., Chapin, F. S., \& Starfield, A. M. (2001). Modeling the influence of topographic barriers on treeline advance at the forest-tundra ecotone of northwestern Alaska. Climatic Change, 48, 399-416.

Schuur, E. G., Bockheim, J., Canadell, J. G., Euskirchen, E. S., Field, C. B., Goryachkin, S. V, Hagemann, S., Kuhry, P., Lafleur, P. M., Lee, H., Mazhitova, G., Nelson, F. E., Rinke, A., Romanovsky, V. E., Shiklomanov, N., Tarnocai, C., Venevsky, S., Vogel, J. G., \& Zimov, S. A. (2008). Vulnerability of permafrost carbon to climate change: Implications for the global carbon cycle. BioScience, 58(8), 701-714. 
Selkowitz, D. J. (2010). A comparison of multi-spectral, mulit-angular, and multi-temporal remote sensing datasets for fractional shrub canopy mapping in Arctic Alaska. Remote Sensing of Environment, 114, 1338-1352.

Semenchuk, P. R., Christiansen, C. T., Grogan, P., Elberling, B., Cooper, E. J. (2016). Long-term experimentally deepened snow decreases growing-season respiration in a low- and highArtic tundra ecosystem. Journal of Geophysical Research: Biogeosciences, 121, 1-13.

Serreze, M. C., \& Barry, R. G. (2011). Processes and impacts of Arctic amplification: A research synthesis. Global and Planetary Change, 77, 85-96.

Silapaswan, C. S., Verbyla, D. L., \& McGuire, A. D. (2001). Land cover change on the Seward Peninsula: The use of remote sensing to evaluate the potential influences of climate warming on historical vegetation dynamics. Canadian Journal of Remote Sensing, 27(5), $542-554$

Simms, E. L., \& Ward, H. (2013). Multisensor NDVI-based monitoring of the tundra-taiga interface (Mealy Mountains, Labrador, Canada). Remote Sensing, 5, 1066-1090.

Smith, L. C., Sheng, Y., MacDonald, G. M., \& Hinzman, L. D. (2005). Disappearing Arctic Lakes. Science, 308, 1429.

Smol, J. P., \& Douglas, M. S. V. (2007). Crossing the final ecological threshold in high Arctic ponds. Proceedings of the National Academy of Sciences of the United States of America, 104(30), 12395-12397.

Slater, A. G., \& Lawrence, D. M. (2013). Diagnosing present and future permafrost from climate models. Journal of Climate, 26, 5608-5623.

Stow, D. A., Hope, A., McGuire, A. D., Verbyla, D. L., Gamon, J. A., Huemmrich, F., Houston, S., Racine, C., Sturm, M., Tape, K. D., Hinzman, L. D., Yoshikawa, K., Tweedie, C. E., Noyle, B., Silapaswan, C. S., Douglas, D., Griffith, B., Jia, G., Epstein, H. E., Walker, D. A., Daeschner, S., Petersen, A., Zhou, L., \& Myneni, R. (2004). Remote sensing of vegetation and land-cover change in Arctic Tundra Ecosystems. Remote Sensing of Environment, 89, 281-308.

Stroeve, J., Holland, M. M., Meier, W., Scambos, T., \& Serreze, M. C. (2007). Arctic sea ice decline: Faster than forecast. Geophysical Research Letters, 34, L09501.

Sturm, M., McFadden, J. P., Liston, G. E., Chapin, F. S., Racine, C. H., \& Holmgren, J. (2001a). Snow-shrub interactions in Arctic tundra: A hypothesis with climatic implications. Journal of Climate, 14, 336-344.

Sturm, M., Racine, C., \& Tape, K. D. (2001b). Increasing shrub abundance in the Arctic. Nature, $411,546-547$.

Sturm, M., Schimel, J. P., Michaelson, G., Welker, J. M., Oberbauer, S. F., Liston, G. E., Fahnestock, J., \& Romanovsky, V. E. (2005a). Winter biological processes could help convert Arctic tundra to shrubland. BioScience, 55(1), 17-26. 
Sturm, M., Douglas, T., Racine, C., \& Liston, G. E. (2005b). Changing snow and shrub conditions affect albedo with global implications. Journal of Geophysical Research, 110, G01004.

Suarez, F., Binkley, D., Kaye, M. W., \& Stottlemyer, R. (1999). Expansion of forest stands into tundra in Noatak National Preserve, northwest Alaska. Ecoscience, 6, 465-470.

Tape, K. D., Sturm, M., \& Racine, C. (2006). The evidence for shrub expansion in Northern Alaska and the Pan-Arctic. Global Change Biology, 12, 686-702.

Tape, K. D., Hallinger, M., Welker, J. M. \& Ruess, R. W. (2012). Landscape heterogeneity of shrub expansion in Arctic Alaska. Ecosystems, 15, 711-724.

Thomas, A. (2003). Canada's Best Canoe Routes. Erin, ON, Canada: Boston Mills Press.

Throop, J., Lewkowicz, A. G., \& Smith, S. L. (2012). Climate and ground temperature relations at sites across the continuous and discontinuous permafrost zones, northern Canada. Canadian Journal of Earth Sciences, 49, 865-876.

Timoney, K. P., La Roi, G. H., Zoltai, S. C., \& Robinson, A. L. (1992). The high Subarctic forest-tundra of northwestern Canada: Position, width, and vegetation gradients in relation to climate. Arctic, 45(1), 1-9.

Timoney, K. P., La Roi, G. H., Zoltai, S. C., \& Robinson, A. L. (1993). Vegetation communities and plant distributions and their relationships with parent materials in the forest-tundra of northwestern Canada. Ecography, 16(2), 174-188.

Timoney, K. P. (1995). Tree and tundra cover anomalies in the Subarctic forest-tundra of Northwestern Canada. Arctic, 48(1), 13-21.

Tou, J. T., \& Gonzalez, R. C. (1974). Pattern Recognition Principles. Reading, MA: Addison-Wesley Publishing Company.

Trant, A. J., Jameson, R. G., \& Hermanutz, L. (2011). Persistence at tree line: Old trees as opportunists. Arctic, 64(3), 367-370.

Tremblay, B., Lévesque, E., \& Boudreau, S. (2012). Recent expansion of erect shrubs in the Low Arctic: Evidence from Eastern Nunavik. Environmental Research Letters, 7, 035501.

Tucker, C. J. (1979). Red and photographic infrared linear combinations for monitoring vegetation. Remote Sensing of Environment, 8, 127-150.

University of East Anglia CRU; Jones, P.D.; Harris, I.C. (2008). Climatic Research Unit (CRU) time-series datasets of variations in climate with variations of other phenomena. NCAS British Atmospheric Data Centre. Retrieved from http://catalogue.ceda.ac.uk/uuid/3f8944800cc48e1cbc29a5ee12d8542d

USGS, Department of the Interior. (2016). Product guide: provisional Landsat 8 surface reflectance code (LaSRC) product. Sioux Falls, SD: U.S. Geological Survey. 
Verbyla, D. L. (2008). The greening and browning of Alaska based on 1982-2003 satellite data. Global Ecology and Biogeography, 17, 547-555.

Vermote, E. F., Tanre, D., Deuze, J. L., Herman, M., \& Morcette, J. J. (1997). Second simulation of the satellite signal in the solar spectrum, 6S: an overview. IEEE Transactions on Geoscience and Remote Sensing, 35(3), 675-686.

Vermote, E. F., Justice, C., Claverie, M., \& Franch, B. (2016). Preliminary analysis of the performance of the Landsat 8/OLI land surface reflectance product. Remote Sensing of Environment, 185, 46-56.

Walker, D. A., Raynolds, M. K., Daniëls, F. J., Einarsson, E., Elvebakk, A., Gould, W. A., Katenin, A. E., Kholod, S. S., Markon, C. J., Melnikov, E. S., Moskalenko, N. G., Talbot, S. S., Yurtsev, B. A., \& the other members of CAVM Team. (2005). The circumpolar Arctic vegetation map. Journal of Vegetation Science, 16, 267-282.

Walker, M. D., Wahren, C. H., Hollister, R. D., Henry, G. H., Ahlquist, L. E., Alatalo, J. M., Bret-Harte, M. S., Calef, M. P., Callaghan, T. V., Carroll, A. B., Epstein, H. E., Jónsdóttir, I. S., Klien, J. A., Magnússon, B., Molau, U., Oberbauer, S. F., Rewa, S. P., Robinson, C. H., Shaver, G. R., Suding, K. N., Thompson, C. C., Tolvanen, A., Totland, $\varnothing$, Turner, P. L., Tweedie, C. E., Webber, P. J., \& Wookey, P. A. (2006). Plant community responses to experimental warming across the tundra biome. Proceedings of the National Academy of Sciences of the United States of America, 103(5), 1342-1346.

Weiss, A. D. (2001). Topographic position and landforms analysis. Poster presentation, ESRI user conference, San Diego, CA (Vol. 200).

White, J. C., \& Wulder, M. A. (2014). The Landsat observation record of Canada: 1972-2012. Canadian Journal of Remote Sensing, 39(6), 455-467.

Wray, O. R. (1980). By canoe up the Yellowknife River in 1932, part one/two. Musk-Ox, 26/27, 21-50/36-59.

Wookey, P. A., Aerts, R., Bardgett R. D., Baptist, F., Bråthen, K. A., Cornelissen, J. H. C., Gough, L., Hartley, I. P., Hopkins, D. W., Lavorel, S., \& Shaver, G. R. Ecosystem feedbacks and cascade processes: Understanding their role in the responses of Arctic and alpine ecosystems to environmental change. Global Change Biology, 15, 1153-1172.

Wulder, M. A., Masek, J. G., Cohen, W. B., Loveland, T. R., \& Woodcock, C. E. (2012). Opening the archive: how free data has enabled the science and monitoring promise of Landsat. Remote Sensing of Environment, 122, 2-10.

Wulder, M. A., White, J. C., Loveland, T. R., Woodcock, C. E., Belward, A. S., Cohen, W. B., Fosnight, E. A., Shaw, J., Masek, J. G., \& Roy, D. P. (2016). The global Landsat archive: status, consolidation, and direction. Remote Sensing of Environment, 185, 271-283.

Xie, Y., Sha, Z., \& Yu, M. (2008). Remote sensing imagery in vegetation mapping: A review. Journal of Plant Ecology, 1(1), 9-23. 
Yuan, W., Liu, S., Zhou, G., Zhou, G., Tieszen, L. L., Baldocchi, D., Bernhofer, C., Gholz, H., Goldstein, A. H., Goulden, M. L., Hollinger, D. Y., Hu, Y., Law, B. E., Stoy, P. C., Vesala, T., \& Wofsy, S. C. (2007). Deriving a light use efficiency model from eddy covariance flux data for predicting daily gross primary production across biomes. Agricultural and Forest Meteorology, 143, 189-207.

Zhang, Y., Xu, M., Adams, J., \& Wang, X. (2009). Can Landsat imagery detect treeline dynamics? International Journal of Remote Sensing, 30, 1327-1340.

Zhang, W., Miller, P. A., Smith, B., Wania, R., Koenigk, T., \& Doscher, R. (2013). Tundra shrubification and tree-line advance amplify climate warming: Results from an individual-based dynamic vegetation model. Environmental Research Letters, 8, 034023. 


\section{Appendix A \\ Field Expedition Preparation and Methodology}

\section{Field Expedition Preparation}

The original plan was to begin at the Daring Lake Tundra Ecosystem Research Station and canoe to Wekweètì (Figure A.1). This would allow for logistical support from both ends of the field expedition and would cross almost all of the tree:tundra cover ratio lines. Research into this potential route indicated that it would not be feasible, however. The main issues were that this route was long $(190 \mathrm{~km})$ and would require the expedition to cross the boundary between the Coppermine River and Mackenzie River watersheds. This would lead to many kilometers of overland travel with heavy gear. This route has also not been extensively explored, making preparation more difficult and leading to more unknowns. It was deemed that this route would be too arduous and time consuming for this project.

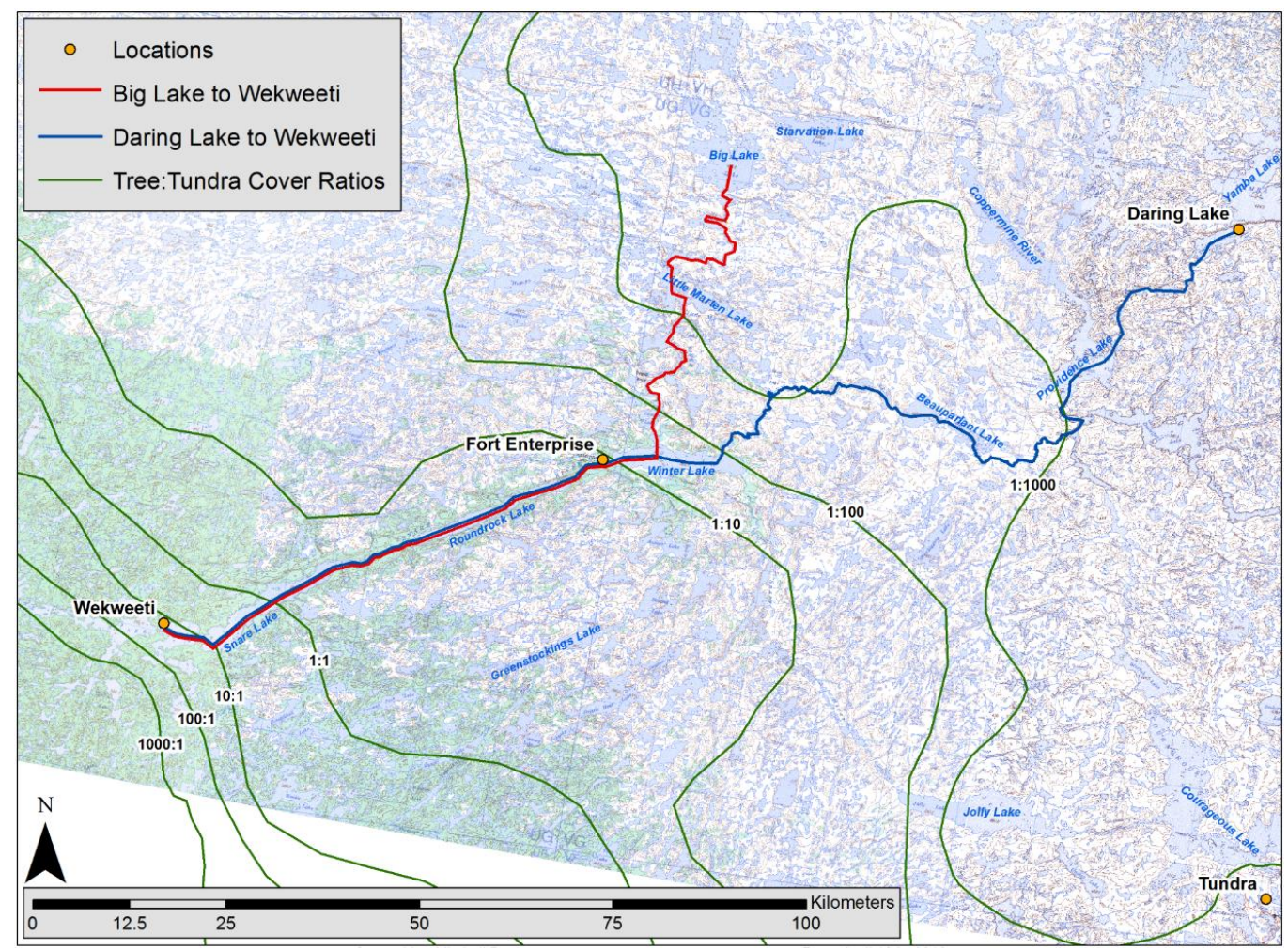

Figure A.1: Field study area and proposed routes. Daring Lake to Wekweètì was eventually phased out. 
The route from Big Lake to Wekweètì, which is shorter $(131 \mathrm{~km})$ and has been extensively traveled, was determined to be the best possible field expedition to conduct our research in the North Slave region of NWT. This route follows the same path as Sir John Franklin's expedition of 1819 to 1822 that aimed to explore Canada's northern coastline and map a potential northwest passage between the Atlantic and Pacific Oceans (Houston, 1994). The Geological Survey of Canada (GSC) conducted an expedition along this route in 1932, providing useful photographs (Figure A.2) and other information (Geological Survey of Canada, 1932; Wray, 1980). Contemporary details about the route, including potential camp sites, rapids, portage and canoe lines, flora, fauna and climate details, were collected from books (Losey, 1973; McCreadie, 1995; Thomas, 2003; Pitt, 2014). Hundreds of photographs and first-hand details on the route were provided by people who had canoed the route in the past. These travelers also provided maps of the locations of campsites, rapids, routes and portages, which were digitized in ArcGIS. The Tłıchǫ community government of Wekweètì confirmed the feasibility and permitted the field expedition on their land after discussions with them.

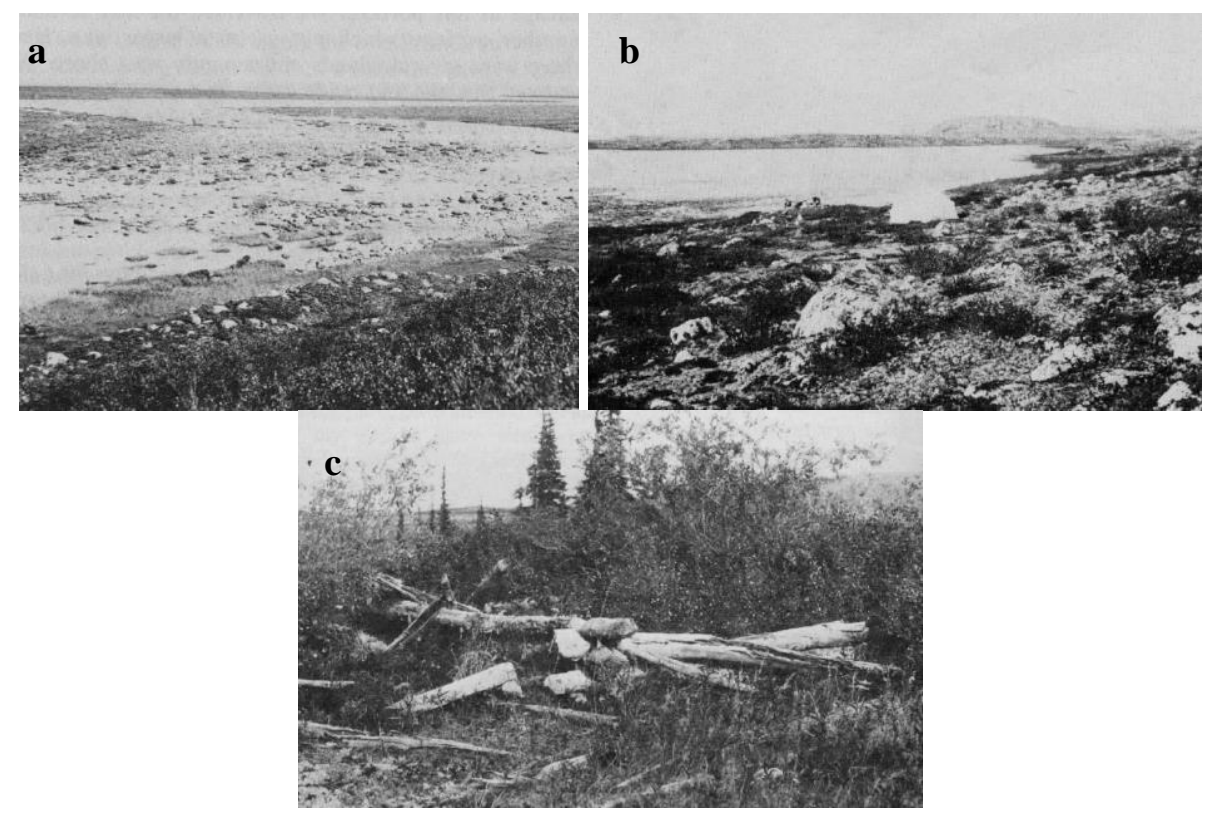

Figure A.2: Photographs from 1932 GSC expedition. (a) Creek flowing out of Big Lake. (b) Dogrib Rock in the distance (between Little Marten Lake and Winter Lake). (c) Remains of Fort Enterprise (camp from Franklin expedition). Photographs from Wray, 1980. 


\section{Methodology: Additional Details}

Once a potential sampling area was deemed suitable (i.e., homogenous area; Figure D.3) for setting up a sample plot then general characteristics were collected. Plot number, class (ISODATA land-cover classification) and a brief visual description (vegetation characteristics) of the sample plot were recorded (Table A.1; Table A.2). The slope and aspect of the location was noted, with most plots being level or gently sloping. The percentage of the plot covered by vegetation, moisture regime, distance to nearest waterbody and any signs of fauna or fire disturbance were also noted. At least two full plot photographs were taken at each sample plot from locations that provided the best view. A $\sim 10 \mathrm{~cm}$ soil profile was collected and photographed at each plot. Soil color, texture and other notable characteristics were recorded.

Sample plots were set up by placing a flag at the southwest corner and using a compass to orient plots north-south as best as possible. The north and south boundary of the plot were marked with flags at $5 \mathrm{~m}$ intervals. A $30 \mathrm{~m}$ tape measure was rolled out between each set of flags and vegetation height was measured at $5 \mathrm{~m}$ intervals (i.e., $0,5,10,15,20,25,30 \mathrm{~m}$ on tape measure). 49 points were thus sampled per plot. GPS coordinates were collected at the four corner points of the sample plot with a Trimble GPS unit. Elevation and GPS coordinates were also collected at the center point of the sample plot. Top-down photographs from breast height were taken of corner points and the plot center.

Vegetation heights of different functional groups were measured at each of the 49 points in all sample plots. Functional groups were set as trees, erect shrubs, dwarf shrubs, horsetail (Equisetum), graminoids, moss, lichen and non-vegetated surfaces (i.e., rock, soil, gravel, water). Trees were sampled at the species level with black spruce (Picea mariana), white spruce (Picea glauca) and paper birch (Betula papyrifera) recorded. Erect shrubs were sampled at the species level with American dwarf birch (Betula glandulosa), willow (Salix spp.), green alder (Alnus viridis) and dwarf birch (Betula nana) recorded. Dwarf shrubs were also sampled at the species level with blueberry (Vaccinium Spp.), black crowberry (Empetrum nigrum), red bearberry 
(Arctostaphylos rubra), northern Labrador tea (Rhododendron tomentosum), cloudberry (Rubus chamaemorus), bog rosemary (Andromeda polifolia), cranberry (Vaccinium vitis-idaea) and kinnikinnick (Arctostaphylos uva-ursi) recorded. All other functional groups were recorded by their functional group name.

Heights were measured for the tallest individuals in each functional group at each point. This means that multiple heights could be measured at each point if different functional groups were present. Heights were most often measured with a tape measure, with the distance between the ground and the tallest part of the individual that intersected the sample point being the recorded measurement. Taller individuals (i.e., trees) were measured with a Vertex IV (Haglöf Sweden). These measurements were completed by attaching a transponder at $1.3 \mathrm{~m}$ height to the tree in question, pointing the Vertex IV at the transponder from at least $5 \mathrm{~m}$ away and then pointing the Vertex IV at the desired height.

Vegetation heights were measured at the exact point where the $5 \mathrm{~m}$ interval was reached on the $30 \mathrm{~m}$ tape measure (Figure A.4). If the tallest individual in a functional group was located with a $5 \mathrm{~cm}$ radius of the point then its height was measured. The red triangles on the tape measure was used to gauge this distance and decide if an individual should be measured or not. If an individual was too tall to be viewed from above in relation to the tape measure then I would get below the tape measure and look up to judge if the individual was within the $5 \mathrm{~cm}$ radius. Heights of the individual plant were measured where it overlapped with the $5 \mathrm{~m}$ interval (i.e., if there was a $1 \mathrm{~m}$ tall shrub but it was only $50 \mathrm{~cm}$ high at the measurement point, then the height would be recorded as $50 \mathrm{~cm}$ ). 

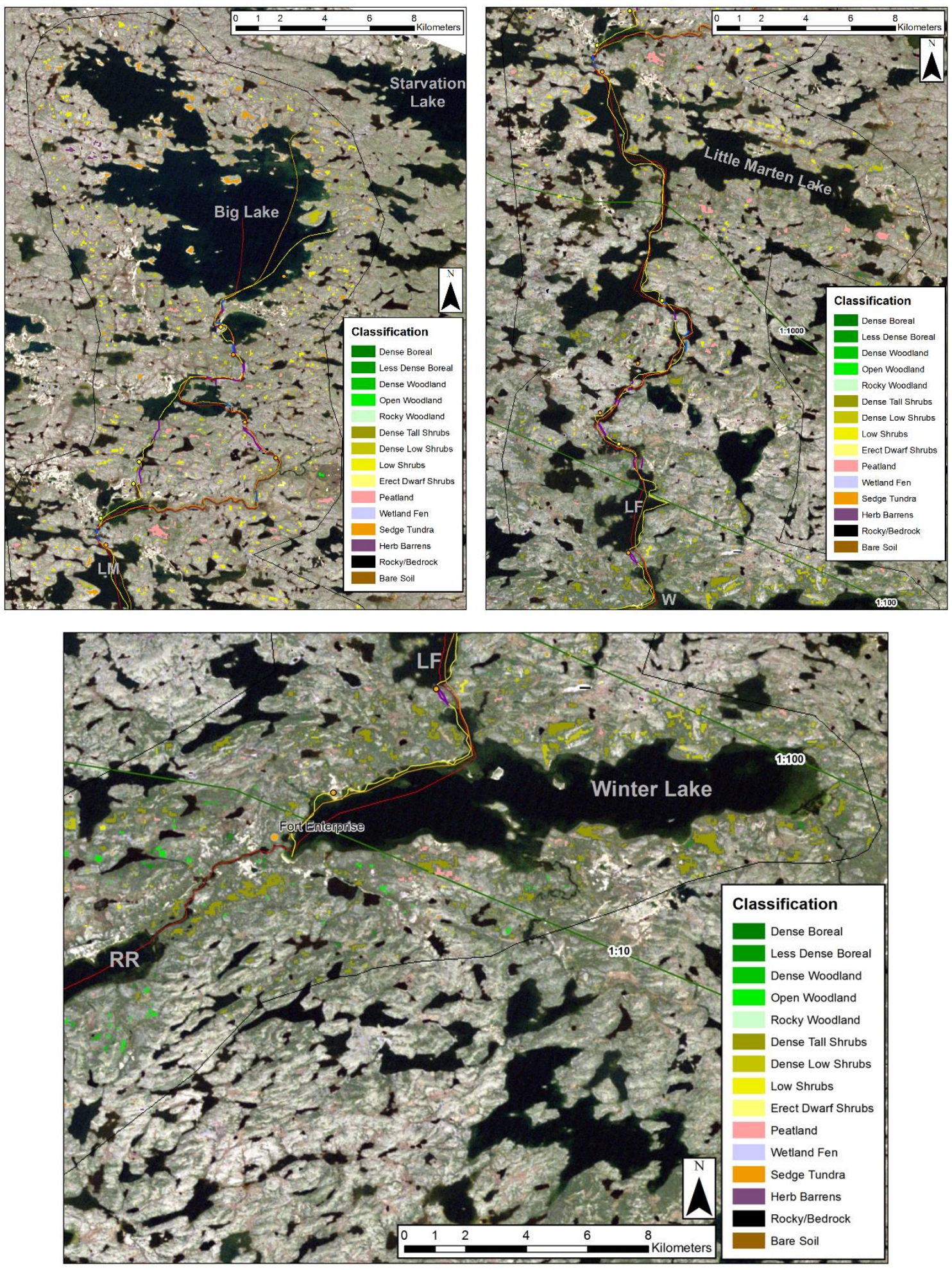

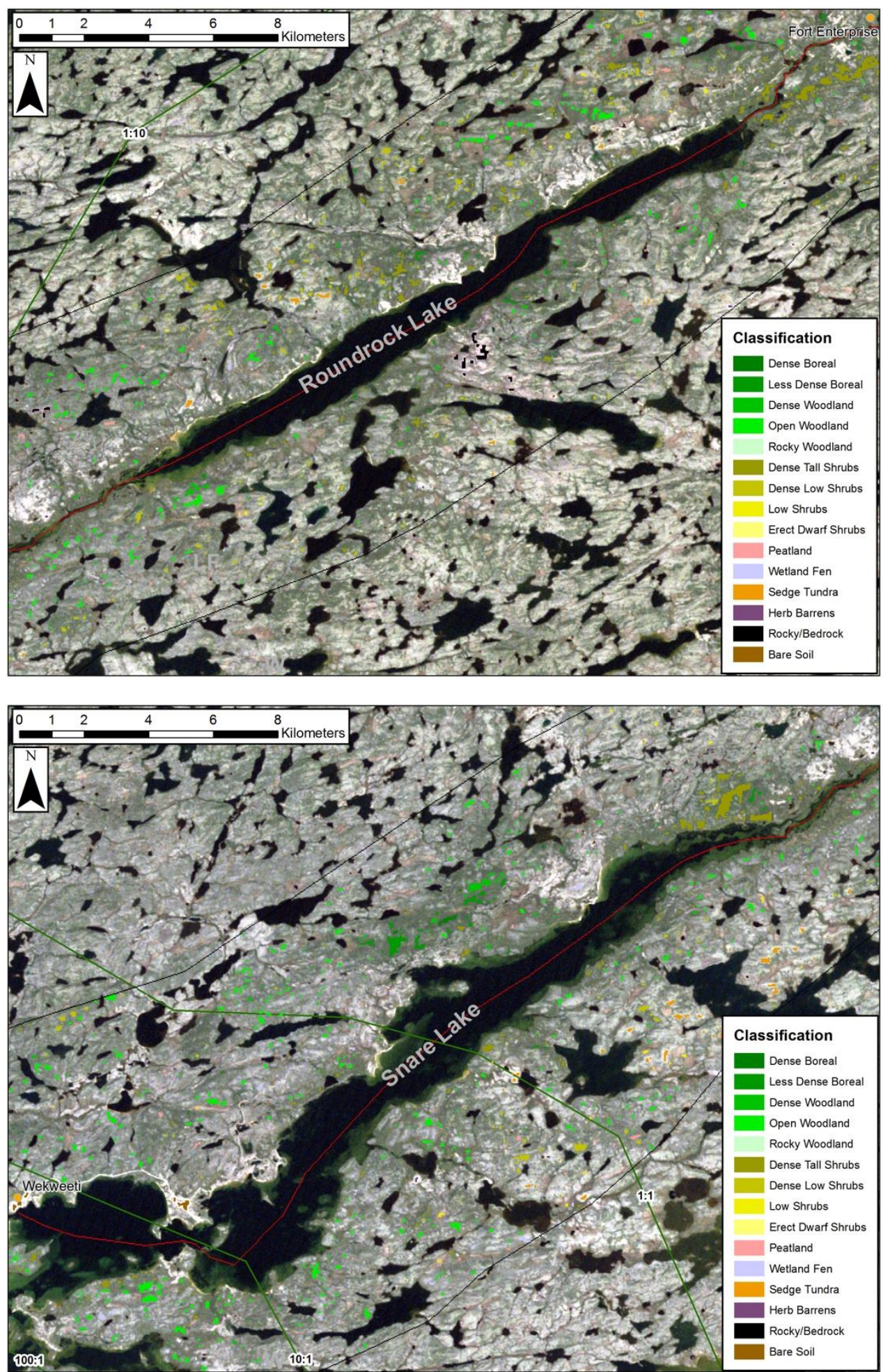

Figure A.3: Field maps from Big Lake to Wekweètì showing potential sampling areas. These maps were brought into the field (as well as input onto a Trimble GPS unit) to locate plots that were easiest to access and sample across a range of land-cover types. Points and colored lines indicate routes and campsites of past travelers 
Table A.1: Sample plot ISODATA class, vegetation descriptions and UTM coordinates. Ledum $=$ northern Labrador tea, cran $=$ cranberry, cro $\mathrm{w}=$ crowberry, blue = blueberry.

\begin{tabular}{|c|c|c|c|c|}
\hline Name & Class & Vegetation Description & UTM E & UTM N \\
\hline BL01 & Herb Barrens & Low birch shrubs, lichen understory, lichen covered boulders & 401492 & 7191982 \\
\hline BL02 & Herb Barrens & Low birch shrubs, lichen/cranberry/ledum understory, lichen boulders & 399685 & 7192743 \\
\hline BL03 & Graminoid Tundra & Lichen-graminoid tundra, hummocky, a lot of graminoids/cloudberry/ledum/cran & 405243 & 7191123 \\
\hline BL04 & Graminoid Tundra & Lichen-graminoid tundra, hummocky, some low birch shrubs + dwarf shrubs & 403438 & 7190637 \\
\hline BL05 & Dense Low Shrubs & Mostly dense low shrub, berry understory & 402887 & 7190163 \\
\hline BL06 & Low Shrubs & Open low birch/willow shrubs, grassy understory, exposed dirt, some berries & 403024 & 7189615 \\
\hline SC01 & Peatland & Dense low shrub, a few mossy wet areas, graminoids & 406170 & 7185728 \\
\hline $\mathrm{SC} 02$ & Low Shrub & Open low shrub, lichen understory, dwarf shrub berries & 406221 & 7185595 \\
\hline LM01 & Dense Tall Shrubs & Dense tall shrubs, scattered spruce trees & 404804 & 7172059 \\
\hline LM02 & Peatland & Open low birch/willow shrub tundra, lichen/berry understory & 404723 & 7171918 \\
\hline LM03 & Dense Low Shrubs & Dense-open Alder shrubs with graminoid understory, some birch, tall blueberries & 405839 & 7171470 \\
\hline LM04 & Wetland Fen & Low shrubs, moss, grasses, hummocky with evidence of water in depressions but now dry & 405229 & 7172536 \\
\hline LM05 & Low Shrubs & Open canopy birch, hummocky, scatted lichen/crow/blue understory, gravel areas, rocky & 405590 & 7171934 \\
\hline LMS01 & Graminoid Tundra & Open low birch canopy, ledum/lichen understory, some blue/bear berry, rocks & 398781 & 7166833 \\
\hline LMS02 & Peatland & Low alder shrubland, hummocky understory & 399105 & 7167025 \\
\hline LMS03 & Dense Tall Shrubs & Dense $\sim 1 \mathrm{~m}$ canopy of alder/birch, ledum understory + blue berries & 398788 & 7167452 \\
\hline LMS04 & Dense Low Shrubs & Dense alder shrubland + birch, ledum/cran mix understory, some rocks & 399086 & 7165649 \\
\hline LMS05 & Dense Tall Shrubs & Dense $1 \mathrm{~m}$ tall shrubs broken by game trails, tall ledum/grassy/blue berry understory & 399757 & 7166249 \\
\hline LF01 & Less Dense Boreal & Short/medium height black spruce, low-mixed shrub understory, tall ledums with moss/horsetail & 402927 & 7159478 \\
\hline LF02 & Dense Woodland & Black spruce dominated forest, seedlings, tall ledums, horsetail, grasses & 402637 & 7159449 \\
\hline LF03 & Open Woodland & Open stands of black spruce separated by boulder gardens/lichen dominated areas, blueberries & 401901 & 7159927 \\
\hline LF04 & Less Dense Boreal & $\begin{array}{l}\text { Pretty dense canopy black spruce, dense understory of shrubs, wetlands, grasses, ledum, horsetail, } \\
\text { dead trees, depressions }\end{array}$ & 402431 & 7160192 \\
\hline LF05 & Erect Dwarf Shrubs & Boulder strewn tundra with scatted birch shrubs, lichen/crow/cran understory & 405140 & 7159338 \\
\hline
\end{tabular}




\begin{tabular}{|c|c|c|c|c|}
\hline LF06 & Dense Low Shrubs & Alder/birch shrubland on edge of ridge, some rocks, small spruce trees in area & 404448 & 7160450 \\
\hline WL01 & Wetland Fen & Previously wet grassy/shrubby area bordering lichen-woodland & 401465 & 7149588 \\
\hline WL02 & Open Woodland & Open black spruce stands, lichen/grassy understory, wet, ledums & 401207 & 7149709 \\
\hline WL03 & Dense Woodland & $\begin{array}{l}\text { Open-Dense black spruce, open shrub understory, ledums, some previously wet/mossy soil covered } \\
\text { areas (but dry now) }\end{array}$ & 400881 & 7150512 \\
\hline WL04 & Less Dense Boreal & Open canopy thin black spruce, with mossy/blue/ledum understory, alder and birch shrubs, wet & 400911 & 7150863 \\
\hline WL05 & Peatland & Hummocky, open low shrub terrain, a few boulders, blueberry, grasses, ledum & 402646 & 7150974 \\
\hline RR01 & Open Woodland & Open canopy tall/thin black spruce, lichen dominated understory with a few shrubs/ledum/blueberry & 389074 & 7148451 \\
\hline RR02 & Rocky Woodland & $\begin{array}{l}\text { Graminoid dominated wetland with a lot of open water, moss below grasses, a few birch shrubs here } \\
\text { and there }\end{array}$ & 390282 & 7148086 \\
\hline SL01 & Dense Woodland & Dense canopy short/thin black spruce, wet areas, stream near, tall ledums, lichen & 361960 & 7130991 \\
\hline SL02 & Dense Boreal & Pretty dense canopy of medium/tall black spruce, shrubby understory, lichen patches & 358574 & 7130862 \\
\hline SL03 & Wetland Fen & $\begin{array}{l}\text { Lichen-woodland: low density tall white spruce/paper birch, lichen dominated understory with some } \\
\text { cran/crow/blue/kinnikinnick }\end{array}$ & 362720 & 7131889 \\
\hline
\end{tabular}

Table A.2: Additional sample plot details. Elevation in meters above sea level. Distance to water in meters.

\begin{tabular}{|c|c|c|c|c|c|c|c|c|}
\hline Name & Elev & Slope-Aspect & PVC Estimate & Moisture & $\begin{array}{l}\text { Distance } \\
\text { to Water }\end{array}$ & Fauna & Fire & Soil \\
\hline BL01 & 420 & Gentle south facing & $35 \%$ birch shrubs & Dry & 180 & Game trails & N/A & $10 \mathrm{~cm}$ organic layer, silty-sand \\
\hline BL02 & 415 & Level & $\begin{array}{l}\text { Open canopy } \\
\text { birch }\end{array}$ & Dry & 200 & Game trails & N/A & $6 \mathrm{~cm}$ organic layer, silty-sand \\
\hline BL03 & 410 & Level & $\begin{array}{l}5 \% \text { shrubs, a few } \\
\text { rocks }\end{array}$ & Mesic & 75 & N/A & N/A & $\begin{array}{l}8 \mathrm{~cm} \text { organic layer, sandy-silt, } \\
\text { cold (shallow permafrost), } \\
\text { decomposing lichen }\end{array}$ \\
\hline BL04 & 402 & Level & $15 \%$ shrubs & Mesic & 50 & N/A & N/A & Cold soil, sandy-silt, thawing \\
\hline BL05 & 416 & Gentle north facing & $65 \%$ shrubs & Dry & 200 & N/A & N/A & N/A \\
\hline BL06 & 415 & Level & $25 \%$ shrubs & Dry & 300 & Game trails & N/A & N/A \\
\hline SC01 & 400 & Level & $75 \%$ shrubs & $\begin{array}{l}\text { Dry- } \\
\text { Mesic }\end{array}$ & 250 & Game trails & $\mathrm{N} / \mathrm{A}$ & N/A \\
\hline $\mathrm{SC02}$ & 391 & Level & $25 \%$ shrubs & Dry & 150 & Game trails & N/A & $3 \mathrm{~cm}$ organic layer, sandy-silt \\
\hline
\end{tabular}




\begin{tabular}{|c|c|c|c|c|c|c|c|c|}
\hline LM01 & 385 & Level & $\begin{array}{l}5-10 \% \text { spruce, } \\
95 \% \text { shrubs }\end{array}$ & $\begin{array}{l}\text { Mesic- } \\
\text { Wet }\end{array}$ & 200 & Game trails & N/A & $\begin{array}{l}5 \mathrm{~cm} \text { organic layer, sandy-silt, } \\
\text { cold }\end{array}$ \\
\hline LM02 & 390 & Level & $35 \%$ shrubs & Dry & 250 & Game trails & N/A & $\begin{array}{l}5 \mathrm{~cm} \text { organic layer, sandy-silt, } \\
\text { cold }\end{array}$ \\
\hline LM03 & 386 & Gentle south facing & $45 \%$ shrubs & Mesic & 100 & N/A & N/A & $\begin{array}{l}3 \mathrm{~cm} \text { organic layer, silty-sand, } \\
\text { not cold }\end{array}$ \\
\hline LM04 & 381 & Level & $25 \%$ shrubs & Dry/Wet & 25 & Game trails & N/A & $\begin{array}{l}\text { All organic soil, moist, peaty } \\
\text { deep, top = muddy, fossilized } \\
\text { moss }\end{array}$ \\
\hline LM05 & 398 & Gentle south facing & $20 \%$ shrubs & Dry & 400 & Game trails & N/A & Little organic layer, sandy soil \\
\hline LMS01 & 434 & Gentle south facing & $25 \%$ shrubs & Dry & 400 & Game trails & N/A & $\begin{array}{l}6 \mathrm{~cm} \text { organic layer, sandy-silt, } \\
\text { slightly cold to touch }\end{array}$ \\
\hline LMS02 & 403 & Gentle north facing & $35 \%$ shrubs & Dry & 300 & Game trails & N/A & $\begin{array}{l}9 \mathrm{~cm} \text { organic layer, muddy, cold } \\
\text { to touch }\end{array}$ \\
\hline LMS03 & 401 & Gentle north facing & $75 \%$ shrubs & Dry & 600 & Game trails & N/A & $\begin{array}{l}3 \mathrm{~cm} \text { organic layer, sandy-silt, } \\
\text { cold }\end{array}$ \\
\hline LMS04 & 404 & $\begin{array}{l}\text { Ridge (gentle } \\
\text { north/south facing) }\end{array}$ & $65 \%$ shrubs & Dry & 300 & Game trails & N/A & $\begin{array}{l}2 \mathrm{~cm} \text { organic layer, sandy-silt, } \\
\text { cool }\end{array}$ \\
\hline LMS05 & 380 & Level & $75 \%+$ shrubs & $\begin{array}{l}\text { Dry- } \\
\text { Mesic }\end{array}$ & 100 & Many game trails & N/A & $\begin{array}{l}6 \mathrm{~cm} \text { organic layer, sandy-silt, } \\
\text { mutli-layer, cold }\end{array}$ \\
\hline LF01 & 362 & Level & $\begin{array}{l}50 \% \text { spruce, } \\
25 \% \text { shrubs }\end{array}$ & Mesic & 150 & Game trails & N/A & $\begin{array}{l}\text { Small organic layer, sticky clay- } \\
\text { silt, cold, a bit wet }\end{array}$ \\
\hline LF02 & 358 & Level & $\begin{array}{l}65 \% \text { spruce, } \\
25 \% \text { shrubs }\end{array}$ & Mesic & 200 & Game trails & $\begin{array}{l}\text { Gray/charred } \\
\text { soil layer }\end{array}$ & $\begin{array}{l}9 \mathrm{~cm} \text { organic layer, fine clay/silt, } \\
\text { cold, gray (potential fire } \\
\text { evidence), hard to break apart }\end{array}$ \\
\hline LF03 & 369 & Level & $\begin{array}{l}25 \% \text { spruce, } \\
10 \% \text { shrubs }\end{array}$ & Dry/Wet & 200 & Game trails & Grayish soil & $\begin{array}{l}5 \mathrm{~cm} \text { organic layer, rocky (hard } \\
\text { to core), cold, damp, brown -> } \\
\text { black } \rightarrow \text { grayish, sandy/clay } \\
\text { (silty/soft at the top) }\end{array}$ \\
\hline LF04 & 357 & Level & $\begin{array}{l}65 \% \text { spruce, } \\
35 \% \text { shrubs }\end{array}$ & Wet & 100 & Game trails & N/A & $\begin{array}{l}4 \mathrm{~cm} \text { organic layer, clayish } \\
\text { layer, deep gray-brown layer, } \\
\text { cold }\end{array}$ \\
\hline LF05 & 387 & Level & $\begin{array}{l}20 \% \text { shrub, } 40 \% \\
\text { rock }\end{array}$ & Dry & 200 & N/A & N/A & $\begin{array}{l}5 \mathrm{~cm} \text { organic layer, rocky (hard } \\
\text { to core), sandy-silt, lighter } \\
\text { grayish layer below }\end{array}$ \\
\hline
\end{tabular}




\begin{tabular}{|c|c|c|c|c|c|c|c|c|}
\hline LF06 & 405 & $\begin{array}{l}\text { Gentle east facing } \\
\text { (coming off ridge } \\
\text { to west) }\end{array}$ & $40 \%$ shrub & Dry & 100 & N/A & $\begin{array}{l}\text { Gray/black } \\
\text { charred soil }\end{array}$ & $\begin{array}{l}12 \mathrm{~cm} \text { organic layer, silty-sand, } \\
\text { deeper black }->\text { gray/brown } \\
\text { layers } 14 \mathrm{~cm} \text { down (old fire) }\end{array}$ \\
\hline WL01 & 355 & $\begin{array}{l}\text { Level/Gentle NE } \\
\text { facing }\end{array}$ & $\begin{array}{l}10 \% \text { spruce, } \\
35 \% \text { shrubs }\end{array}$ & Wet & 300 & Game trails & N/A & $\begin{array}{l}4 \mathrm{~cm} \text { peaty organic layer, deep } \\
\text { gray layer, big middle brown } \\
\text { layer, sandy-silt }\end{array}$ \\
\hline WL02 & 354 & Level & $\begin{array}{l}35 \% \text { spruce, } \\
25 \% \text { shrubs }\end{array}$ & $\begin{array}{l}\text { Wet- } \\
\text { Mesic }\end{array}$ & 400 & Game trails & N/A & $\begin{array}{l}\text { Small organic layer, silty-tan } \\
\text { color soil, moist }\end{array}$ \\
\hline WL03 & 356 & Level & $\begin{array}{l}40 \% \text { spruce, } 30 \\
\% \text { shrubs }\end{array}$ & Dry/Wet & 400 & Game trails & N/A & $\begin{array}{l}\text { Small organic layer }(1-2 \mathrm{~cm}), \\
\text { Brown }->\text { tan }->\text { gray (big layer) } \\
->\text { tan }->\text { gray, cool, silty-sand }\end{array}$ \\
\hline WL04 & 347 & $\begin{array}{l}\text { Gentle north facing } \\
\text { (into Winter Lake) }\end{array}$ & $\begin{array}{l}40 \% \text { spruce, } \\
25 \% \text { shrubs }\end{array}$ & Wet & 150 & Game trails, birds & N/A & $\begin{array}{l}7 \mathrm{~cm} \text { organic layer, wet/mucky } \\
\text { soil, air holes }\end{array}$ \\
\hline WL05 & 358 & Level & $25 \%$ shrubs & Dry & 300 & N/A & N/A & $\begin{array}{l}7 \mathrm{~cm} \text { organic layer, peaty, rich } \\
\text { soil, dark brown/black -> lighter } \\
\text { below, silty -> sandy at bottom }\end{array}$ \\
\hline RR01 & 390 & Gentle south facing & $\begin{array}{l}25 \% \text { spruce, } \\
10 \% \text { shrubs }\end{array}$ & Dry & 300 & Game trails & N/A & $\begin{array}{l}7 \mathrm{~cm} \text { organic layer (light/fluffy), } \\
\text { buried wood } 8 \mathrm{~cm} \text { (root), deep } \\
\text { mineral soil is yellow (sandy) }\end{array}$ \\
\hline RR02 & 373 & Level & $5 \%$ shrubs & Very Wet & 0 & N/A & N/A & $\begin{array}{l}\text { Mucky soil, floating matts } \\
\text { (trampoline), too airy/mucky for } \\
\text { good core }\end{array}$ \\
\hline SL01 & 339 & Level & $\begin{array}{l}35 \% \text { spruce, } \\
10 \% \text { shrubs }\end{array}$ & Mesic & 75 & Game trails & $\begin{array}{l}\text { charred } \\
\text { stumps, soil }\end{array}$ & $\begin{array}{l}6 \mathrm{~cm} \text { organic layer, below is } \\
\text { firm sandy-silt soil, tan shades, } \\
\text { charred wood } 3-4 \mathrm{~cm} \text { down } \\
\text { (small more recent fire) }\end{array}$ \\
\hline SL02 & 390 & Gentle north facing & $\begin{array}{l}50 \% \text { spruce, } \\
30 \% \text { shrub }\end{array}$ & Dry & 1500 & Game trails & $\begin{array}{l}\text { charred } \\
\text { stumps, soil }\end{array}$ & $\begin{array}{l}5 \mathrm{~cm} \text { organic layer, sandy deep } \\
\text { yellow layer, silty/peaty above, } \\
\text { fire evidence just below organic } \\
\text { layer (humus) }\end{array}$ \\
\hline SL03 & 350 & Level & $15 \%$ treed & Dry & 350 & Game trails & $\begin{array}{l}\text { charred } \\
\text { stumps, soil }\end{array}$ & $\begin{array}{l}4 \mathrm{~cm} \text { organic layer, coarse } \\
\text { grained sand, black }->\text { gray }-> \\
\text { tan }->\text { orange, roots (not much } \\
\text { fire signs) }\end{array}$ \\
\hline
\end{tabular}


Table A.3: Points of interest where photographs were taken and details noted.

\begin{tabular}{|l|l|l|r|r|}
\hline Name & Description & Class & UTM E & UTM N \\
\hline BLS_Esker & Esker south of Big Lake & Bear Soil & 404433 & 7185317 \\
\hline LMN_Boulder1 & $\begin{array}{l}\text { Boulder garden on "river" north of Little } \\
\text { Marten Lake }\end{array}$ & Rocky/Bedrock & 408620 & 7182241 \\
\hline LMN_Boulder2 & $\begin{array}{l}\text { Boulder garden on "river" north of Little } \\
\text { Marten Lake }\end{array}$ & Rocky-Bedrock & 408506 & 7182068 \\
\hline LMS_Boulder & Boulder garden at Little Marten South & Rocky-Bedrock & 398966 & 7168069 \\
\hline WL_Lichen & Lichen Woodland on Winter Lake & Wetland & 401545 & 714630 \\
\hline RR_Burn & $\begin{array}{l}\text { Recent ( 10 years) burn scar off south } \\
\text { short of Roundrock Lake }\end{array}$ & Rocky/Bedrock & 385246 & 7141191 \\
\hline Wek_Road & $\begin{array}{l}\text { Gravel intersection in front of Admin } \\
\text { building in Wekweètì }\end{array}$ & Bare Soil & 345416 & 7122116 \\
\hline Wek_Airport & Gravel airport east of Wekweètì & Bare Soil & 350597 & 7122134 \\
\hline
\end{tabular}

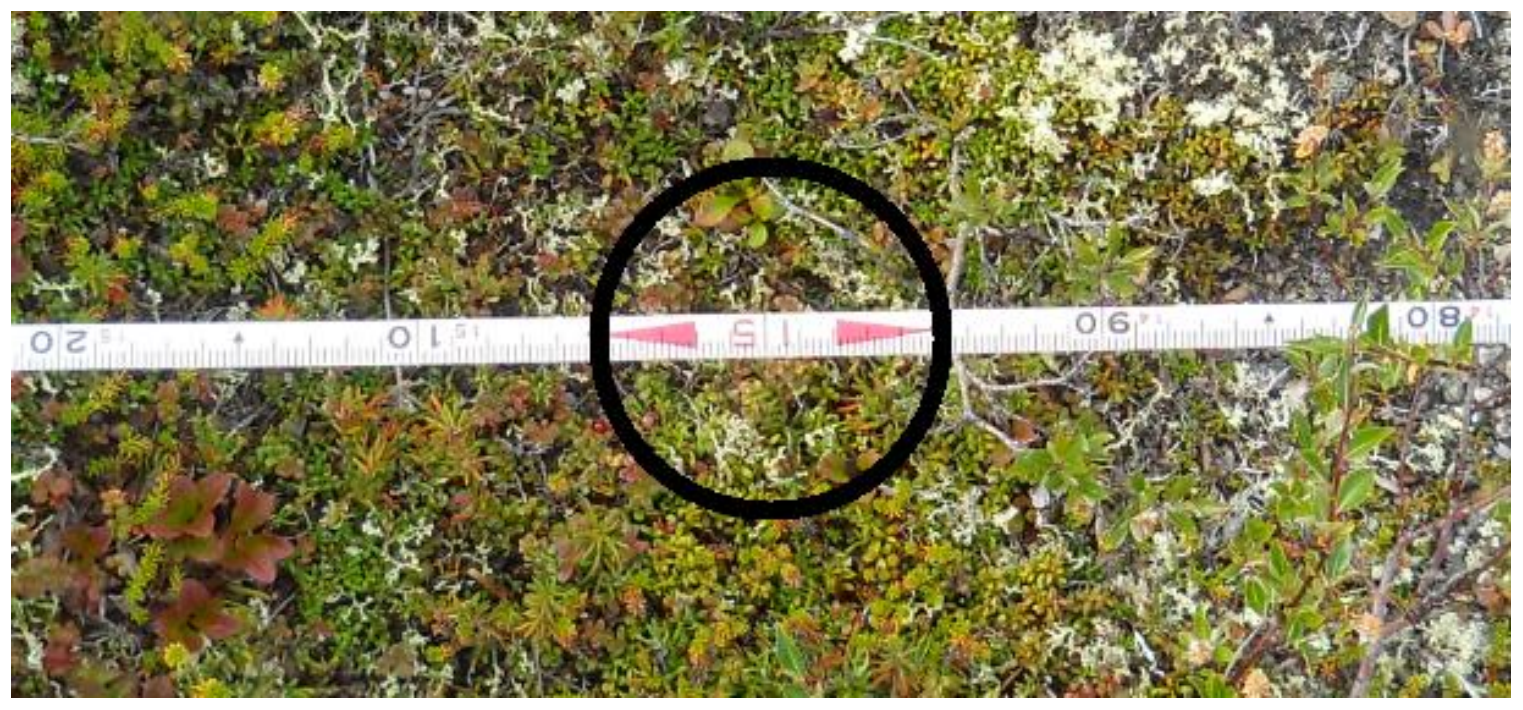

Figure A.4: The highest point for each functional group that was present within a $5 \mathrm{~cm}$ radius of the sample point (black circle) was recorded. 


\section{Appendix B}

\section{Information on Selected Landsat Data}

Table B.1: Selected Landsat scenes. 2011 pass used for PIFs and land-cover classifications in bold.

\begin{tabular}{|c|c|c|c|c|}
\hline Path-Row & ID & Date & Satellite & Quality \\
\hline $47-13$ & 194LGN00 & $7 / 13 / 2014$ & L8 OLI-TIRS & 7 \\
\hline $47-13$ & 218GLC01 & $8 / 6 / 2011$ & L4-5 TM & 9 \\
\hline $47-13$ & 217PAC00 & $8 / 5 / 2005$ & L4-5 TM & 6 \\
\hline $47-13$ & 201EDC00 & $7 / 20 / 2002$ & L7 ETM+ SLC-on & 9 \\
\hline $47-13$ & 212PAC01 & $7 / 30 / 2000$ & L7 ETM+ SLC-on & 10 \\
\hline $47-13$ & 198PAC00 & $7 / 17 / 1998$ & L4-5 TM & 10 \\
\hline $47-13$ & $222 \times X X 00$ & $8 / 10 / 1995$ & L4-5 TM & 8 \\
\hline $47-13$ & 195PAC00 & $7 / 14 / 1991$ & L4-5 TM & 10 \\
\hline $47-13$ & 203PAC00 & $7 / 21 / 1988$ & L4-5 TM & 6 \\
\hline $47-13$ & 197PAC00 & $7 / 16 / 1986$ & L4-5 TM & 6 \\
\hline $47-14$ & 194LGN00 & $7 / 13 / 2014$ & L8 OLI-TIRS & 8 \\
\hline $47-14$ & 223LGN00 & $8 / 11 / 2013$ & L8 OLI-TIRS & 9 \\
\hline $47-14$ & 218GLC01 & $8 / 6 / 2011$ & L4-5 TM & 10 \\
\hline $47-14$ & 220PAC01 & $8 / 8 / 2006$ & L4-5 TM & 7 \\
\hline $47-14$ & 201EDC00 & $7 / 20 / 2002$ & L7 ETM+ SLC-on & 10 \\
\hline $47-14$ & 209PAC00 & $7 / 27 / 1996$ & L4-5 TM & 9 \\
\hline $47-14$ & 195PAC00 & $7 / 14 / 1991$ & L4-5 TM & 9 \\
\hline $47-14$ & 221PAC00 & $8 / 9 / 1989$ & L4-5 TM & 8 \\
\hline $47-14$ & 197PAC00 & $7 / 16 / 1986$ & L4-5 TM & 7 \\
\hline $47-14$ & 208PAC00 & $7 / 26 / 1984$ & L4-5 TM & 6 \\
\hline $47-15$ & 216LGN00 & $8 / 3 / 2016$ & L8 OLI-TIRS & 5 \\
\hline $47-15$ & 223LGN00 & $8 / 11 / 2013$ & L8 OLI-TIRS & 10 \\
\hline $47-15$ & 218GLC01 & $8 / 6 / 2011$ & L4-5 TM & 10 \\
\hline $47-15$ & 220PAC02 & $8 / 8 / 2006$ & L4-5 TM & 8 \\
\hline $47-15$ & 201EDC00 & $7 / 20 / 2002$ & L7 ETM+ SLC-on & 9 \\
\hline $47-15$ & 209PAC00 & $7 / 27 / 1996$ & L4-5 TM & 8 \\
\hline $47-15$ & 214PAC00 & $8 / 1 / 1992$ & L4-5 TM & 9 \\
\hline $47-15$ & 195PAC00 & $7 / 14 / 1991$ & L4-5 TM & 8 \\
\hline $47-15$ & 192PAC00 & $7 / 11 / 1990$ & L4-5 TM & 10 \\
\hline $47-15$ & 208PAC00 & $7 / 26 / 1984$ & L4-5 TM & 7 \\
\hline $47-16$ & 223LGN00 & $8 / 11 / 2013$ & L8 OLI-TIRS & 9 \\
\hline $47-16$ & 218GLC02 & $8 / 6 / 2011$ & L4-5 TM & 10 \\
\hline $47-16$ & 215PAC01 & $8 / 2 / 2004$ & L4-5 TM & 10 \\
\hline $47-16$ & 206LGS01 & $7 / 25 / 2001$ & L4-5 TM & 7 \\
\hline $47-16$ & 214PAC00 & $8 / 2 / 1998$ & L4-5 TM & 9 \\
\hline $47-16$ & 211PAC00 & $7 / 30 / 1997$ & L4-5 TM & 9 \\
\hline $47-16$ & 214PAC00 & $8 / 1 / 1992$ & L4-5 TM & 8 \\
\hline $47-16$ & 192PAC00 & $7 / 11 / 1990$ & L4-5 TM & 9 \\
\hline $47-16$ & 221PAC00 & $8 / 9 / 1989$ & L4-5 TM & 7 \\
\hline $47-16$ & 208PAC00 & $7 / 26 / 1984$ & L4-5 TM & 7 \\
\hline
\end{tabular}




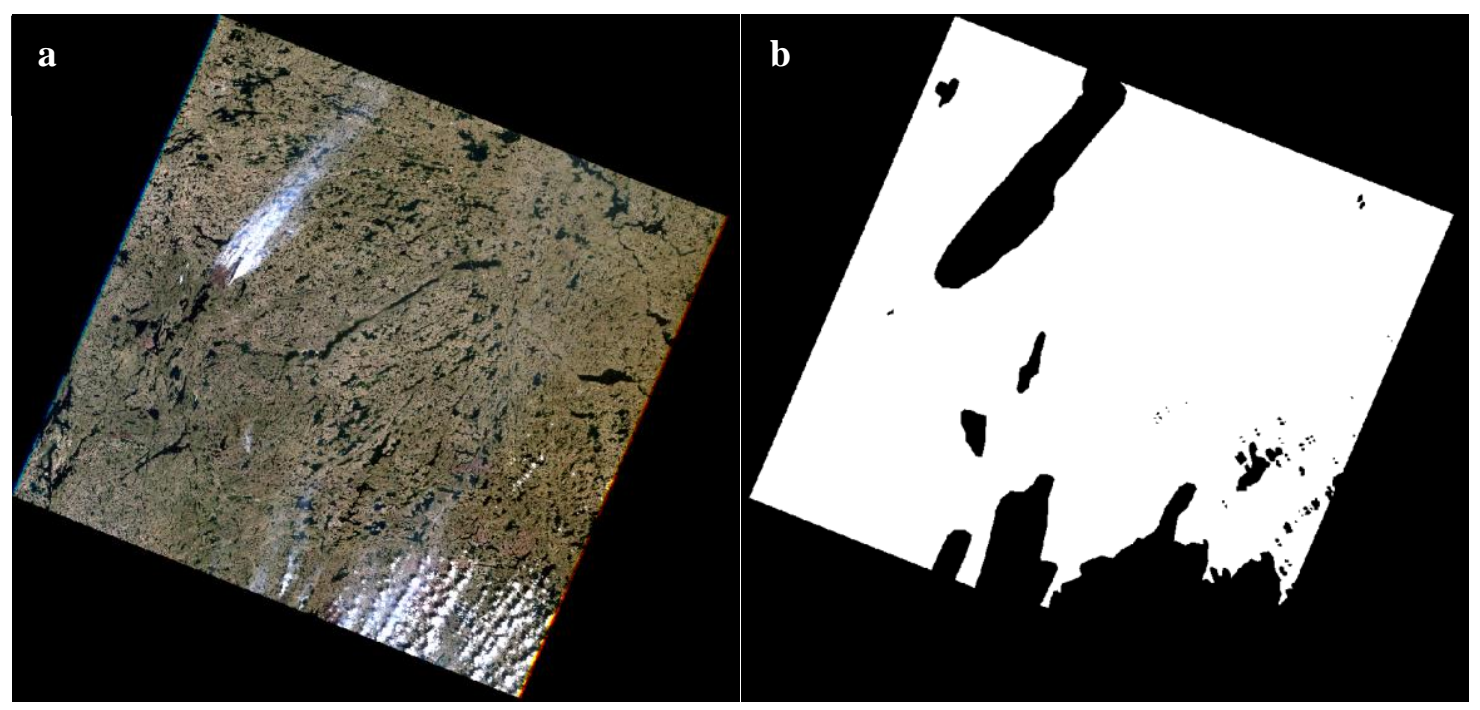

Figure B.1: Example cloud mask. (a) Top-of-atmosphere Landsat TM scene from July $27^{\text {th }}, 1996$, frame 47-15. (b) Cloud mask for that same scene (black = cloud covered).

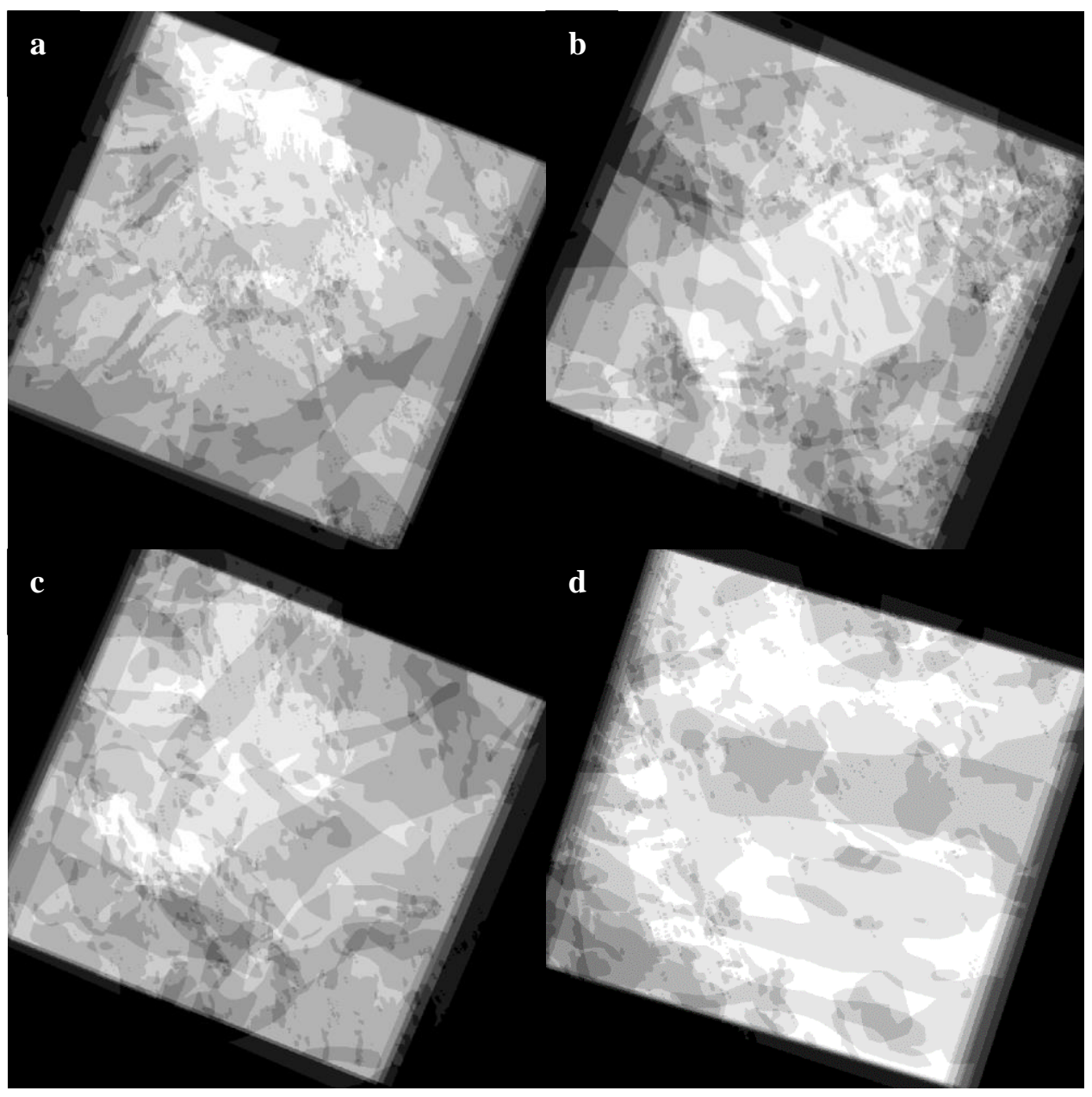

Figure B.2: Cloud cover sum rasters (Black $=10 / 10$ cloud covered, white $=0 / 10$ cloud covered). (a) Frame 47-13 (furthest north). (b) Frame 47-14. (c) Frame 47-15. (d) Frame 47-16 (furthest south). 


\section{Appendix C \\ Pseudo-Invariant Feature Normalization}

Selected scenes were supplied from GloVis with pixel values as digital numbers (DN); 8bit $(0-255)$ for Landsat $4-5$ and 7 and 16 -bit $(0-65,535)$ for Landsat 8 . These values needed to be calibrated in order to be useful for remote sensing analysis. Scenes were then converted from DN to top-of-atmosphere (TOA) reflectance in ENVI.

$$
\rho \lambda=\frac{\pi L_{\lambda} d^{2}}{E S U N_{\lambda} \sin \theta}
$$

TOA reflectance represents the reflectance measured by Landsat above the Earth's atmosphere without correction for atmospheric effects. Information needed to complete this calculation is available in the metadata for each Landsat scene. $L_{\lambda}$ is radiance $\left(\mathrm{W} /\left(\mathrm{m}^{2} * \mathrm{sr} * \mu \mathrm{m}\right)\right), d$ is Earthsun distance in astronomical units, $\operatorname{ESUN}_{\lambda}$ is solar irradiance $\left(\mathrm{W} /\left(\mathrm{m}^{2} * \mu \mathrm{m}\right)\right)$ and $\theta$ is sun elevation in degrees. $L_{\lambda}$ is computed from scene metadata (gain * DN + offset). The output TOA reflectance value for each band ranges between 0 and 1 . Once scenes were converted to TOA reflectance, PIF normalization was then applied.

This relative atmospheric correction method aimed to use pixels in the study area that are not expected to change in value over time (i.e., are pseudo-invariant). These features included deep non-turbid waterbodies, bedrock, eskers and anthropogenic features (i.e., mines, roads, buildings). In addition to having spectral characteristics that change little through time, PIFs should also be at similar elevations, be in relatively flat areas and contain minimal vegetation (Jensen, 2016). The base layer to which all other scenes would be normalized to using PIFs was from a mostly cloud free pass through all four frames taken on August $6^{\text {th }}, 2011$.

PIFs were chosen manually in each of the four frames. 25 PIFs were chosen per frame, meaning that 100 PIFs were chosen over the study area (Table C.1). PIFs were only selected in areas that were cloud free in all 10 scenes using the cloud cover sum rasters. About half of the 
PIFs in each frame were chosen from the middle of larger lakes that were not ice covered in any of the scenes in the stack. The other half of the PIFs were usually chosen from rocky areas, sandy beaches and large eskers. In order to ensure that only areas with minimal vegetation were selected on land, a raster layer consisting of NDVI values between 0 and 0.2 from the 2011 base layer was used and PIFs were only chosen if they overlapped with that raster. Pixels that were not directly on the coast (to avoid influence of changing waterbody size) and close to other low NDVI values were prioritized for PIF selection. High resolution satellite imagery available in Google Earth was referenced where available to confirm quality PIF selection.

Once PIFs were chosen, regression analysis was conducted to compare R $(0.63-0.69$ $\mu \mathrm{m}$ ) values of the 2011 base layer PIFs with PIF R values for each image in a frame (Figure C.1). This was completed for NIR $(0.76-0.90 \mu \mathrm{m})$ values as well. These regressions are used to relate the base layer PIFs spectral characteristics with the spectral characteristics of the same pixels from the other scenes in a frame (Jensen, 2016). 18 regressions (nine R and nine NIR) were calculated for each frame, meaning 72 total regressions were created. $\mathrm{R}^{2}$ values calculated for each regression and were above 0.95 in every case.

Regression equations (i.e., R year X vs. R 2011 and NIR year X vs. NIR 2011) were brought into ENVI and band math was used to create new normalized data for the R and NIR bands of each scene in each frame. This normalization procedure was tested by checking nonvegetated features throughout the image in order to ensure that there was no trend in the results (i.e., pixel values do not change much over time). These PIF normalized R and NIR bands were then converted to NDVI scenes $((\mathrm{NIR}-\mathrm{R}) /(\mathrm{NIR}+\mathrm{R}))$ and cloud masks were applied. See results in Figure C.2. Overall PIF NDVI trends were slightly less positive than surface reflectance trends, but still with more greening than browning across the study area. Surface reflectance NDVI trends were analyzed instead of PIF trends since it allowed a more direct comparison with other surface reflectance studies and because PIF trends were less consistent between Landsat frames. 
Table C.1: Selected PIFs, their associated cover type and coordinates. Each PIF is a Landsat pixel selected in an area with minimal vegetation.

\begin{tabular}{|c|c|c|}
\hline Frame & Cover Type & Lat-Long \\
\hline $47-13$ & Bedrock cliff & $67^{\circ} 45^{\prime} 23.96^{\prime \prime} \mathrm{N}, 111^{\circ} 49^{\prime} 34.70^{\prime \prime W}$ \\
\hline $47-13$ & Middle of lake & $67^{\circ} 40^{\prime} 31.86^{\prime \prime N}, 112^{\circ} 4^{\prime} 14.05^{\prime \prime} \mathrm{W}$ \\
\hline $47-13$ & Middle of lake & $67^{\circ} 25^{\prime} 35.01^{\prime \prime N}, 110^{\circ} 42^{\prime} 42.98^{\prime \prime W}$ \\
\hline $47-13$ & Middle of lake & $67^{\circ} 26^{\prime} 44.72^{\prime \prime N}, 110^{\circ} 42^{\prime} 7.04^{\prime \prime} \mathrm{W}$ \\
\hline $47-13$ & Middle of lake & $67^{\circ} 38^{\prime} 1.42^{\prime \prime N}, 111^{\circ} 12^{\prime} 19.29^{\prime \prime} \mathrm{W}$ \\
\hline $47-13$ & Middle of lake & $67^{\circ} 37^{\prime} 46.47^{\prime \prime N}, 111^{\circ} 45^{\prime} 42.78^{\prime \prime W}$ \\
\hline $47-13$ & Bedrock cliff & $67^{\circ} 42^{\prime} 15.67^{\prime \prime N}, 112^{\circ} 1^{\prime} 22.95^{\prime \prime} \mathrm{W}$ \\
\hline $47-13$ & Bedrock cliff & $67^{\circ} 44^{\prime} 52.25^{\prime \prime} \mathrm{N}, 112^{\circ} 00^{\prime} 5.40^{\prime \prime} \mathrm{W}$ \\
\hline $47-13$ & Bedrock & $67^{\circ} 38^{\prime} 57.98^{\prime \prime N}, 112^{\circ} 3^{\prime} 1.90^{\prime \prime} \mathrm{W}$ \\
\hline $47-13$ & Bedrock & $67^{\circ} 39^{\prime} 55.00^{\prime \prime N}, 111^{\circ} 59^{\prime} 27.13^{\prime \prime} \mathrm{W}$ \\
\hline $47-13$ & Bedrock & $67^{\circ} 41^{\prime} 25.83^{\prime \prime N}, 111^{\circ} 54^{\prime} 18.50^{\prime \prime} \mathrm{W}$ \\
\hline $47-13$ & Bare soil & $66^{\circ} 57^{\prime} 31.28^{\prime \prime N}, 111^{\circ} 23^{\prime} 45.84^{\prime \prime W}$ \\
\hline $47-13$ & Middle of lake & $67^{\circ} 11^{\prime} 4.33^{\prime \prime N}, 110^{\circ} 33^{\prime} 52.09^{\prime \prime} \mathrm{W}$ \\
\hline $47-13$ & Rocky area & $67^{\circ} 38^{\prime} 35.81^{\prime \prime N}, 111^{\circ} 56^{\prime} 8.35^{\prime \prime W}$ \\
\hline $47-13$ & Bedrock & $67^{\circ} 36^{\prime} 44.88^{\prime \prime N}, 112^{\circ} 32.37^{\prime \prime W}$ \\
\hline $47-13$ & Bedrock cliff & $67^{\circ} 43^{\prime} 14.82^{\prime \prime N}, 112^{\circ} 12^{\prime} 57.24 " \mathrm{~W}$ \\
\hline $47-13$ & Bedrock & $67^{\circ} 38^{\prime} 22.56^{\prime \prime N}, 111^{\circ} 13^{\prime} 27.93^{\prime \prime W}$ \\
\hline $47-13$ & Bedrock & $67^{\circ} 41^{\prime} 57.50^{\prime \prime N}, 111^{\circ} 14^{\prime} 59.08^{\prime \prime W}$ \\
\hline $47-13$ & Bedrock & $67^{\circ} 24^{\prime} 32.88^{\prime \prime N}, 110^{\circ} 42^{\prime} 33.34^{\prime \prime W}$ \\
\hline $47-13$ & Bedrock & $67^{\circ} 34^{\prime} 34.78^{\prime \prime N}, 112^{\circ} 10^{\prime} 3.37^{\prime \prime} \mathrm{W}$ \\
\hline $47-13$ & Bedrock & $67^{\circ} 37^{\prime} 42.43^{\prime \prime N}, 111^{\circ} 46^{\prime} 26.23^{\prime \prime W}$ \\
\hline $47-13$ & Bedrock & $67^{\circ} 40^{\prime} 44.23 " \mathrm{~N}, 111^{\circ} 66^{\prime} 41.60^{\prime \prime} \mathrm{W}$ \\
\hline $47-13$ & Bedrock & $67^{\circ} 40^{\prime} 44.34^{\prime \prime N}, 111^{\circ} 18^{\prime} 14.94^{\prime \prime W}$ \\
\hline $47-13$ & Bedrock & $67^{\circ} 37^{\prime} 49.26^{\prime \prime N}, 111^{\circ} 17^{\prime} 16.35^{\prime \prime W}$ \\
\hline $47-13$ & Bedrock & $67^{\circ} 40^{\prime} 18.98^{\prime \prime N}, 111^{\circ} 55^{\prime} 1.61^{\prime \prime W}$ \\
\hline $47-14$ & Middle of lake & $65^{\circ} 53^{\prime} 28.64^{\prime \prime N}, 111^{\circ} 59^{\prime} 34.58^{\prime \prime W}$ \\
\hline $47-14$ & Esker & $65^{\circ} 20^{\prime} 35.68^{\prime \prime N}, 113^{\circ} 41^{\prime} 18.27^{\prime \prime W}$ \\
\hline $47-14$ & Rocky area & $65^{\circ} 18^{\prime} 40.74^{\prime \prime N}, 113^{\circ} 31^{\prime} 36.14^{\prime \prime W}$ \\
\hline $47-14$ & Middle of lake & $65^{\circ} 40^{\prime} 19.96^{\prime \prime} \mathrm{N}, 112^{\circ} 18^{\prime} 25.13^{\prime \prime W}$ \\
\hline $47-14$ & Rocky area & $65^{\circ} 7^{\prime} 14.92^{\prime \prime N}, 113^{\circ} 26^{\prime} 59.09^{\prime \prime} \mathrm{W}$ \\
\hline $47-14$ & Middle of lake & $65^{\circ} 44^{\prime} 37.90^{\prime \prime N}, 112^{\circ} 33^{\prime} 29.44^{\prime \prime W}$ \\
\hline $47-14$ & Middle of lake & $65^{\circ} 46^{\prime} 38.49^{\prime \prime} \mathrm{N}, 112^{\circ} 9^{\prime} 24.81^{\prime \prime} \mathrm{W}$ \\
\hline $47-14$ & Esker & $65^{\circ} 46^{\prime} 13.47^{\prime \prime N}, 112^{\circ} 24^{\prime} 30.01^{\prime \prime W}$ \\
\hline $47-14$ & Esker & $65^{\circ} 46^{\prime} 59.99^{\prime \prime} \mathrm{N}, 112^{\circ} 34^{\prime} 1.46^{\prime \prime} \mathrm{W}$ \\
\hline $47-14$ & Esker & $65^{\circ} 47^{\prime} 48.11^{\prime \prime N}, 112^{\circ} 43^{\prime} 52.50 " \mathrm{~W}$ \\
\hline $47-14$ & Esker & $65^{\circ} 47^{\prime} 38.11^{\prime \prime N}, 112^{\circ} 38^{\prime} 37.32^{\prime \prime W}$ \\
\hline $47-14$ & Esker & $65^{\circ} 49^{\prime} 58.29^{\prime \prime} \mathrm{N}, 112^{\circ} 26^{\prime} 10.26^{\prime \prime W}$ \\
\hline $47-14$ & Rocky area & $65^{\circ} 49^{\prime} 59.90^{\prime \prime} \mathrm{N}, 112^{\circ} 15^{\prime} 55.39^{\prime \prime W}$ \\
\hline $47-14$ & Rocky area & $65^{\circ} 49^{\prime} 54.97^{\prime \prime N}, 112^{\circ} 10^{\prime} 26.27^{\prime \prime W}$ \\
\hline $47-14$ & Esker & $65^{\circ} 44^{\prime} 59.53^{\prime \prime N}, 112^{\circ} 17^{\prime} 44.96^{\prime \prime W}$ \\
\hline $47-14$ & Rocky area & $65^{\circ} 43^{\prime} 48.15^{\prime \prime N}, 112^{\circ} 13^{\prime} 10.77^{\prime \prime W}$ \\
\hline $47-14$ & Rocky area & $65^{\circ} 44^{\prime} 43.53^{\prime \prime} \mathrm{N}, 111^{\circ} 58^{\prime} 49.21^{\prime \prime W}$ \\
\hline $47-14$ & Rocky area & $65^{\circ} 43^{\prime} 46.81^{\prime \prime N}, 111^{\circ} 46^{\prime} 34.03 " \mathrm{~W}$ \\
\hline $47-14$ & Esker & $65^{\circ} 44^{\prime} 55.14 " \mathrm{~N}, 111^{\circ} 44^{\prime} 52.66^{\prime \prime W}$ \\
\hline $47-14$ & Rocky area & $65^{\circ} 46^{\prime} 53.26^{\prime \prime} \mathrm{N}, 111^{\circ} 52^{\prime} 0.43^{\prime \prime} \mathrm{W}$ \\
\hline $47-14$ & Esker & $65^{\circ} 42^{\prime} 18.65^{\prime \prime N}, 112^{\circ} 00^{\prime} 38.29^{\prime \prime} \mathrm{W}$ \\
\hline $47-14$ & Esker & $65^{\circ} 38^{\prime} 38.90^{\prime \prime N}, 112^{\circ} 10^{\prime} 28.19^{\prime \prime W}$ \\
\hline $47-14$ & Rocky area & $65^{\circ} 53^{\prime} 30.63^{\prime \prime N}, 112^{\circ} 29^{\prime} 40.90^{\prime \prime W}$ \\
\hline $47-14$ & Rocky area & $65^{\circ} 51^{\prime} 50.69^{\prime \prime N}, 112^{\circ} 33^{\prime} 3.34^{\prime \prime} \mathrm{W}$ \\
\hline
\end{tabular}




\begin{tabular}{|c|c|c|}
\hline $47-14$ & Esker & $65^{\circ} 31^{\prime} 41.60^{\prime \prime} \mathrm{N}, 113^{\circ} 3{ }^{\prime} 27.31^{\prime \prime} \mathrm{W}$ \\
\hline $47-15$ & Middle of lake & $64^{\circ} 6^{\prime} 27.87^{\prime \prime N}, 115^{\circ} 5^{\prime} 57.79^{\prime \prime} \mathrm{W}$ \\
\hline $47-15$ & Middle of lake & $64^{\circ} 12^{\prime} 29.16^{\prime \prime N}, 115^{\circ} 15^{\prime} 4.43^{\prime \prime W}$ \\
\hline $47-15$ & Middle of lake & $64^{\circ} 19^{\prime} 33.54^{\prime \prime N}, 114^{\circ} 14^{\prime} 20.52^{\prime \prime W}$ \\
\hline $47-15$ & Middle of lake & $64^{\circ} 3^{\prime} 55.00 " \mathrm{~N}, 115^{\circ} 7^{\prime} 4.58^{\prime \prime} \mathrm{W}$ \\
\hline $47-15$ & Middle of lake & $63^{\circ} 59^{\prime} 24.24 " \mathrm{~N}, 115^{\circ} 11^{\prime} 32.44^{\prime \prime} \mathrm{W}$ \\
\hline $47-15$ & Middle of lake & $64^{\circ} 25^{\prime} 33.61^{\prime \prime N}, 114^{\circ} 11^{\prime} 46.39^{\prime \prime} \mathrm{W}$ \\
\hline $47-15$ & Esker & $64^{\circ} 4{ }^{\prime} 57.86^{\prime \prime N}, 114^{\circ} 32^{\prime} 58.00^{\prime \prime W}$ \\
\hline $47-15$ & Middle of lake & $64^{\circ} 1^{\prime} 16.59^{\prime \prime N}, 114^{\circ} 38^{\prime} 45.82^{\prime \prime W}$ \\
\hline $47-15$ & Rocky area & $64^{\circ} 0149.60^{\prime \prime N}, 114^{\circ} 26^{\prime} 50.63^{\prime \prime W}$ \\
\hline $47-15$ & Middle of lake & $64^{\circ} 14^{\prime} 47.66^{\prime \prime N}, 115^{\circ} 16^{\prime} 23.90^{\prime \prime W}$ \\
\hline $47-15$ & Rocky area & $64^{\circ} 2^{\prime} 10.38^{\prime \prime N}, 114^{\circ} 36^{\prime} 33.56^{\prime \prime W}$ \\
\hline $47-15$ & Rocky area & $64^{\circ} 26^{\prime} 10.22^{\prime \prime N}, 113^{\circ} 45^{\prime} 7.08^{\prime \prime W}$ \\
\hline $47-15$ & Rocky area & $64^{\circ} 13^{\prime} 13.93^{\prime \prime N}, 115^{\circ} 16^{\prime} 9.21^{\prime \prime W}$ \\
\hline $47-15$ & Rocky area & $64^{\circ} 8^{\prime} 39.82^{\prime \prime N}, 115^{\circ} 18^{\prime} 33.88^{\prime \prime W}$ \\
\hline $47-15$ & Middle of lake & $64^{\circ} 4^{\prime} 22.41^{\prime \prime N}, 114^{\circ} 53^{\prime} 4.97^{\prime \prime W}$ \\
\hline $47-15$ & Middle of lake & $64^{\circ} 26^{\prime} 45.84^{\prime \prime N}, 113^{\circ} 47^{\prime} 2.85^{\prime \prime} \mathrm{W}$ \\
\hline $47-15$ & Middle of lake & $64^{\circ} 30^{\prime} 12.59^{\prime \prime} \mathrm{N}, 114^{\circ} 20^{\prime} 41.37^{\prime \prime W}$ \\
\hline $47-15$ & Rock garden & $64^{\circ} 21^{\prime} 13.01^{\prime \prime N}, 114^{\circ} 11^{\prime} 4.29^{\prime \prime W}$ \\
\hline $47-15$ & Rocky area & $64^{\circ} 27^{\prime} 24.43^{\prime \prime N}, 114^{\circ} 14^{\prime} 56.43^{\prime \prime W}$ \\
\hline $47-15$ & Rocky area & $64^{\circ} 2 ' 20.58^{\prime \prime N}, 114^{\circ} 50^{\prime} 42.76^{\prime \prime W}$ \\
\hline $47-15$ & Rocky area & $64^{\circ} 8^{\prime} 33.11^{\prime \prime N}, 115^{\circ} 6^{\prime} 3.85^{\prime \prime} \mathrm{W}$ \\
\hline $47-15$ & Rocky area & $64^{\circ} 9^{\prime} 6.46^{\prime \prime N}, 115^{\circ} 3^{\prime} 39.78^{\prime \prime W}$ \\
\hline $47-15$ & Middle of lake & $64^{\circ} 6^{\prime} 59.98^{\prime \prime N}, 115^{\circ} 5^{\prime} 5.16^{\prime \prime W}$ \\
\hline $47-15$ & Rocky area & $64^{\circ} 9^{\prime} 18.05^{\prime \prime N}, 115^{\circ} 7^{\prime} 10.46 " \mathrm{~W}$ \\
\hline $47-15$ & Rocky area & $64^{\circ} 20^{\prime} 29.88^{\prime \prime N}, 113^{\circ} 37^{\prime} 5.28^{\prime \prime W}$ \\
\hline $47-16$ & Middle of lake & $62^{\circ} 21^{\prime} 46.92^{\prime \prime N}, 114^{\circ} 22^{\prime} 4.47^{\prime \prime} \mathrm{W}$ \\
\hline $47-16$ & Bedrock & $62^{\circ} 42^{\prime} 50.84^{\prime \prime N}, 115^{\circ} 25^{\prime} 20.86^{\prime \prime} \mathrm{W}$ \\
\hline $47-16$ & Bedrock & $62^{\circ} 41^{\prime} 17.22^{\prime \prime N}, 115^{\circ} 21^{\prime} 50.32^{\prime \prime} \mathrm{W}$ \\
\hline $47-16$ & Bedrock & $62^{\circ} 39^{\prime} 57.48^{\prime \prime N}, 115^{\circ} 31^{\prime} 34.75^{\prime \prime W}$ \\
\hline $47-16$ & Bedrock & $62^{\circ} 40^{\prime} 40.06^{\prime \prime} \mathrm{N}, 115^{\circ} 41^{\prime} 12.90^{\prime \prime} \mathrm{W}$ \\
\hline $47-16$ & Bedrock & $62^{\circ} 35^{\prime} 15.36^{\prime \prime N}, 115^{\circ} 36^{\prime} 36.72^{\prime \prime} \mathrm{W}$ \\
\hline $47-16$ & Sandy area & $62^{\circ} 28^{\prime} 46.69^{\prime \prime N}, 115^{\circ} 18^{\prime} 11.49^{\prime \prime W}$ \\
\hline $47-16$ & Bedrock & $62^{\circ} 32^{\prime} 15.95^{\prime \prime N}, 115^{\circ} 13^{\prime} 25.30^{\prime \prime} \mathrm{W}$ \\
\hline $47-16$ & Bedrock & $62^{\circ} 23^{\prime} 23.07^{\prime \prime N}, 115^{\circ} 47^{\prime} 13.99^{\prime \prime} \mathrm{W}$ \\
\hline $47-16$ & Middle of lake & $62^{\circ} 33^{\prime} 4.86^{\prime \prime N}, 113^{\circ} 48^{\prime} 57.07^{\prime \prime W}$ \\
\hline $47-16$ & Bedrock & $62^{\circ} 46^{\prime} 12.01^{\prime \prime N}, 114^{\circ} 46^{\prime} 31.12^{\prime \prime W}$ \\
\hline $47-16$ & Bedrock & $62^{\circ} 34^{\prime} 47.27^{\prime \prime N}, 113^{\circ} 41^{\prime} 10.42^{\prime \prime W}$ \\
\hline $47-16$ & Bedrock & $62^{\circ} 42^{\prime} 44.59^{\prime \prime} \mathrm{N}, 113^{\circ} 53^{\prime} 9.16^{\prime \prime W}$ \\
\hline $47-16$ & Bedrock & $63^{\circ} 5^{\prime} 25.35^{\prime \prime N}, 113^{\circ} 54^{\prime} 17.59^{\prime \prime} \mathrm{W}$ \\
\hline $47-16$ & Middle of lake & $62^{\circ} 42^{\prime} 28.09^{\prime \prime N}, 114^{\circ} 5 ' 27.63^{\prime \prime W}$ \\
\hline $47-16$ & Middle of lake & $62^{\circ} 14^{\prime} 24.64^{\prime \prime N}, 114^{\circ} 51^{\prime} 10.32^{\prime \prime W}$ \\
\hline $47-16$ & Middle of lake & $62^{\circ} 14^{\prime} 37.53^{\prime \prime N}, 115^{\circ} 4^{\prime} 21.74^{\prime \prime W}$ \\
\hline $47-16$ & Bedrock & $63^{\circ} 21^{\prime} 32.52^{\prime \prime N}, 115^{\circ} 58^{\prime} 27.90^{\prime \prime} \mathrm{W}$ \\
\hline $47-16$ & Bedrock & $63^{\circ} 17^{\prime} 41.11 " \mathrm{~N}, 115^{\circ} 56^{\prime} 54.46^{\prime \prime W}$ \\
\hline $47-16$ & Bedrock & $63^{\circ} 22^{\prime} 7.95^{\prime \prime N}, 115^{\circ} 45^{\prime} 35.30^{\prime \prime} \mathrm{W}$ \\
\hline $47-16$ & Bedrock & $63^{\circ} 22^{\prime} 18.211^{\prime \prime N}, 115^{\circ} 34^{\prime} 18.73^{\prime \prime W}$ \\
\hline $47-16$ & Bedrock & $63^{\circ} 34^{\prime} 30.62^{\prime \prime N}, 115^{\circ} 22^{\prime} 47.38^{\prime \prime W}$ \\
\hline $47-16$ & Bedrock & $63^{\circ} 39^{\prime} 4.44^{\prime \prime N}, 115^{\circ} 12^{\prime} 36.46^{\prime \prime W}$ \\
\hline $47-16$ & Bedrock & $63^{\circ} 21^{\prime} 21.50^{\prime \prime} \mathrm{N}, 115^{\circ} 10^{\prime} 37.24^{\prime \prime} \mathrm{W}$ \\
\hline $47-16$ & Bedrock & $63^{\circ} 27^{\prime} 21.73^{\prime \prime N}, 115^{\circ} 5^{\prime} 30.10^{\prime \prime W}$ \\
\hline
\end{tabular}



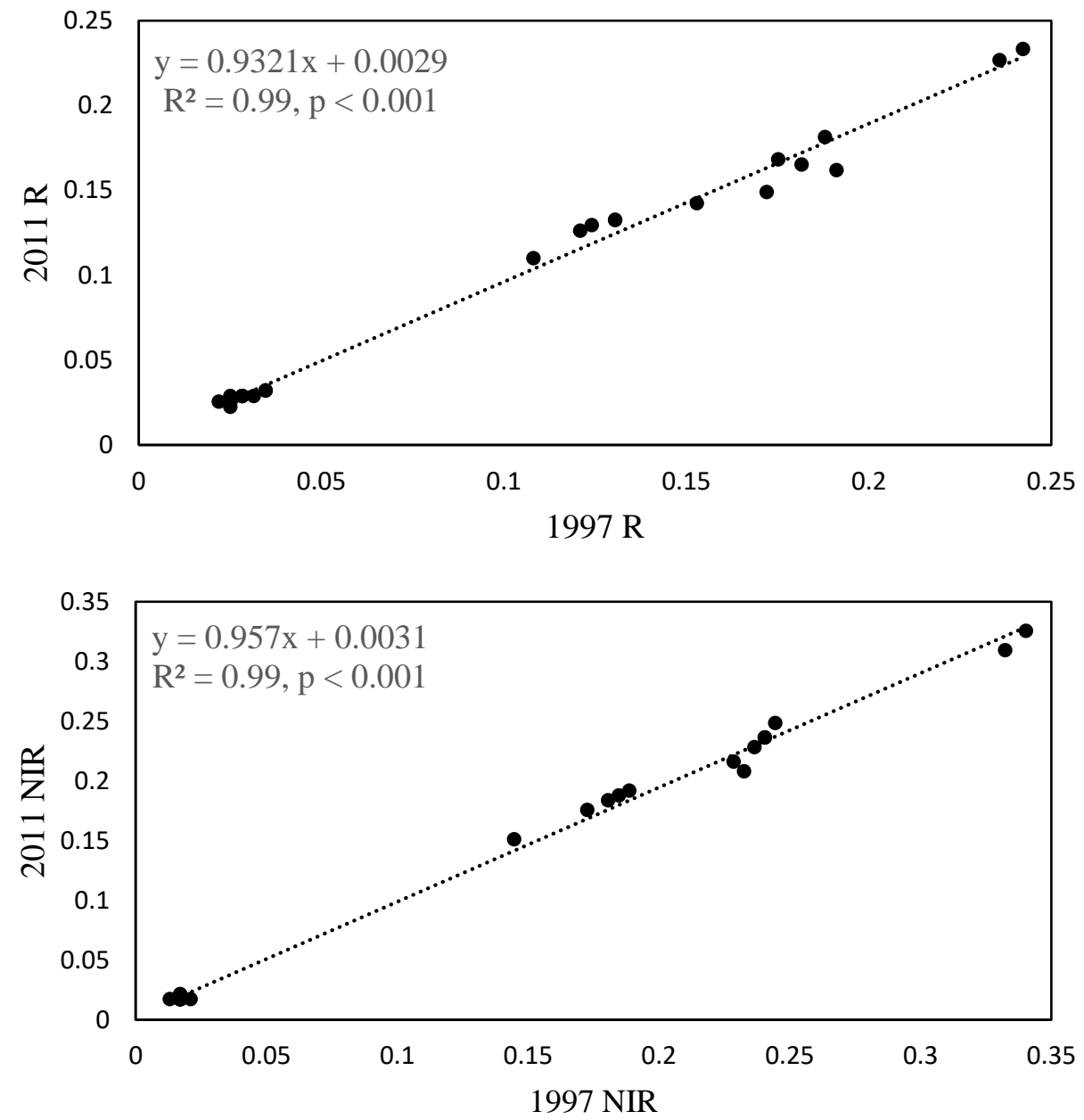

Figure C.1: Example linear regressions (R and NIR) between the 2011 base layer and July $30^{\text {th }}$, 1997, scene from frame 47-16, based on selected PIFs. Regression equations were used to create PIF normalized NDVI scenes. 


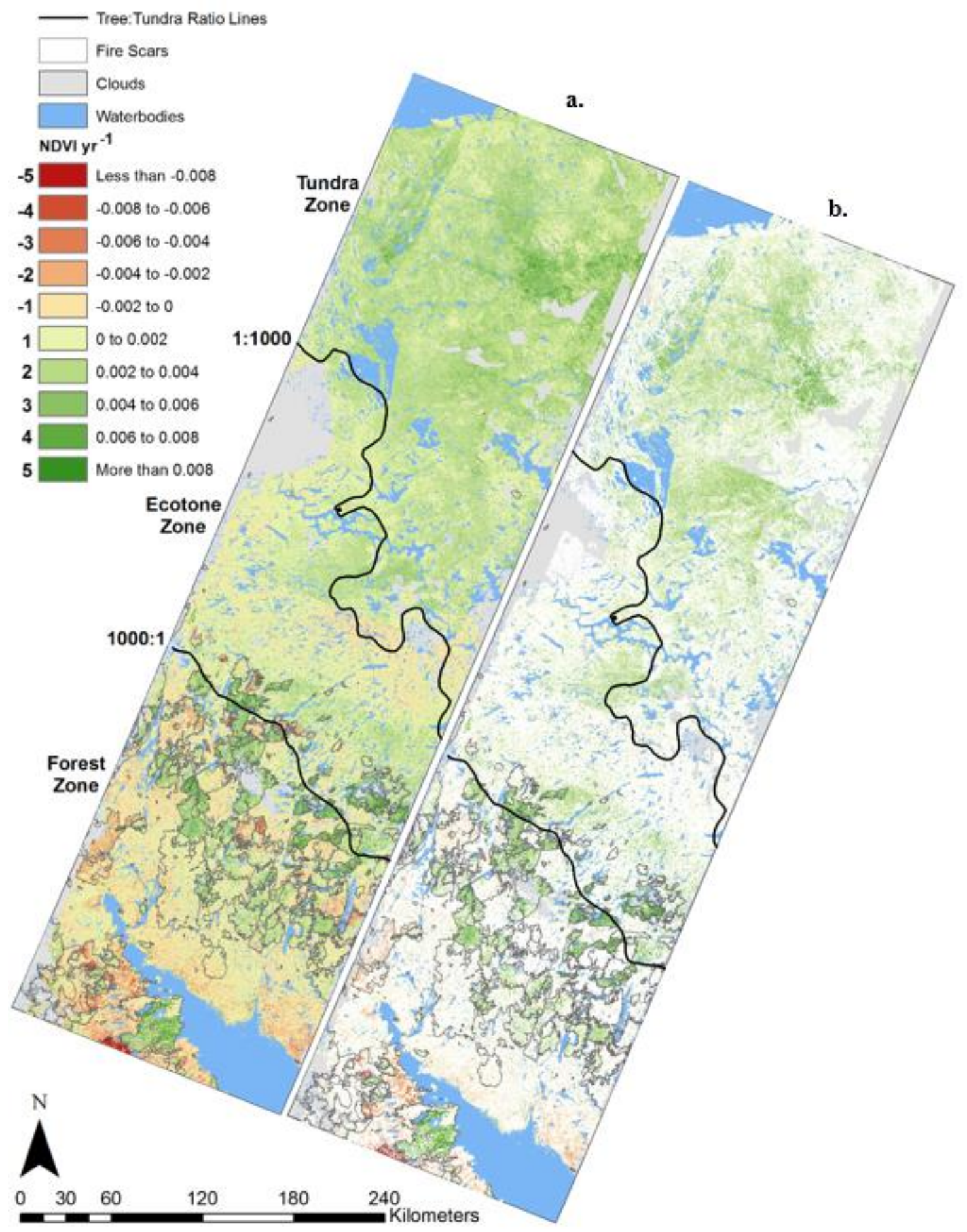

Figure C.2: Landsat PIF NDVI trends (1984-2016) from the study area as determined using ordinary least squares regression. NDVI trends were binned into 10 levels $(-5=$ most negative, $5=$ most positive $)$, as seen in the legend, for visualization purposes. (a) All NDVI trends. (b) Significant $(\mathrm{p}<0.05)$ greening and browning trends. Note consistency issues between Landsat frames (i.e., where trends drastically change in a line). 


\section{Appendix D}

\section{NDVI Trend Code}

' $\mathrm{R}$ ' Code used to create NDVI trend and significance rasters from NDVI data. Example here is from Landsat frame 47-15.

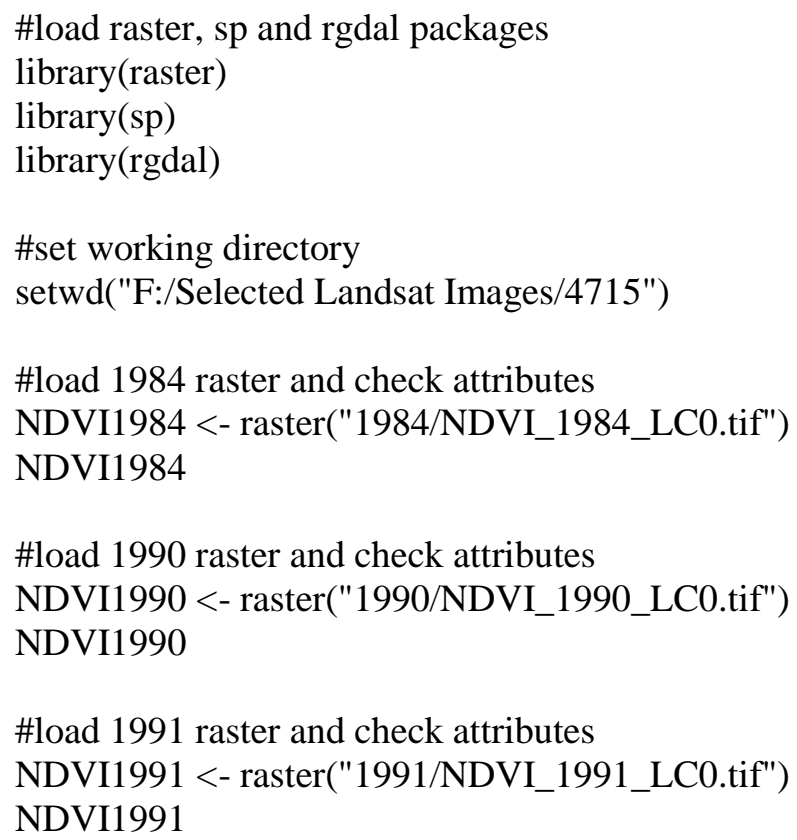

\#load 1992 raster and check attributes NDVI1992 <- raster("1992/NDVI_1992_LC0.tif") 
\#load 2016 raster and check attributes

NDVI2016 <- raster("2016 Corrected/C_NDVI_2016_1.tif")

NDVI2016

\#change 0 value to NA

NAvalue(NDVI1984) <- 0

NAvalue(NDVI1990) <- 0

NAvalue(NDVI1991) $<-0$

NAvalue(NDVI1992) <- 0

NAvalue(NDVI1996) <- 0

NAvalue(NDVI2002) $<-0$

NAvalue(NDVI2006) $<-0$

NAvalue(NDVI2011) $<-0$

NAvalue(NDVI2013) $<-0$

NAvalue(NDVI2016) <- 0

\#plot NDVI rasters

plot(NDVI1984, main = "1984")

plot(NDVI1990, main = "1990")

plot(NDVI1991, main $=" 1991 ")$

plot(NDVI1992, main = "1992")

plot(NDVI1996, main = "1996")

plot(NDVI2002, main = "2002")

plot(NDVI2006, main = "2006")

plot(NDVI2011, main = "2011")

plot(NDVI2013, main = "2013")

plot(NDVI2016, main = "2016")

\#create raster stack

NDVI4715 <- stack("1984/NDVI_1984_LC0.tif", "1990/NDVI_1990_LC0.tif", "1991/NDVI_1991_LC0.tif", "1992/NDVI_1992_LC0.tif", "1996/NDVI_1996_LC0.tif", "2002 Corrected/C_NDVI_2002.tif", "2006/NDVI_2006_LC0.tif", "2011/NDVI_2011_LC0.tif", "2013 Corrected/C_NDVI_2013_1.tif", "2016 Corrected/C_NDVI_2016_1.tif")

NDVI4715

plot(NDVI4715)

\#change 0 value to NA

NDVI4715_NA <- NDVI4715

NAvalue(NDVI4715_NA) $<-0$

plot(NDVI4715_NA)

\#write this raster stack to working directory

writeRaster(NDVI4715, "NDVI4715.tif", "GTiff")

writeRaster(NDVI4715_NA, "NDVI4715_NA.tif", "GTiff")

\#years variable

years <- c(1984, 1990, 1991, 1992, 1996, 2002, 2006, 2011, 2013, 2016) 


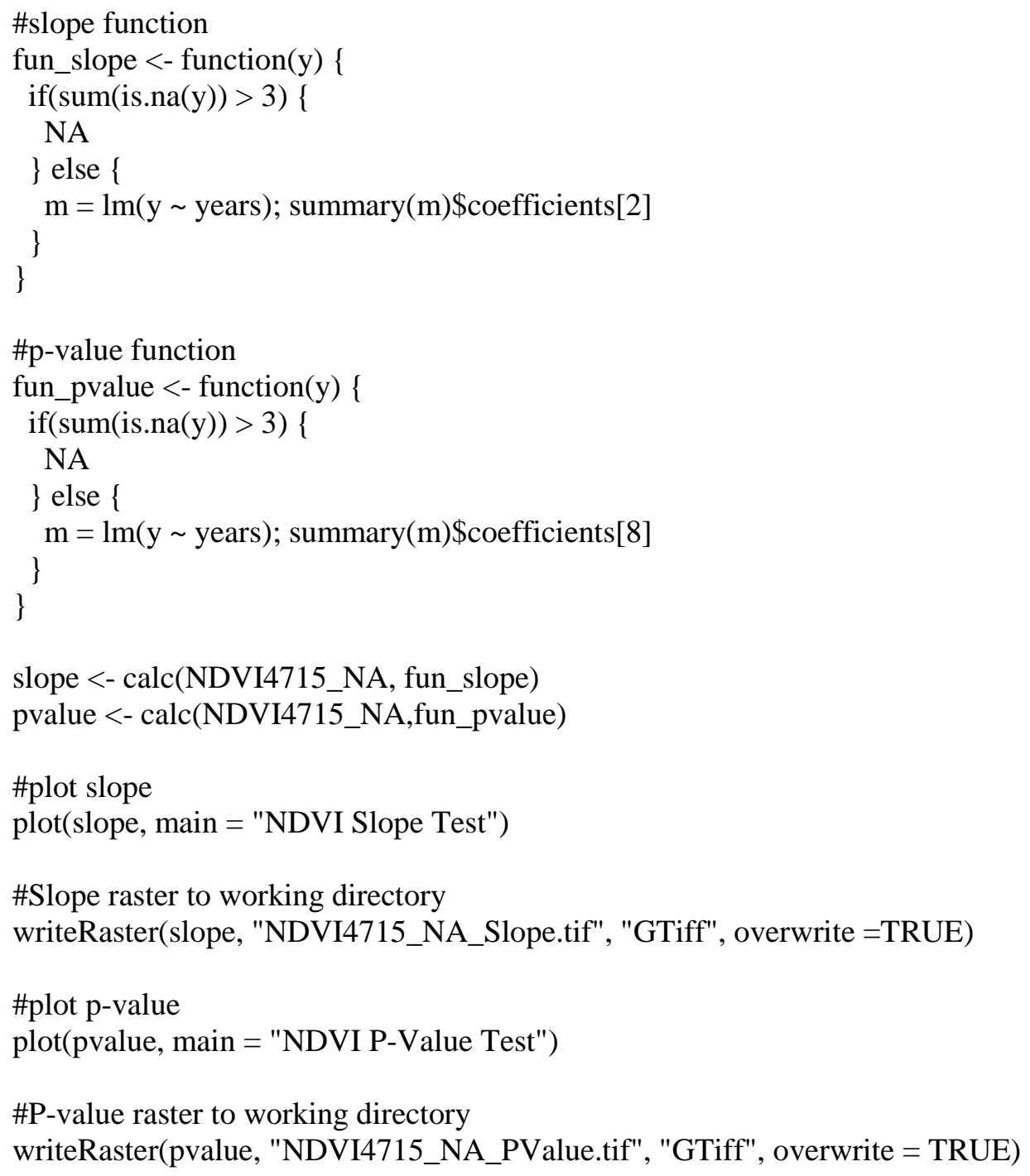




\section{Appendix E}

\section{Details on Environmental Variables}

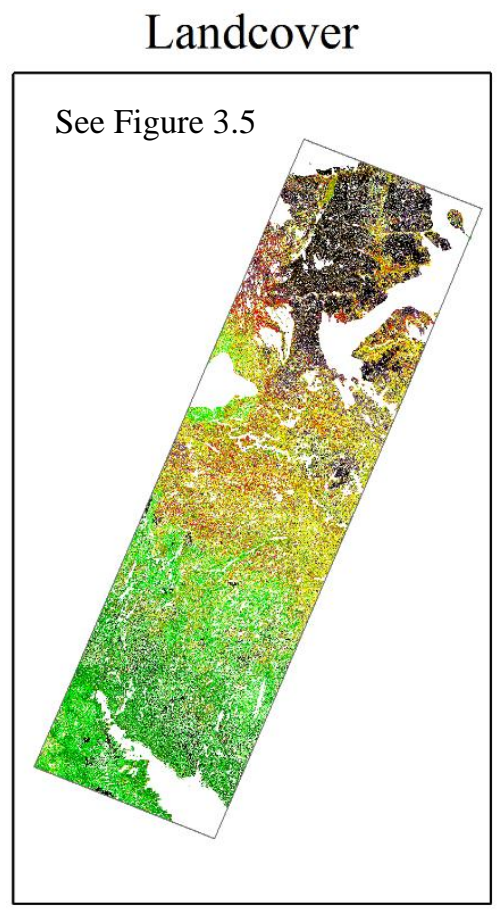

Major Lakes

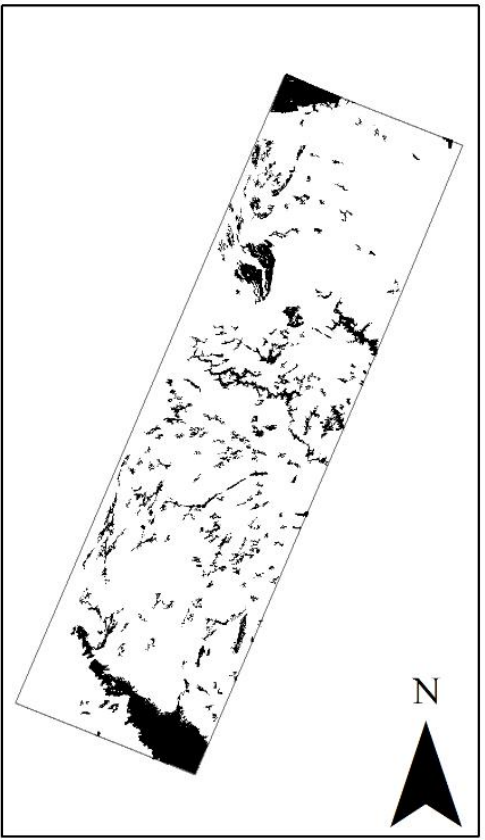

Elevation

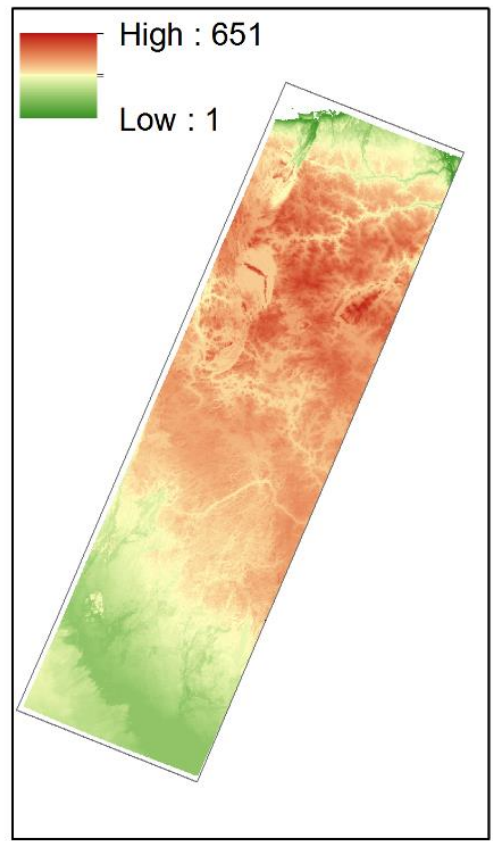

Temperature Change

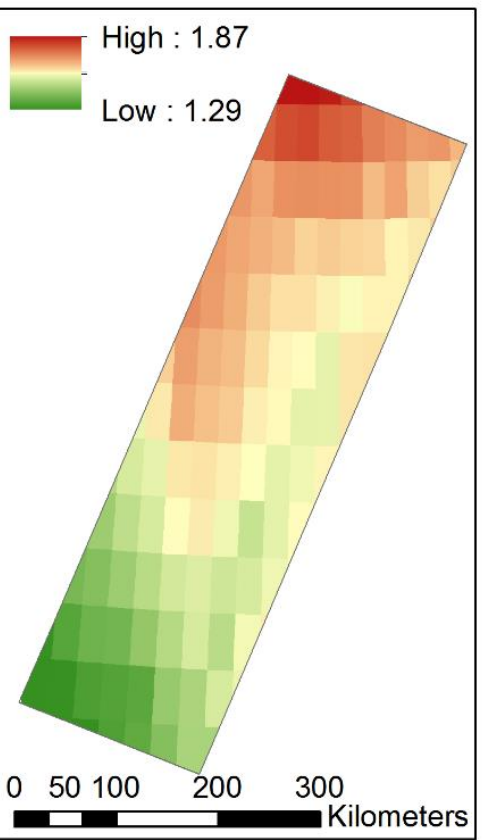

Drainage Systems

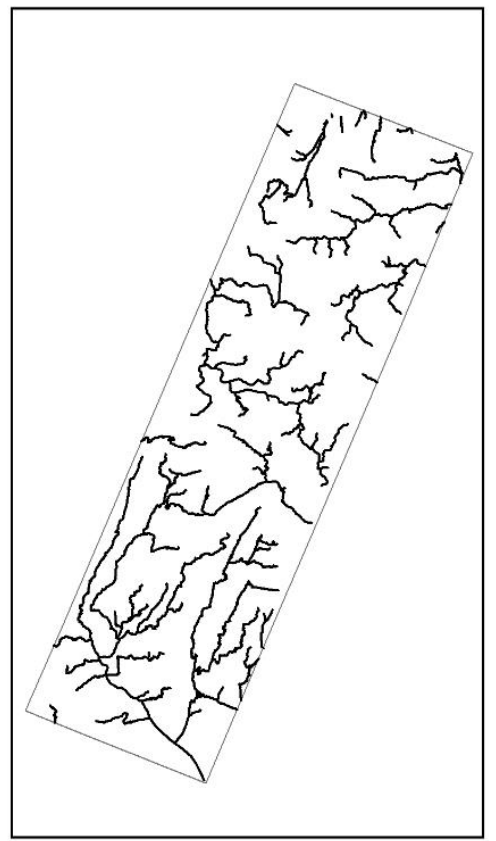

Precipitation Change

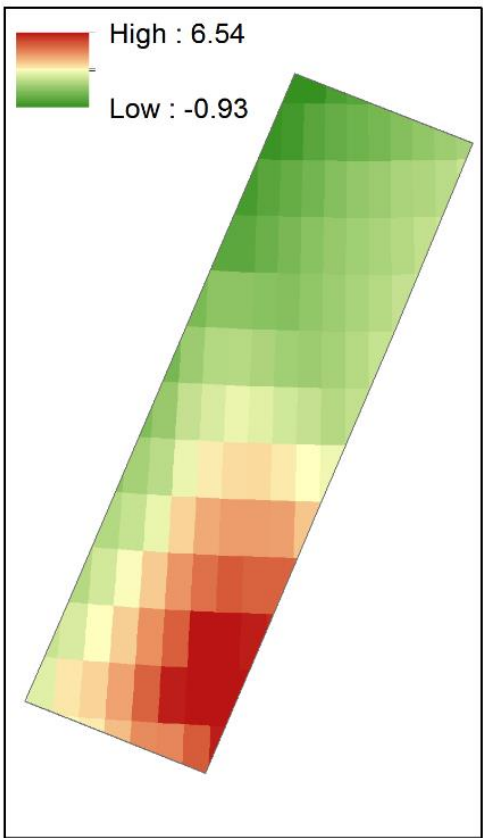

Figure E.1: Environmental variable raster layers. Drainage systems and major lakes shown as shapefiles used to create distance rasters. The study area is shown here for these six broad-scale variables. 


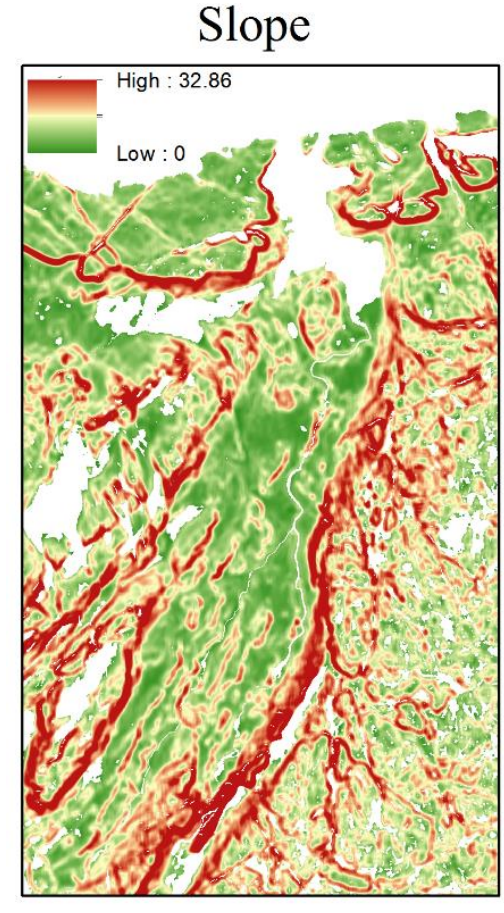

TWI

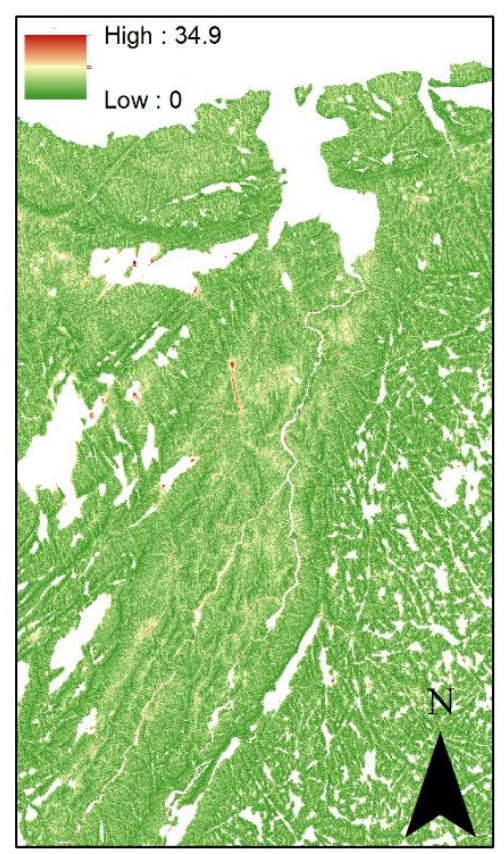

Aspect

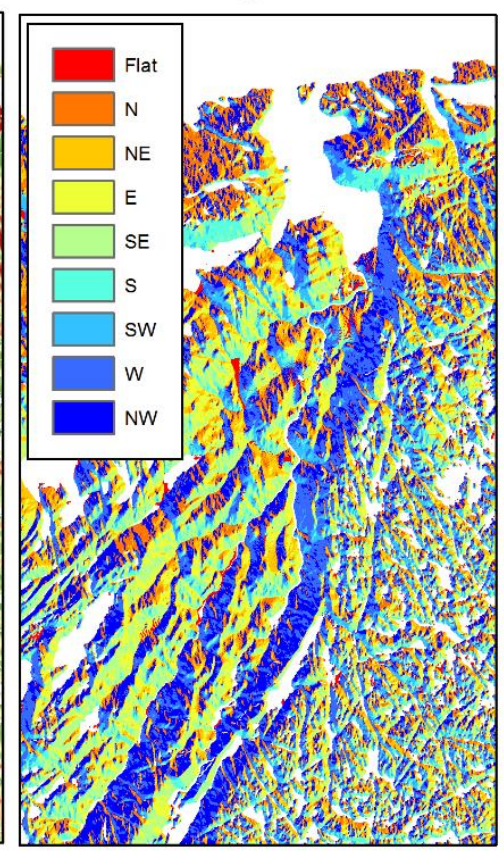

Rivers

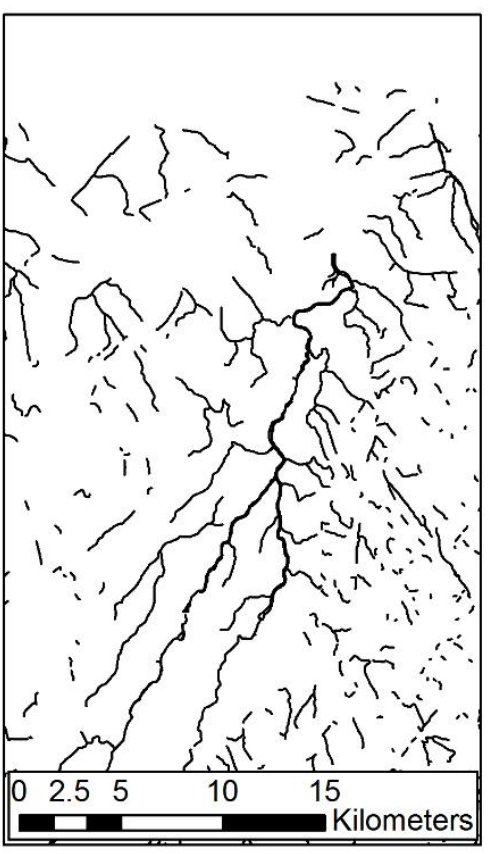

TPI

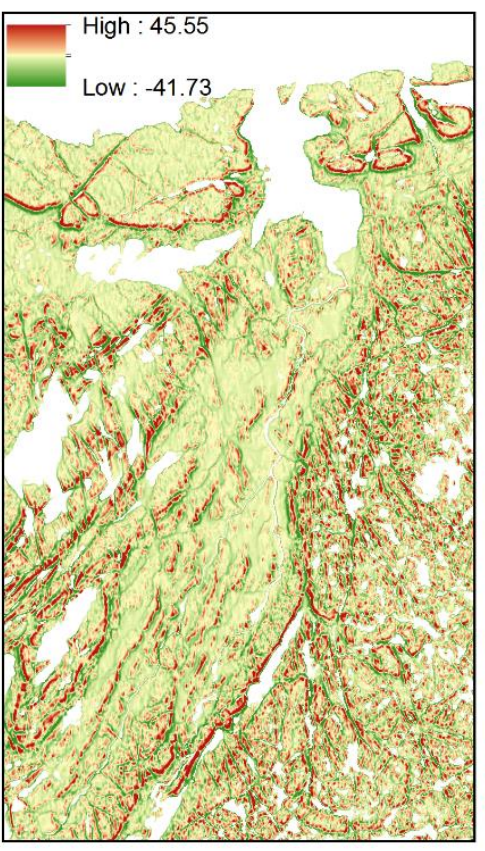

Lakes

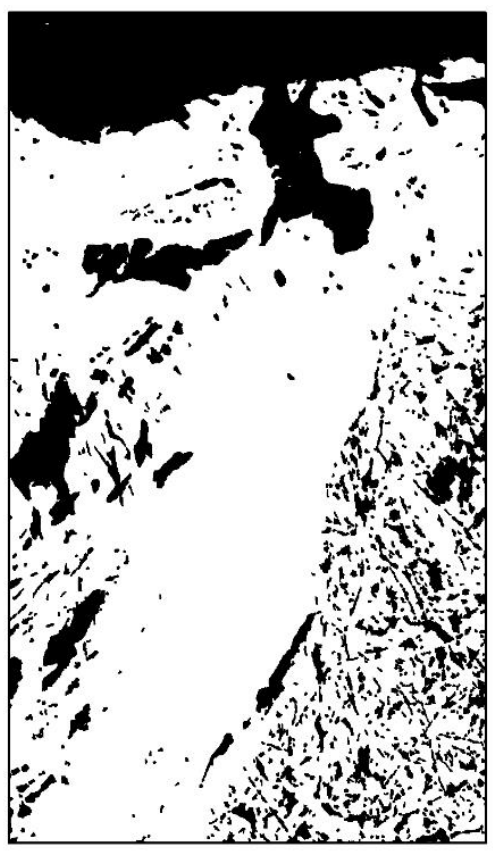

Figure E.2: Environmental variable raster layers. Rivers and lakes shown as shapefiles used to create distance raster layers. The area around the Tree River outlet into the Arctic Ocean is shown here for these six fine-scale variables. 


\section{Land cover Descriptions}

Class F: Forest - Shrubby Understory (6.7 \% of study area)

- Broad description: Dense (> 50\%) canopy cover boreal forest, shrub-dominated understory. Graminoids, lichens and mosses (wetter areas) are common groundcover.

- Forest Zone: Very common land-cover class (26.7 \%). High Boreal ecoregion: dense black spruce canopy (also white spruce, jack pine [Pinus banksiana], trembling aspen [Populus tremuloids] and paper birch), shrubby-feathermoss understory (Ecosystem Classification Report, 2012). Fire disturbance is common. Found throughout the zone, but most common in Great Slave Lake lowlands (esp. near west arm of Great Slave Lake and east of Yellowknife) and along the Emile and Yellowknife River.

- Ecotone Zone: Rare land-cover class (2.1\%). Mostly black spruce (some white spruce) dense canopies with shrub-dominated understories. Occupy lower slope positions and near shorelines (Ecosystem Classification Report, 2012) in southern portion of the zone (i.e., along Snare River system near Wekweètì, around Indin Lake near the abandoned Colomac Mine and southeast of Squalus Lake).

- Tundra Zone: Very rare land-cover class $(0.1 \%)$. Small black and white spruce forest stands along rivers and lakes in the extreme southern portion of the zone (i.e., near Little Marten Lake, south shore of Redrock Lake).
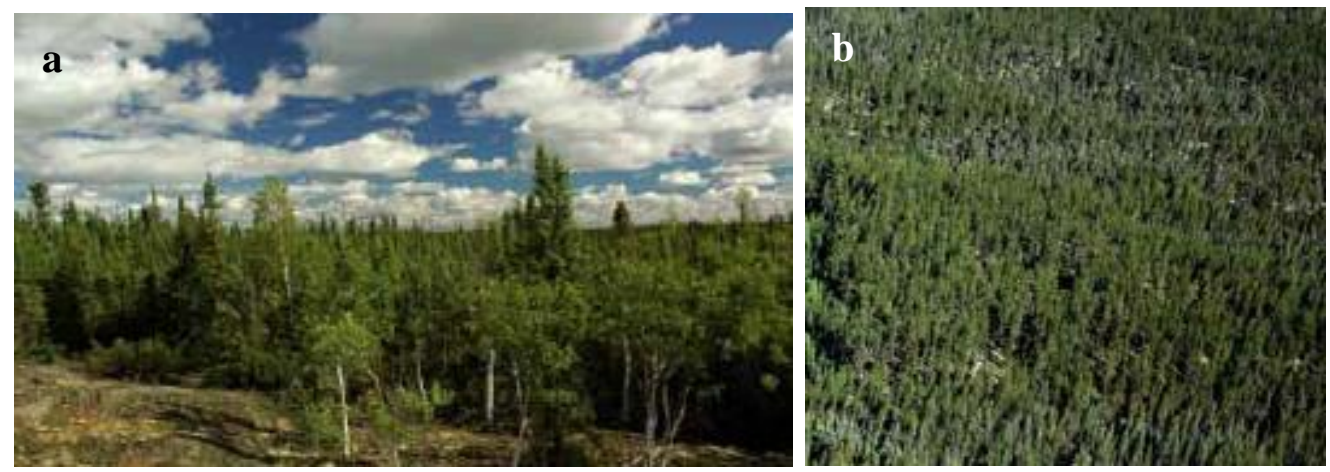

Figure E.3: Examples of F class. (a) Closed-canopy forest typical in the High Boreal Ecoregion of NWT. (b) Aerial view of this dense forest community. Photographs from Ecosystem Classification Report (2008). 
Class W: Woodland - Shrubby Understory (11.4\% of study area)

- Broad description: Open (<50\%) canopy cover boreal woodland, shrub-dominated understory. Trees shorter and thinner than F. Graminoids, lichens and mosses (wetter areas) are common groundcover. Differentiated from F mainly by a decrease in canopy cover and biomass of trees across the landscape.

- Forest Zone: Most common land-cover class (30.3\%). High Boreal and Low sub-Arctic ecoregion: black spruce canopy (also white spruce, jack pine, trembling aspen and paper birch), shrubby-feathermoss understory (Ecosystem Classification Report, 2012).

Generally occupies more exposed, higher slope positions than F. Found throughout the zone, but is most common near western arm of Great Slave Lake, surrounding bedrock outcrops north of Great Slave Lake and across the northern portions of the zone where F is less common.

- Ecotone Zone: Common land-cover class (13.2 \%). Mostly black spruce (some white spruce) open canopies with shrub-dominated understories. Occupies mid-slope and flat positions across south and east portions of the zone (i.e., around the Snare River system and areas west and east), as well as in the far north of zone (i.e., around the Coppermine River and west and south of Redrock Lake).

- Tundra Zone: Very rare land-cover class (1.5\%). Small black and white spruce forest stands near rivers, lakes and other sheltered areas in the southern portion of the zone (i.e., near Little Marten and Redrock lakes).
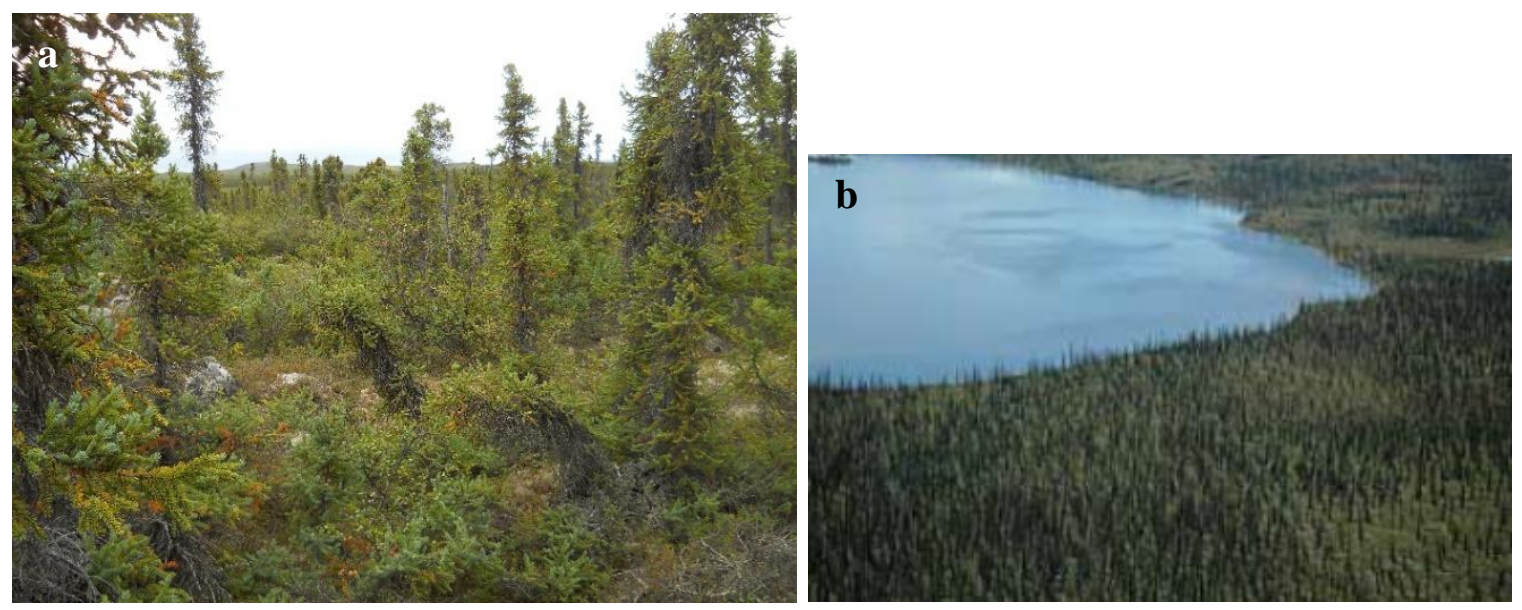

Figure E.4: Examples of W class. (a) Open-canopy woodland in the North Slave region of NWT, plot LF03. Photograph taken by Mitchell Bonney. (b). Open spruce woodlands, with dwarf-birch and lichen understory found throughout the High sub-Arctic ecoregion. Photograph from Ecosystem Classification Group (2008). 
Class LRW: Lichen-Rocky Woodland (8.8 \% of study area)

- Broad description: Open (> $50 \%$ ) canopy cover boreal woodland (lacking shrubby understory found in $\mathrm{F}$ and $\mathrm{W}$ ). Open-canopy of mostly spruce scattered in parkland-like landscape, usually on well-drained soils. Groundcover dominated by lichens, mosses and dwarf shrubs that are rarely more than $5 \mathrm{~cm}$ tall. Low density forest stands interspaced by lichen-covered boulder gardens and bedrock outcrops are also contained within this class.

- Forest Zone: Common land-cover class (18.2 \%). High Boreal and Low sub-Arctic ecoregion: lichen woodland/rock-lichen woodland with black spruce, white spruce, jack pine and paper birch on thin soils over bedrock (Ecosystem Classification Report, 2012). Often found between denser-canopy F/W and bedrock outcrops (LBT, SLV) that have not been colonized. Common across bedrock plains north of Great Slave Lake (i.e., Great Slave Upland HB ecoregion) and farther north close to the ecotone zone in lichendominated landscapes that are recovering from long-term fire disturbance (Girard et al., 2008).

- Ecotone Zone: Common land-cover class (9.7\%). Found mostly in southern portion of the zone in lichen-dominated areas near the Snare River system and areas west and east. Bedrock outcrops are less common in this zone, meaning this class is generally similar to Figure E.5a with tall white and black spruce trees (with some paper birch) scattered in a parkland landscape.

- Tundra Zone: Rare land-cover class (3.8\%). Mostly small, open patches of white and black spruce in rocky and lichen-dominated landscapes. Found mostly in extreme southern portions of the zone near Redrock Lake and south of Daring Lake. Some pixels in this class were mis-classified (esp. in areas where ridges cast shadows) and likely belong in shrubland classes.
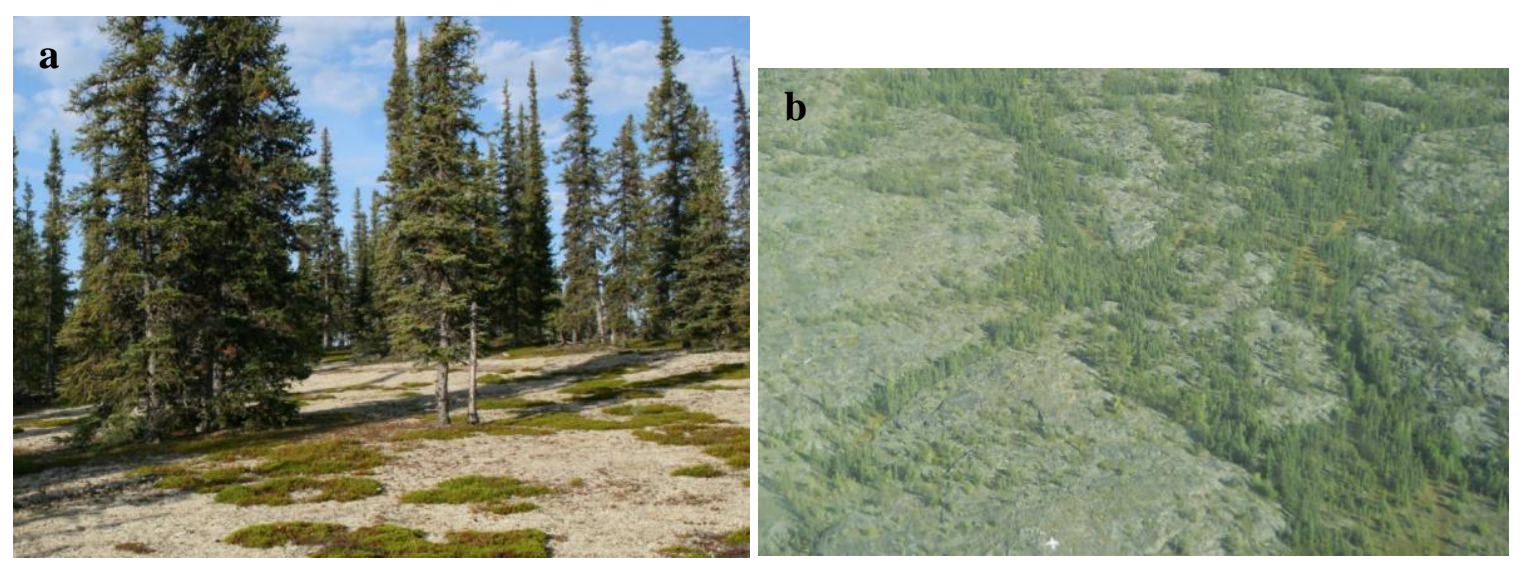

Figure E.5: Examples of LRW class. (a) Lichen-woodland of scattered tall white spruce on the west coast of Snare Lake north of Wekweètì, near plot SL03. Photograph taken by Greg King. (b) Bedrock-woodlands common north of Great Slave Lake. Photograph taken from the air just north of Yellowknife by Mitchell Bonney. 
Class DS: Dense Shrubland (7.3\% of study area)

- Broad description: Dense (> $50 \%$ ) canopy cover shrubland (mostly birch, with some willows and alder). Scattered trees present in some cases (but shrub cover is dominant). Dwarf shrubs and graminoids dominate the understory with lichen and moss groundcover.

- Forest Zone: Rare land-cover class (4.1\%). Dense canopies of tall $(\sim 1+\mathrm{m})$ shrubs with scattered black spruce, jack pine and paper birch often present. Found in wetter areas where tree cover is low. Most common in wetter areas surrounding Great Slave Lake.

- Ecotone Zone: Common land-cover class (15.4\%). Dense canopies of tall shrubs, sometimes with scattered black spruce present (Figure E.6a). Found in wetter sites across the zone (i.e., in broad band across the central portion, especially around Winter Lake, and off coast of Redrock Lake). This zone overlaps closely with the Snare Plain HS ecoregion, which has a higher percentage of wetlands than elsewhere in the High subArctic (Ecosystem Classification Report, 2008).

- Tundra Zone: Rare land-cover class (3.9\%). Dense canopies of shrubs $(\sim 50+\mathrm{cm})$ often found near waterbodies and other areas with wet moisture regimes. Found most commonly in sheltered areas marked as riparian corridors (i.e., the outlet of the Tree River into the Arctic Ocean [Figure E.6b], near the Hood and Burnside Rivers and near the north coast of Redrock Lake) on the CAVM (Walker et al., 2005).

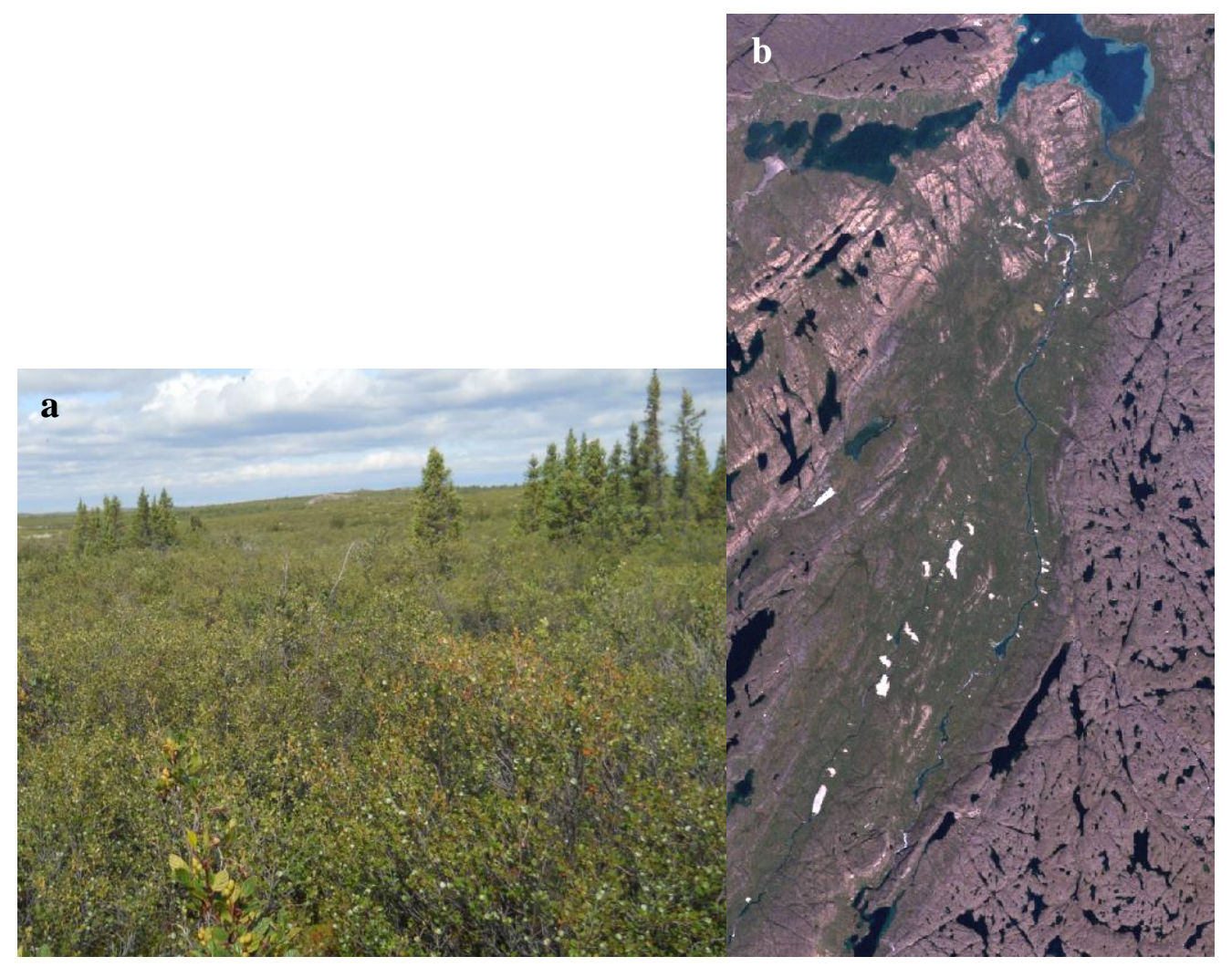

Figure E.6: Examples of DS class. (a) Dense $\sim 1 \mathrm{~m}$ shrubs, with some scattered black spruce trees, near Little Marten Lake (plot LM01). Photograph taken by Mitchell Bonney. (b) True color Landsat image of the Tree River outlet into the Arctic Ocean. Most pixels in this river valley were classified as DS. 
Class OS: Open Shrubland (13.6\% of study area)

- Broad description: Open ( $<50 \%$ ) canopy cover shrubland (mostly birch, with some willows and alder). Understory less dense than DS, with graminoids and dwarf berry shrubs most common.

- Forest Zone: Very rare land-cover class (1.4\%). Treeless, often wet, landscapes. Found in successional areas of recently drained lakes and floodplains near rivers. Most common in bedrock plains north of Great Slave Lake and in the far north of the zone.

- Ecotone Zone: Most common land-cover class (23.4\%). Nearly level terrain and presence of fine texture till veneers across this zone leads to development of continuous tundra cover with an open canopy of (mostly birch) low (below $<50 \mathrm{~cm}$ ) shrubs (Ecosystem Classification Report, 2008). Found across the zone, but most common in the north and east away from forested classes (i.e., east of Snare River system, around Redrock Lake).

- Tundra Zone: Common land-cover class (13.4\%). Similar vegetation structure as OS in the ecotone zone; forms main land cover of Point Upland and Contwoyto Upland Low Arctic South ecoregions in south of zone before entering Nunavut (Ecosystem Classification Report, 2012). Class structure mostly similar to CAVM class S1 (Erectdwarf shrub tundra), but also overlaps with S2 (low-shrub tundra) in some cases (Walker et al., 2005). Most common in southern portion of the zone south of Contwoyto Lake and along major drainage systems farther north.

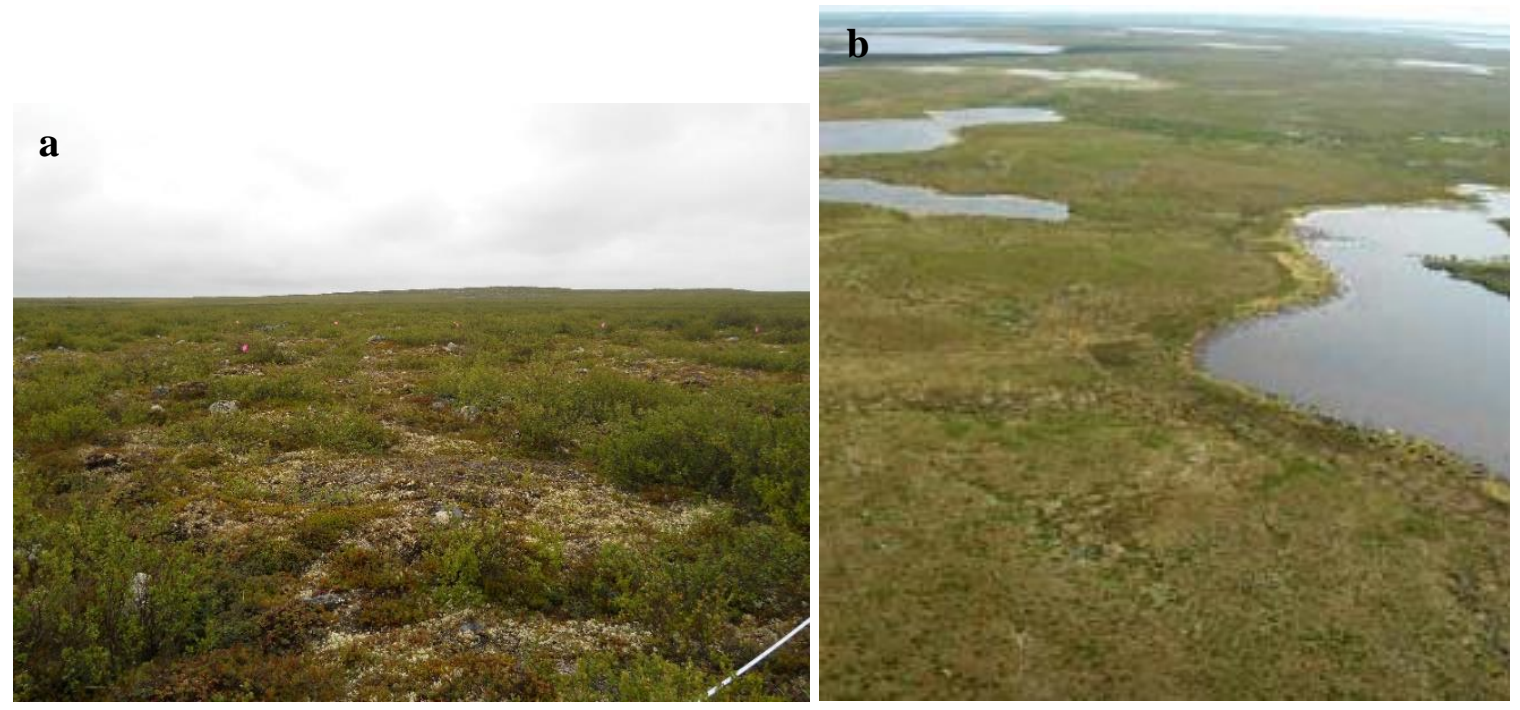

Figure E.7: Examples of OS class. (a) An open low erect-shrub (mostly birch) site with dwarf-berry shrubs and lichen understory, south of Big Lake (plot SC02). Photograph taken by Mitchell Bonney. (b) Nearly level terrain leads to low erect-shrub cover, with lichen groundcover, across the landscape. Photograph taken east of Lac De Gras, from Ecosystem Classification Report (2012). 


\section{Class LRS: Lichen-Rocky Shrubland (18.1\% of study area)}

- Broad description: Open $(<50 \%)$ density shrubland (mostly birch, with some willows and alder). Shrubs shorter and less densely packed than OS class. Boulders/bedrock and lichen are the most common groundcover between shrubs.

- Forest Zone: Rare land-cover class (6.6\%). Open-canopy low shrubs are dominant vegetation cover located in fractures (scattered trees likely present) between bedrock outcrops (Ecosystem Classification Report, 2008). Found mostly at the edges of upland bedrock outcrops as they transition to more sheltered forested classes in between. Most common in the bedrock plains north of Great Slave Lake (i.e., Great Slave Upland HB ecoregion).

- Ecotone Zone: Common land-cover class (12.1\%). Open-canopy low birch $(<50 \mathrm{~cm})$ shrubs (some alders, willows and small krummholz spruce sometimes present) interspersed between extensive boulder gardens (Figure E.8a). Lichen dominates the groundcover between shrubs and on boulders. Found scattered throughout zone in more exposed areas upslope of denser shrubland and forested classes.

- Tundra Zone: Most common land-cover class (27.1\%). Found throughout the zone, but most common at the edges of major river valleys as the landscape transitions to less vegetated classes (LBT, SLV). Also common in upland regions across the southern portion of the zone.

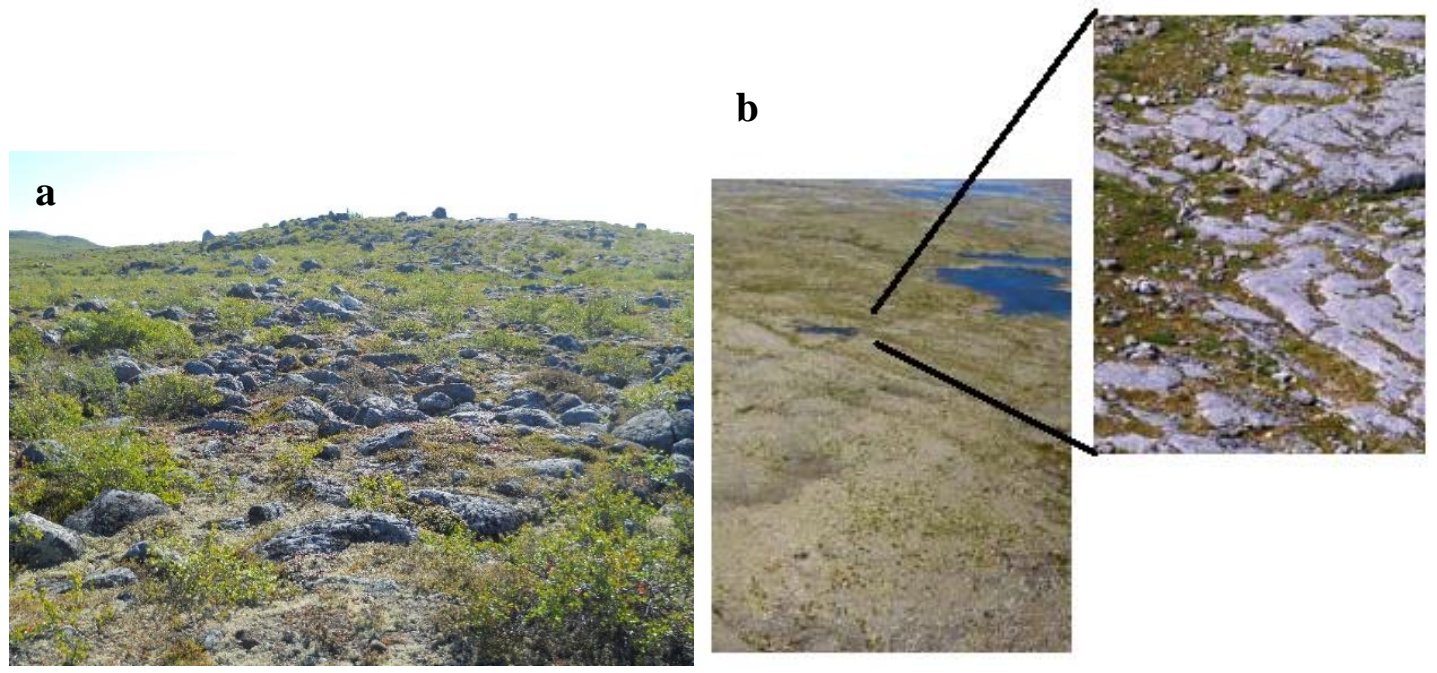

Figure E.8: Examples of LRS class. (a) Low $(<50 \mathrm{~cm})$ birch shrub site strewn with boulders, lichendominated groundcover. Found east of Lastfire Lake (plot LF05). Photograph taken by Mitchell Bonney. (b) Aerial photographs from west of Lac de Gras show bedrock and lichen-dominated areas interspersed by low shrubs (Ecosystem Classification Report, 2012). 


\section{Class GT: Graminoid Tundra - Moist (13.5\% of study area)}

- Broad description: Graminoid (i.e., grasses, rushes, non-tussock sedges) dominated landscapes. Low shrubs common but not dominant. Moss is the most common groundcover, but lichen is also present. Areas are usually moist with water table close to surface and small pockets of water often present.

- Forest Zone: Very rare land-cover class $(0.5 \%)$. Found mostly in Great Slave Plain and Great Slave Lowland High Boreal ecoregions aroundof the west arm of Great Slave Lake, in sedge-dominated calcium-rich wetland fens that do not support tree growth (Ecosystem Classification Report, 2008; 2009). This area is dotted with many small marl lakes that support these wetlands.

- Ecotone Zone: Very common land-cover class (21.3\%). Graminoid tundra, often with scattered birch and willow shrubs, with wet moss and lichen groundcover. Most common in western portions of the zone (west of Snare River system and south of Redrock Lake). This area corresponds to the Snare Plain HS ecoregion, which is known for its extensive wetlands near the thousands of small lakes in the region (Ecosystem Classification Report, 2012).

- Tundra Zone: Common land-cover class (14.8\%). Corresponds in both vegetation structure and geographic location to CAVM class G3 (non-tussock sedge, dwarf-shrub, moss tundra) within the graminoid tundra group (Walker et al., 2005). Found mostly west of Takijug Lake (Figure E.9b) and in scattered peaty-wetland areas near lakes and rivers across the zone.
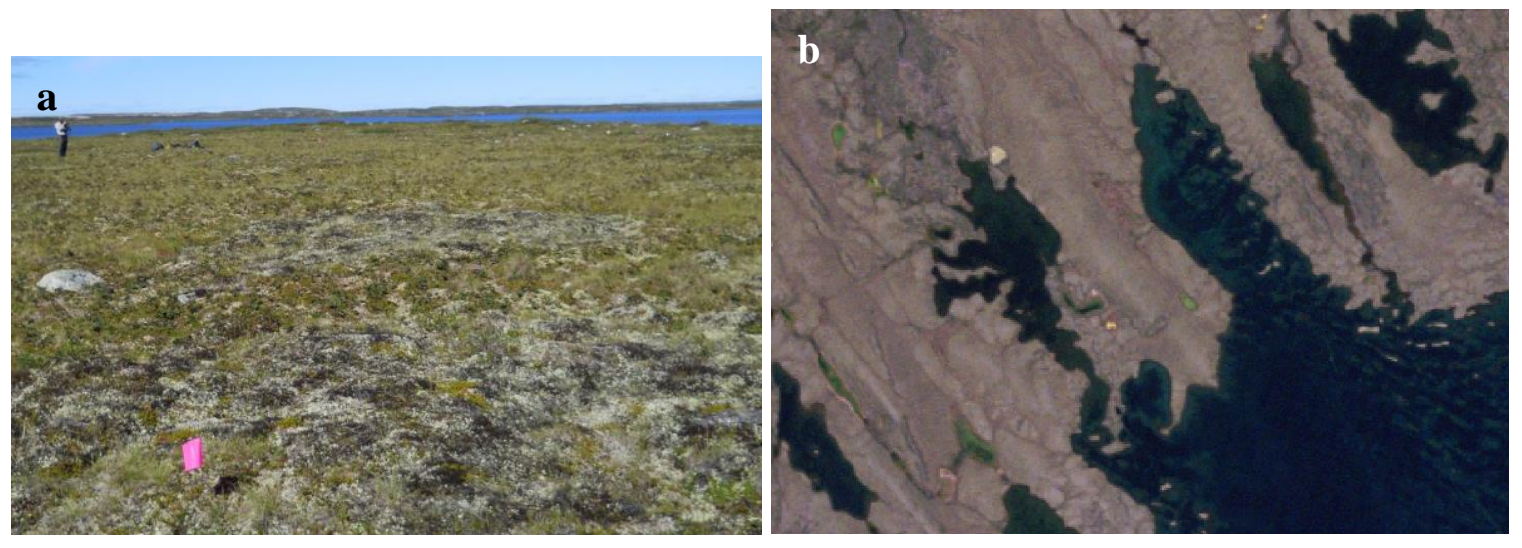

Figure E.9: Examples of GT class. (a) Graminoid-dominated site at an island on Big Lake, with some dwarf shrubs and lichen groundcover (plot BL03). Photograph taken by Mitchell Bonney. (b) True color Landsat image of the lowlands west of Takijuq Lake. Most pixels in this area were classified as GT and are located in the G3 class in the CAVM. 


\section{Class LBT: Lichen-Barren Tundra (12.4\% of study area)}

- Broad description: Exposed consolidated sediments (i.e., bedrock, boulder gardens) interspersed with lichen-dominated areas most commonly (Walker et al., 2005). Low shrubs and other tundra vegetation are present (i.e., more sheltered locations), but are not dominant.

- Forest Zone: Rare land-cover class (4.3\%). Represents bedrock outcrops (Figure E.10a) found across Great Slave Upland HB ecoregion (Ecosystem Classification Report, 2008). Dominant vegetation are lichens and other low growing vegetation. Shrubs and trees are rare.

- Ecotone Zone: Very rare land-cover class (0.8\%). Represents bedrock outcrops similar to what is found in forest zone, as well as rock gardens located where river water levels have dropped (Figure E.10b). Found scattered in small patches across the zone.

- Tundra Zone: Very common land-cover class (23.3\%). Corresponds closely in both vegetation structure and geographic location to CAVM class B2 (Cryptogam barren complex) within the barrens group (Walker et al., 2005; Figure E.10c). Defined as areas of exposed rock and lichens with tundra vegetation (i.e., graminoids, low shrubs) found in more sheltered areas.

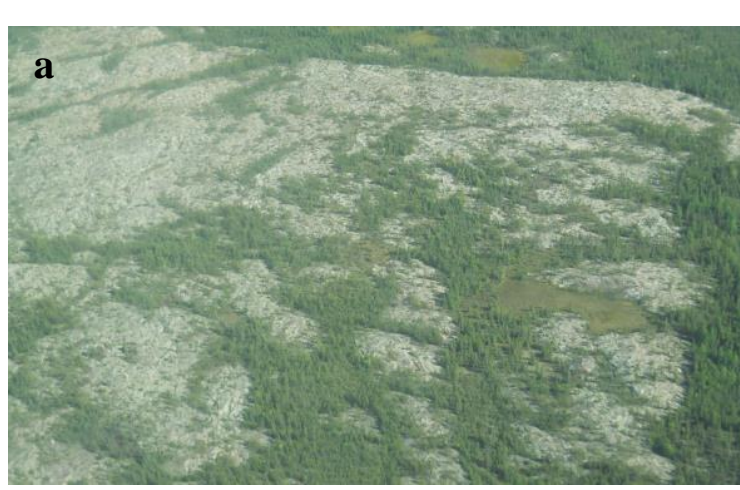

\section{b}
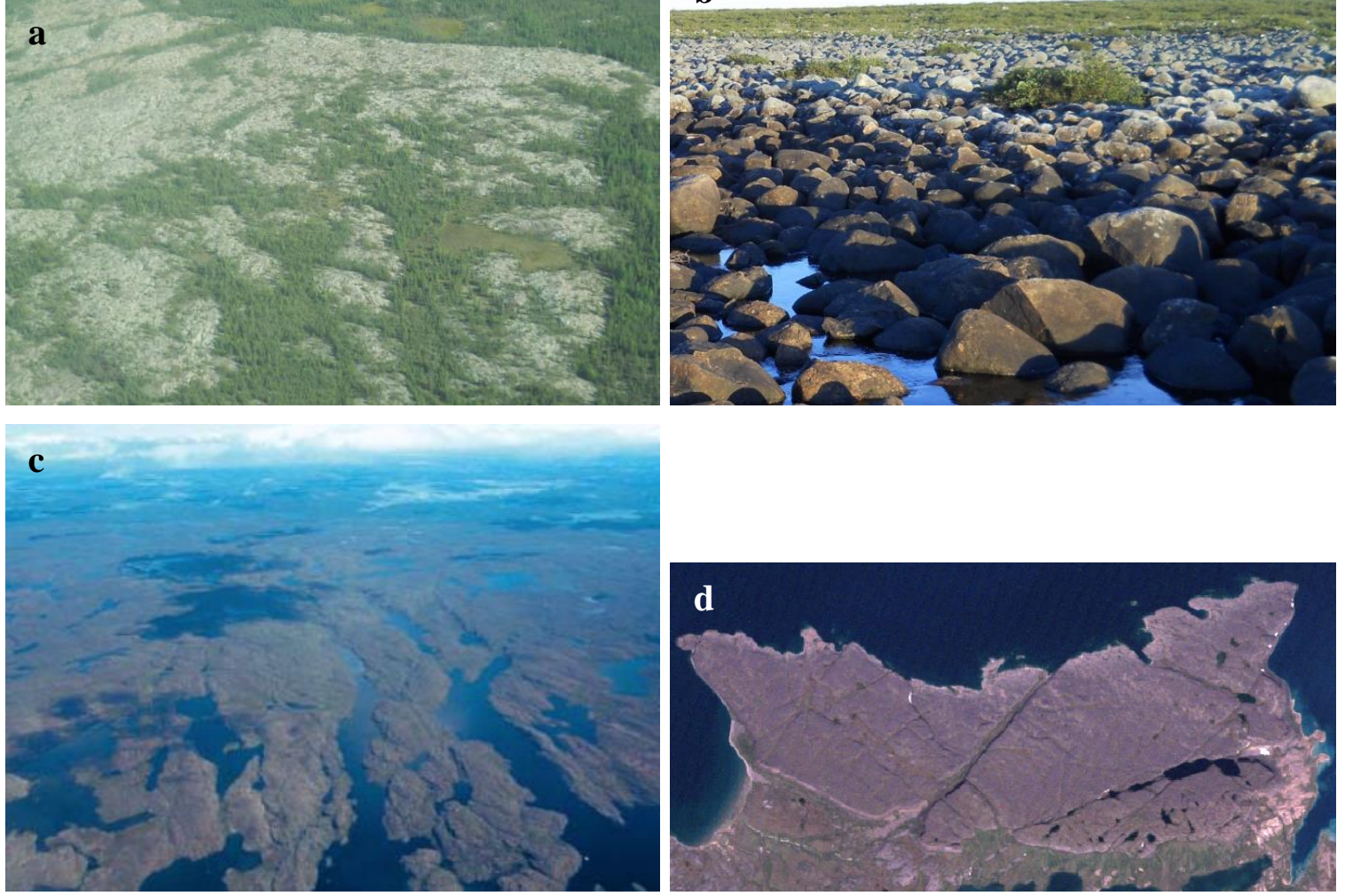

Figure E.10: Examples of the LBT class. (a) Bedrock outcrops (top left corner) common in the Great Slave Upland HB ecoregion. Photograph taken from the air just north of Yellowknife by Mitchell Bonney. (b) Boulder garden, with small patches of shrubs interspersed, where the water level of rivers has dropped. Photograph taken south of Big Lake by Mitchell (point of interest LMN_Boulder2). (c) CAVM Class B2 landscape located near the Daring Lake Tundra Ecosystem Research Station (Walker et al., 2005). (d) True color Landsat image of large cliffs located near the outlet of the Tree River. Most pixels in this area were classified as LBT. 
Class SLV: Sediments - Low Vegetation (8.1\% of study area)

- Broad description: Exposed unconsolidated sediments (i.e., sand and gravel) interspersed with low vegetation. Low vegetation mostly consists of lichens and dwarf shrubs. Erect shrubs and scattered trees can be found (e.g., on eskers), but are not dominant. Some class overlap with LBT.

- $\quad$ Forest Zone: Rare land-cover class (7.8 \%). Represents low vegetation outcrops across Great Slave Upland HB ecoregion (Ecosystem Classification Report, 2008). More often found in areas with exposed grained sediments and lichen, rather than bedrock and lichen. Built-up areas and excavation sites are in this class (Figure E.11a).

- Ecotone Zone: Very rare land-cover class (1.9\%). Represents eskers (i.e., glacial landforms consisting of long and narrow ridges of unconsolidated sediments) found scattered throughout the zone (Ecosystem Classification Report, 2008). Eskers can be many kilometers in length but are rarely more than $100 \mathrm{~m}$ wide. Low vegetation (dwarf shrubs, lichens) can be found on eskers, as well as krummholz spruce trees in many locations (Figure E.11b,c).

- Tundra Zone: Common land-cover class (12\%). Found mostly in areas classified as B2 (Cryptogam barren complex) within the barrens group of the CAVM (Walker et al., 2005). Differentiated from LBT in that this class is more often found in areas closer to waterbodies. It is likely these areas have more exposed unconsolidated sediments and lichens (rather than bedrock and lichens as in LBT).
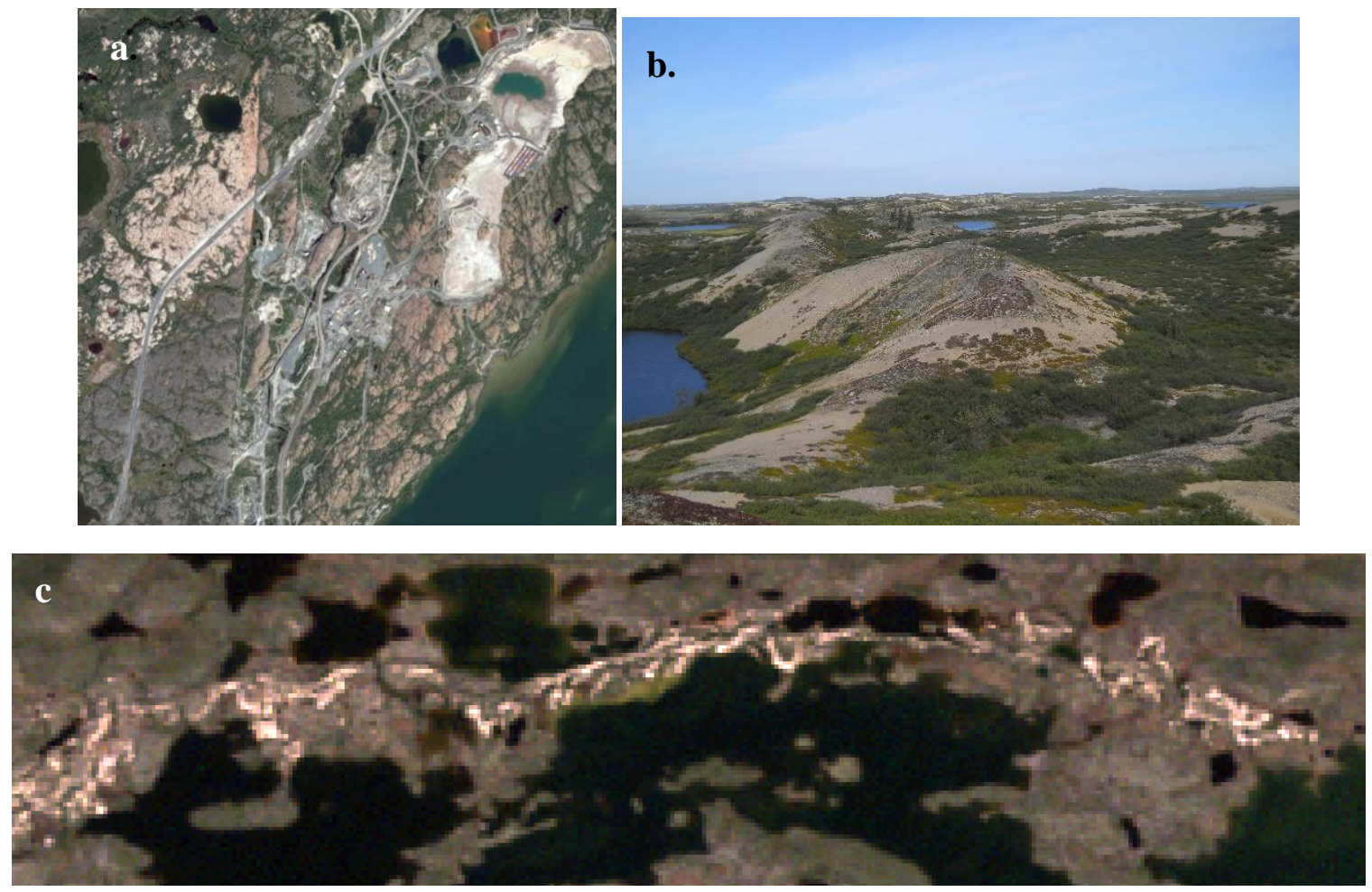

Figure E.11: Examples of the SLV class. (a) Built-up areas, excavation sites and some bedrock outcrops near Yellowknife were classified as SLV. (b) Eskers located on the north end of Little Marten Lake. (c) True color Landsat image of a long esker located west of Big Lake. 


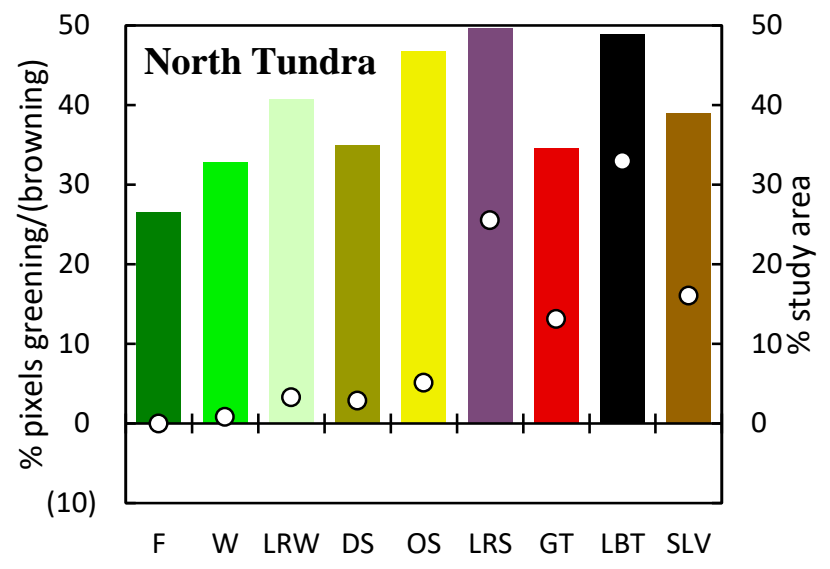

Figure E.12: Percentage of Landsat pixels with significant NDVI trends in the northern portions of the tundra zone, where the most greening has occurred. Values above 0 indicate greening while values below 0 (in parenthesis) indicate browning. The percentage of the zone in question that is comprised by each land-cover class is indicated as points plotted against the right y-axis. Land-cover classes are colored as in Figure 3.5. 


\section{Appendix F}

\section{Random Forest Code and Other Partial Dependence Plots}

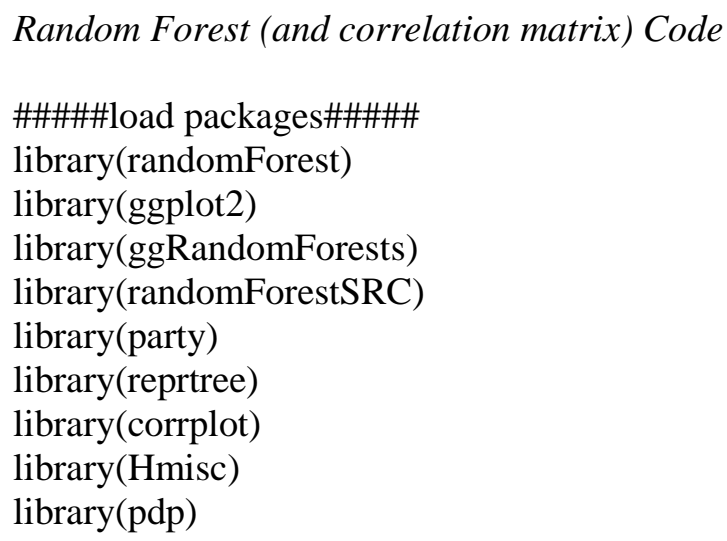

Random Forest (and correlation matrix) Code

\#\#\#\#\#load packages\#\#\#\#\#

library(randomForest)

library(ggplot2)

library(ggRandomForests)

library(randomForestSRC)

library(party)

library(reprtree)

library(corrplot)

library(Hmisc)

library(pdp)

\#\#\#\#\#define workspace\#\#\#\#

setwd("E:/NDVI Trend Analysis/FINAL TABLE/Raster2Point")

sample_600k_100 <-read.delim("sample_600k_100.txt")

sample_600k_100

sample_600k_100_F <-read.delim("sample_600k_100_F.txt")

sample_600k_100_F

sample_600k_100_E <-read.delim("sample_600k_100_E.txt")

sample_600k_100_E

sample_600k_100_T <- read.delim("sample_600k_100_T.txt")

sample_600k_100_T

\#\#\#\#\#correlation matrix\#\#\#\#

cor600k_100 <-cor(sample_600k_100)

round(cor600k_100, 2)

cor600k_NDVI <-cor(sample_600k_100[ , c(3:5)])

round(cor600k_NDVI, 2)

corrplot.mixed(cor600k_NDVI)

cor600k_Vars <- cor(sample_600k_100[ , -c(4:9, 12, 14, 15, 21, 22)])

round(cor600k_Vars, 2)

corrplot.mixed(cor600k_Vars)

corrplot(cor600k_Vars, method = "circle")

corrplot(cor600k_100, method = "number")

corrplot.mixed(cor600k_100)

\#with pvalues\#

cor600k_Vars2 <-rcorr(as.matrix(sample_600k_100[, -c(4:9,14,15, 21, 22)])) 
cor600k_Vars2

cor600k_Vars $2 \$ \mathrm{r}$

cor600k_Vars $2 \$ P$

corrplot(cor600k_Vars, type = "upper", tl.col = "black", tl.srt =45)

colnames(cor600k_Vars2\$r) <- c("easting", "northing", "ndvi yr-1", "elev", "slope", "aspect", "TPI", "TWI", "lakes", "rivers", "mlakes", "drainages", "precip", "temp")

rownames(cor600k_Vars2\$r) <- c("easting", "northing", "ndvi yr-1", "elev", "slope", "aspect", "TPI", "TWI", "lakes", "rivers", "mlakes", "drainages", "precip", "temp")

$\operatorname{par}(\mathrm{xpd}=\mathrm{TRUE})$

corrplot(cor600k_Vars2\$r, type $=$ "upper", method $=$ "square", p.mat $=$ cor600k_Vars2\$P, sig.level $=0.01$, insig $=$ "pch", tl.col $=$ "black", tl.srt $=45$, mar $=c(1,0,3,0)$, diag $=$ TRUE $)$

\#\#\#

cor600k_100_F <-cor(sample_600k_100_F)

round(cor600k_100_F, 2)

cor600k_100_E <-cor(sample_600k_100_E)

round(cor600k_100_E, 2)

cor600k_100_T <- cor(sample_600k_100_T)

round(cor600k_100_T, 2)

\#\#\#\#\#set variables to categories\#\#\#\#

sample_600k_100\$LANDCOVER <- as.factor(sample_600k_100\$LANDCOVER)

sample_600k_100\$ASPECT <- as.factor(sample_600k_100\$ASPECT)

sample_600k_100_F\$LANDCOVER <- as.factor(sample_600k_100_F\$LANDCOVER)

sample_600k_100_F\$ASPECT <- as.factor(sample_600k_100_F\$ASPECT)

sample_600k_100_E\$LANDCOVER <- as.factor(sample_600k_100_E\$LANDCOVER)

sample_600k_100_E\$ASPECT <- as.factor(sample_600k_100_E\$ASPECT)

sample_600k_100_T\$LANDCOVER <- as.factor(sample_600k_100_T\$LANDCOVER)

sample_600k_100_T\$ASPECT <- as.factor(sample_600k_100_T\$ASPECT)

\#\#\#\#\#randomForest\#\#\#\#\#

variablesrf $=$ NDVI_C $\sim$ LANDCOVER + ELEVATION + SLOPE + ASPECT + TPI + TWI + LAKE + RIVER + MAJLAKE + MAJRIVER + PRECIP + TEMP

rf600k_100_0_500_4_100 <-randomForest $($ variablesrf, data $=$ sample_600k_100, ntree $=500$, nodesize $=100$, mtry $=4$, importance $=$ TRUE)

print(rf600k_100_0_500_4_100)

round(importance(rf600k_100_0_500_4_100), 3) 
rf600k_100_F_0_500_4_100 <-randomForest $($ variablesrf, data $=$ sample_600k_100_F, ntree $=$ 500 , nodesize $=100$, mtry $=4$, importance $=$ TRUE)

print(rf600k_100_F_0_500_4_100)

round(importance(rf600k_100_F_0_500_4_100), 3)

rf600k_100_E_0_500_4_100 <-randomForest $($ variablesrf, data $=$ sample_600k_100_E, ntree $=$ 500 , nodesize $=100$, mtry $=4$, importance $=$ TRUE)

print(rf600k_100_E_0_500_4_100)

round(importance(rf600k_100_E_0_500_4_100), 3)

rf600k_100_T_0_500_4_100 <-randomForest $($ variablesrf, data $=$ sample_600k_100_T, ntree $=$ 500 , nodesize $=100$, mtry $=4$, importance $=$ TRUE)

print(rf600k_100_T_0_500_4_100)

round(importance(rf600k_100_T_0_500_4_100), 3)

\#\#\#Save/Load randomForests\#\#\#

save(rf600k_100_0_500_4_100, file = "rf_600k_100_0_500_4_100.RData")

load("rf_600k_100_0_500_4_100.RData")

print(rf600k_100_0_500_4_100)

save (rf600k_100_F_0_500_4_100, file = "rf_600k_100_F_0_500_4_100.RData")

load("rf_600k_100_F_0_500_4_100.RData")

print(rf600k_100_F_0_500_4_100)

save $(r f 600 k$ 100_E_0_500_4_100, file = "rf_600k_100_E_0_500_4_100.RData")

load("rf_600k_100_E_0_500_4_100.RData")

print(rf600k_100_E_0_500_4_100)

save(rf600k_100_T_0_500_4_100, file = "rf_600k_100_T_0_500_4_100.RData")

load("rf_600k_100_T_0_500_4_100.RData")

print(rf600k_100_T_0_500_4_100)

\#\#\#Plot randomForest outputs\#\#\#

plot(rf600k_100_0_500_4_100)

varImpPlot(rf600k_100_0_500_4_100)

plot(rf600k_100_F_0_500_4_100)

varImpPlot(rf600k_100_F_0_500_4_100)

plot(rf600k_100_E_0_500_4_100)

varImpPlot(rf600k_100_E_0_500_4_100)

plot(rf600k_100_T_0_500_4_100)

varImpPlot(rf600k_100_T_0_500_4_100)

\#\#\#PDs\#\#\#

partialPlot(rf600k_100_0_500_4_100, sample_600k_100, LANDCOVER)

partialPlot(rf600k_100_0_500_4_100, sample_600k_100, TEMP)

partialPlot(rf600k_100_0_500_4_100, sample_600k_100, MAJRIVER)

partialPlot(rf600k_100_0_500_4_100, sample_600k_100, MAJLAKE) 
partialPlot(rf600k_100_0_500_4_100, sample_600k_100, ELEVATION) partialPlot(rf600k_100_0_500_4_100, sample_600k_100, PRECIP) partialPlot(rf600k_100_0_500_4_100, sample_600k_100, LAKE) partialPlot(rf600k_100_0_500_4_100, sample_600k_100, RIVER) partialPlot(rf600k_100_0_500_4_100, sample_600k_100, SLOPE) partialPlot(rf600k_100_0_500_4_100, sample_600k_100, ASPECT) partialPlot(rf600k_100_0_500_4_100, sample_600k_100, TWI) partialPlot(rf600k_100_0_500_4_100, sample_600k_100, TPI)

partialPlot(rf600k_100_F_0_500_4_100, sample_600k_100_F, LANDCOVER) partialPlot(rf600k_100_F_0_500_4_100, sample_600k_100_F, TEMP) partialPlot(rf600k_100_F_0_500_4_100, sample_600k_100_F, MAJRIVER) partialPlot(rf600k_100_F_0_500_4_100, sample_600k_100_F, MAJLAKE) partialPlot(rf600k_100_F_0_500_4_100, sample_600k_100_F, ELEVATION) partialPlot(rf600k_100_F_0_500_4_100, sample_600k_100_F, PRECIP) partialPlot(rf600k_100_F_0_500_4_100, sample_600k_100_F, LAKE) partialPlot(rf600k_100_F_0_500_4_100, sample_600k_100_F, RIVER) partialPlot(rf600k_100_F_0_500_4_100, sample_600k_100_F, SLOPE) partialPlot(rf600k_100_F_0_500_4_100, sample_600k_100_F, ASPECT) partialPlot(rf600k_100_F_0_500_4_100, sample_600k_100_F, TWI) partialPlot(rf600k_100_F_0_500_4_100, sample_600k_100_F, TPI)

partialPlot(rf600k_100_E_0_500_4_100, sample_600k_100_E, LANDCOVER) partialPlot(rf600k_100_E_0_500_4_100, sample_600k_100_E, TEMP) partialPlot(rf600k_100_E_0_500_4_100, sample_600k_100_E, MAJRIVER) partialPlot(rf600k_100_E_0_500_4_100, sample_600k_100_E, MAJLAKE) partialPlot(rf600k_100_E_0_500_4_100, sample_600k_100_E, ELEVATION) partialPlot(rf600k_100_E_0_500_4_100, sample_600k_100_E, PRECIP) partialPlot(rf600k_100_E_0_500_4_100, sample_600k_100_E, LAKE) partialPlot(rf600k_100_E_0_500_4_100, sample_600k_100_E, RIVER) partialPlot(rf600k_100_E_0_500_4_100, sample_600k_100_E, SLOPE) partialPlot(rf600k_100_E_0_500_4_100, sample_600k_100_E, ASPECT) partialPlot(rf600k_100_E_0_500_4_100, sample_600k_100_E, TWI) partialPlot(rf600k_100_E_0_500_4_100, sample_600k_100_E, TPI)

partialPlot(rf600k_100_T_0_500_4_100, sample_600k_100_T, LANDCOVER) partialPlot(rf600k_100_T_0_500_4_100, sample_600k_100_T, TEMP) partialPlot(rf600k_100_T_0_500_4_100, sample_600k_100_T, MAJRIVER) partialPlot(rf600k_100_T_0_500_4_100, sample_600k_100_T, MAJLAKE) partialPlot(rf600k_100_T_0_500_4_100, sample_600k_100_T, ELEVATION) partialPlot(rf600k_100_T_0_500_4_100, sample_600k_100_T, PRECIP) partialPlot(rf600k_100_T_0_500_4_100, sample_600k_100_T, LAKE) partialPlot(rf600k_100_T_0_500_4_100, sample_600k_100_T, RIVER) partialPlot(rf600k_100_T_0_500_4_100, sample_600k_100_T, SLOPE) partialPlot(rf600k_100_T_0_500_4_100, sample_600k_100_T, ASPECT) partialPlot(rf600k_100_T_0_500_4_100, sample_600k_100_T, TWI) partialPlot(rf600k_100_T_0_500_4_100, sample_600k_100_T, TPI) 


\section{Study Area}
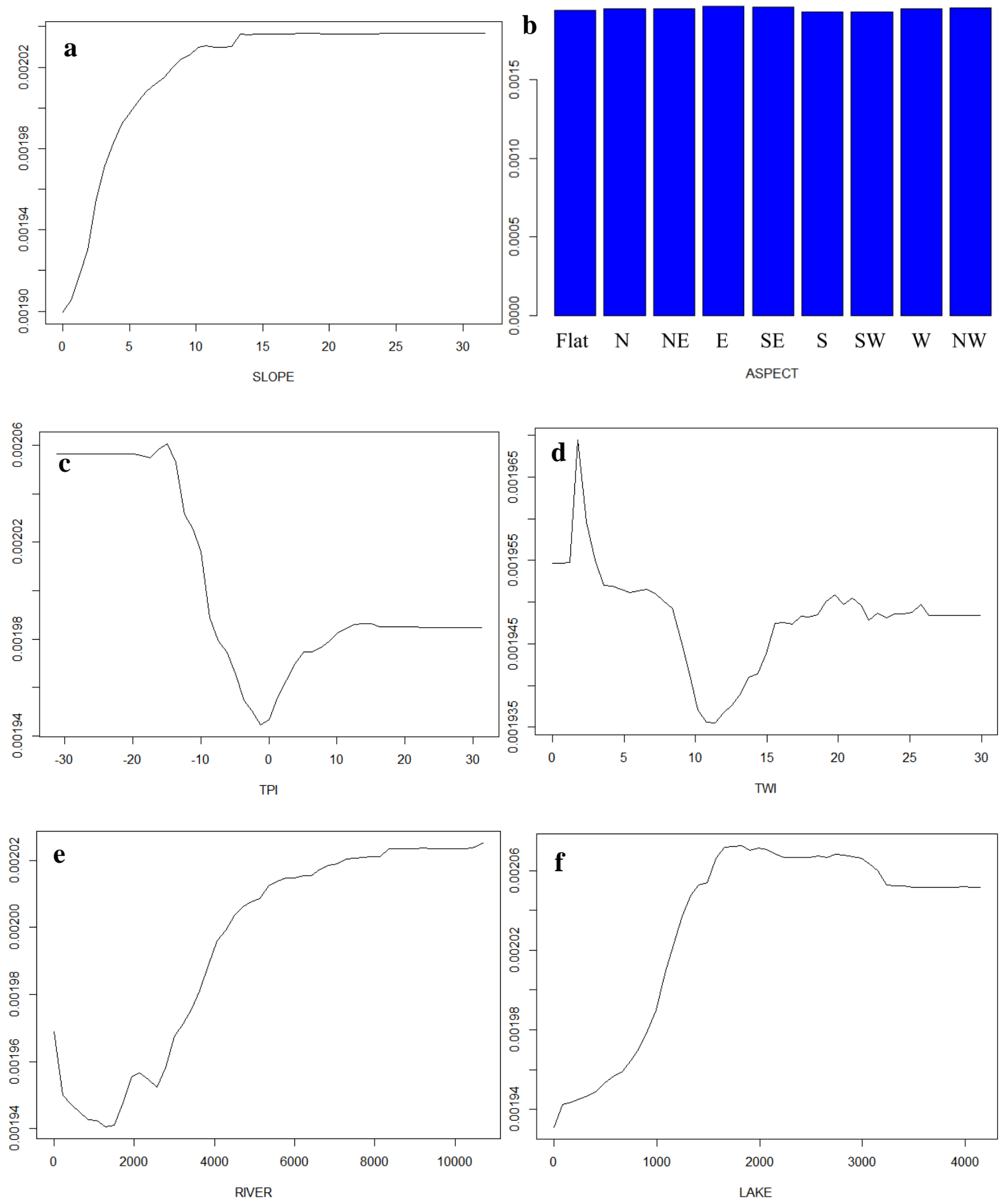

Figure F.1: Partial dependence plots for (a) slope, (b) aspect, (c) TPI, (d) TWI, (e) distance to rivers and (f) distance to lakes for the study area (see Table 3.2). These plots show the marginal influence of each of these environmental variables on NDVI trends (y-axis). Note that y-axis for these plots cover a much smaller range than Figure 3.13, since most plots would show nearly flat trends at that scale. 


\section{Forest Zone}
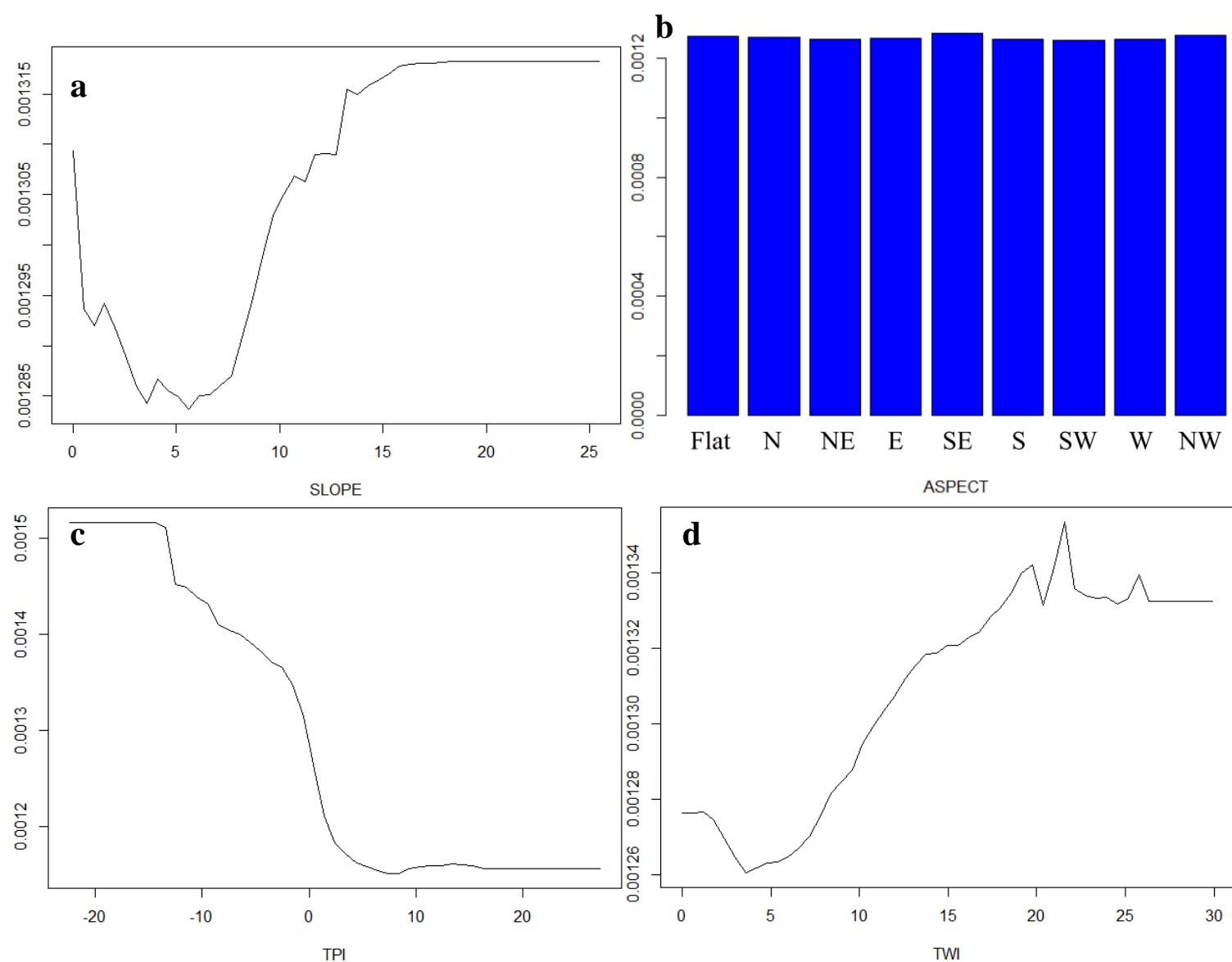

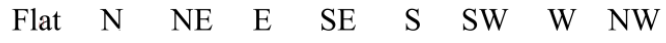
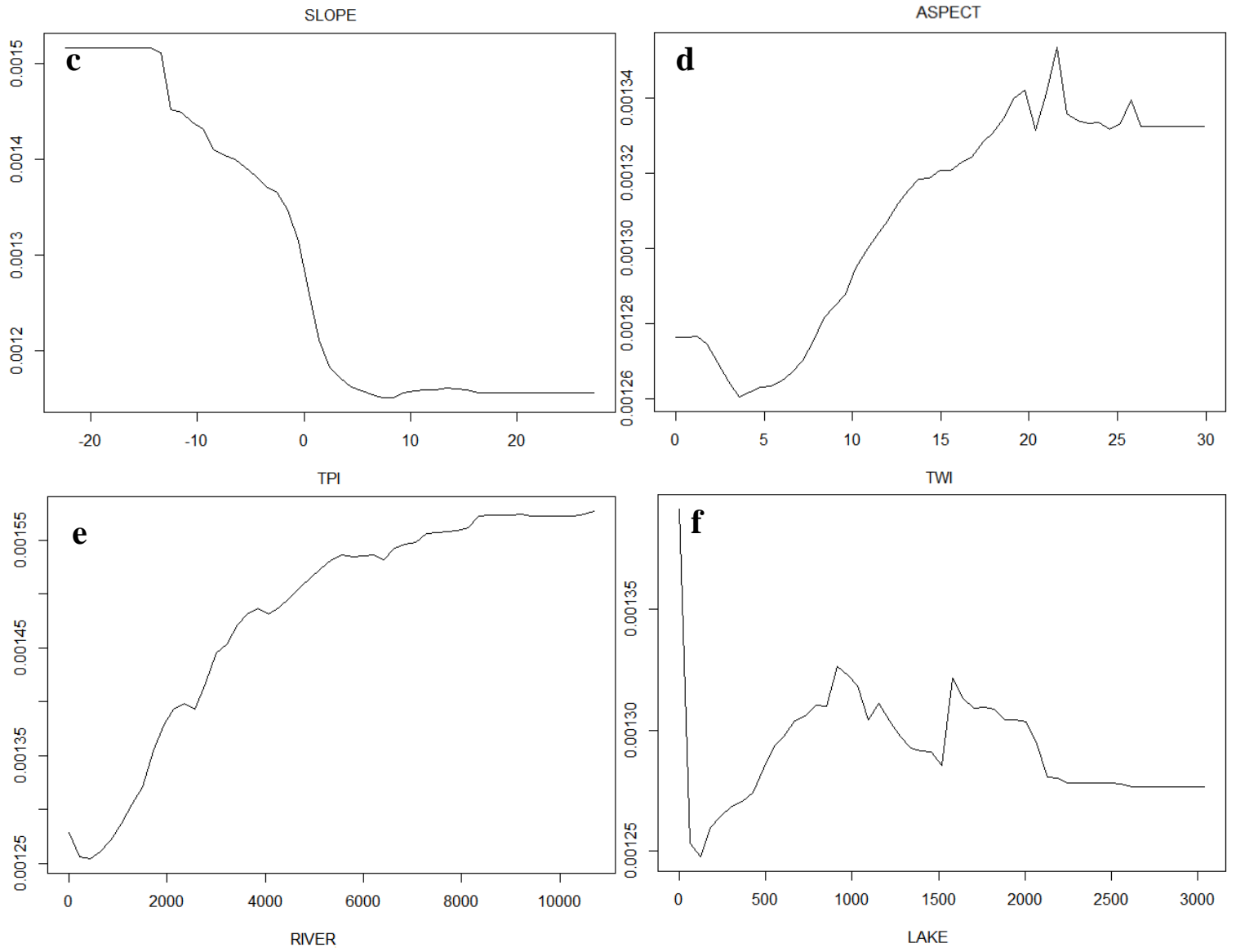

Figure F.2: Partial dependence plots for (a) slope, (b) aspect, (c) TPI, (d) TWI, (e) distance to rivers and (f) distance to lakes for the forest zone (see Table 3.2). These plots show the marginal influence of each of these environmental variables on NDVI trends (y-axis). Note that $y$-axis for these plots cover a much smaller range than Figure 3.13, since most plots would show nearly flat trends at that scale. TPI (c) is an exception, with NDVI trends being more positive in sheltered areas than in exposed areas. This is indicative of lowland areas seeing a greater increase in NDVI than upland outcrops. Distance to rivers (e) also has a stronger influence, with NDVI trends being more positive when farther away. 


\section{Ecotone Zone}
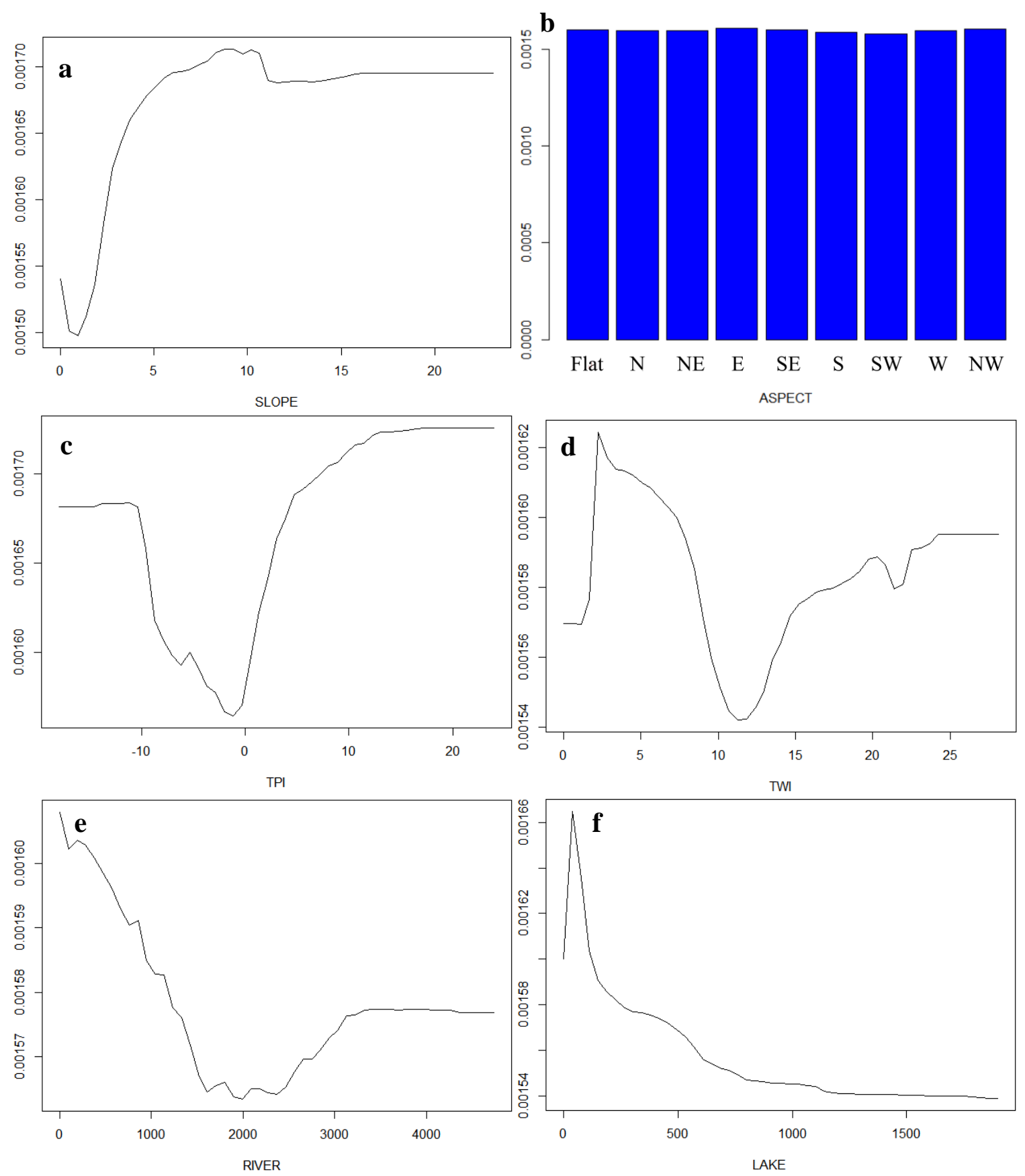

Figure F.3: Partial dependence plots for (a) slope, (b) aspect, (c) TPI, (d) TWI, (e) distance to rivers and (f) distance to lakes for the ecotone zone (see Table 3.2). These plots show the marginal influence of each of these environmental variables on NDVI trends (y-axis). Note that y-axis for these plots cover a much smaller range than Figure 3.13, since most plots would show nearly flat trends at that scale. Slope (a) and TPI (c) are an exception, with NDVI trends being more positive at steeper slopes as well as in more exposed and sheltered areas. This could be indicative of increasing vegetation productivity on hill slopes in this zone. 
Tundra Zone
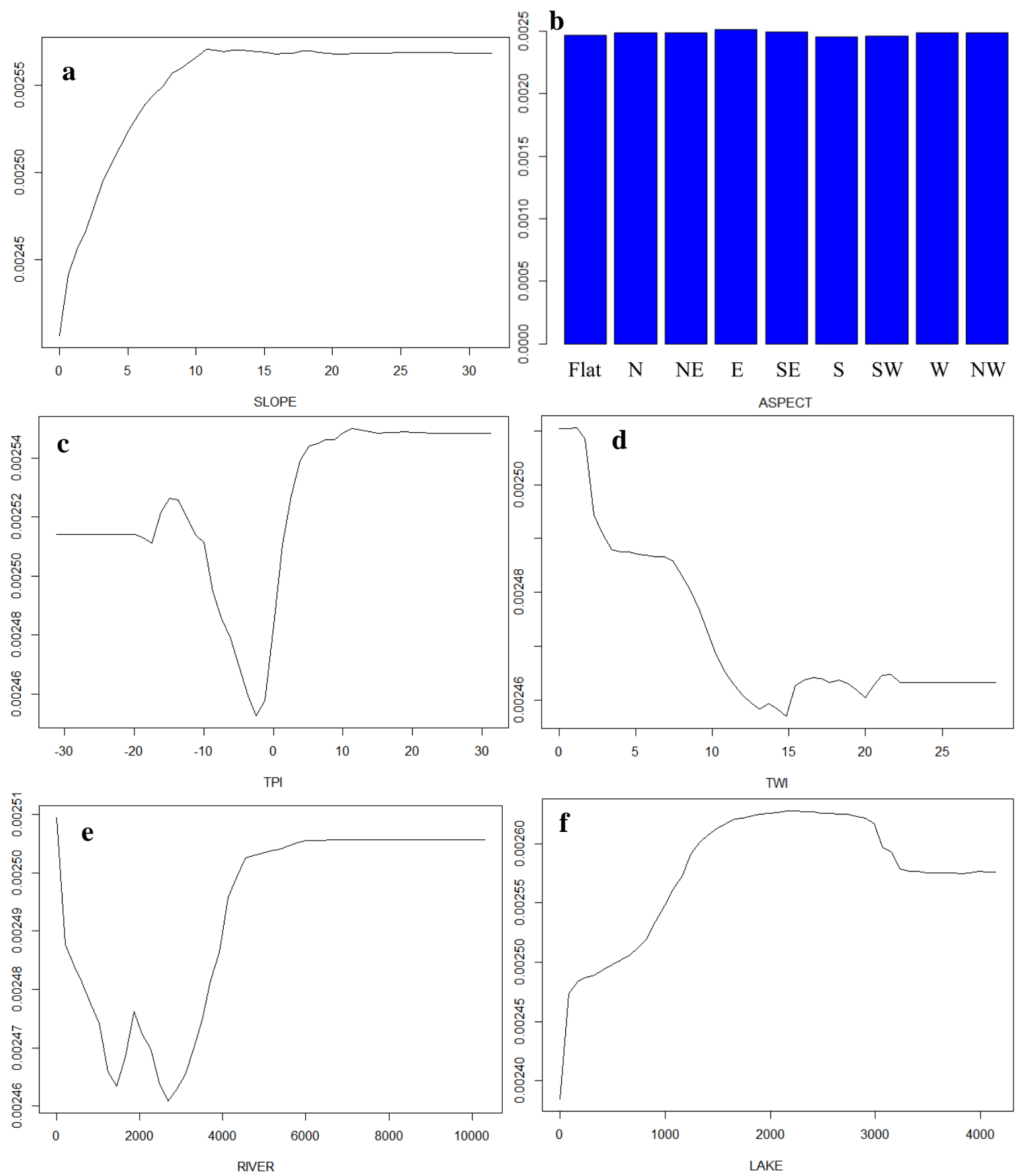

Figure F.4: Partial dependence plots for (a) slope, (b) aspect, (c) TPI, (d) TWI, (e) distance to rivers and (f) distance to lakes for the tundra zone (see Table 3.2). These plots show the marginal influence of each of these environmental variables on NDVI trends (y-axis). Note that y-axis for these plots cover a much smaller range than Figure 3.13, since most plots would show nearly flat trends at that scale. Distance to lakes (f) is an exception with NDVI trends being more positive farther away, similar to the relationship with major lakes but at a smaller scale of influence. 